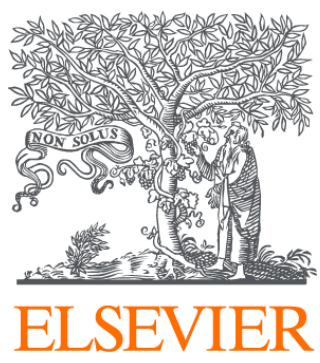

Since January 2020 Elsevier has created a COVID-19 resource centre with free information in English and Mandarin on the novel coronavirus COVID-

19. The COVID-19 resource centre is hosted on Elsevier Connect, the company's public news and information website.

Elsevier hereby grants permission to make all its COVID-19-related research that is available on the COVID-19 resource centre - including this research content - immediately available in PubMed Central and other publicly funded repositories, such as the WHO COVID database with rights for unrestricted research re-use and analyses in any form or by any means with acknowledgement of the original source. These permissions are granted for free by Elsevier for as long as the COVID-19 resource centre remains active. 


\title{
Guía de Práctica Clínica para el Diagnóstico y Tratamiento de Pacientes con Enfermedad Pulmonar Obstructiva Crónica (EPOC) - Guía Española de la EPOC (GesEPOC)
}

\author{
Clinical Practice Guideline for the Diagnosis and Treatment of Patients with Chronic Obstructive \\ Pulmonary Disease (COPD) - Spanish Guideline for COPD (GesEPOC) \\ Grupo de Trabajo de GesEPOC \\ Task Force of GesEPOC
}

\section{Introducción}

La enfermedad pulmonar obstructiva crónica (EPOC) se caracteriza esencialmente por una limitación crónica al flujo aéreo poco reversible y asociada principalmente al humo de tabaco. Se trata de una enfermedad infradiagnosticada y con una elevada morbimortalidad, y supone un problema de salud pública de gran magnitud. Representa un elevado coste sanitario y constituye la cuarta causa de muerte en los países de nuestro entorno. Además, se prevé que su prevalencia siga aumentando.

La EPOC es una enfermedad compleja, multicomponente, crónica y progresiva. Los síntomas principales son la disnea, la tos y la expectoración. Su presentación clínica es muy heterogénea, y dentro de lo que hoy denominamos EPOC se pueden definir diversas formas clínicas o fenotipos con repercusión clínica, pronóstica y terapéutica ${ }^{1}$. Aunque la EPOC no es una enfermedad curable, la deshabituación tabáquica es la medida más eficaz para prevenirla y frenar su progresión ${ }^{2}$.

Desde 2009, el Ministerio de Sanidad y Política Social, a través del Plan de Calidad del Sistema Nacional de Salud (SNS) y la Estrategia en EPOC, ha estado trabajando para reducir el número de personas con EPOC y para identificar la manera de mejorar la atención y la calidad de vida de las personas que la sufren ${ }^{3}$. En este contexto nace la Guía Española de la EPOC (GesEPOC) a partir de una iniciativa de la Sociedad Española de Neumología y Cirugía Torácica (SEPAR) que, conjuntamente con las sociedades científicas implicadas en la atención a pacientes con EPOC, el Foro Español de Pacientes y la Unidad de Evaluación de Tecnologías Sanitarias de la Agencia Laín Entralgo, ha desarrollado GesEPOC, la guía de referencia de la EPOC en España.

A nivel mundial, las recomendaciones de la Global Initiative for Obstructive Lung Diseases (GOLD) para el diagnóstico y el tratamiento de la EPOC, publicadas por primera vez en 2001 y revisadas cada año, han sido las más utilizadas ${ }^{4}$. En España, las guías de referencia han sido las elaboradas por SEPAR junto a otras sociedades científicas ${ }^{5,6}$. La multitud de avances que han surgido en los últimos años hace que los contenidos de estas guías necesiten actualizarse.

GesEPOC es una guía actualizada para responder a las cuestiones planteadas en la asistencia al paciente con EPOC. GesEPOC persigue la atención eficiente de los pacientes con EPOC a partir de un trabajo coordinado y multidisciplinario con la participación de representantes de los diferentes ámbitos asistenciales.

\section{Alcance y objetivos}

El objetivo principal de la guía es proporcionar a los profesionales sanitarios encargados de la asistencia a pacientes con EPOC una herramienta que les permita tomar las mejores decisiones sobre los problemas que plantea su atención.

Se trata de optimizar el proceso diagnóstico identificando, en la medida de lo posible, aquellos atributos de la enfermedad que, solos o combinados, describen las diferencias entre individuos con EPOC ( fenotipos) en relación con parámetros que tienen significado clínico (síntomas, agudizaciones, respuesta al tratamiento, velocidad de progresión de la enfermedad o muerte) ${ }^{7}$. La aproximación al paciente basada en fenotipos clínicos permite clasificar a los enfermos en subgrupos con valor pronóstico, a la vez que determina el tratamiento más adecuado que permite lograr mejores resultados clínicos. Esta nueva perspectiva representa un cambio significativo en el tratamiento de la EPOC, ya que supone pasar de un acercamiento centrado en la gravedad de la obstrucción a un enfoque más personalizado ${ }^{8-10}$.

La guía incluye el diagnóstico y el tratamiento de la EPOC, en fase estable, agudizada y al final de la vida. El proceso diagnóstico se estructura en tres partes: el diagnóstico de la EPOC, la caracterización del fenotipo y la valoración de la gravedad de forma multidimensional.

Esta guía va dirigida a médicos de familia, profesionales de enfermería de atención primaria y especializada, neumólogos, internistas y otros especialistas que atienden a estos pacientes con EPOC, y también a los propios pacientes que sufren esta enfermedad. Al tener la guía un enfoque nacional, no afronta temas organizativos, pero sí propone recomendaciones explícitas que faciliten la implementación de la guía, de acuerdo con unos estándares de calidad asistencial que se proponen.

\section{Método}

La Guía Española de la EPOC (GesEPOC) es un proyecto compartido iniciado en junio de 2010 por las diversas sociedades científicas implicadas en la atención a pacientes con EPOC y el Foro Español de Pacientes, para discutir y consensuar recomendaciones, pautas de actuación y estrategias de tratamiento de la EPOC, con la finalidad de estimular la calidad en la atención a los pacientes con esta enfermedad que acuden a la consulta de los profesionales de atención primaria y especializada. 
GesEPOC nace por iniciativa de la Sociedad Española de Neumología y Cirugía Torácica (SEPAR) y cuenta con la colaboración de semFYC (Sociedad Española de Medicina de Familia y Comunitaria), SEMERGEN (Sociedad Española de Médicos de Atención Primaria), SEMG (Sociedad Española de Médicos Generales y de Familia), GRAP (Sociedad de Respiratorio en Atención Primaria), SEMI (Sociedad Española de Medicina Interna), SEMES (Sociedad Española de Medicina de Urgencias y Emergencias), SERMEF (Sociedad Española de Rehabilitación y Medicina Física), SORECAR (Sociedad Española de Rehabilitación Cardiorrespiratoria), así como el Comité Nacional para la Prevención del Tabaquismo (CNPT). En la elaboración han participado profesionales representantes de todas las sociedades científicas implicadas, especialistas en epidemiología, metodólogos, personas conocedoras del uso de nuevas tecnologías y pacientes.

Esta guía incluye, por un lado, las recomendaciones publicadas en la GPC para el tratamiento de pacientes con EPOC, elaborada conjuntamente por el grupo GesEPOC y metodólogos especialistas en elaboración de GPC de la Unidad de Evaluación de Tecnologías Sanitarias (UETS), Agencia Laín Entralgo (Consejería de Sanidad y Consumo, Madrid) en el contexto de las actuaciones derivadas de la Estrategia Nacional de EPOC del Sistema Nacional de Salud. La metodología empleada se recoge de forma detallada en el Manual Metodológico para la elaboración de guías de práctica clínica del Sistema Nacional de Salud $^{11}$. En el portal de GuíaSalud (www.guiasalud.es), así como en la página web de la UETS (www.madrid.org/lainentralgo), está disponible el material, donde se presenta de forma detallada la información sobre el proceso metodológico. Los pasos seguidos por la UETS se recogen de manera explícita en el anexo 1. Esta metodología se aplicó a las preguntas respondidas en la GPC para el tratamiento de pacientes con EPOC $^{12-14}$, cuya descripción detallada se encuentra en los anexos 1 y 2.

El resto de recomendaciones que se recogen en la guía se han actualizado de las contenidas en la GPC de EPOC SEPAR-SemFYC de 2010, cuya metodología se detalla en la publicación ${ }^{6}$. En las tablas se especifica la procedencia de cada recomendación y en los anexos se encuentran las evaluaciones completas elaboradas para cada pregunta.

\section{Epidemiología de la EPOC}

Puntos clave:

- La EPOC es actualmente la cuarta causa de muerte en el mundo.

- La prevalencia de la EPOC en adultos de 40-80 años en España se estima del $10,2 \%$, aunque varía ampliamente según las distintas áreas geográficas.

- Hay un alto grado de infradiagnóstico de la EPOC.

- Se aprecia una reducción del infratratamiento de la EPOC.

- En España se observa una tendencia a disminuir la mortalidad.

\section{Prevalencia}

La Organización Mundial de la Salud (OMS) estima que actualmente hay 210 millones de personas en el mundo que presentan EPOC ${ }^{15}$. En el estudio The Global Burden of Disease publicado en 1996, la OMS cifraba las tasas de prevalencia mundial de la EPOC en el año 1990 en 9,3 casos/1.000 habitantes en los hombres, y en 7,3 casos/1.000 habitantes en las mujeres ${ }^{16}$. En una revisión sistemática se estima que la prevalencia de EPOC en la población general es de alrededor del $1 \%$ en todas las edades, incrementándose al 8-10\% o superior en aquellos adultos de 40 años o más ${ }^{17}$. En Europa, según los resultados de una revisión sistemática, la prevalencia varía entre el 2,1 y el 26,1\%, dependiendo del país, los diferentes métodos utilizados para estimar la prevalencia en términos de definición, las escalas de gravedad y los grupos de población ${ }^{18}$.

En España, hasta hace poco, el único estudio de prevalencia de EPOC y ámbito nacional disponible era el IBERPOC, realizado en 1997 para medir la prevalencia y la variación de la distribución de la EPOC en siete zonas geográficas. La prevalencia de EPOC (definida según los criterios antiguos de la European Respiratory Society como cociente posbroncodilatador $\mathrm{FEV}_{1} / \mathrm{FVC}<88 \%$ del teórico en hombres y $<89 \%$ en mujeres) fue del 9,1\% (el 14,3\% en hombres y el 3,9\% en mujeres) ${ }^{19}$. Según el hábito tabáquico, la prevalencia fue del 15,0\% en fumadores, del $12,8 \%$ en ex fumadores y del $4,1 \%$ en no fumadores. El estudio IBERPOC encontró, además, diferencias muy importantes según el área geográfica, desde sólo el 4,9\% en Cáceres hasta el 18\% en Manlleu (Barcelona), posiblemente relacionadas con factores ambientales o laborales no estudiados. En este sentido, el exceso de casos detectado en algunas áreas geográficas solía corresponder a mujeres mayores de 55 años, no fumadoras, con antecedentes de enfermedades respiratorias en la infancia y que no presentaban síntomas de expectoración o sibilantes ${ }^{20}$. Un aspecto muy importante de los resultados del estudio IBERPOC fue el alto grado de infradiagnóstico, pues el 78,2\% de los casos confirmados por espirometría no tenían diagnóstico previo de EPOC.

Desde hace poco se dispone de nuevos datos de la distribución actual de la EPOC en España, obtenidos del estudio EPI-SCAN ${ }^{21}$. Las áreas participantes fueron Barcelona, Burgos, Córdoba, Huesca, Madrid, Oviedo, Sevilla, Requena (Valencia), Vic (Barcelona) y Vigo (Pontevedra). La prevalencia actual de EPOC, definida por el criterio GOLD como un cociente $\mathrm{FEV}_{1} / \mathrm{FVC}<0,70$ posbroncodilatador en la población de $40-80$ años fue del $10,2 \%$ (el 15,1\% en hombres y el 5,7\% en mujeres). Comparado con el estudio IBERPOC, el infradiagnóstico de EPOC en España se redujo sólo levemente del 78 al 73\%, aunque sí se apreció una gran reducción del infratratamiento de la EPOC en España dentro de este marco de 10 años, del 81 al 54\% ( $p<0,05)^{22}$.

Actualmente, y según EPI-SCAN, se estima que 2.185.764 españoles presentan EPOC de entre los 21,4 millones con edad entre 40 y 80 años. Por sexos, las cifras corresponden a $1.571,868$ hombres y 628,102 mujeres. Y ya que el $73 \%$ aún no está diagnosticado, puede decirse que más de 1.595,000 españoles aún no lo saben y, por tanto, no reciben ningún tratamiento para su EPOC.

\section{Impacto de la EPOC}

\section{Mortalidad de la EPOC}

La EPOC es actualmente la cuarta causa de muerte en el mundo y la OMS estima que será la tercera en el año $2030^{23}$. En el año 2008, las enfermedades crónicas de las vías respiratorias inferiores representaron la cuarta causa de muerte en España (responsables del 11,4\% del total de defunciones), después del cáncer (26,1\%), las enfermedades del corazón (20,8\%) y las enfermedades cerebrovasculares (18,2\% $)^{24}$.

La tasa de mortalidad por EPOC por 100.000 habitantes, ajustada por población mundial, en el año 2008 fue de 449,22 en hombres y 238,47 en mujeres ${ }^{25}$. En hombres el intervalo de estas tasas se sitúa entre el 399,13 de Navarra y el 526,57 de Ceuta. En mujeres se sitúa entre el 205,36 de Navarra y el 310,53 de Ceuta. Las tasas de mortalidad aumentan de manera significativa, sobre todo en hombres, a partir de los 55 años ${ }^{25}$.

La mortalidad por EPOC en España, comparando las tasas ajustadas por población mundial, muestra una tendencia a la disminución durante la última década, tanto en hombres como en mujeres ${ }^{25}$ (fig. 1).

\section{Otros datos sobre magnitud, coste y carga de enfermedad}

Según el Registro de Altas de los Hospitales Generales del Sistema Nacional de Salud (SNS) de 2010, se reconocieron 58.066 altas hospitalarias en relación con episodios de EPOC (52.995 bronquitis CIE-9MC 491 y 5.071 enfisema CIE-9MC 492) en el año 2010, con una estancia media de 8,25 días $^{26}$.

Dadas sus características de enfermedad crónica y progresiva, la EPOC supone un coste elevado, tanto en consumo de recursos sanitarios como en pérdida de la calidad de vida relacionada con la salud (CVRS) de los pacientes. La estimación de los costes de la EPOC en España revisados en el documento Estrategia en EPOC del SNS del Mi- 


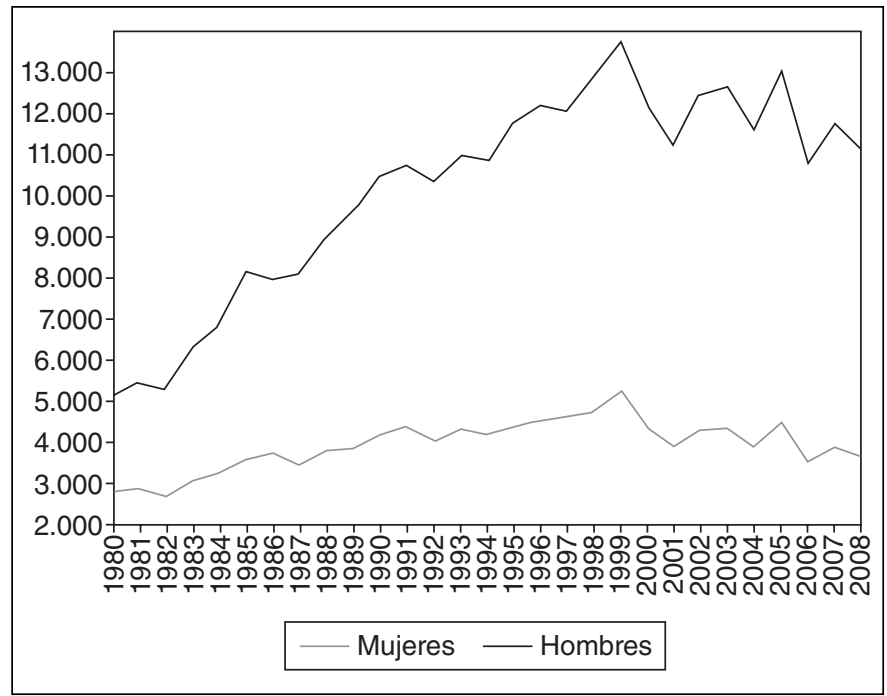

Figura 1 Tendencia temporal en el número de fallecimientos por EPOC en España.

nisterio de Sanidad y Consumo se estima en 750-1000 millones de euros/año, incluidos los costes directos, indirectos e intangibles ${ }^{27}$. El coste medio directo por paciente con EPOC se estima entre $1.712 \mathrm{y}$ 3.238 euros/año. Estos costes directos se distribuyen en gastos hospitalarios (40-45\%), fármacos (35-40\%) y visitas y pruebas diagnósticas (15-25\%); a estos costes se deben añadir los costes indirectos ${ }^{28}$. Los pacientes que incurren en un mayor coste son los más graves y/o con agudizaciones frecuentes ${ }^{28}$.

\section{Organización y asistencia a las personas con EPOC en el Sistema} Nacional de Salud

Según una encuesta ad hoc realizada por el Ministerio de Sanidad y Política Social para la elaboración de la Estrategia Nacional de la EPOC, todas las comunidades autónomas consideran la EPOC como un área prioritaria de intervención en salud ${ }^{27}$. Sin embargo, en la mayoría de comunidades autónomas no hay un plan de actuación activo para esta enfermedad ni un organismo responsable de la planificación o consejo asesor. Tampoco existen normas que regulen la atención a la EPOC; por el contrario, en la mayoría de comunidades autónomas sí existen planes de lucha contra el tabaquismo y unidades de deshabituación tabáquica ${ }^{27}$.

La EPOC es diagnosticada y atendida mayoritariamente por médicos de atención primaria y por neumólogos de referencia. La estrategia refiere que en la mayoría de las comunidades autónomas se ha establecido una coordinación entre atención primaria y especializada, mayoritariamente mediante protocolos consensuados, comités de mejora, sesiones clínicas y actividades formativas.

Los profesionales que atienden al paciente con EPOC han de tener competencias en el diagnóstico temprano de la enfermedad, la interpretación de la espirometría forzada y el tratamiento de la fase estable y las exacerbaciones ${ }^{27}$. Los profesionales de atención primaria, además, han de tener competencias en la prevención y el tratamiento del tabaquismo y las exacerbaciones, y en la atención al paciente en el final de la vida (tratamiento paliativo, decisiones finales, etc. $)^{27}$. Los médicos de atención especializada deben tener competencias en ventilación mecánica no invasiva y en la valoración multidimensional del paciente con $\mathrm{EPOC}^{27}$.

Los profesionales de enfermería de atención primaria han de tener competencias en: promoción de estilos de vida saludables, prevención del tabaquismo y deshabituación tabáquica, detección temprana de la EPOC, realización adecuada de espirometrías forzadas, valoración de necesidades de la persona con EPOC y su familia, realización de un plan de cuidados, prevención de exacerbaciones en función del estadio de la EPOC y de la comorbilidad, y educación para la salud de pacientes y familiares y el aumento de su autonomía ${ }^{27}$. En atención especializada los profesionales de enfermería deben tener, además, competencias en: ventilación mecánica no invasiva, valoración multidimensional, evaluación global del paciente complejo, plan de trabajo, coordinación, evaluación de resultados y atención en el final de la vida (tratamiento paliativo, decisiones finales, etc.) y en la situación aguda ${ }^{27}$.

La Estrategia Nacional de la EPOC establece un conjunto de líneas estratégicas con objetivos y recomendaciones que, de forma realista y en función de los recursos disponibles y el ámbito de competencias de las comunidades autónomas, contribuyan a mejorar la calidad de las intervenciones y los resultados en la $\mathrm{EPOC}^{27}$.

Actualmente, la calidad de la atención a las personas con EPOC y los resultados en salud son aspectos difíciles de evaluar. Desde la Estrategia se ha propuesto una serie de indicadores que permiten recoger y elaborar la información necesaria para una evaluación sistemática y continua ${ }^{27,29}$. Estos estándares se incluyen en la presente normativa como referencia.

\section{Definición, fenotipos, factores de riesgo e historia natural de la EPOC}

Puntos clave:

- La EPOC es una enfermedad respiratoria crónica, compleja y heterogénea.

- El principal factor etiológico es el tabaco.

- La identificación de fenotipos clínicos permite un tratamiento más personalizado.

\section{Definición}

La EPOC se define como una enfermedad respiratoria caracterizada esencialmente por una limitación crónica al flujo aéreo que no es totalmente reversible. Esta limitación al flujo aéreo se suele manifestar en forma de disnea y, por lo general, es progresiva. La limitación al flujo aéreo se asocia a una respuesta inflamatoria anormal de los pulmones a partículas nocivas y gases, principalmente derivados del humo de tabaco, que pueden producir otros síntomas como tos crónica, acompañada o no de expectoración. La EPOC se caracteriza también por la presencia de agudizaciones y por la frecuente presencia de comorbilidades que pueden contribuir a la gravedad en algunos pacientes.

Esta definición, que incluye criterios espirométricos de obstrucción al flujo aéreo, mecanismos patogénicos, aspectos etiológicos y manifestaciones sintomáticas, está de acuerdo y extiende las definiciones propuestas por la American Thoracic Society (ATS), la European Respiratory Society (ERS) ${ }^{30}$ y por la Sociedad Española de Neumología y Cirugía Torácica (SEPAR) ${ }^{5}$. Reconoce que la espirometría por sí sola no puede considerarse diagnóstica, sino que debe utilizarse como prueba de confirmación ante la sospecha diagnóstica en un paciente que presenta síntomas respiratorios crónicos y es o ha sido fumador. En casos menos frecuentes podemos obtener una historia de exposición a otros agentes tóxicos inhalados en el hogar o en el lugar de trabajo.

\section{Fenotipos clínicos de la EPOC}

La EPOC es una enfermedad muy heterogénea y por ello no es posible describirla utilizando sólo el volumen espiratorio forzado durante el primer segundo $\left(\mathrm{FEV}_{1}\right)$. La denominación de fenotipo se utiliza para referirse a formas clínicas de los pacientes con EPOC ${ }^{7}$. Un grupo de expertos internacionales ha definido el fenotipo clínico de la EPOC como "aquellos atributos de la enfermedad que, solos o combinados, describen las diferencias entre individuos con EPOC en relación con parámetros que tienen significado clínico (síntomas, agudizaciones, 
respuesta al tratamiento, velocidad de progresión de la enfermedad, o muerte)"7. Por tanto, el fenotipo debería ser capaz de clasificar a los pacientes en subgrupos con valor pronóstico que permitan determinar el tratamiento más adecuado para lograr mejores resultados clínicos ${ }^{7,9}$.

Los estudios disponibles sobre fenotipificación de la EPOC han identificado diversos fenotipos clínicos ${ }^{16}$. La guía GesEPOC propone cuatro fenotipos que determinan un tratamiento diferenciado:

1. No agudizador, con enfisema o bronquitis crónica.

2. Mixto EPOC-asma.

3. Agudizador con enfisema.

4. Agudizador con bronquitis crónica.

Se han propuesto otros posibles fenotipos como el declinador rápi$\mathrm{do}^{31}$, las bronquiectasias ${ }^{32,33}$ o el sistémico ${ }^{34}$, pero su trascendencia a la hora de dirigir el tratamiento no está establecida, u otros que por su escasa prevalencia (déficit de alfa-1-antitripsina) ${ }^{35}$ no se consideran de forma específica en esta guía.

La importancia de establecer estos fenotipos es que el tratamiento se dirigirá según las características propias de cada paciente, en lo que constituye un enfoque personalizado del tratamiento farmacológico y de rehabilitación (véase apartado Tratamiento de la EPOC estable) $)^{8,9}$, que será modulado por la gravedad (véase apartado Clasificación de gravedad de la EPOC). A continuación se exponen las características y la definición de los fenotipos básicos, que en el caso de los agudizadores se combinan con la bronquitis crónica o el enfisema para establecer el fenotipo definitivo.

\section{Definición de fenotipo agudizador}

Se define como fenotipo agudizador a todo paciente con EPOC que presente dos o más agudizaciones moderadas o graves al año ${ }^{36}$. Estas exacerbaciones deben estar separadas al menos 4 semanas desde la finalización del tratamiento de la agudización previa o 6 semanas desde el inicio de la misma en los casos que no han recibido tratamiento, para diferenciar el nuevo evento de un fracaso terapéutico previo ${ }^{37}$.

La identificación del fenotipo agudizador se basa en la historia clínica y se ha demostrado que el diagnóstico basado en la declaración del paciente sobre su historial de agudizaciones es fiable ${ }^{38}$. El fenotipo agudizador subraya la importancia de preguntar por la historia de agudizaciones en la entrevista clínica e identifica a pacientes que pueden tener indicación de tratamiento antiinflamatorio añadido a los broncodilatadores. Es importante señalar que hay diferentes tipos de agudizaciones, relacionados con su etiología, y que el tipo de agudización que presenta un paciente (bacteriana, viral o eosinofílica) suele mantenerse constante en episodios sucesivos ${ }^{39}$.

Las agudizaciones frecuentes pueden presentarse en cualquiera de los tres fenotipos restantes: enfisema, bronquitis crónica o mixto EPOC-asma. Es importante porque modularán el tipo y/o la intensidad del tratamiento de todos ellos.

\section{Definición de fenotipo mixto EPOC-asma}

El fenotipo mixto en la EPOC se define por la presencia de una obstrucción no completamente reversible al flujo aéreo acompañada de síntomas o signos de una reversibilidad aumentada de la obstrucción ${ }^{40}$. Dentro del espectro de la obstrucción crónica al flujo aéreo se encuentran individuos asmáticos fumadores que desarrollan obstrucción no completamente reversible al flujo aéreo ${ }^{41,42}$ y fumadores sin antecedentes conocidos de asma cuyo patrón inflamatorio bronquial tiene un predominio de eosinófilos y se manifiesta clínicamente por un aumento de la reversibilidad al flujo aéreo. En otras normativas se los conoce como "pacientes con EPOC con componente asmático prominente" 43 o como "asma que complica la EPOC" 44 .

Para el diagnóstico de fenotipo mixto, un grupo de expertos ha consensuado unos criterios que se presentan en el apartado Caracterización del fenotipo ${ }^{37}$.
Hay estudios epidemiológicos de incidencia de EPOC en los que se demuestra que los jóvenes asmáticos que desarrollan EPOC tienen una enfermedad de características diferentes de las que presentan los pacientes con EPOC sin antecedentes de asma. En el primer caso son más frecuentes la rinitis alérgica, la hiperreactividad bronquial inespecífica y la presencia de sibilantes, y son mayores las concentraciones plasmáticas de $\operatorname{IgE}^{45}$, lo que indica que se trata de un síndrome mixto entre asma y $\mathrm{EPOC}^{46}$. En pacientes asmáticos, el principal factor de riesgo del desarrollo de una obstrucción al flujo aéreo no completamente reversible es el consumo de tabaco ${ }^{41}$. Por ello, estas vías patogénicas confluirán al final en un fenotipo de paciente con obstrucción crónica al flujo aéreo y aumento de la reversibilidad, que es lo que define al fenotipo mixto.

Se ha observado un mayor riesgo de presentar agudizaciones frecuentes entre los pacientes con fenotipo mixto EPOC-asma ${ }^{47}$. En estos casos la agudización suele tener un perfil eosinofílico, lo que indica que la respuesta al tratamiento es distinta ${ }^{39}$.

La prevalencia del fenotipo mixto es desconocida, pero existen diferentes estimaciones de su importancia en el contexto de la EPOC. Los resultados del estudio COPDGene estiman que un 13\% de los pacientes con EPOC comparten un diagnóstico de asma ${ }^{46}$. Soriano et $\mathrm{al}^{48}$ estimaron que aproximadamente un $23 \%$ de pacientes con EPOC entre 50 y 59 años podían tener un fenotipo mixto, cifra que aumentaba con la edad hasta el 52\% de los casos de EPOC entre los 70 y los 79 años ${ }^{48}$.

\section{Definición de fenotipo bronquitis crónica}

La bronquitis crónica se definió en el Simposio Ciba en 1958, ratificado por la OMS en 1961 y por la ATS un año después, como la presencia de tos productiva o expectoración durante más de 3 meses al año y durante más de 2 años consecutivos ${ }^{49}$. El fenotipo bronquitis crónica identifica al paciente con EPOC, en el cual la bronquitis crónica es el síndrome predominante. La hipersecreción bronquial en la EPOC se ha asociado a una mayor inflamación en la vía aérea y a un mayor riesgo de infección respiratoria ${ }^{50}$, lo que puede explicar que los pacientes con bronquitis crónica tengan una mayor frecuencia de agudizaciones que los pacientes sin expectoración crónica ${ }^{51-53}$. En un número significativo de pacientes con bronquitis crónica y agudizaciones repetidas se pueden detectar bronquiectasias mediante una exploración por tomografía computarizada de tórax de alta resolución $(\text { TACAR) })^{33,54}$.

\section{Definición del fenotipo enfisema}

El enfisema se define como la afección de los pulmones caracterizada por un aumento de tamaño de los espacios aéreos situados más allá del bronquiolo terminal y que se acompaña de cambios destructivos en sus paredes. Debido a que el concepto de enfisema es anatómico, el diagnóstico del fenotipo enfisema es un diagnóstico clínico, radiológico y funcional que expresa la probabilidad de que los síntomas y signos del paciente puedan adscribirse a un estado morfológico de enfisema.

El fenotipo enfisema incluye a los pacientes con EPOC con diagnóstico clínico/radiológico/funcional de enfisema, que presentan disnea e intolerancia al ejercicio como síntomas predominantes. Los pacientes con fenotipo enfisema presentan una tendencia a un índice de masa corporal (IMC) reducido. No debe confundirse el diagnóstico de fenotipo enfisema con la presencia de enfisema pulmonar. Los signos de enfisema pueden encontrarse en cualquiera de los fenotipos, e incluso en fumadores sin criterios de EPOC.

Este fenotipo de la EPOC se caracteriza por la presencia de datos funcionales de hiperinsuflación ${ }^{55}$, por la existencia de enfisema en el estudio por TACAR, y/o por un test de difusión inferior al valor de referencia, medido mediante el cociente DLCO/VA ajustado para la hemoglobina ${ }^{56}$. La realización de estas pruebas en un segundo ámbito asistencial permitirá la clasificación de certeza como fenotipo enfisema.

El fenotipo enfisema suele tener menos agudizaciones que el fenotipo bronquitis crónica, pero es posible que pacientes con enfisema 
sean también agudizadores, en especial los que presentan formas más graves de la enfermedad ${ }^{57}$. El enfisema grave también se asocia a un mal pronóstico al ser predictor de un mayor descenso anual del $\mathrm{FEV}_{1}^{58}$.

\section{Etiología de la EPOC}

\section{Consumo de tabaco}

Desde la década de 1950 se conoce que el tabaco es el factor de riesgo más importante en el desarrollo de $\mathrm{EPOC}^{59,60}$, y su relación causal ha sido establecida a través de numerosos estudios prospectivos de cohortes, entre ellos el British Medical Research Council ${ }^{61}$ y el Framingham Heart Study Offspring62.

En estudios de cohortes prospectivos se estima que el riesgo absoluto de desarrollar EPOC entre fumadores está entre el 25 y el 30\%63. Además, se ha demostrado que el riesgo es proporcional al consumo acumulado de tabaco, de tal forma que el riesgo pasa del $26 \%$ en los fumadores de $15-30$ paquetes al año, al 51\% en los fumadores de más de 30 paquetes al año ${ }^{21}$.

El consumo de tabaco, tanto en los países industrializados como en los países en vías de desarrollo, está muy extendido. En España, según los datos de la Encuesta Nacional de Salud de 2006 ${ }^{64}$, el 29,5\% de la población adulta fuma (el $26,4 \%$ de manera regular y el 3,1\% esporádicamente), con una tendencia temporal clara hacia una disminución del consumo, muy marcada en hombres (del 42,1 al 31,6\% entre 1997 y 2006) y menor en mujeres (del 24,8 al $21,5 \%$ en el mismo período). Entre los jóvenes de 16 a 24 años, fuma un 33\%, lo que significa que alrededor de 1,7 millones de jóvenes españoles son fumadores. El 28\% de los jóvenes fuma a diario y el $5 \%$ lo hace ocasionalmente. Fuman el $34,4 \%$ de las chicas y el 32,1\% de los chicos. La edad media de inicio en el consumo se sitúa alrededor de los 13 años.

\section{Tabaquismo pasivo}

Una proporción de casos de EPOC ocurre en personas que no han fumado nunca. Entre estas personas no fumadoras ${ }^{65}$ el tabaquismo pasivo es un factor de riesgo que se ha implicado en la patogenia de la EPOC. El tabaquismo pasivo, también llamado humo ambiental de tabaco, es la inhalación involuntaria del humo de otra persona que fuma tabaco. Aunque se produzcan obviamente riesgos de salud menores a los del tabaquismo activo, éstos no sólo son evitables, sino involuntarios.

Diversos estudios observacionales han demostrado que el tabaquismo pasivo se asocia a un mayor riesgo de EPOC ${ }^{66-69}$. El estudio más definitivo que relaciona tabaquismo pasivo con EPOC se ha realizado en Guanzhou, China ${ }^{68}$. Se trata de un estudio en más de 6.000 participantes no fumadores. La mayoría (un $89,6 \%$ ) eran mujeres y la media de edad fue de 61 años ${ }^{68}$. Más de la mitad de los participantes afirmó ser fumador pasivo, y la duración del tabaquismo pasivo resultó directamente relacionada con el riesgo de EPOC ${ }^{68}$.

En nuestro medio se ha evaluado la repercusión de la exposición pasiva al tabaco sobre la función pulmonar de niños y adolescentes ${ }^{70}$, concluyendo que los parámetros espirométricos fueron significativamente inferiores entre los niños con algún progenitor fumador, siendo mayor el efecto negativo del tabaquismo pasivo sobre los parámetros relacionados con la vía aérea distal.

Según datos de la ENS de 2006, la exposición infantil al humo de tabaco en el domicilio se estima que es del $24,1 \%$ en niños y del $21,8 \%$ en niñas de 0 a 4 años, del 32,4 y el 32,7\%, respectivamente, en niños y niñas de 5 a 9 años, y del 39,6 y el 42,3\% en niños y niñas de 10 a 14 años ${ }^{64}$.

\section{Quema de combustible biomasa}

En todo el mundo, aproximadamente el $50 \%$ de todas las casas y el 90\% de casas rurales usan el combustible de biomasa (madera, carbón vegetal, otras materias vegetales y el estiércol) como su fuente principal de energía doméstica ${ }^{65}$.
En diversas revisiones sistemáticas se han identificado la biomasa y otros combustibles para uso en la calefacción o la cocina en países en vías de desarrollo como factor de riesgo de la EPOC en áreas rurales ${ }^{65,71-74}$. Un ejemplo de estos resultados es la revisión sistemática que analiza 15 estudios epidemiológicos (11 transversales y 4 casos y controles), y estima en las personas expuestas a la biomasa un riesgo de desarrollar EPOC más elevado que en los no expuestos (odds ratio $[\mathrm{OR}]=2,44$; intervalo de confianza [IC] del 95\%, 1,9-3,33), tanto en hombres como en mujeres, en pacientes con EPOC, fumadores y no fumadores $^{72}$.

En España se ha documentado un aumento del riesgo de ingreso por EPOC en mujeres que habían estado expuestas de forma significativa en su infancia y su juventud al humo de leña o de carbón. Este riesgo fue independiente del tabaquismo ${ }^{75}$. Los antecedentes de exposición a humo de leña o carbón deben interrogarse, en particular en personas con obstrucción crónica al flujo aéreo no fumadoras o con escasa exposición al tabaco.

\section{Factores de riesgo para el desarrollo de la EPOC}

\section{Contaminación atmosférica}

Las revisiones recientes concluyen que los factores de riesgo para el desarrollo de EPOC son cada vez mejor identificados e incluyen también muchas otras exposiciones ambientales, como la exposición ocupacional o ambiental al polvo y humos, tanto en países desarrollados como en vías de desarrollo ${ }^{65,76}$. Los contaminantes específicos estudiados en su relación con EPOC son el ozono, las partículas en suspensión (PM), el monóxido de carbono (CO), el dióxido de sulfuro $\left(\mathrm{SO}_{2}\right)$, el dióxido de nitrógeno $\left(\mathrm{NO}_{2}\right)$ y otros gases $^{65}$. La alta contaminación atmosférica, sobre todo asociada al tráfico rodado, es un factor desencadenante de exacerbaciones de EPOC en individuos susceptibles ${ }^{78}$.

Existen controversias respecto a la contaminación atmosférica como causa directa de $\mathrm{EPOC}^{65}$ y se considera que es cuantitativamente mínima. Un estudio reciente relaciona la exposición a largo plazo a concentraciones bajas de contaminación atmosférica y el aumento de riesgo de desarrollar EPOC grave; esta asociación se mantuvo significativa al tener en cuenta otros factores, como el tabaquismo ${ }^{78}$.

Hay varios indicadores multicomponente de la calidad del aire que respiramos, que combinan según pesos variables las partículas PM con los diferentes gases y actualmente se puede realizar una monitorización continua a tiempo real y en muchos casos a pequeña escala geográfica $^{79}$, lo que permite alertar a individuos con EPOC susceptibles, al igual que ocurre con los mapas de dispersión polínica en el asma y la rinitis.

\section{Exposición ocupacional}

Diversos estudios de cohortes de trabajadores han identificado que la exposición ocupacional a diversos polvos, gases y humos tóxicos se asocia a un mayor riesgo de EPOC, incluso después de tener en cuenta los factores confusores como el tabaco ${ }^{65,80}$. Los individuos con EPOC que están expuestos en su lugar de trabajo a polvos minerales o de todo tipo, gases o humos presentan una mayor gravedad de su EPOC que los que no tienen una exposición profesional significativa ${ }^{81}$. Estos hallazgos justifican la investigación de la exposición profesional en todos los pacientes y la adopción de medidas preventivas en el lugar de trabajo siempre que sea posible.

\section{Tuberculosis pulmonar}

La tuberculosis pulmonar se asocia a EPOC. En un estudio realizado en China en 8.784 personas mayores de 50 años, los pacientes con radiografías de tórax que demostraban que habían tenido una tuberculosis pulmonar presentaron un incremento de la obstrucción al flujo aéreo, independientemente de que fueran fumadores, estuvieran expuestos a biomasa o tuvieran antecedentes de asma ${ }^{82}$. En el estudio epidemiológico de EPOC en América Latina (PLATINO), el antecedente 
de tuberculosis se asociaba a un riesgo entre 2 y 4 veces mayor de desarrollar una EPOC, de forma independiente de otros factores de riesgo, en particular el tabaquismo ${ }^{83}$.

\section{Factores genéticos}

El enfisema hereditario debido a la deficiencia de alfa-1-antitripsina es el principal ejemplo de un factor genético. El déficit congénito de alfa-1-antitripsina predispone a una disminución acelerada de la función pulmonar. Es una enfermedad autosómica de expresión recesiva que causa EPOC y cirrosis hepática $35,84,85$. Se estima que es responsable del $1 \%$ de los casos de EPOC y del 2-4\% de los enfisemas. Es importante el diagnóstico temprano porque se puede administrar un tratamiento específico con la infusión intravenosa de alfa-1-antitripsina procedente de plasma de donantes en los casos que cumplan los estrictos criterios de tratamiento establecidos por las normativas nacionales e internacionales ${ }^{35}$. Todo paciente con EPOC debe tener al menos una determinación de sus concentraciones plasmáticas de alfa-1-antitripsina para descartar esta deficiencia ${ }^{86}$.

\section{Otros factores}

Otros factores de riesgo que se han descrito son la edad, el sexo, el envejecimiento pulmonar, las infecciones respiratorias repetidas del niño o adulto en edades tempranas y factores socioeconómicos ${ }^{87}$. La mayoría de estos factores asociados al desarrollo de EPOC no pueden ser modificados.

La prevalencia de la EPOC aumenta con la edad y es más frecuente en hombres, pero este hecho parece estar más relacionado con el efecto acumulativo de otros factores de riesgo a los que se ha expuesto el individuo a lo largo de la vida que con la edad o el sexo ${ }^{87}$. El papel de los antecedentes familiares es una mezcla de factores genéticos y ambientales.

En las clases sociales más desfavorecidas hay un mayor número de factores que se asocian al desarrollo de la enfermedad: mayor consumo de alcohol y tabaco, peores condiciones de las viviendas, infecciones frecuentes en la infancia y menos recursos sanitarios ${ }^{87}$.

\section{Comorbilidades en la EPOC}

Los pacientes con EPOC presentan con frecuencia efectos extrapulmonares, como pérdida no intencionada de peso, miopatía y un aumento de los parámetros de inflamación sistémica. También presentan un aumento de enfermedades crónicas asociadas, conocidas como comorbilidades, entendidas como la presencia de una o varias enfermedades reconocidas que coexisten con la patología de interés, en este caso, la EPOC.

En su revisión de 2011, la iniciativa GOLD recomienda explícitamente que la evaluación de la EPOC se haga midiendo los síntomas del paciente, el riesgo futuro de exacerbaciones, la gravedad de la anormalidad espirométrica y, por primera vez también, la identificación de las comorbilidades ${ }^{4}$.

Las causas para este aumento de la prevalencia de comorbilidades son, entre otras, el tabaquismo, la edad avanzada, la inflamación sistémica ${ }^{88} \mathrm{y}$, probablemente con menor relevancia, algunos factores genéticos no bien conocidos ${ }^{89}$.

Entre las comorbilidades más frecuentemente asociadas a la EPOC destacan las enfermedades cardiovasculares (cardiopatía isquémica, insuficiencia cardíaca o ictus), la hipertensión, la diabetes mellitus, la insuficiencia renal, la osteoporosis, las enfermedades psiquiátricas (ansiedad y depresión), el deterioro cognitivo, la anemia o las neoplasias, en especial, el cáncer de pulmón ${ }^{90}$ (tabla 1 ). Su presencia empeora el pronóstico de la EPOC y es una causa frecuente de mortalidad en esta población ${ }^{93}$. Aunque algunas comorbilidades se encuentran presentes en el momento del diagnóstico ${ }^{94}$, su cantidad y gravedad aumenta con la evolución de la $\mathrm{EPOC}^{95}$, hasta ser prácticamente la norma en pacientes con EPOC avanzada e ingresos hospitalarios por exacerbaciones ${ }^{96}$.
Tabla 1

Comorbilidades asociadas a la EPOC

Cardiopatía isquémica
Insuficiencia cardíaca
Arritmias
Hipertensión pulmonar
Cáncer de pulmón
Osteoporosis
Miopatía
Caquexia
Glaucoma/Cataratas
Trastornos psicológicos (ansiedad y depresión)
Deterioro cognitivo
Hipertensión arterial
Diabetes mellitus
Síndrome metabólico
Anemia
Síndrome de apnea del sueño
Enfermedad tromboembólica

Adaptada de: Barnes et $\mathrm{al}^{91}$ y Soriano et $\mathrm{al}^{92}$.

La probabilidad de tener cardiopatía isquémica -infarto de miocardio o angina - y la de presentar insuficiencia cardíaca se incremen$\tan 2$ y 4 veces, respectivamente, en los pacientes con EPOC, con independencia de otros factores de riesgo vascular, incluido el tabaquismo ${ }^{97}$. En la población de 35-44 años, la incidencia de infarto de miocardio es 10 veces mayor en los pacientes con EPOC, y la de tener un accidente cerebrovascular aumenta 2,5 veces $^{98}$. La incidencia de estas enfermedades aumenta en las semanas posteriores a una exacerbación de la EPOC ${ }^{99}$. La prevalencia de insuficiencia cardíaca se incrementa también con la gravedad de la EPOC: el 20\% en pacientes ambulatorios mayores de 65 años y el 30\% en pacientes hospitalizados por exacerbación ${ }^{100}$. Los pacientes con ambas enfermedades tienen menor capacidad de esfuerzo y mayor mortalidad a los 3 años del alta ${ }^{101,102}$. Los pacientes con enfisema e hiperinsuflación pulmonar pueden presentar insuficiencia cardíaca secundaria a la dificultad del llenado diastólico cardíaco ${ }^{103}$.

La EPOC es un factor de riesgo independiente para presentar cáncer de pulmón, con una prevalencia aumentada de 2 a 6 veces, con independencia de la historia de tabaquismo ${ }^{104,105}$.

Hasta el $40 \%$ de los pacientes con EPOC presentan simultáneamente ansiedad y/o depresión. Estos pacientes tienen peor calidad de vida, mayor deterioro funcional y mayor mortalidad ${ }^{106,107}$.

El uso de estatinas, inhibidores de la enzima de conversión de la angiotensina, antagonistas de receptores de la angiotensina II y bloqueadores beta es seguro en los pacientes con EPOC, en aquellos casos en los que estén indicados por su comorbilidad, y se ha relacionado en estudios retrospectivos con una disminución de la mortalidad ${ }^{108-110 .}$

\section{Historia natural}

El curso clínico de la EPOC refleja la disminución progresiva en el tiempo de la función pulmonar. Los datos referentes a la historia natural de los pacientes con EPOC se basan en los estudios de cohortes que incluyen como variable la función pulmonar. El estudio del British Medical Research Council (BMRC) ${ }^{61}$ muestra la diferente evolución de la función pulmonar según el hábito tabáquico y la susceptibilidad a éste. Los pacientes fumadores susceptibles, que suponen alrededor del 25\% de los fumadores, presentan una pendiente más pronunciada en el descenso del $\mathrm{FEV}_{1}$ relacionado con la edad. Si estos pacientes dejan de fumar, no mejoran su capacidad ventilatoria, pero su curva 
de deterioro de la función pulmonar adopta la pendiente de los no fumadores, con lo que se ralentiza la evolución de la enfermedad ${ }^{61}$.

Resultados más recientes de la cohorte del Framingham Heart Study Offspring ${ }^{62}$ y diversos estudios de intervención ${ }^{111,112}$ indican que la progresión de la enfermedad no es uniforme, aunque el efecto beneficioso de dejar de fumar se observa de forma constante en todos ellos. La cohorte Framingham muestra que los cambios en la función pulmonar de los no fumadores desde la adolescencia hasta la vejez son diferentes en los hombres que en las mujeres, pero muestra un similar aumento en la tasa de declinación del $\mathrm{FEV}_{1}$ y un mayor beneficio cuanto más temprano sea el abandono del hábito tabáquico, especialmente si se realiza antes de los 40 años $^{62}$.

Los pacientes con síntomas de EPOC representan un grupo susceptible de disminución acelerada de la función pulmonar ${ }^{62}$. La hipersecreción de moco y las infecciones recurrentes de las vías respiratorias bajas aumentan el riesgo de exacerbaciones e inciden, por tanto, en la historia natural de la enfermedad, favoreciendo el descenso del FEV 1 . Además, los pacientes con frecuentes agudizaciones presentan un descenso mayor del FEV ${ }_{1}^{51,113}$.

Los diversos fenotipos intentan explicar la existencia de pacientes con EPOC en los que predominan la destrucción parenquimatosa y la pérdida de elasticidad (enfisema) o la hiperreactividad bronquial (mixto EPOC-asma), o pacientes agudizadores con pérdida acelerada de función pulmonar causada por las agudizaciones. Los resultados del estudio ECLIPSE han mostrado que los tres factores pronósticos significativamente asociados a una pérdida acelerada de función pulmonar son los que identifican y caracterizan a tres de los fenotipos descritos en GESEPOC: la presencia de enfisema, la positividad de la prueba broncodilatadora y las agudizaciones frecuentes ${ }^{114}$.

\section{Proceso diagnóstico e intervenciones de cribado de la EPOC}

Puntos clave: en el proceso diagnóstico de la EPOC se deben seguir 3 pasos:

- Primer paso: diagnóstico de EPOC.

- Segundo paso: caracterización del fenotipo clínico.

- Tercer paso: valoración multidimensional de la gravedad.

La espirometría es imprescindible para poder establecer el diagnóstico de EPOC.

\section{Paso 1: diagnóstico de la EPOC}

\section{Sospecha clínica}

Los tres pasos del proceso diagnóstico se resumen en la figura 2. El diagnóstico clínico de sospecha de EPOC ha de considerarse en todas las personas adultas con exposición a factores de riesgo, básicamente el hábito tabáquico (con una exposición de al menos 10 años-paquete) que presentan tos crónica, con o sin producción de esputo o disnea. Habitualmente el paciente con EPOC es o ha sido fumador durante un tiempo prolongado y refiere el comienzo de sus síntomas a partir de los 35 años.

Las manifestaciones clínicas de la EPOC son inespecíficas y en las etapas tempranas de la enfermedad la sintomatología puede ser mínima y la progresión e intensidad de los síntomas muy variable en cada individuo. Con cierta frecuencia los pacientes con EPOC pueden permanecer asintomáticos hasta estadios avanzados de la enfermedad. La presencia de tos crónica y expectoración suele preceder en varios años a la obstrucción de la vía aérea, y no todos los individuos que presenten estos síntomas acabarán desarrollando una EPOC.

La disnea es el síntoma principal de la enfermedad y el que mayor pérdida de calidad de vida produce, aunque no es apreciada de forma similar por todos los pacientes, especialmente en los de mayor edad. Aparece en fases avanzadas, es persistente, empeora con el ejercicio y se desarrolla de forma progresiva hasta limitar las actividades de la

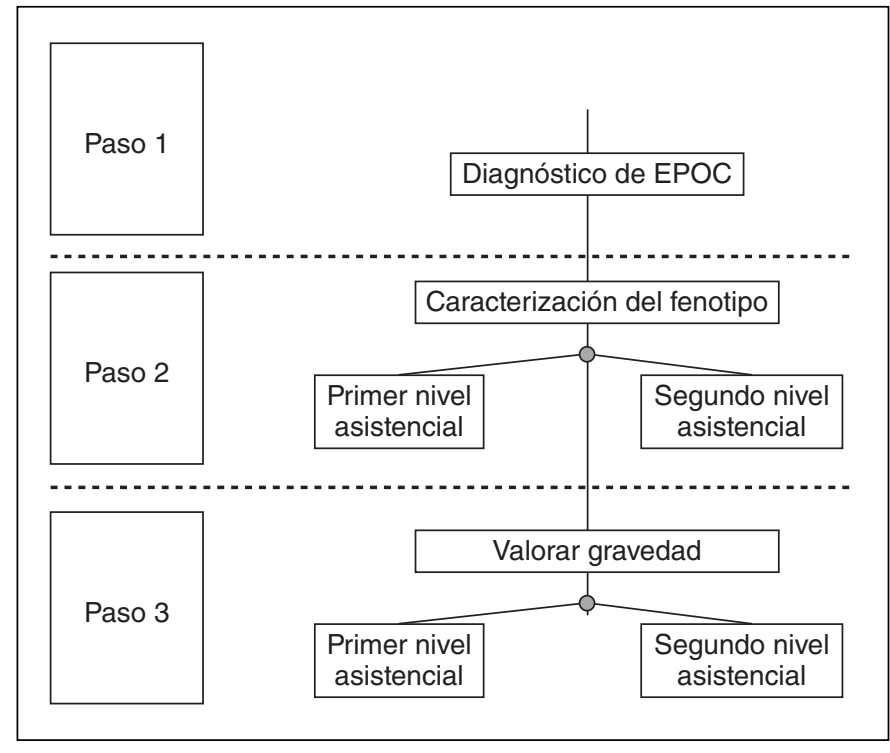

Figura 2 Pasos en la evaluación diagnóstica del paciente con EPOC.

vida diaria ${ }^{115}$. Cuando se consulta por este motivo es frecuente que ya tenga una evolución de años y que el paciente haya ido adaptándose a la limitación de sus actividades.

La tos crónica se caracterizada por su inicio insidioso, aunque más tarde aparece a diario, de predominio matutino, suele ser productiva y puede no tener relación con el grado de obstrucción al flujo aéreo ni con la gravedad de la enfermedad.

La expectoración suele ser mucoide y deben valorarse siempre sus características por su utilidad clínica. Así, el cambio de color o de volumen del esputo puede ser indicativo de una exacerbación, un volumen excesivo ( $>30 \mathrm{ml} /$ día) indica la presencia de bronquiectasias, la expectoración hemoptoica obliga a descartar otros diagnósticos, principalmente carcinoma broncopulmonar.

Pueden presentarse también otros síntomas inespecíficos, como sibilancias u opresión torácica, y en los estadios avanzados de la enfermedad son comunes la pérdida de peso, la anorexia y síntomas de depresión y ansiedad.

Se ha observado una relación estrecha entre la afectación respiratoria de la EPOC y la afectación de diversa índole en otros órganos, así como una mayor prevalencia de diversas enfermedades crónicas, ya sean respiratorias o no, en pacientes con EPOC respecto a la población general $^{94,95}$. Los diversos efectos asociados a la enfermedad que afectan a otros órganos se han denominado efectos sistémicos. Entre estos efectos sistémicos figuran como más relevantes la pérdida de peso, la disfunción muscular, la osteoporosis, la depresión y la inflamación sistémica.

La sospecha clínica debe confirmarse por medio de una espirometría forzada con prueba broncodilatadora realizada en la fase estable de la enfermedad, imprescindible para establecer el diagnóstico de EPOC (fig. 3).

\section{Espirometría}

La espirometría forzada es la prueba que permite el diagnóstico de la EPOC, ya que define la limitación al flujo aéreo. La espirometría es una prueba no invasiva, sencilla, barata, estandarizada, reproducible y objetiva que mide la limitación al flujo aéreo. Su técnica requiere unas condiciones que garanticen su calidad para que los resultados tengan valor clínico. Estas condiciones están bien establecidas, tanto para el instrumental como para la técnica, y es imprescindible que el profesional que la realice esté formado y entrenado ${ }^{116}$.

En el ámbito de la atención primaria, que es donde se atiende a la gran mayoría de los pacientes con EPOC, se debe realizar una espiro- 
Figura 3 Primer paso en la evaluación del paciente con EPOC. Algoritmo de sosecha diagnóstica y diagnóstico de la EPOC. LIN: límite inferior de la normalidad; PBD: prueba broncodilatadora.

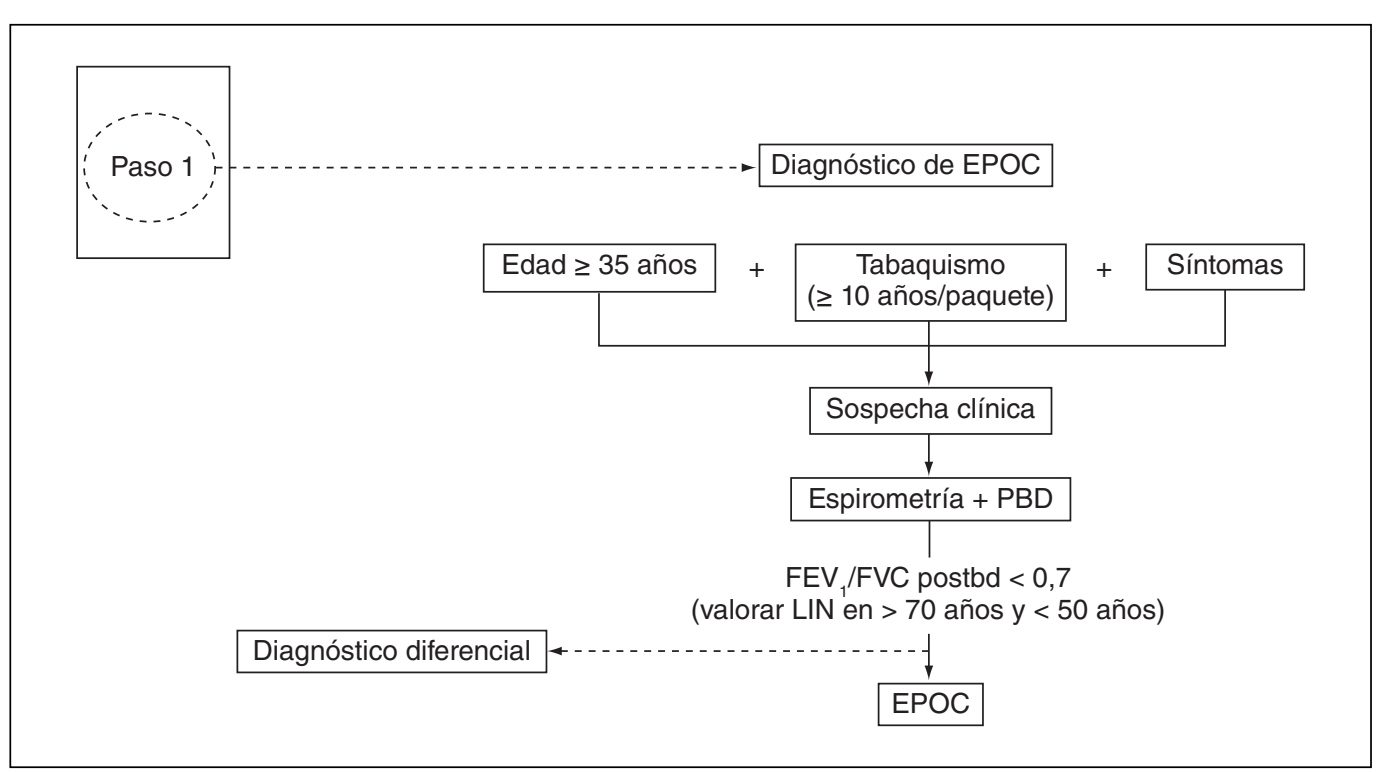

metría de buena calidad, para lo cual se debe proporcionar una formación adecuada y continuada que garantice la calidad ${ }^{117,118}$.

El diagnóstico de la EPOC se basa en la disminución del flujo espiratorio, medido a través del $\mathrm{FEV}_{1}$ y su cociente con la capacidad vital forzada $\left(\mathrm{FEV}_{1} / \mathrm{FVC}\right)$. Se considera que hay obstrucción al flujo aéreo si

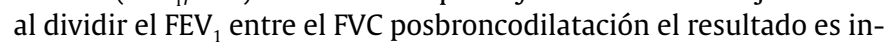
ferior a 0,7. Los objetivos de la espirometría en la evaluación inicial del paciente son la confirmación del diagnóstico de sospecha y evaluar la gravedad de la obstrucción al flujo aéreo.

La utilización del cociente $\mathrm{FEV}_{1} / \mathrm{FVC}$ posbroncodilatación en el diagnóstico de la EPOC comporta un riesgo de infradiagnóstico en edades jóvenes y de sobrediagnóstico en edades avanzadas ${ }^{119,120}$. Esta consideración es particularmente importante para evitar el sobrediagnóstico de EPOC en individuos de edad avanzada (mayores de 70 años) que no tengan exposición significativa al tabaco, con síntomas respiratorios poco importantes o con un $\mathrm{FEV}_{1}$ posbroncodilatador normal ${ }^{119}$.

La prueba broncodilatadora, que consiste en repetir la espirometría después de administrar un broncodilatador de forma estandarizada, permite objetivar la reversibilidad de la obstrucción. Es positiva si se confirma un aumento en el $\mathrm{FEV}_{1}$ superior a $200 \mathrm{ml}$ y al $12 \%$ del valor prebroncodilatación. La reversibilidad de la obstrucción después de la prueba broncodilatadora es muy variable en la EPOC y con frecuencia se observan cambios a lo largo del tiempo. Por este motivo, en la actualidad, la existencia de una prueba broncodilatadora significativa no excluye el diagnóstico de EPOC ni confirma el de asma. Los pacientes con un fenotipo mixto EPOC-asma se caracterizan, entre otras cosas, por manifestar una gran reversibilidad de su obstrucción ${ }^{1}$.

\section{Otras pruebas diagnósticas}

Radiografía simple de tórax. La radiografía de tórax puede ser normal en la mayoría de los casos o mostrar signos de hiperinsuflación pulmonar, atenuación vascular y radiotransparencia, que indican la presencia de enfisema. También pueden detectarse bullas, zonas radiolucentes o signos de hipertensión arterial pulmonar. La sensibilidad es baja para detectar la EPOC (del 50\% en los pacientes moderados-graves) $)^{121,122}$, pero una lectura sistemática de la radiografía de tórax es muy útil para la detección de enfisema ${ }^{123}$. Se debe solicitar para la valoración inicial y para descartar complicaciones: disnea inexplicada de origen brusco (neumotórax), cambio en el patrón de la tos o esputo hemoptoico (neoplasia), o sospecha de neumonía.
Tomografía computarizada de tórax. La tomografía computarizada (TC) de tórax permite evaluar los cambios patológicos en la estructura pulmonar asociados a la EPOC y separar los diversos fenotipos de la EPOC de acuerdo con la contribución de la enfermedad de la vía aérea o del enfisema. La gravedad de la disnea se correlaciona con la medida cuantitativa del enfisema y del grosor de la vía aérea en la TC, y la tos y las sibilancias se correlacionan con el grosor de la vía aérea ${ }^{124}$. También las vías aéreas engrosadas se asocian a síntomas de bronquitis crónica y agudizaciones frecuentes ${ }^{125}$. Por último, la extensión del enfisema medido por TC cuantitativa se correlaciona con la pérdida de función pulmonar ${ }^{126}$ y con mayor mortalidad ${ }^{127}$.

La TC es muy útil en el diagnóstico de los pacientes con fenotipo agudizador, ya que puede demostrar la presencia de bronquiectasias, así como su gravedad y extensión ${ }^{33}$. La presencia de bronquiectasias en un paciente con EPOC y agudizaciones infecciosas frecuentes implicará la necesidad de adoptar pautas de tratamiento similares a las recomendadas para pacientes con bronquiectasias de diferente etiología ${ }^{128}$.

Se recomienda realizar la TC de tórax en el segundo ámbito asistencial en pacientes con fenotipo enfisema si se plantea algún tipo de tratamiento quirúrgico y en pacientes con fenotipo agudizador, sea enfisematoso o bronquítico crónico.

Análisis de sangre. El hemograma no suele afectarse, a menos que se presenten complicaciones. La leucocitosis con neutrofilia puede aparecer en las exacerbaciones de causa infecciosa. Una leucocitosis leve puede ser debida al tabaquismo activo o al tratamiento con corticoides. La eosinofilia puede hacer pensar en la posibilidad de un fenotipo mixto EPOC-asma, al igual que una concentración elevada de IgE. La poliglobulia es proporcional a la gravedad y a la antigüedad de la insuficiencia respiratoria. Aproximadamente, un 12,6\% de los hombres y un $18,5 \%$ de las mujeres con EPOC pueden presentar anemia, de predominio normocítico-normocrómico. Esta anemia se ha relacionado con la presencia de inflamación sistémica y comporta un peor pronóstico ${ }^{129}$.

En todo paciente con EPOC se determinará la concentración plasmática de alfa-1-antitripsina, al menos en una ocasión ${ }^{35,130}$.

Pulsioximetría. Es la medida no invasiva de la saturación de oxígeno de la hemoglobina de la sangre arterial. No sustituye la gasometría arterial. Es útil en la valoración de la sospecha de hipoxemia, ya sea en los pacientes muy graves o en el tratamiento de las exacerbaciones. 
Tabla 2

Pruebas complementarias en el estudio del paciente con EPOC

\begin{tabular}{|c|c|}
\hline Prueba & Indicaciones \\
\hline Gasometría arterial & $\begin{array}{l}\text { Obstrucción grados III y IV o } \mathrm{FEV}_{1}<1 \mathrm{l} \\
\text { Disnea MRC } 3-4 \\
\text { Signos de hipertensión pulmonar y/o cor pulmonale } \\
\text { Indicación y seguimiento de pacientes con OCD } \\
\text { Hematocrito }>55 \% \\
\text { Cianosis y/o pulsioximetría }<92 \%\end{array}$ \\
\hline Volúmenes pulmonares estáticos & $\begin{array}{l}\text { Sospecha de componente restrictivo } \\
\text { Obstrucción grados III y IV para estudio de hiperinsuflación pulmonar }\end{array}$ \\
\hline Capacidad de difusión del monóxido de carbono (DLCO) & $\begin{array}{l}\text { Obstrucción grados III y IV } \\
\text { Hipoxia o disnea intensa, no proporcional al grado de obstrucción } \\
\text { Estudio de enfisema }\end{array}$ \\
\hline Alfa-1 antitripsina sérica & En todo paciente con EPOC al menos en una ocasión \\
\hline TC torácica & $\begin{array}{l}\text { Fenotipo agudizador para diagnóstico de bronquiectasias } \\
\text { Descartar otras neumopatías asociadas } \\
\text { Diagnóstico y evaluación del enfisema }\end{array}$ \\
\hline Prueba de la marcha de 6 minutos & $\begin{array}{l}\text { Calcular índice BODE } \\
\text { Obstrucción grados III-IV } \\
\text { Valoración previa a rehabilitación respiratoria }\end{array}$ \\
\hline Presiones máximas inspiratoria/respiratoria & $\begin{array}{l}\text { Sospecha de miopatía-neuropatía asociada } \\
\text { Valoración previa a rehabilitación respiratoria }\end{array}$ \\
\hline Pulsioximetría nocturna & Sospecha de desaturación durante el sueño o síndrome de apnea-hipopnea del sueño \\
\hline Electrocardiograma & $\begin{array}{l}\text { Obstrucción grados III y IV } \\
\text { Sospecha de enfermedad cardiovascular asociada o cor pulmonale }\end{array}$ \\
\hline Estudio del sueño & $\begin{array}{l}\text { Oximetría nocturna/polisomnografía: sólo si se sospecha síndrome de apnea-hipopnea del sueño, poliglobulia } \\
\text { y/o insuficiencia cardíaca }\end{array}$ \\
\hline Prueba de esfuerzo & Valoración previa a la rehabilitación pulmonar \\
\hline Ecocardiografía & $\begin{array}{l}\text { Sospecha de hipertensión pulmonar: cor pulmonale } \\
\text { Sospecha de cardiopatía asociada o tromboembolia pulmonar }\end{array}$ \\
\hline
\end{tabular}

Prueba de marcha de 6 minutos. Consiste en que el paciente recorra la mayor distancia posible en 6 minutos, en terreno llano y siguiendo un protocolo estandarizado. El paciente deberá ir en compañía del examinador, quien previamente le ha informado de las características de la prueba. Es una prueba de referencia de la capacidad de tolerancia a esfuerzos submáximos y ha demostrado ser un buen predictor de supervivencia y de la tasa de reingresos hospitalarios por exacerbación ${ }^{131}$. Además, es un componente del índice BODE.

Otras pruebas complementarias. En la tabla 2 se relacionan diversas pruebas complementarias en el estudio del paciente con EPOC.

\section{Estrategias de cribado de la EPOC}

Debido al elevado índice de infradiagnóstico, es necesario adoptar una actitud proactiva en la detección y el diagnóstico temprano de la EPOC. Esta enfermedad cumple los criterios aceptados para la aplicación de estrategias de cribado: a) que sea una enfermedad prevalente; b) que el resultado del diagnóstico modifique el hábito tabáquico, y c) que el tratamiento en fases tempranas modifique el pronóstico de la EPOC $^{132}$

El tipo de cribado preferido en EPOC sería un cribado "oportunista" en consulta: es la situación en la que el paciente acude a la consulta por otros motivos y se aprovecha la ocasión para, utilizando cuestionarios y/o medidas objetivas sencillas de la función pulmonar, detectar a los pacientes con alto riesgo de presentar la enfermedad. En éstos se realizaría posteriormente una confirmación diagnóstica mediante una espirometría, considerada la prueba de referencia para el diagnóstico de la EPOC².

En general, se considera más eficiente el cribado de pacientes con síntomas. Así, se necesitaría realizar espirometría en 5 pacientes fumadores asintomáticos para detectar un solo caso de EPOC; en cam- bio, la relación es de 1:2 o 1:3 si se realiza a pacientes seleccionados tras aplicarles cuestionarios de síntomas. Por tanto, por consenso, se establece la conveniencia de hacer una espirometría a todo paciente mayor de 35 años con una historia de tabaquismo y la presencia de algún síntoma respiratorio ${ }^{2,133}$. Sin embargo, dada la dificultad para realizar espirometría en todos los casos, suelen utilizarse cuestionarios con preguntas de tipo clínico que sirven de "filtro" al posible paciente. También se han utilizado aparatos sencillos que miden de manera fiable y rápida alguna variable relacionada con la función respiratoria, como el $\mathrm{FEV}_{1}$ y el $\mathrm{FEV}_{6}$. De este modo, se realizaría espirometría confirmatoria sólo a los casos positivos por cuestionario o por espirometría de cribado.

Se han diseñado diferentes cuestionarios que pudieran servir para reclutar a los pacientes con más posibilidades de presentar EPOC antes de realizar la espirometría. Podrían utilizarse antes de entrar en la consulta médica, para autoseleccionar a pacientes, o en la población general, como cuestionarios de acceso libre.

El punto de corte es el resultado del cuestionario que ofrece el mejor rendimiento para clasificar correctamente a los verdaderos positivos y negativos sometidos al test. Esto supone un equilibrio entre sensibilidad y especificidad; entre valor predictivo positivo y negativo. En el cribado de enfermedades de alta prevalencia como la EPOC se precisan pruebas de alta sensibilidad (pocos falsos negativos) y gran valor predictivo negativo. En España sólo está validado en castellano el COPD-PS ${ }^{134}$, a partir del original de Martínez et al ${ }^{135}$ (anexo 4). Incluye 5 preguntas relativas a la disnea, la expectoración, la limitación de actividades, el hábito de fumar y la edad. La puntuación total máxima es de 10 puntos, y de 0 la mínima, siendo de fácil autocumplimentación, incluso por medio de internet. El punto de corte más útil para la sospecha de EPOC es de 5.

Otra estrategia es la utilización de sistemas portátiles, económicos y sencillos que midan algunos parámetros respiratorios escogidos 
para ser utilizados como método de "cribado" en pacientes con alto riesgo de presentar EPOC. Éstos son:

1. Espirometría de 1 segundo: determina $\mathrm{FEV}_{1}$ y PEF. Se ha usado el $\mathrm{FEV}_{1}$ como correlato funcional de la obstrucción en algún estudio de cribado. Puede ser útil para la monitorización domiciliaria de un paciente ya diagnosticado ${ }^{136}$.

2. Espirometría de 2 segundos: mediante el espirómetro "Multifev". Utiliza la capacidad vital no forzada (CV) en lugar de la capacidad vital forzada (FVC), evitando así la aparición de un falso patrón restrictivo por atrapamiento aéreo ${ }^{137}$.

3. Espirometría de 6 segundos: determina el flujo espiratorio en los primeros 6 segundos de la maniobra espiratoria forzada $\left(\mathrm{FEV}_{6}\right)$, en lugar de la FVC. El PIKO-6 y el Vitalograph-COPD-6, son los más utilizados. Para el índice $\mathrm{FEV}_{1} / \mathrm{FEV}_{6}$ se propone usar 0,75 como punto de corte, con lo que clasificaría correctamente como EPOC al 82,4\% de los individuos estudiados ${ }^{134,138,139}$.

\section{Paso 2: caracterización del fenotipo}

Tal como se ha descrito en el apartado Fenotipos clínicos de la EPOC, GesEPOC reconoce 4 fenotipos con características clínicas, pronósticas y de respuesta al tratamiento diferentes. Estos fenotipos son: no agudizador, mixto EPOC-asma, agudizador con enfisema y agudizador con bronquitis crónica ${ }^{1,9}$.

Las denominaciones de mixto, enfisema y bronquitis crónica son excluyentes y el diagnóstico se basa en las manifestaciones clínicas predominantes y el cumplimiento de los criterios diagnósticos. Cualquiera de estos tres tipos de pacientes puede ser un agudizador frecuente, de manera que estas característcas se combinan para formar los 4 fenotípos clínicos con tratamiento diferenciado (fig. 4):

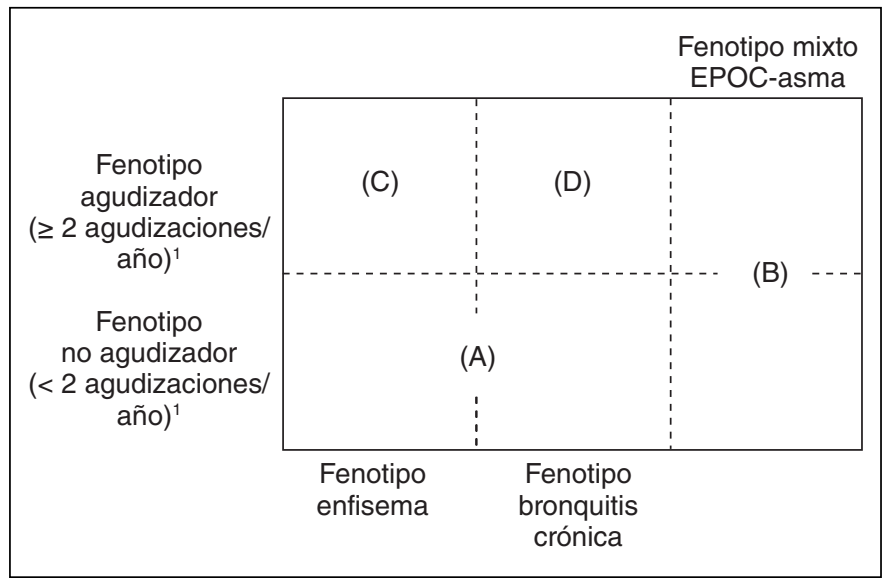

Figura 4 Fenotipos clínicos de la EPOC según GesEPOC.

- Tipo A: EPOC no agudizador con enfisema o bronquitis crónica.

- Tipo B: EPOC mixto con asma, tenga o no agudizaciones frecuentes.

- Tipo C: EPOC agudizador con enfisema.

- Tipo D: EPOC agudizador con bronquitis crónica.

Para el proceso diagnóstico de identificación de los 4 fenotipos se deben seguir los siguientes pasos (fig. 5):

1. ¿Ha presentado el paciente 2 o más agudizaciones al menos de moderada gravedad (que han requerido tratamiento con corticides

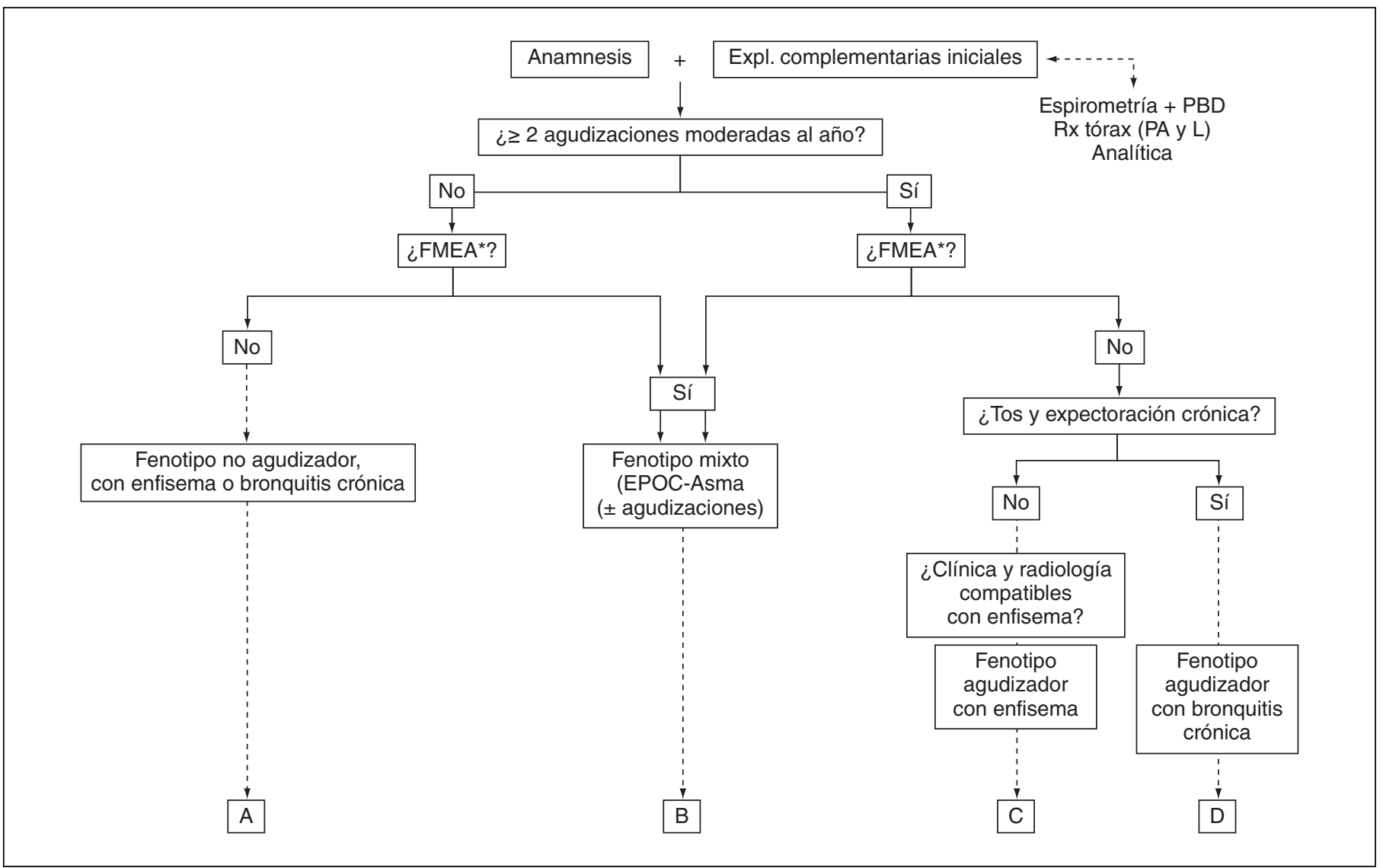

Figura 5 Algoritmo diagnóstico de los fenotipos clínicos de la EPOC. BC: bronquitis crónica (tos y expectoración crónica); FMEA: fenotipo mixto EPOC-asma; L: lateral; PA: postero-anterior; PBD: prueba broncodilatadora. 
sistémicos y/o antibióticos) el año previo separadas al menos por un mes? Si la respuesta es afirmativa, el paciente se clasifica como agudizador.

2. ¿Tiene el paciente características de fenotipo mixto? Para el diagnóstico de fenotipo mixto debe cumplir al menos dos criterios mayores o un criterio mayor y dos menores, según se describe más adelante $^{140}$. Si la respuesta es afirmativa se clasificará como mixto, tanto si es agudizador como si no.

3. ¿Presenta el paciente tos y expectoración al menos durante 3 meses al año en 2 años consecutivos? En caso afirmativo se clasificará como bronquitis crónica.

4. ¿Presenta el paciente características clínicas, radiológicas y/o funcionales de enfisema pulmonar? En caso afirmativo se clasificará como fenotipo enfisema. En la mayoría de estos casos los pacientes presentan disnea como síntoma principal. Para su confirmación se requiere la demostración de atrapamiento aéreo (capacidad residual funcional $[\mathrm{FRC}]>120 \%$, volumen residual $[\mathrm{RV}]>140 \%$ del teórico o cociente capacidad inspiratoria/capacidad pulmonar total [IC/TLC] < $25 \%$ o demostración de enfisema por técnicas de imagen (TC) o alteración significativa de la capacidad de difusión del monóxido de carbono corregida por la hemoglobina (KCO < 80\%).

\section{Tipo A: EPOC no agudizador con enfisema o bronquitis crónica}

El paciente tipo A se caracteriza por presentar como máximo un episodio de agudización al año. Es un paciente de menor riesgo de deterioro de su calidad de vida, de pérdida de función pulmonar o de mortalidad que el agudizador y presenta unas peculiaridades en su tratamiento. Los fármacos antiinflamatorios de que disponemos actualmente para el tratamiento de la EPOC (corticides inhalados y roflumilast) están indicados, entre otros criterios, para pacientes con agudizaciones, por lo que no estarán recomendados en este tipo de pacientes, sean bronquíticos crónicos o enfisematosos.

\section{Tipo B: EPOC mixto con asma, tenga o no agudizaciones frecuentes}

Para caracterizar al fenotipo mixto, un amplio grupo de expertos ha llegado al consenso de establecer unos criterios mayores y menores (tabla 3). La historia previa o diagnóstico previo de asma, la positividad de la prueba broncodilatadora y la eosinofilia en el esputo son los más importantes.

Para el diagnóstico de fenotipo mixto se deben cumplir 2 criterios mayores o uno mayor y 2 menores ${ }^{140}$. Esta clasificación es muy restrictiva debido a la falta de pruebas científicas concluyentes entre la relación de los distintos criterios y la respuesta al tratamiento en la EPOC. Se requieren estudios prospectivos para la validación de estos criterios.

Algunos estudios han demostrado que los pacientes con fenotipo mixto pueden tener agudizaciones frecuentes. Si cursan con escasa expectoración o con expectoración blanca y mucoide es probable que sean agudizaciones no infecciosas, de tipo inflamatorio o eosinofílico ${ }^{46,47}$.

\section{Tipo C: EPOC agudizador con enfisema}

Los pacientes con fenotipo agudizador tienen mayor riesgo de hospitalización y mortalidad; debido a la diferente respuesta a los tratamientos farmacológicos es importante diferenciar los que tienen un fenotipo enfisematoso o bronquítico crónico.

En el primer ámbito asistencial, el diagnóstico de enfisema será clínico/funcional y radiológico. Serán pacientes con escasa o sin expectoración crónica, con disnea de esfuerzo y "hábito enfisematoso" definido por tendencia al bajo IMC, debilidad muscular periférica y respiratoria, y signos de atrapamiento aéreo a la inspección o en la radiología de tórax (aplanamiento diafragmático y aumento del espacio aéreo retroesternal).

Para caracterizar mejor el enfisema en un segundo ámbito asistencial nos podemos ayudar de la medición del atrapamiento aéreo mediante los volúmenes estáticos pulmonares y la prueba de transferencia del monóxido de carbono (DLCO). La realización de una TC de tórax de forma habitual para diagnosticar el enfisema no suele ser
Tabla 3

Criterios mayores y menores para establecer el diagnóstico de fenotipo mixto EPOC-asma en la EPOC

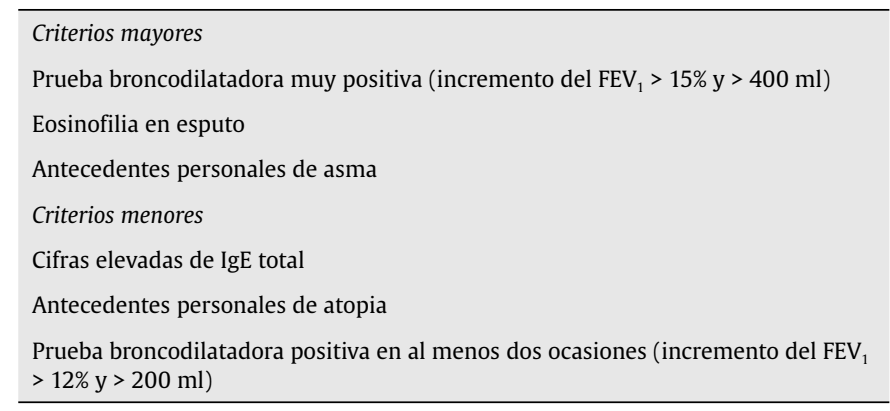

Tomada de: Soler-Cataluña et al $^{140}$.

necesaria y no se recomienda. En cambio, la TC de tórax en los pacientes con enfisema será necesaria cuando se piense en la posibilidad de un tratamiento quirúrgico o si presentan agudizaciones frecuentes ${ }^{57}$.

\section{Tipo D: EPOC agudizador con bronquitis crónica}

En el caso de un paciente con fenotipo agudizador debemos saber si coexiste con el fenotipo bronquitis crónica, por lo que preguntaremos por la presencia de tos con expectoración al menos 3 meses al año de 2 años consecutivos.

En el caso de paciente de fenotipo agudizador con bronquitis crónica debemos realizar una TACAR para comprobar si el paciente tiene bronquiectasias ${ }^{33}$, ya que puede requerir un tratamiento diferenciado, como se expone en las normativas de tratamiento de las bronquiectasias no debidas a fibrosis quística y que se comentará más adelante.

En pacientes agudizadores con bronquitis crónica y bronquiectasias se debe realizar un cultivo de esputo en fase estable, en especial si la expectoración no es blanca o mucoide durante las fases de estabilidad clínica ${ }^{141}$. Si el cultivo es positivo se trata de una infección bronquial crónica, que requiere un tratamiento específico y especializado.

\section{Casos de fenotipo no aclarado}

Puede haber casos de difícil clasificación, que compartan características propias de más de un fenotipo. En este caso prestaremos atención al problema más importante para el paciente. En primer lugar, si presenta agudizaciones frecuentes debemos dirigir el tratamiento a su prevención, y en segundo lugar, si presenta signos de fenotipo mixto debemos tratar el componente inflamatorio. En pacientes con bronquitis crónica es posible descubrir lesiones de enfisema si se realiza una TC de tórax, pero la presencia de tos con expectoración seguirá siendo el síntoma principal que clasifica a estos pacientes como fenotipo bronquitis crónica.

\section{¿Se puede cambiar de fenotipo?}

A pesar de que los fenotipos son en general estables, puede ser que espontáneamente o por acción del tratamiento cambien en su expresión. Por ejemplo, un paciente agudizador puede dejar de presentar agudizaciones o un paciente mixto puede negativizar su prueba broncodilatadora y reducir su inflamación eosinofílica gracias al tratamiento. En los casos en que los cambios son debidos al tratamiento es recomendable continuar con la misma pauta. Excepto para el caso de los corticoides inhalados, no hay estudios de retirada de fármacos en la EPOC estable.

\section{Paso 3: clasificación de gravedad de la EPOC}

Puntos clave:

- La clasificación de gravedad de la EPOC debe hacerse de forma multidimensional y se basa esencialmente en el índice BODE. 
- En atención primaria, puede utilizarse el índice BODEx como alternativa al BODE. Si la puntuación del BODEx es $\geq 5$ puntos se precisará la realización de la prueba de ejercicio para precisar el nivel de gravedad.

- Se establecen 5 niveles de gravedad pronóstica de la EPOC: I (leve), II (moderada), III (grave), IV (muy grave) y V (final de vida).

- La gravedad de la obstrucción se clasifica según los 4 grados de GOLD: leve $\left(\mathrm{FEV}_{1}>80 \%\right)$, moderada $\left(\mathrm{FEV}_{1}: 50-80 \%\right)$, grave $\left(\mathrm{FEV}_{1}: 30\right.$ $49 \%)$ y muy grave $\left(\mathrm{FEV}_{1}<30 \%\right)$.

- Otros parámetros como la puntuación del CAT, la intensidad de los síntomas o el número y la gravedad de agudizaciones también deben valorarse en la toma de decisiones terapéuticas.

\section{Escalas de gravedad}

En las últimas décadas, la clasificación de gravedad de la EPOC se ha basado casi exclusivamente en la determinación del grado de limitación al flujo aéreo, evaluado a través del $\mathrm{FEV}_{1}$ posbroncodilatador. Múltiples estudios han demostrado que, tanto los valores basales del $\mathrm{FEV}_{1}$ como su descenso anual, son poderosos predictores de mortalidad y también de morbilidad ${ }^{142}$.

En la actualidad se reconoce que la EPOC es una enfermedad heterogénea y que un único parámetro como el $\mathrm{FEV}_{1}$, a pesar de ser de utilidad, no permite estratificar adecuadamente a los pacientes. En este sentido, datos recientes indican la existencia de otros marcadores que, bien solos o combinados, pueden mejorar la información pronóstica aportada por el $\mathrm{FEV}_{1}$. La disnea, la capacidad de ejercicio, la hiperinsuflación, la presencia de agudizaciones graves repetidas o, por ejemplo, el estado nutricional, son algunas de las variables pronósticas más importantes ${ }^{55,143,144}$.

Aglutinar las principales variables pronósticas en un mismo índice ha sido propósito de estudio en los últimos años, generándose distintos índices pronósticos. El primero de todos ellos, y el considerado de referencia, es el índice BODE propuesto por Celli et al ${ }^{145}$. Este índice integra la información del índice de masa corporal (IMC) (B, de bode mass index), $\mathrm{FEV}_{1}$ (O, de airflow obstruction), disnea (D) y capacidad de ejercicio (E), evaluada mediante la prueba de marcha de 6 minutos. Un incremento en un punto del índice BODE se asocia a un aumento del 34\% en la mortalidad por todas las causas (hazard ratio [HR], 1,34; IC del 95\%, $1,26-1,42 ; \mathrm{p}<0,001)$ y del $62 \%$ en la mortalidad de causa respiratoria $(\mathrm{HR}=1,62 \text {; IC del 95\%, 1,48-1,77; } \mathrm{p}<0,001)^{145}$. En su conjunto, el índice BODE es más util que el $\mathrm{FEV}_{1}$ como variable pronóstica.

La tabla 4 muestra los componentes del BODE y su ponderación, que oscila entre 0 y 10 puntos, de menor a mayor riesgo de mortalidad. Esta puntuación se agrupa en los siguientes cuatro cuartiles:

- Cuartil 1: 0-2 puntos.

- Cuartil 2: 3-4 puntos.

- Cuartil 3: 5-6 puntos.

- Cuartil 4: 7-10 puntos.

Existe una amplia experiencia en el uso del índice BODE y se ha comprobado su utilidad en distintas situaciones clínicas, como la pre-

Tabla 4

Índice BODE

\begin{tabular}{|c|c|c|c|c|c|}
\hline \multicolumn{2}{|c|}{ Marcadores } & \multicolumn{4}{|c|}{ Puntuación } \\
\hline & & $\mathbf{0}$ & 1 & 2 & 3 \\
\hline B & IMC & $>21$ & $\leq 21$ & & \\
\hline 0 & $\mathrm{FEV}_{1}(\%)$ & $\geq 65$ & $50-64$ & $36-49$ & $\leq 35$ \\
\hline D & Disnea (MRC) & $0-1$ & 2 & 3 & 4 \\
\hline E & $6 \mathrm{MM}(\mathrm{m})$ & $\geq 350$ & $250-349$ & $150-249$ & $\leq 149$ \\
\hline
\end{tabular}

IMC: índice de masa corporal; MRC: escala modificada de la MRC; 6 MM: distancia recorrida en la prueba de los 6 minutos marcha.

Propuesto por Celli et al ${ }^{145}$. dicción de agudizaciones ${ }^{146}$, la asociación con ansiedad-depresión ${ }^{147}$, la respuesta a la rehabilitación respiratoria ${ }^{148}$ o la cirugía de reducción de volumen ${ }^{149}$.

Aunque la determinación de los cuatro componentes del BODE es relativamente sencilla, lo cierto es que la generalización del índice ha sido más lenta de lo esperado, en especial en atención primaria, probablemente debido a la necesidad de realizar la prueba de marcha de 6 minutos que, aunque de baja complejidad y coste, exige disponibilidad de tiempo y un espacio adecuado para su realización. Por este motivo, algunos autores han propuesto la sustitución de esta prueba de ejercicio (E del índice BODE) por el registro de las exacerbaciones graves (Ex de exacerbaciones graves), en lo que se denomina índice $\mathrm{BODEx}^{150}$. Ambos índices muestran un elevado grado de correlación y similar capacidad pronóstica de mortalidad $(r=0,86$; $p<0,001$; estadístico $C$ de 0,75 para BODE y 0,74 para BODEx; $\mathrm{p}=\mathrm{NS}$ ).

La tabla 5 muestra los componentes del BODEx y su ponderación. En este índice la puntuación obtenida oscila entre 0 y 9 puntos y se agrupa en los siguientes cuartiles:

- Cuartil 1: 0-2 puntos.

- Cuartil 2: 3-4 puntos.

- Cuartil 3: 5-6 puntos.

- Cuartil 4: 7-9 puntos.

Tabla 5

Índice BODEx

\begin{tabular}{llllll}
\hline \multicolumn{5}{l}{ Marcadores } & \multicolumn{2}{l}{ Puntuación } \\
\hline & & $\mathbf{0}$ & $\mathbf{1}$ & $\mathbf{2}$ & $\mathbf{3}$ \\
\hline $\mathrm{B}$ & $\mathrm{IMC}\left(\mathrm{kg} / \mathrm{m}^{2}\right)$ & 21 & $\leq 21$ & & \\
$\mathrm{O}$ & $\mathrm{FEV}_{1}(\%)$ & $\geq 65$ & $50-64$ & $36-49$ & $\leq 35$ \\
$\mathrm{D}$ & Disnea (mMRC) & $0-1$ & 2 & 3 & 4 \\
Ex & Exacerbaciones graves & 0 & $1-2$ & $\geq 3$ & \\
\hline
\end{tabular}

IMC: índice de masa corporal; mMRC: escala modificada de la MRC; Ex: exacerbaciones graves (se incluyen únicamente visitas a urgencias hospitalarias o ingresos).

Propuesto por Soler-Cataluña et al ${ }^{150}$.

Para la evaluación de la disnea en los índices BODE/BODEx se recomienda la escala modificada del Medical Research Council (mMRC) ${ }^{151}$, que clasifica la disnea en 4 grados (tabla 6).

\section{Clasificación de gravedad según GesEPOC}

De acuerdo con el principio de valoración multidimensional, GesEPOC propone una clasificación de gravedad en 5 niveles, cuyo determinante principal de gravedad es el índice BODE y sus distintos cuartiles (fig. 6).

Tabla 6

Escala de disnea modificada del MRC (mMRC)

\begin{tabular}{ll}
\hline Grado & Actividad \\
\hline 0 & Ausencia de disnea al realizar ejercicio intenso \\
1 & $\begin{array}{l}\text { Disnea al andar de prisa en llano, o al andar subiendo una pendiente } \\
\text { poco pronunciada }\end{array}$ \\
2 & $\begin{array}{l}\text { La disnea le produce una incapacidad de mantener el paso de otras } \\
\text { personas de la misma edad caminando en llano o tener que parar a } \\
\text { descansar al andar en llano a su propio paso }\end{array}$ \\
& $\begin{array}{l}\text { La disnea hace que tenga que parar a descansar al andar unos } 100 \mathrm{~m} \\
\text { o pocos minutos después de andar en llano }\end{array}$ \\
4 & $\begin{array}{l}\text { La disnea le impide al paciente salir de casa o aparece con } \\
\text { actividades como vestirse o desvestirse }\end{array}$ \\
\hline
\end{tabular}




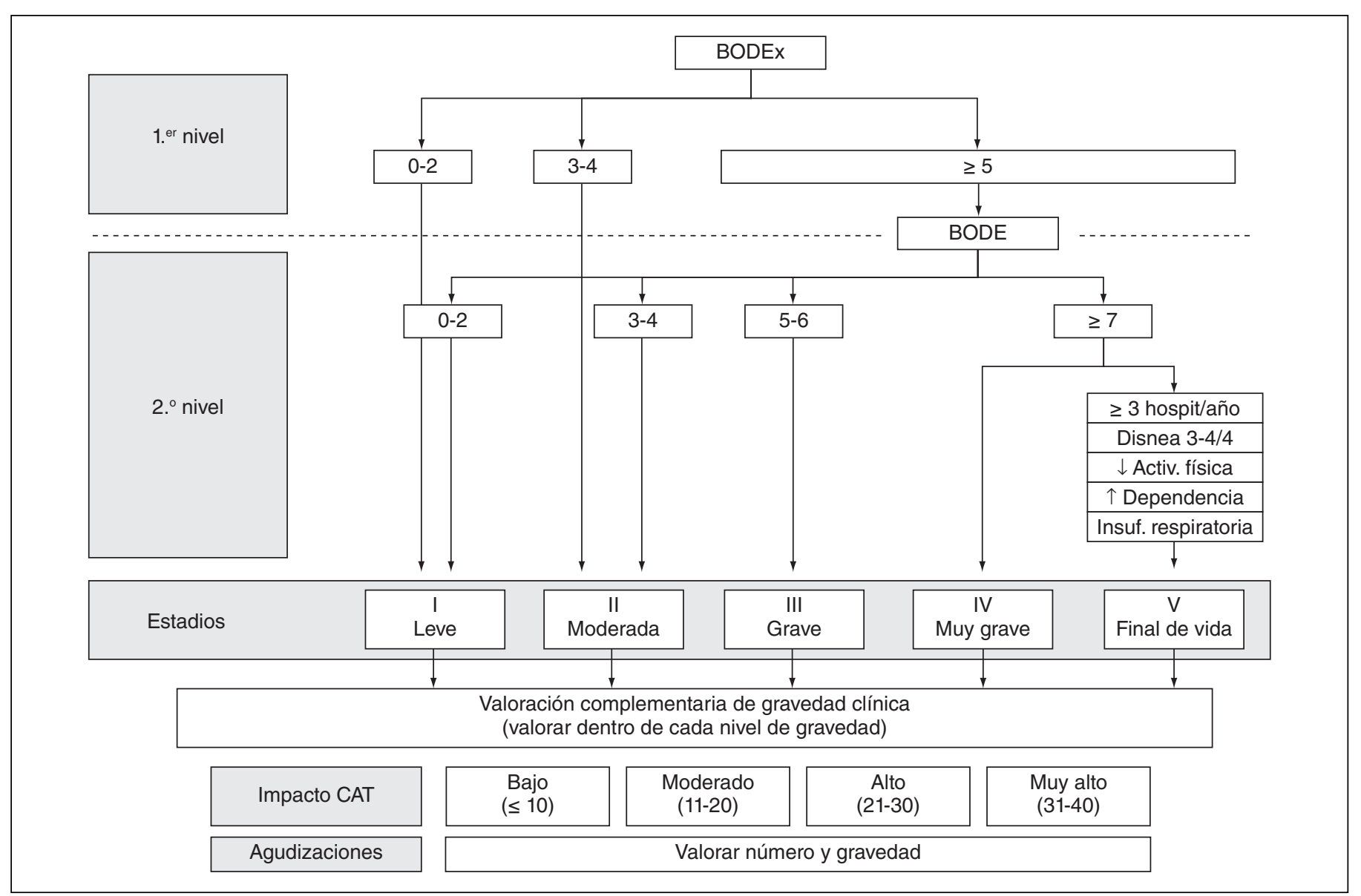

Figura 6 Clasificación de la EPOC en niveles de gravedad según evaluación multidimensional.

En ausencia de información sobre la distancia recorrida en la prueba de marcha de 6 minutos, GesEPOC reconoce al índice BODEx como una alternativa, únicamente para los niveles I y II (EPOC leve o moderada).

Todos los pacientes que tengan un BODEx igual o superior a los 5 puntos deberán realizar la prueba de ejercicio para precisar su nivel de gravedad. Los centros que no dispongan de esta prueba en su cartera de servicios deberán remitir al paciente a un segundo ámbito asistencial.

GesEPOC propone un quinto nivel de gravedad, destinado a identificar a los pacientes con elevado riesgo de muerte o de final de vida. Los criterios establecidos para reconocer este nivel V son los siguientes:

BODE $\geq 7$ puntos y además al menos uno de los siguientes:

$\bullet \geq 3$ hospitalizaciones al año.

- Disnea 3 o 4 de la escala mMRC, a pesar de tratamiento óptimo.

- Baja actividad física.

- Elevada dependencia para las actividades diarias.

- Insuficiencia respiratoria crónica.

Valoración alternativa de la gravedad de la EPOC

Los índices multidimensionales guardan una relación más estrecha con el pronóstico de la EPOC que cualquier variable considerada individualmente. Sin embargo, aún no hay pruebas científicas disponibles que indiquen que el tratamiento orientado por estos índices obtenga mejores resultados clínicos que el orientado por los síntomas clásicos y la función pulmonar. Por este motivo, debemos conocer otros parámetros de gravedad y su posible correspondencia con los niveles de gravedad medidos mediante BODE/BODEx.
La implementación de los índices BODE/BODEx en la práctica asistencial requiere familiarizarse con la utilización de escalas de riesgo. Esta aproximación puede precisar un período de adaptación y, por este motivo, GesEPOC señala una aproximación que puede ser orientativa de la gravedad del paciente y que es más intuitiva a partir de los datos habituales recogidos en la visita clínica. La última normativa GOLD 2011, aunque con una aproximación discretamente diferente, también recomienda realizar una valoración multidimensional en la que, además del $\mathrm{FEV}_{1}$, se contempla la frecuencia de agudizaciones, los síntomas (disnea) y la puntuación del COPD Assessment Test (CAT) (anexo 5$)^{4}$.

Las variables que se pueden utilizar para esta aproximación al nivel de gravedad son: la obstrucción al flujo aéreo medida por el $\mathrm{FEV}_{1}(\%)$, la disnea medida por la escala mMRC, el nivel de actividad física y las hospitalizaciones en los 2 años precedentes.

De acuerdo con la guía GOLD, clasificaremos la obstrucción bronquial medida por el $\mathrm{FEV}_{1}(\%)$ en 4 grados (tabla 7 ). Consideramos el punto de corte de $\mathrm{FEV}_{1}(\%)$ del $50 \%$ como el umbral para considerar a un paciente grave o muy grave.

La escala mMRC de disnea (tabla 6) nos permite una aproximación a la gravedad del paciente. Diversos estudios han demostrado el valor pronóstico de la disnea, que en algunos trabajos incluso supera en valor predictivo de mortalidad al $\mathrm{FEV}_{1}(\%)^{143}$.

La medida de la actividad física también tiene un valor pronóstico muy importante en la EPOC, tanto para exacerbaciones y descenso de la función pulmonar, como para hospitalizaciones y, finalmente, para la mortalidad ${ }^{152-154}$. Para evaluar la actividad física se han utilizado métodos objetivos, como acelerómetros; también se utilizan cuestionarios validados ${ }^{155}$, pero diversos estudios demuestran que las medidas autorreferidas por los pacientes son sencillas, están al alcance de 
Tabla 7

Clasificación de la gravedad de la obstrucción bronquial

\begin{tabular}{ll}
\hline Grado de obstrucción & FEV $_{\mathbf{1}}$ posbroncodilatador \\
\hline I. Leve & $\geq 80 \%$ \\
II. Moderada & $50 \% \leq \mathrm{FEV}_{1}<80 \%$ \\
III. Grave & $30 \% \leq \mathrm{FEV}_{1}<50 \%$ \\
IV. Muy grave & $\mathrm{FEV}_{1}<30 \%$ \\
\hline
\end{tabular}

$\mathrm{FEV}_{1}$ : volumen espiratorio máximo en 1 segundo.

todos los ámbitos asistenciales y han ofrecido muy buenos resultados como predictores de desenlaces de gravedad (hospitalización y muerte $)^{152}$. Además, los cambios en la actividad física en la EPOC se asocian a cambios significativos en la calidad de vida ${ }^{152}$. Para la medida de la actividad física se propone el cálculo de los minutos de actividad física diaria de intensidad equivalente a más de 3,0 MET ${ }^{156}$ o minutos diarios de actividad física moderada. Según estos datos, los puntos de corte que se obtendrían son: baja actividad $<30$ minutos, actividad moderada entre 30 y 120 minutos y actividad intensa $>120$ minutos. Como actividad física moderada se entiende: caminar, tareas domésticas (limpiar, barrer, pasar el aspirador, etc.), pasear con animales domésticos.

Respecto a las hospitalizaciones, se ha demostrado que son un factor muy importante de riesgo de mortalidad futura en pacientes con cualquier nivel de gravedad de la obstrucción al flujo aéreo ${ }^{157}$. Además, son circunstancias fáciles de recordar por los pacientes. Las hospitalizaciones sufridas en los 2 años precedentes proporcionan una importante información sobre la gravedad de la EPOC.

Los puntos de corte orientativos se exponen en la figura 7. Se debe recordar que ningún parámetro por si solo permite clasificar el nivel de gravedad de la EPOC. Si no se ha calculado el índice BODE o BODEx, el médico que atiende el paciente debe considerar todos los aspectos enumerados y clasificar de forma orientativa al paciente en uno de los niveles de gravedad GesEPOC, según una valoración global de todos los factores. Así, por ejemplo, si un paciente tiene un $\mathrm{FEV}_{1} \%$ posbroncodilatador del $45 \%$, disnea de grado 1 , actividad física moderada y ausencia de hospitalizaciones, la aproximación tradicional a partir del grado de obstrucción bronquial sugiere un nivel III de gravedad $\left(\mathrm{FEV}_{1}\right.$ del 30-50\%). Sin embargo, al valorar en su conjunto el resto de parámetros clínicos se deberá reducir su nivel de gravedad y clasificarlo como moderado o nivel II de gravedad. El cálculo del índice BODE o BODEx precisará, en cualquier caso, la clasificación definitiva de gravedad y se recomienda su uso como primera opción.

En la tabla 8 se presenta un perfil clínico-funcional de un paciente tipo de cada nivel de gravedad de GesEPOC.

Ajuste de la intensidad del tratamiento en cada nivel de gravedad de la EPOC

La elección del tratamiento debe basarse en el fenotipo clínico del paciente y su intensidad se determinará por el nivel de gravedad multidimensional, de acuerdo con el esquema anterior. Sin embargo, dentro de un mismo nivel de gravedad, existen otros parámetros que pueden modular la intensidad del tratamiento, entre los que destacan la gravedad de los síntomas, la frecuencia y la intensidad de las agudizaciones o el deterioro de la calidad de vida relacionada con la salud (CVRS).

\section{Frecuencia y gravedad de las agudizaciones}

La valoración multidimensional de la EPOC deberá completarse con el registro del número de agudizaciones y su gravedad. Si bien las agudizaciones graves o muy graves quedan incluidas dentro del índice BODEx, y las hospitalizaciones se consideran en la evaluación complementaria de la gravedad, las agudizaciones de menor intensidad (leves o moderadas) también han demostrado impactar sobre el estado de salud de los pacientes, por lo que deben ser tenidas en cuenta, con independencia del nivel de gravedad de la EPOC. La prevención de agudizaciones de cualquier intensidad es un objetivo terapéutico de primer orden.

Los cambios en la frecuencia y la intensidad de las agudizaciones se deben considerar dentro de cada nivel de gravedad como un criterio para modificar la intensidad de tratamiento.

\section{Cuestionario CAT (COPD Assessment Test)}

Para cuantificar directamente el impacto de la EPOC sobre la CVRS se han desarrollado distintos cuestionarios específicos. Sin embargo, debido a su extensión y la complejidad, su uso no se ha generalizado.

El CAT es un cuestionario estandarizado, breve y sencillo que ha sido recientemente desarrollado para ser utilizado en la práctica clí-

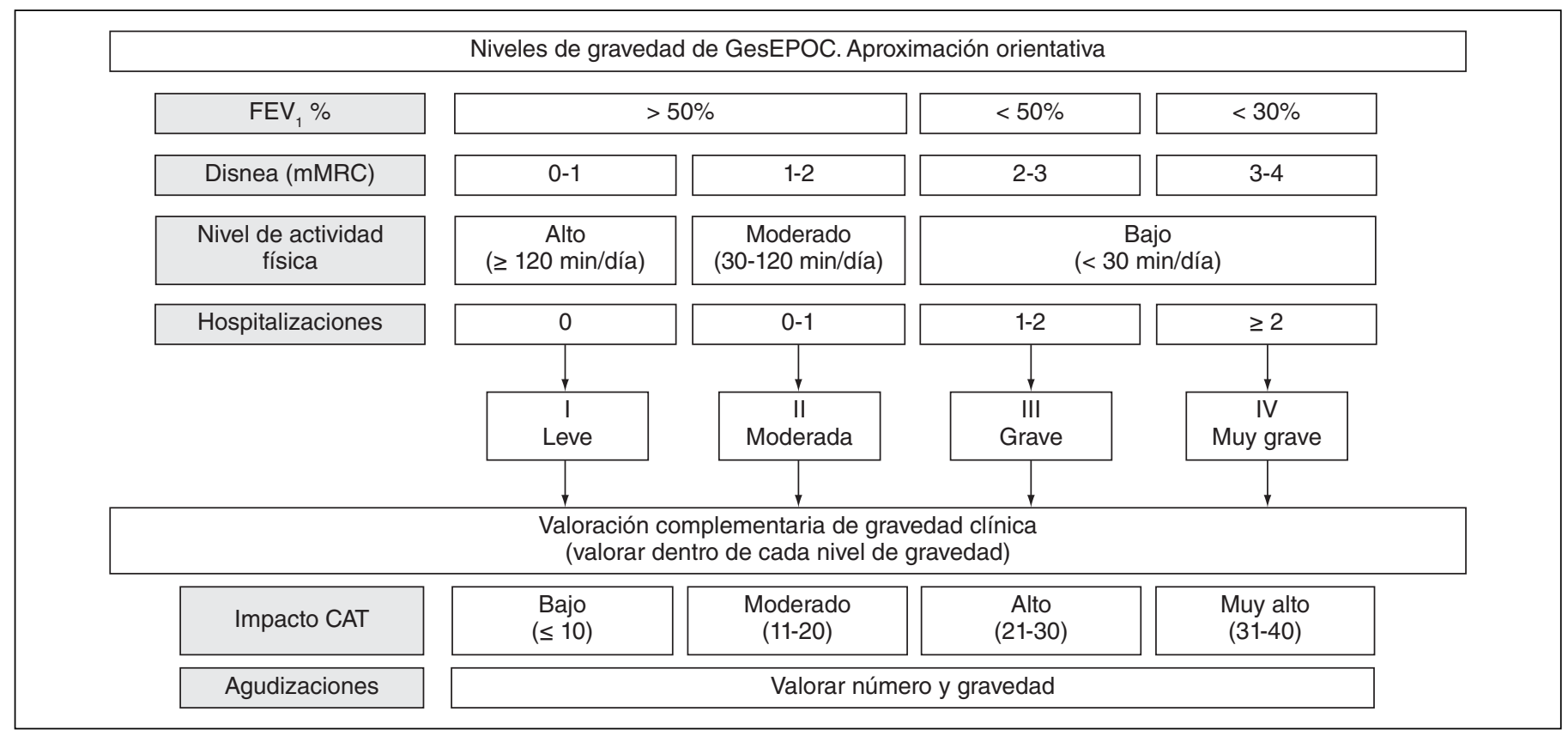

Figura 7 Aproximación orientativa a la gravedad de la EPOC. CAT: COPD Assessment Test. 
Tabla 8

Características clínico-funcionales tipo de los pacientes incluidos en cada nivel de gravedad de GesEPOC

\begin{tabular}{|c|c|c|c|}
\hline Nivel de gravedad & BODE & BODEX & Perfil clínico-funcional tipo* \\
\hline I. Leve & $0-2$ & $0-2$ & $\begin{array}{l}\text { Pocos síntomas (disnea } 0-1) \\
\text { Bajo impacto en el CAT }(\leq 10) \\
\text { Pocas agudizaciones }(<2 / \text { año }) \\
\text { Buena actividad física } \\
\text { Escasa obstrucción bronquial }\left(\mathrm{FEV}_{1}>50 \%\right)\end{array}$ \\
\hline II. Moderado & $3-4$ & $3-4$ & $\begin{array}{l}\text { Síntomas moderados (disnea 1-2) } \\
\text { Bajo o moderado impacto en el CAT }(<20) \\
\text { Puede haber algunas agudizaciones (1-2/año), en general leves o moderadas. En raras ocasiones precisan } \\
\text { hospitalización } \\
\text { Aceptable actividad física } \\
\text { FEV }_{1} 50-65 \%\end{array}$ \\
\hline III. Grave & $5-6$ & $\geq 5$ & $\begin{array}{l}\text { Síntomas importantes (disnea 2-3) } \\
\text { Moderado-alto impacto en el CAT } \\
\text { Frecuentes agudizaciones, algunas de ellas graves } \\
\text { Moderada o escasa actividad física } \\
\text { FEV }_{1} 30-50 \%\end{array}$ \\
\hline IV. Muy grave & $\geq 7$ & $\geq 5$ & $\begin{array}{l}\text { Paciente muy sintomático (disnea } 3-4) \\
\text { Alto o muy alto impacto en el CAT }(>30) \text {. } \\
\text { Frecuentes agudizaciones que pueden precisar ingreso hospitalario } \\
\text { Actividad física baja o casi nula } \\
\text { Insuficiencia respiratoria habitualmente hipoxémica } \\
\text { Obstrucción bronquial muy grave }\left(\mathrm{FEV}_{1}<30 \%\right)\end{array}$ \\
\hline V. Final de la vida & $\geq 7+$ & $\geq 5^{+}$ & $\begin{array}{l}\text { Paciente muy sintomático (disnea } 4) \\
\text { Muy alto impacto en el CAT }(>30) \\
\text { - } \geq 3 \text { hospitalizaciones al año } \\
\text { - Actividad física casi nula } \\
\text { - Insuficiencia respiratoria habitualmente hipercápnica } \\
\text { - Obstrucción bronquial muy grave }\left(\mathrm{FEV}_{1}<30 \%\right)\end{array}$ \\
\hline
\end{tabular}

*El perfil clínico-funcional es sólo orientativo y no sustituye a la clasificación de gravedad por el índice BODE/BODEx. CAT: COPD Assessment Test.

nica asistencial ${ }^{158,159}$. Consta de 8 sencillas preguntas que miden aspectos sobre la tos, la expectoración, la opresión torácica, la disnea, las actividades domésticas, la autoconfianza, el sueño y la energía (anexo 5). Cada una de estas preguntas puede ser ponderada en una puntuación que oscila entre 0 (mejor) y 5 (peor), por lo que su puntuación global se sitúa entre 0 y 40 puntos y el impacto sobre la CVRS guarda estrecha relación con estas puntuaciones ${ }^{160}$. La validación internacional muestra que el CAT tiene buena validez y fiabilidad. La consistencia interna es excelente (alfa de Cronbach $=0,99$ ), el test-retest en pacientes estables es muy bueno (coeficiente de correlación intraclase de 0,8 ) y la correlación con el St' George Respiratory Questionnaire (SGRQ) es del 0,8 , con diferencias significativas entre pacientes estables y agudizados ( 5 unidades sobre una escala de 40 puntos $)(\mathrm{p}<0,0001)^{158}$. En España, además de la validación específica, también se han analizado otros aspectos, como la sensibilidad al cambio durante las exacerbaciones o la posibilidad de uso autoadministrado, con buenos resultados (resultados pendientes de publicación).

En la actualidad no hay umbrales de CAT que permitan recomendar una modificación en la pauta terapéutica, aunque la Guía GOLD
2011 recomienda usar 10 unidades como punto de corte de gravedad para intensificar el tratamiento. Para orientar sobre la gravedad de los pacientes y el impacto de la enfermedad se recomiendan los umbrales reconocidos en el desarrollo y la validación del cuestionario (www. catestonline.org) (fig. 7) ${ }^{161}$.

\section{Recomendaciones sobre diagnóstico de la EPOC}

Se resumen en la tabla 9.

Estándares de calidad asistencial sobre diagnóstico de la EPOC

Se resumen en la tabla 10.

\section{Prevención de la EPOC. Tratamiento del tabaquismo}

Puntos clave:

- El tratamiento integral de la EPOC debe contemplar la intervención terapéutica sobre el tabaquismo como medida prioritaria.

Tabla 9

Recomendaciones sobre diagnóstico de la EPOC

\begin{tabular}{|c|c|c|c|c|}
\hline & NR & Recomendación & Calidad de la evidencia & Fuerza de la recomendación \\
\hline \multirow[t]{2}{*}{ Cribado } & R001 & $\begin{array}{l}\text { La espirometría de cribado se debe realizar en las personas mayores de } 35 \\
\text { años con historia acumulada de tabaquismo (> } 10 \text { años-paquete) y con } \\
\text { síntomas respiratorios }\end{array}$ & Moderada $^{\mathrm{a}}$ & Fuerte a favor ${ }^{\mathrm{a}}$ \\
\hline & R002 & $\begin{array}{l}\text { En ausencia de síntomas respiratorios, de momento no se dispone de } \\
\text { suficiente información para recomendar o no la búsqueda activa y sistemática } \\
\text { de pacientes con EPOC }\end{array}$ & Moderada $^{\mathrm{a}}$ & Débil en contra ${ }^{a}$ \\
\hline
\end{tabular}

NR: numeración de las recomendaciones.

aReferencia de SEPAR-semFyC ${ }^{6}$. 
Tabla 10

Estándares de calidad asistencial sobre diagnóstico de la EPOC

\begin{tabular}{|c|c|c|c|}
\hline & ECA & Criterio de calidad & Indicador \\
\hline Diagnóstico de EPOC & E01 & $\begin{array}{l}\text { Se considerará EPOC a todo paciente mayor de } 35 \text { años que } \\
\text { tenga factores de riesgo, como exposición a humo de tabaco (> } \\
10 \text { años-paquete), síntomas respiratorios y presente una } \\
\text { espirometría en fase de estabilidad con obstrucción escasamente } \\
\text { reversible, definida por un cociente } \mathrm{FEV}_{1} / \mathrm{FVC}<0,70 \text {, tras } \\
\text { broncodilatador }\end{array}$ & $\begin{array}{l}\text { N.o de pacientes correctamente diagnosticados de EPOC/N. } .^{\circ} \text { total de } \\
\text { pacientes etiquetados de EPOC }\end{array}$ \\
\hline $\begin{array}{l}\text { Evaluación clínica } \\
\text { inicial }\end{array}$ & E02 & $\begin{array}{l}\text { La historia clínica del paciente con sospecha de EPOC deberá } \\
\text { incluir, como mínimo, la siguiente información: } \\
\text { - Anamnesis tabáquica y/o factores de riesgo para EPOC } \\
\text { - Comorbilidad } \\
\text { - Presencia de síntomas indicativos de EPOC (disnea, tos y/o } \\
\text { expectoración) } \\
\text { - Agudizaciones }\end{array}$ & $\begin{array}{l}\text { N. }{ }^{\circ} \text { de historias clínicas donde se recoge completamente esta } \\
\text { información/N. }{ }^{\circ} \text { total de historias clínicas de pacientes con EPOC }\end{array}$ \\
\hline $\begin{array}{l}\text { Caracterización } \\
\text { (fenotipo clínico) }\end{array}$ & E03 & $\begin{array}{l}\text { En todo paciente con EPOC se debe intentar establecer el } \\
\text { fenotipo clínico. GesEPOC establece } 4 \text { fenotipos clínicos } \\
\text { diferentes: } \\
\text { A) Fenotipo no agudizador, con enfisema y/o bronquitis crónica } \\
\text { B) Fenotipo mixto EPOC-asma } \\
\text { C) Fenotipo agudizador con enfisema } \\
\text { D) Fenotipo agudizador con bronquitis crónica }\end{array}$ & $\begin{array}{l}\text { N.․ de pacientes con EPOC en los que se establece el fenotipo clínico/ } \\
\text { №. total de pacientes con EPOC }\end{array}$ \\
\hline Clasificación & E04 & $\begin{array}{l}\text { El nivel de gravedad de un paciente con EPOC se determinará } \\
\text { mediante el índice BODE. Como alternativa, para pacientes } \\
\text { leves-moderados se puede utilizar el índice BODEx. Los niveles } \\
\text { de gravedad serán los siguientes: } \\
\text { I (leve): BODE 0-2 puntos o BODEx 0-2 puntos } \\
\text { II (moderado): BODE } 3-4 \text { puntos o BODEx 3-4 puntos } \\
\text { III (grave): BODE: 5-6 puntos } \\
\text { IV (muy grave): BODE: } \geq 7 \text { puntos } \\
\text { V (final de vida): BODE } \geq 7 \text { puntos y alguno de los siguientes } \\
\text { criterios: } \\
\text { • } \geq 3 \text { hospitalizaciones en el último año } \\
\text { - Disnea de grado } 3 \text { o } 4 \text { (escala mMRC) } \\
\text { - Bajo nivel de actividad física } \\
\text { - Alta dependencia } \\
\text { - Insuficiencia respiratoria }\end{array}$ & $\begin{array}{l}\text { N. }{ }^{\circ} \text { de pacientes correctamente clasificados/N. } .^{\circ} \text { total de pacientes con } \\
\text { EPOC }\end{array}$ \\
\hline Criterios de remisión & E05 & $\begin{array}{l}\text { Los pacientes con nivel de gravedad III, IV o V deberán ser } \\
\text { evaluados por un especialista en neumología, al menos en una } \\
\text { ocasión }\end{array}$ & $\begin{array}{l}\text { N. }{ }^{\circ} \text { de pacientes con nivel de gravedad III-V que son evaluados, al } \\
\text { menos en una ocasión, por especialista de neumología/N.. total de } \\
\text { pacientes con EPOC en nivel III, IV o V }\end{array}$ \\
\hline $\begin{array}{l}\text { Exploraciones } \\
\text { complementarias } \\
\text { iniciales }\end{array}$ & E06 & $\begin{array}{l}\text { En la primera evaluación de un paciente con EPOC se debe } \\
\text { realizar: } \\
\text { - Espirometría con prueba broncodilatadora } \\
\text { - Analítica } \\
\text { - Radiografía de tórax }\end{array}$ & $\begin{array}{l}\text { N. }{ }^{\circ} \text { de pacientes con estas pruebas realizadas/N. } .^{\circ} \text { total de pacientes } \\
\text { con EPOC }\end{array}$ \\
\hline Alfa-1-antitripsina & E07 & $\begin{array}{l}\text { En todo paciente con EPOC se determinará la concentración } \\
\text { plasmática de alfa-1-antitripsina, al menos en una ocasión }\end{array}$ & $\begin{array}{l}\text { N. de pacientes a los que se les determina la concentración } \\
\text { plasmática de alfa-1-antitripsina, al menos en una ocasión/N. }{ }^{\circ} \text { total } \\
\text { de pacientes con EPOC }\end{array}$ \\
\hline $\begin{array}{l}\text { Exploraciones } \\
\text { complementarias } \\
\text { adicionales }\end{array}$ & E08 & $\begin{array}{l}\text { En pacientes con nivel de gravedad } \geq 3 \text {, se realizarán las } \\
\text { siguientes determinaciones, al menos en una ocasión: } \\
\text { - Medición de volúmenes pulmonares estáticos } \\
\text { - Capacidad de difusión de monóxido de carbono } \\
\text { - Prueba de esfuerzo }\end{array}$ & $\begin{array}{l}\text { N. }{ }^{\circ} \text { de pacientes con EPOC grave-muy grave a los que se les realiza } \\
\text { cada una de estas pruebas, al menos en una ocasión/N. }{ }^{\circ} \text { total de } \\
\text { pacientes con EPOC grave-muy grave }\end{array}$ \\
\hline
\end{tabular}

ECA: estándares de calidad asistencial (Soler-Cataluña et al ${ }^{150}$ ).

- El tratamiento del tabaquismo en la EPOC debe comprender dos aspectos importantes:

1. Apoyo psicológico con soporte social.

2. Tratamiento farmacológico con medicación de primera línea, según dosis ajustada y duración adecuada.

El tabaquismo es una enfermedad adictiva crónica y recidivante, que está catalogada con el código F-17 en la Clasificación Internacional de las Enfermedades. Es la primera causa evitable de muerte prematura en el mundo. Todos los profesionales sanitarios estamos obligados a diagnosticar y tratar correctamente a los fumadores para ayudarles a dejar de serlo.

El tabaco es el factor de riesgo más importante para desarrollar EPOC: existen evidencias morfológicas, epidemiológicas y genéticas que así lo avalan. La eliminación del hábito tabáquico es la medida más eficaz en la prevención de esta enfermedad y tiene un impacto determinante en la reducción de la mortalidad ${ }^{162}$.

El abandono del tabaco es la medida más eficaz y coste-efectiva en el tratamiento de la EPOC (evidencia alta, recomendación fuerte a favor). Una revisión sistemática apoya el hecho de que la eliminación del tabaco retrasa la pérdida de función pulmonar y mejora la supervivencia, incluso en la EPOC grave ${ }^{163}$. El abandono del tabaco, a cualquier edad, también mejora la respuesta al tratamiento con corticoides inhalados, reduce el riesgo de desarrollar cáncer y enfermedades cardiovasculares, y mejora la salud de los pacientes con EPOC ${ }^{164}$. Un aspecto importante que cabe destacar es que si el porcentaje de recaídas en la población general fumadora es del 70-80\% en el primer año, en el grupo de los fumadores con EPOC estas cifras se incrementan 
Tabla 11

Recomendaciones sobre tabaquismo

\begin{tabular}{|c|c|c|c|c|}
\hline & NR & Recomendación & Calidad global de la evidencia & Fuerza de la recomendación \\
\hline \multirow[t]{2}{*}{$\begin{array}{l}\text { Consejo médico/ } \\
\text { psicológico }\end{array}$} & R003 & $\begin{array}{l}\text { En los pacientes fumadores con EPOC se recomienda ofrecer } \\
\text { consejo médico/psicológico antitabáquico }\end{array}$ & Moderada $^{a}$ & Fuerte a favor ${ }^{\mathrm{a}}$ \\
\hline & R004 & $\begin{array}{l}\text { En los pacientes con EPOC fumadores y que presentan baja } \\
\text { motivación para dejar de fumar, se sugiere el uso de consejo } \\
\text { médico/psicológico acompañado de terapia farmacológica }\end{array}$ & Moderada ${ }^{a}$ & Débil a favora \\
\hline $\begin{array}{l}\text { Tratamiento psicológico } \\
\text { y farmacológico }\end{array}$ & R005 & $\begin{array}{l}\text { La terapia conductual, en la que se incluye el soporte social, } \\
\text { combinada con los tratamientos farmacológicos disponibles, } \\
\text { debe utilizarse, en ausencia de contraindicaciones, en aquellos } \\
\text { fumadores dispuestos a dejar el consumo }\end{array}$ & Moderada & Fuerte a favor \\
\hline
\end{tabular}

NR: numeración de las recomendaciones.

${ }^{a}$ Guía UETS-Laín Entralgo.

significativamente ${ }^{165}$. Las razones que pueden explicar las dificultades de éxito en la deshabituación tabáquica de los enfermos con EPOC son las siguientes ${ }^{166}$ :

1. Trastornos fisiopatológicos en los pacientes con obstrucción al flujo aéreo que favorecerían una mayor cantidad de inhalación y depósito de sustancias tóxicas.

2. Mayor dependencia física por la nicotina entre los fumadores con EPOC. Según el estudio IBERPOC, el 30\% de los fumadores con EPOC tenía 7 puntos o más en el test de Fagerström ${ }^{167}$. Es conocido que los pacientes con mayor dependencia tienen más probabilidades de recaídas.

3. Presencia de comorbilidad psiquiátrica en los fumadores con EPOC.

4. Diferentes grados de motivación entre los distintos tipos de fumadores con EPOC.

La situación clínica, en función del nivel de gravedad de la enfermedad, puede condicionar la motivación ante el abandono. Así, los pacientes con EPOC leve, que en gran número de ocasiones no refieren sintomatología alguna, tienen una baja motivación, sobre todo si se compara con los casos de mayor gravedad y con mayor sintomatología respiratoria, que serán los enfermos más motivados para el abandono.

El consejo médico es eficaz y debe ofrecerse en la consulta a todo fumador (evidencia moderada, recomendación fuerte a favor) y la terapia conductual, en la que se incluye el soporte social, combinada con los tratamientos farmacológicos disponibles, debe utilizarse, en ausencia de contraindicaciones, en los fumadores dispuestos a dejar el consumo (evidencia alta, recomendación fuerte a favor).

\section{Apoyo psicológico}

A continuación se resumen las características de la intervención:

1. Intensidad: a mayor intensidad de la intervención, mejores resultados obtenidos. La intervención mínima es menos eficaz en pacientes con EPOC.

2. Contenidos: es preciso explicar la estrecha relación existente entre la EPOC y el consumo de tabaco, haciendo ver al paciente que el tabaco es el principal responsable de su enfermedad. También conviene explicarle que el abandono del tabaco es la única medida eficaz para frenar la progresión de la EPOC.

3. Autoeficacia: se debe intentar incrementar la eficacia del propio fumador con EPOC en la consecución del abandono definitivo del consumo del tabaco.

4. Prevención de recaídas: la atención a estos pacientes, debido a la dificultad que tienen para el abandono del tabaco, debe prever la aparición de recaídas, por lo que es preciso disponer de un completo programa de prevención y tratamiento de recaídas.

\section{Tratamiento farmacológico}

\section{Tratamiento sustitutivo con nicotina (TSN)}

Se sabe que los fumadores con EPOC padecen más alto grado de dependencia física por la nicotina que los fumadores "sanos". El TSN, tanto en forma de parches como de chicles, es eficaz para ayudar a los fumadores con EPOC a dejar de fumar. No obstante, en estos casos se prefiere la utilización de altas dosis de nicotina y la prolongación del tratamiento tanto tiempo cuanto sea necesario ${ }^{168}$.

\section{Bupropión}

Ha demostrado ser eficaz en el tratamiento del tabaquismo de los fumadores con EPOC. Los estudios realizados han constatado su eficacia hasta los 6 meses de seguimiento.

\section{Vareniclina}

Es un fármaco de primera línea, agonista parcial de los receptores nicotínicos, que ha demostrado eficacia en los principales metaanálisis publicados ${ }^{168}$. Recientemente, se ha publicado un estudio que avala la eficacia de su uso en EPOC leve-moderada con un buen perfil de seguridad $^{169}$.

\section{Recomendaciones sobre tabaquismo}

Se resumen en la tabla 11.

Recomendación: ¿Qué tratamientos son los más adecuados para la deshabituación tabáquica en los pacientes con EPOC? (Anexo 2).

\begin{tabular}{|l|l|}
\hline Fuerte & $\begin{array}{l}\text { En los pacientes fumadores con EPOC se recomien- } \\
\text { da ofrecer consejo médico/psicológico antitabáqui- } \\
\text { co }\end{array}$ \\
\hline
\end{tabular}

\begin{tabular}{|l|l|}
\hline Débil & $\begin{array}{l}\text { En los pacientes con EPOC fumadores y que presen- } \\
\text { tan baja motivación para dejar de fumar, se sugiere el } \\
\text { uso de consejo médico/psicológico acompañado de } \\
\text { tratamiento farmacológico }\end{array}$ \\
\hline
\end{tabular}

\section{Estándares de calidad asistencial sobre tabaquismo}

Se resumen en la tabla 12 .

\section{Tratamiento de la EPOC estable}

Puntos clave:

- La base del tratamiento de la EPOC estable son los broncodilatadores de larga duración (BDLD). 
Tabla 12

Estándares de calidad asistencial sobre tabaquismo

\begin{tabular}{|c|c|c|c|}
\hline & ECA & Criterio de calidad & Indicador \\
\hline $\begin{array}{l}\text { Tratamiento de } \\
\text { deshabituación tabáquica }\end{array}$ & E09 & $\begin{array}{l}\text { Todos los pacientes con EPOC que siguen fumando, con } \\
\text { independencia de la edad, deben ser alentados a abandonar el } \\
\text { tabaco, ofreciéndoles intervención específica para ello en todo } \\
\text { momento }\end{array}$ & $\begin{array}{l}\text { N. e de fumadores activos con EPOC a los que se les prescribe } \\
\text { intervención específica/№ total de fumadores activos con EPOC }\end{array}$ \\
\hline
\end{tabular}

ECA: estándares de calidad asistencial (Soler-Cataluña et al ${ }^{150}$ ).

- Los fármacos que se deben añadir a BDLD dependerán del fenotipo del paciente.

- El tratamiento del fenotipo no agudizador, sea enfisema o bronquitis crónica, se basa en el uso de los BDLD en combinación

- El tratamiento del fenotipo mixto se basa en la utilización de BDLD combinados con corticoides inhalados (CI).

- El tratamiento del fenotipo agudizador con enfisema se basa en BDLD a los que se pueden añadir los $\mathrm{Cl}$ y la teofilina según el nivel de gravedad.

- El tratamiento del fenotipo agudizador con bronquitis crónica se basa en los BDLD, a los que se pueden añadir CI, inhibidores de la fosfodiesterasa 4 o mucolíticos según la gravedad o, en casos especiales, antibióticos de forma preventiva.

- Se debe prestar especial atención a las comorbilidades y optimizar su control.

\section{Objetivos del tratamiento}

Los objetivos generales del tratamiento de la EPOC se resumen en tres: reducir los síntomas crónicos de la enfermedad, disminuir la frecuencia y la gravedad de las agudizaciones y mejorar el pronóstico. Se deben alcanzar tanto los beneficios a corto plazo (control de la enfermedad) como los objetivos a medio y largo plazo (reducción del riesgo $)^{4,170}$.

\section{Medidas generales}

Las medidas generales que se deben tener en cuenta en todo paciente con EPOC comprenden el abandono del tabaco, la adecuada nutrición, la actividad física regular, la evaluación y el tratamiento de las comorbilidades y la vacunación. La rehabilitación forma parte del tratamiento integral del paciente con EPOC.

\section{Vacunación}

Las vacunas son una estrategia para reducir el riesgo de exacerbaciones relacionadas con infecciones que pueden derivar en complicaciones y, por tanto, pretenden reducir la morbilidad y los costes sanitarios asociados a la EPOC.

La administración anual de la vacuna antigripal reduce el número de exacerbaciones durante los períodos epidémicos, pero los estudios disponibles son demasiado pequeños y breves en duración para determinar cualquier efecto sobre la mortalidad ${ }^{171}$. Una reciente revisión sistemática señala que la evidencia sobre el efecto de esta vacuna en los pacientes con EPOC en cuanto a la reducción de neumonías, hospitalizaciones y mortalidad es de baja calidad ${ }^{172}$. Sobre la base de estos estudios, se recomienda la vacunación anual contra la gripe en todos los pacientes con EPOC (evidencia baja, recomendación fuerte a favor).

La actualización de la revisión sistemática Cochrane sobre la vacuna antineumocócica en los pacientes con EPOC incluye 7 estudios, los dos más antiguos realizados con la vacuna de 14 serotipos y los más recientes con la vacuna neumocócica polisacárida de 23 serotipos (PPV23) ${ }^{173}$. Los resultados indican que, si bien es posible que las vacunas antineumocócicas polivalentes inyectables proporcionen alguna protección contra la morbilidad en los pacientes con EPOC, no se observaron efectos significativos en ninguno de los resultados (riesgo de neumonía, riesgo de exacerbación, admisiones al hospital, mortalidad). Es cierto que para demostrar la eficacia clínica de una vacuna se precisan poblaciones muy amplias, que son difíciles de reclutar en el caso de la EPOC, y los estudios antes mencionados carecían de una muestra suficiente de pacientes con EPOC para demostrar efectos. En un estudio específico en pacientes con EPOC, la vacuna antineumocócica de 23 serotipos fue efectiva para reducir el riesgo de neumonía en pacientes menores de 65 años y en aquellos con EPOC grave. Por este motivo, y por su escaso coste y gran seguridad, la mayoría de normativas recomiendan la vacunación sistemática en pacientes con EPOC, con una revacunación a partir de los 8 años de la primera administración ${ }^{174}$ (evidencia baja, recomendación fuerte a favor).

\section{Intervenciones farmacológicas en pacientes con EPOC en fase estable}

El importante desarrollo farmacológico en el campo de la EPOC ha permitido disponer de diferentes opciones de tratamiento que han puesto de manifiesto que la respuesta clínica puede ser diferente según determinadas características de la enfermedad. De esta manera, en esta guía se propone un tratamiento personalizado, condicionado por el fenotipo clínico y a su vez modulado por la gravedad ${ }^{8-10,175}$ (fig. 8).

Tratamiento de la EPOC A: fenotipo no agudizador con enfisema o bronquitis crónica

Puntos clave:

- El tratamiento de este fenotipo consistirá en el uso de BDLD.

- Estos pacientes, al no presentar agudizaciones de repetición, no precisan del uso de antinflamatorios.

- Tiotropio es superior a salmeterol en la prevención de agudizaciones.

- Indacaterol es superior a salmeterol y formoterol en la mejoría de la función pulmonar y de los síntomas.

- Cuando, a pesar del tratamiento con un BDLD, el paciente sigue sintomático y/o con limitación importante al ejercicio, el segundo paso es la introducción de un segundo BDLD de un grupo farmacológico distinto.

- No se conocen todavía factores que puedan orientar hacia una mayor respuesta a agentes antimuscarínicos de acción larga (LAMA) o a agonistas beta-2 adrenérgicos de acción prolongada (LABA) en un paciente concreto.

- En un nivel de gravedad superior se pueden añadir teofilinas.

\section{Broncodilatadores de acción corta}

Después de establecer el diagnóstico de EPOC según la clínica y la demostración de la obstrucción no completamente reversible en la espirometría, el primer paso en el tratamiento farmacológico es la broncodilatación.

Los broncodilatadores de acción corta (anticolinérgicos [SAMA, por su nombre en inglés short-acting muscarinic antagonist] como el 


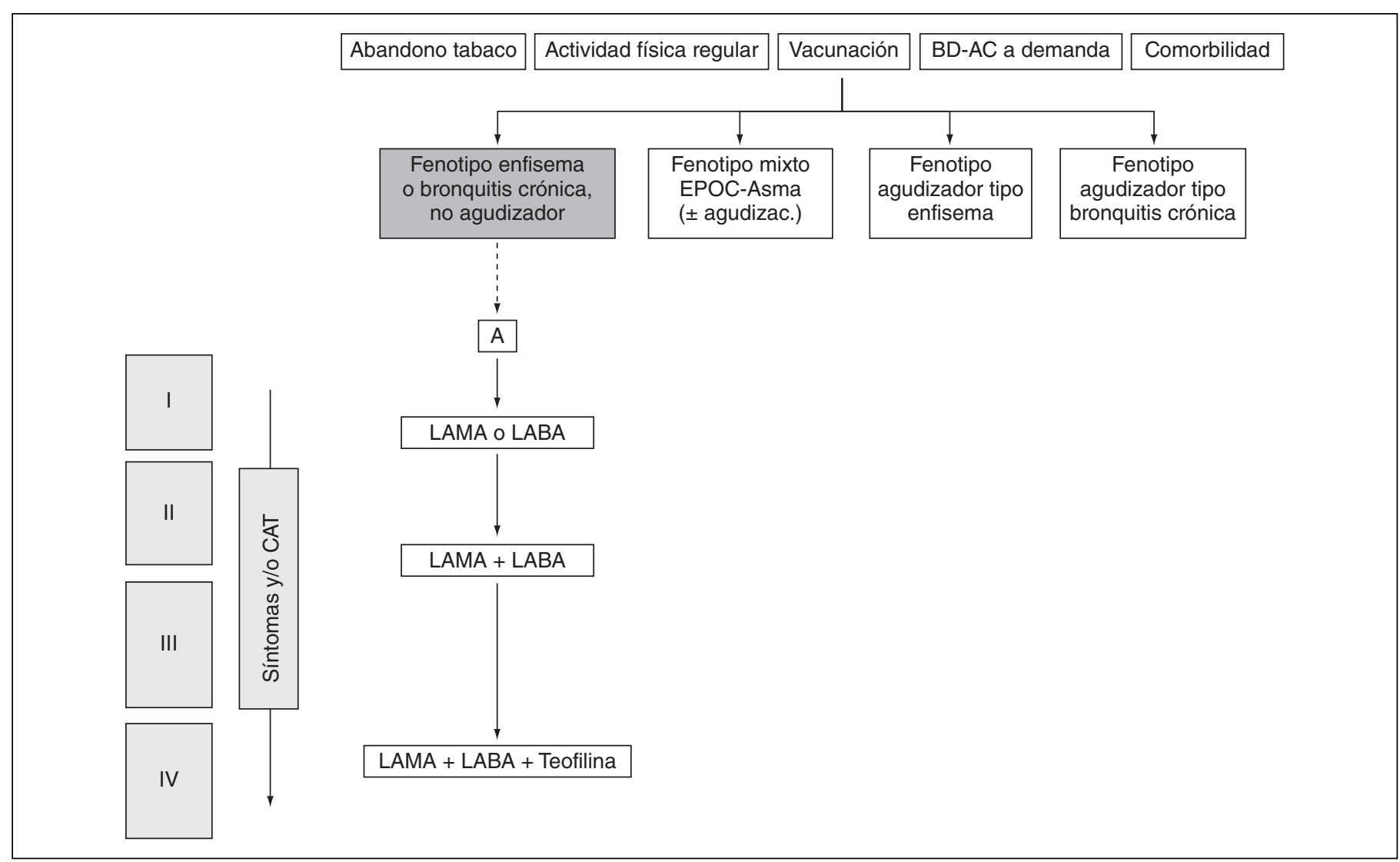

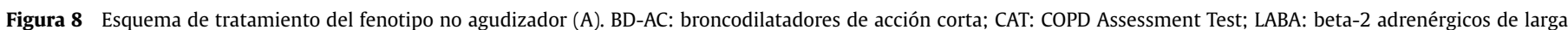
duración; LAMA: antimuscarínicos de larga duración.

bromuro de ipratropio y los agonistas beta-2 de acción corta [SABA, por su nombre en inglés short-acting b-agonist] como salbutamol o terbutalina) son fármacos eficaces en el control rápido de los síntomas. En pacientes con síntomas ocasionales, el tratamiento con broncodilatadores de acción corta reduce los síntomas y mejora la tolerancia al esfuerzo ${ }^{176}$. Estos fármacos, añadidos al tratamiento de base, son de elección para el tratamiento de los síntomas a demanda, sea cual sea el nivel de gravedad de la enfermedad (evidencia moderada, recomendación débil a favor).

Cuando el paciente tiene síntomas permanentes, precisa tratamiento con broncodilatadores de corta duración de forma frecuente $o$ presenta una limitación al ejercicio, requerirá un tratamiento de base regular. En este caso se deberá administrar un broncodilatador de larga duración (BDLD).

\section{Broncodilatadores de larga duración}

Los BDLD pueden ser beta-2 adrenérgicos (salmeterol, formoterol e indacaterol; LABA por su nombre en inglés long-acting beta-agonists) o anticolinérgicos (bromuro de tiotropio; LAMA por su nombre en inglés long-acting muscarinic antagonist). Deben utilizarse como primer escalón en el tratamiento de todos los pacientes con síntomas permanentes que precisan tratamiento de forma regular, porque permiten un mayor control de los síntomas y mejoran tanto la calidad de vida como la función pulmonar ${ }^{177-182}$ (evidencia alta, recomendación fuerte a favor) (fig. 8).

En ocasiones, los beneficios clínicos conseguidos no se acompañan de una mejoría significativa del grado de obstrucción (cambios en el $\mathrm{FEV}_{1}$ ), pero incluso en estos casos su utilización está justificada por sus efectos al disminuir la hiperinsuflación dinámica y, por consiguiente, mejorar la capacidad inspiratoria, el grado de disnea y la tolerancia al ejercicio ${ }^{183,184}$. Además de su impacto directo sobre la capacidad de ejercicio, mejoran de forma indirecta la función cardíaca al disminuir la hiperinsuflación, y este hecho podría explicar en parte la tendencia a la reducción de la mortalidad observada en los grandes ensayos clínicos con BDLD en la EPOC ${ }^{185}$.

Además, los BDLD han demostrado reducir el número de exacerbaciones ${ }^{186}$, tanto los LABA ${ }^{179,187,188}$ como el bromuro de tiotropio ${ }^{186,189}$. Los resultados del ensayo clínico aleatorizado (ECA) UPLIFT (Understanding Potential Long-term Impacts on Function with Tiotropium $)^{190}$ demostraron una reducción en el riesgo de exacerbaciones, hospitalizaciones e insuficiencia respiratoria con tiotropio frente a tratamiento habitual durante 4 años.

Existen diferencias entre los diversos BDLD; los hay con una duración de acción de 12 h (salmeterol y formoterol) y de 24 h (tiotropio e indacaterol). Formoterol e indacaterol tienen un rápido inicio de acción, mientras que tiotropio y salmeterol inician su acción broncodilatadora de forma más lenta. Las comparaciones de LAMA frente a LABA en dos revisiones sistemáticas ${ }^{186,189}$ no mostraron diferencias en la frecuencia de exacerbaciones entre ambos tratamientos ${ }^{186}$, pero sí en el subanálisis de los pacientes con $\mathrm{FEV}_{1} \leq 40 \%$, donde tiotropio fue más eficaz en la reducción de agudizaciones ${ }^{186}$. Más recientemente, un ECA potenciado para agudizaciones demostró que tiotropio era más eficaz que salmeterol en la prevención de agudizaciones en pacientes con EPOC e historia de al menos una agudización el año previo $^{191}$. Estos resultados corresponden a comparaciones entre tiotropio y salmeterol. No disponemos de estudios comparativos entre tiotropio e indacaterol en la prevención de agudizaciones.

En general, los broncodilatadores de acción prolongada son bien tolerados y presentan escasos efectos adversos. No obstante, se deben tener en cuenta los siguientes:

- LABA: temblor fino de las extremidades, calambres musculares, taquicardia, hipertensión arterial, vasodilatación periférica, cefalea, hiperglucemia, hipocalemia, tos, broncoespasmo, irritación orofaríngea y dispepsia. 


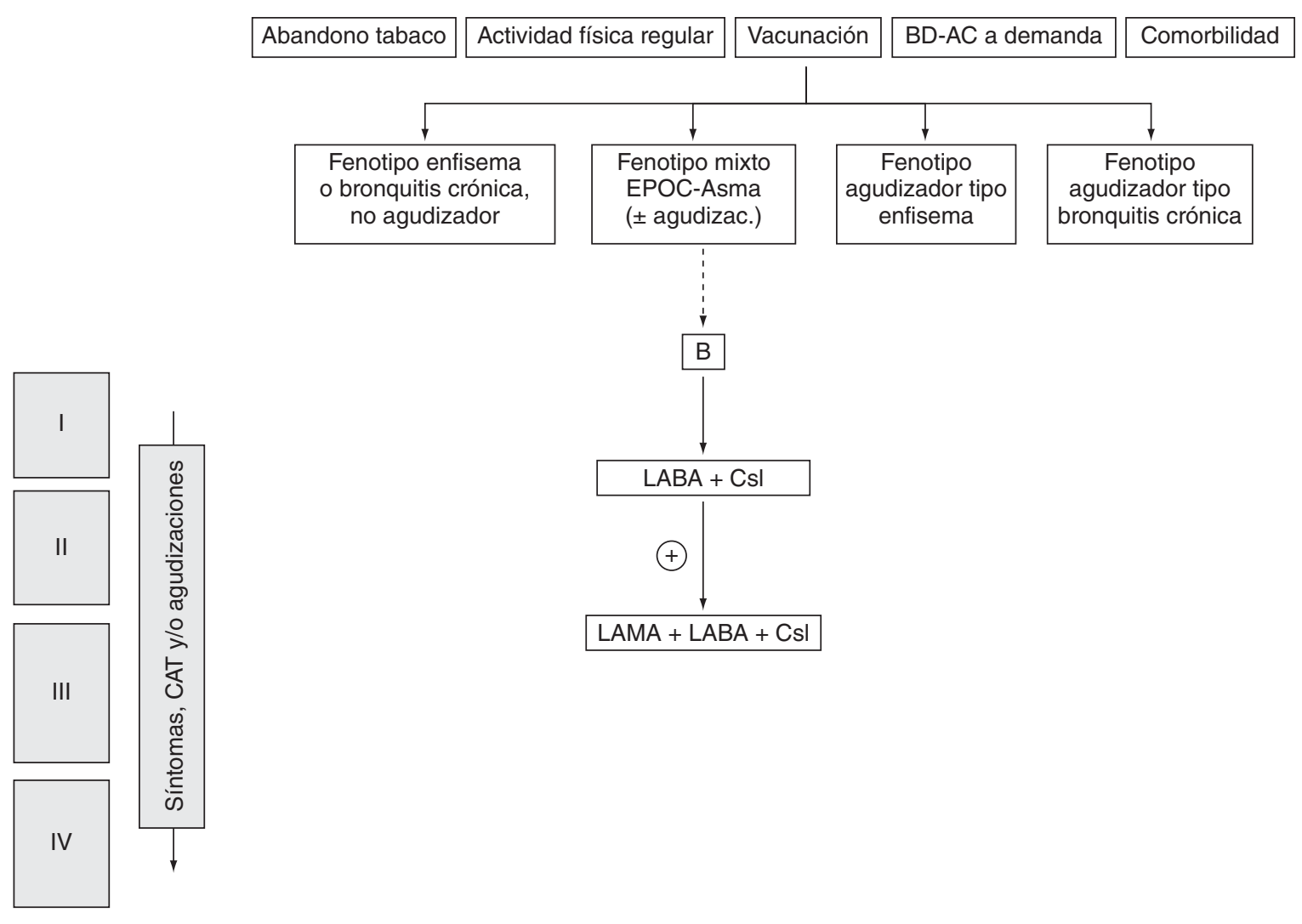

Figura 9 Esquema de tratamiento del fenotipo mixto EPOC-asma (B). FMEA: fenotipo mixto EPOC-asma. BD-AC: broncodilatadores de acción corta; CAT: COPD Assessment Test; CsI: corticosteroides inhalados; LABA: beta-2 adrenérgicos de larga duración; LAMA: antimuscarínicos de larga duración.

- El tratamiento con LAMA se puede asociar a sequedad de boca ${ }^{192}$. Otros efectos adversos observados son: retención urinaria, incremento de la presión ocular e irritación faríngea.

Recomendación: ¿Existe evidencia para aconsejar un tipo concreto de broncodilatador de acción mantenida en monoterapia cuando se inicia el tratamiento de la EPOC estable? (anexo 2).

\begin{tabular}{|c|c|}
\hline $\begin{array}{l}\text { Buena práctica } \\
\text { clínica }\end{array}$ & $\begin{array}{l}\text { En pacientes con EPOC en fase estable que pre- } \\
\text { cisen un broncodilatador de acción mantenida } \\
\text { en monoterapia se indica basar la elección fi- } \\
\text { nal del broncodilatador en criterios como las } \\
\text { preferencias de los pacientes individuales, la } \\
\text { respuesta individual al fármaco y/o aspectos } \\
\text { económicos }\end{array}$ \\
\hline Débil & $\begin{array}{l}\text { En pacientes con EPOC en fase estable y que } \\
\text { hayan presentado al menos una exacerbación } \\
\text { previa que ha requerido hospitalización y/o } \\
\text { tratamiento con glucocorticoides sistémicos } \\
\text { y/o antibióticos durante el año anterior y que } \\
\text { precisen un broncodilatador de acción mante- } \\
\text { nida en monoterapia, se sugiere el uso de tio- } \\
\text { tropio frente a salmeterol }\end{array}$ \\
\hline $\begin{array}{l}\text { Recomendación } \\
\text { para la } \\
\text { investigación }\end{array}$ & $\begin{array}{l}\text { Se recomienda realizar ensayos clínicos con- } \\
\text { trolados y aleatorizados para evaluar la eficacia } \\
\text { y seguridad del indacaterol frente al tiotropio } \\
\text { en pacientes con EPOC en fase estable que re- } \\
\text { quieren broncodilatadores de acción manteni- } \\
\text { da en monoterapia, dado que la evidencia } \\
\text { identificada es insuficiente para recomendar } \\
\text { uno frente a otro }\end{array}$ \\
\hline
\end{tabular}

\section{Doble tratamiento broncodilatador}

En pacientes sintomáticos o con una limitación al ejercicio evidente aun tras la monoterapia broncodilatadora se debe ensayar el doble tratamiento broncodilatador. La asociación de LABA y LAMA ofrece un beneficio funcional añadido, con reducción de la necesidad de medicación de rescate, mejoría de los síntomas y de la calidad de vida frente a la monoterapia ${ }^{193,194}$. Por este motivo, en un segundo escalón de tratamiento, en pacientes con un nivel de gravedad II en adelante, se puede asociar un BDLD de un tipo farmacológico distinto del que utilizaba el paciente en el primer nivel de gravedad. De esta manera se consigue optimizar el efecto broncodilatador.

Las combinaciones de BDLD deben utilizarse en los pacientes con EPOC que persisten sintomáticos a pesar de la monoterapia con un único BDLD (evidencia alta, recomendación fuerte a favor).

\section{Teofilinas}

Las teofilinas son fármacos broncodilatadores débiles, pero que presentan efectos aditivos a los broncodilatadores habituales. Se ha descrito un efecto positivo de estos fármacos sobre la fuerza del diafragma, un aumento del rendimiento de los músculos respiratorios, una reducción del atrapamiento aéreo y una mejoría del aclaramiento mucociliar. También han demostrado tener efectos antiinflamatorios en la EPOC. La dosis habitual es de $200-300 \mathrm{mg} / 12 \mathrm{~h}$ por vía oral en comprimidos de liberación sostenida. En cualquier caso, su limitada eficacia clínica y su estrecho margen terapéutico las relega a ocupar un lugar de tercera línea, principalmente en pacientes con nivel de gravedad IV o V ${ }^{195}$ (evidencia moderada, recomendación débil a favor).

La toxicidad de la teofilina es dosis-dependiente. Su uso incrementa el riesgo de náuseas, diarrea, dolor de cabeza, irritabilidad y, en dosis elevadas (concentraciones plasmáticas de $20 \mathrm{mg} / \mathrm{ml}$ ), puede producir arritmias cardíacas, convulsiones, taquicardia e hipopotasemia ${ }^{195}$. Se han descrito también casos de dolor en epigastrio, hematemesis, hemorragia gastrointestinal y, en consecuencia, un número 


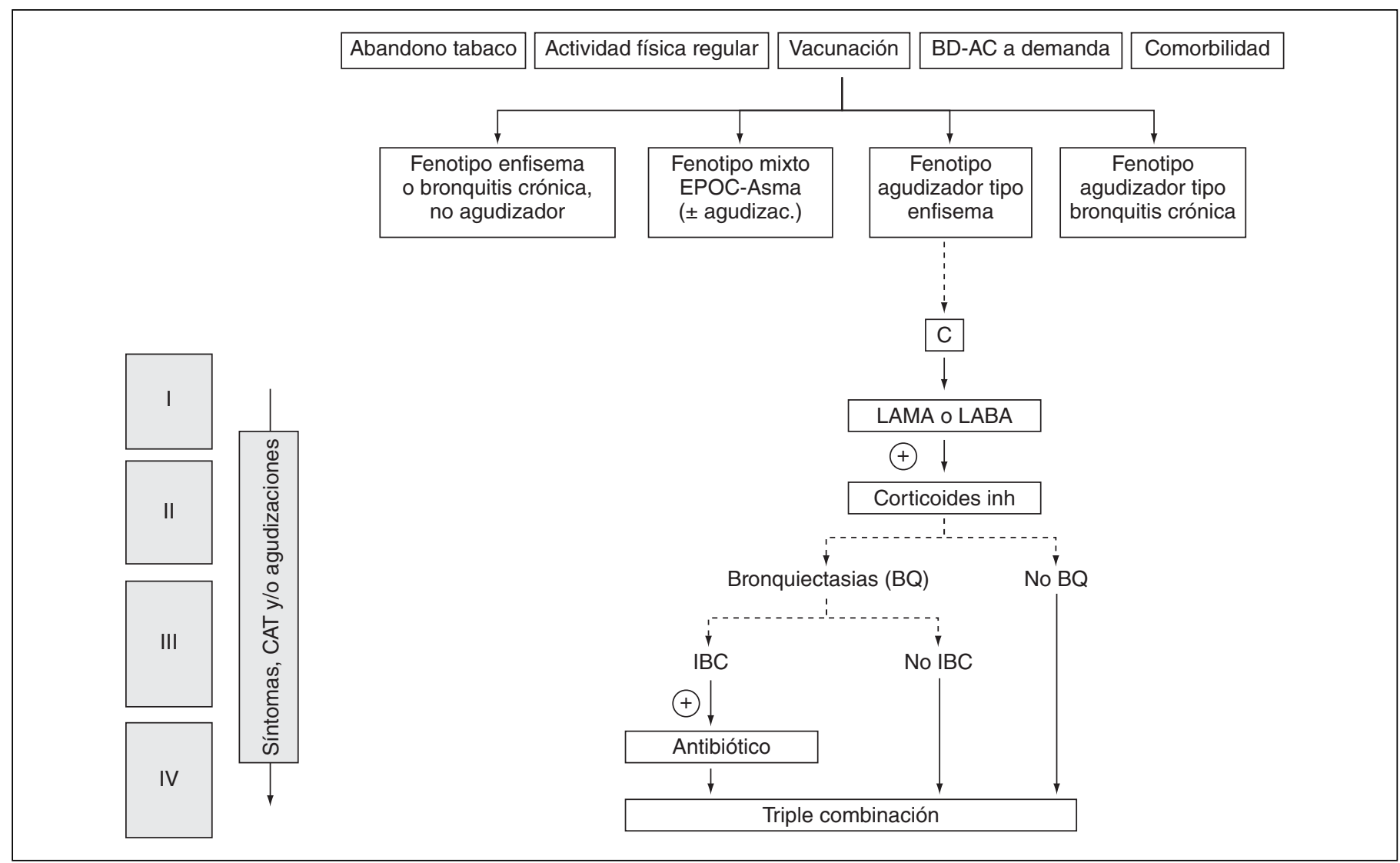

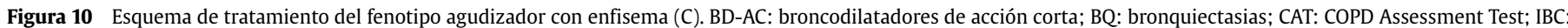
infección bronquial crónica; LABA: beta-2 adrenérgicos de larga duración; LAMA: antimuscarínicos de larga duración.

importante de personas abandona la medicación ${ }^{196}$. Cuando se administran de forma prolongada se deben verificar sus concentraciones plasmáticas y se debe tener en cuenta el riesgo de interacciones con otros fármacos, como alopurinol, ciprofloxacino, eritromicina, benzodiacepinas y cimetidina, entre otros.

\section{Tratamiento sustitutivo con alfa-1 antitripsina}

El tratamiento sustitutivo con alfa-1 antitripsina purificada (AAT) es recomendado por las principales sociedades científicas (American Thoracic Society, European Respiratory Society y la Sociedad Española de Neumología y Cirugía Torácica $)^{35,197}$ en los pacientes con enfisema pulmonar con un déficit de AAT grave y con fenotipo homocigoto PiZZ o variantes raras deficitarias por su efecto en enlentecer la pérdida de densidad pulmonar medida por TACAR. Sus criterios de inclusión y exclusión están bien definidos en las normativas específicas ${ }^{35,197}$.

Todo paciente con EPOC, y en especial si se trata de un fenotipo enfisema, debe tener al menos una medición de sus concentraciones de alfa-1 antitripsina sérica para descartar que pueda presentar un déficit de esta enzima.

\section{Tratamiento de la EPOC B: fenotipo mixto EPOC-asma}

Puntos clave:

- Los pacientes con fenotipo mixto comparten características clínicas e inflamatorias con el asma, por lo que se caracterizan por una buena respuesta al tratamiento antiinflamatorio con $\mathrm{CI}$.

- Debemos evitar el tratamiento con LABA en monoterapia y asociar siempre un $\mathrm{CI}$, incluso en niveles de gravedad iniciales.

- En el siguiente paso se puede establecer el tratamiento triple: tiotropio $+\mathrm{CI}+$ LABA en pacientes más graves o con agudizaciones a pesar de la asociación $\mathrm{CI}+\mathrm{LABA}$.
- Por último, se puede ensayar añadir teofilina o roflumilast (si hay expectoración crónica y agudizaciones frecuentes) al régimen anterior.

Los pacientes con un fenotipo mixto se caracterizan por cumplir criterios diagnósticos de EPOC pero presentar características compatibles también con asma bronquial. GesEPOC define el fenotipo mixto mediante unos criterios diagnósticos ${ }^{198}$.

Estos pacientes presentan un mayor grado de inflamación eosinofílica bronquial, que sería la responsable de su mayor respuesta clínica y espirométrica a los $\mathrm{CI}^{199}$ y justifican el uso de los $\mathrm{CI}$ asociados a un BDLD como primera opción en el nivel de gravedad I o II, con el objetivo de mejorar la función pulmonar y los síntomas respiratorios, y reducir las agudizaciones si las hubiere ${ }^{10,200}$

Los pacientes con fenotipo mixto, definido en esta ocasión como pacientes con EPOC que tuvieron un diagnóstico de asma antes de los 40 años, demostraron tener una mayor frecuencia de agudizaciones que los pacientes sin diagnóstico previo de asma ${ }^{46}$. Por otro lado, sabemos que los pacientes con EPOC y predominio de inflamación eosinofílica suelen tener agudizaciones también eosinofílicas ${ }^{47}$ y los $\mathrm{CI}$ son especialmente eficaces en reducir la frecuencia de agudizaciones en pacientes con EPOC e inflamación bronquial eosinofílica ${ }^{201}$. Estas agudizaciones no suelen cursar con expectoración purulenta, sino con síntomas de rinitis, sibilantes y tos con expectoración blanquecina, y son las que se pueden beneficiar más del tratamiento preventivo con $\mathrm{Cl}^{47}$. Por este motivo, los $\mathrm{CI}$ en asociación con un BDLD son un tratamiento eficaz en la prevención de agudizaciones en pacientes con fenotipo mixto.

En los pacientes con fenotipo mixto es razonable iniciar el tratamiento con BDLD más $\mathrm{CI}$ en fases iniciales de la enfermedad, como ocurre en el asma (nivel de gravedad I-II) (fig. 9). En estos casos es necesario realizar un seguimiento clínico y espirométrico para eva- 
luar la respuesta y, al igual que sucede con el asma, seleccionar la mínima dosis necesaria de $\mathrm{CI}$ para el tratamiento a largo plazo. De hecho, estos pacientes, por compartir características de EPOC y asma, pueden ser tratados de acuerdo con ambas normativas ${ }^{202}$. Es posible que un mismo paciente de este tipo pueda ser catalogado como EPOC mixto o como asmático fumador no completamente reversible.

En los casos de mayor gravedad (niveles de gravedad III y IV) puede ser necesario el tratamiento triple CI/LABA más LAMA. Esta triple combinación ha demostrado su eficacia en pacientes con EPOC que presentaban gran reversibilidad en la obstrucción al flujo aéreo ${ }^{203}$. Además, tiotropio ha demostrado eficacia en pacientes con asma ${ }^{204}$.

También en los casos más graves (nivel de gravedad IV) se puede añadir teofilina al tratamiento o, si hay agudizaciones frecuentes y tos con expectoración crónica, roflumilast. No hay estudios específicos de la eficacia y seguridad de estos fármacos en la EPOC grave con fenotipo mixto, pero se conoce la eficacia de ambos fármacos en el asma.

Tratamiento de la EPOC C: fenotipo agudizador con enfisema

\section{Puntos clave:}

- Los BDLD son el primer escalón terapéutico en pacientes con agudizaciones y fenotipo enfisema.

- Cuando los BDLD no son suficientes para el control de los síntomas o de las agudizaciones se puede añadir un $\mathrm{CI}$ y, en casos más graves, teofilina.

El objetivo fundamental del tratamiento en los pacientes con fenotipo agudizador será la prevención de las agudizaciones. Los pacientes con enfisema también pueden ser agudizadores y requerirán un tratamiento dirigido a la reducción de agudizaciones, además de mejorar el resto de parámetros de la enfermedad. Los BDLD en el primer escalón de tratamiento (nivel de gravedad I-II), solos o combinados, son eficaces en reducir las agudizaciones, pero en algunos pacientes serán insuficientes y precisarán una intensificación del tratamiento farmacológico.

\section{Corticoides inhalados}

Distintas guías de práctica clínica ${ }^{5,205,206}$ reconocen la utilidad del empleo de los $\mathrm{Cl}$ en pacientes que presentan frecuentes agudizaciones pese a realizar un tratamiento broncodilatador óptimo, por cuanto su uso asociado a los BDLD produce una disminución significativa del número de agudizaciones y una mejoría en la calidad de vida, si bien no han mostrado un efecto beneficioso sobre la mortalidad (evidencia alta, recomendación fuerte a favor ${ }^{93,207-210}$. Aunque la prevención de agudizaciones se ha evaluado en la mayoría de los estudios para los pacientes graves o muy graves (grado de obstrucción II y IV, $\mathrm{FEV}_{1}<50 \%$ ) y con frecuentes agudizaciones, en algunos estudios realizados en pacientes con menor gravedad funcional ( $\left.\mathrm{FEV}_{1}<60 \%\right)$ también los resultados avalan el uso de estos fármacos, por lo que parece que el principal determinante del beneficio sea la presencia de agudizaciones repetidas, es decir, el fenotipo agudizador, y no el grado de obstrucción al flujo aéreo ${ }^{93}$. Por este motivo pueden ensayarse en pacientes en nivel de gravedad II que persisten con agudizaciones a pesar de un tratamiento con uno o dos broncodilatadores de larga duración. En la EPOC, los CI se deben utilizar siempre asociados a un BDLD (evidencia alta, recomendación fuerte a favor) (fig. 10).

Se debe buscar un equilibrio entre los efectos beneficiosos de los $\mathrm{CI}$ y sus posibles efectos adversos. Se ha observado en los grandes ensayos clínicos que efectos secundarios tales como aftas orales, disfonía y hematomas eran más comunes en los pacientes tratados con $\mathrm{Cl}^{211}$. También se ha apreciado una reducción en la densidad mineral ósea ${ }^{212}$; sin embargo, no se ha detectado un incremento significativo del riesgo de fracturas óseas en estudios de hasta 3 años de seguimiento. Los resultados de TORCH y otros estudios a largo plazo han demostrado un mayor riesgo de neumonía en los pacientes tratados con fluticasona sola o en combinación con broncodilatadores de larga duración, pero sin aumento de la mortalidad ${ }^{213}$.

Recomendación: ¿Cuáles son los beneficios del tratamiento combinado (betaadrenérgicos de larga duración/corticoides inhalados) frente al doble tratamiento broncodilatador? (anexo 2).

\begin{tabular}{|l|l|}
\hline Recomendación \\
para la \\
investigación
\end{tabular}$\quad$\begin{tabular}{l}
$\begin{array}{l}\text { Se recomienda realizar ensayos clínicos con- } \\
\text { trolados y aleatorizados para evaluar la efica- } \\
\text { cia y la seguridad del tratamiento combinado } \\
\text { (LAMA/CI o LABA/CI) frente al doble trata- } \\
\text { miento broncodilatador (LAMA + LABA) en } \\
\text { pacientes con EPOC en fase estable, dado que } \\
\text { la evidencia identificada es insuficiente para } \\
\text { recomendar una de estas opciones frente a la } \\
\text { otra }\end{array}$ \\
\hline
\end{tabular}

Triple tratamiento $(L A M A+L A B A+C I)$

En pacientes con nivel de gravedad III y que no presentan un nivel de control de los síntomas o de las agudizaciones con 2 fármacos (sean dos BDLD o un BDLD más un $\mathrm{CI}$ ) se puede utilizar el triple tratamiento LAMA + LABA + CI. Los escasos estudios disponibles con triple tratamiento indican un mayor efecto sobre la función pulmonar ${ }^{203} \mathrm{y}$ una disminución de las agudizaciones y las hospitalizaciones en pacientes graves ${ }^{203,214,215}$ (evidencia moderada, recomendación fuerte a favor).

\section{Teofilinas}

Además del efecto broncodilatador de las teofilinas, estos fármacos tienen también un efecto activador de la enzima histona deacetilasa (HDAC) y, por tanto, podrían revertir el efecto del estrés oxidativo del humo del tabaco y restaurar así la respuesta a los $\mathrm{CI}$ en pacientes con $\mathrm{EPOC}^{216}$.

Las teofilinas en dosis bajas reducen el número total de neutrófilos en esputo inducido, la concentración de IL-8 y de mieloperoxidasas, así como la respuesta quimiotáctica de los neutrófilos. Para conseguir este efecto antiinflamatorio se necesitan concentraciones plasmáticas bajas (5-10 mg/l) y, por tanto, con menos efectos adversos. Si los estudios que están actualmente en marcha lo confirman, este fármaco puede tener un papel como antiinflamatorio en la prevención de las agudizaciones en combinación con los $\mathrm{Cl}^{217}$. Se puede ensayar su utilización en pacientes muy graves (nivel de gravedad IV).

Tratamiento de la EPOC D: fenotipo agudizador con bronquitis crónica

Puntos clave:

- Los BDLD son eficaces en la reducción de agudizaciones, pero en pacientes con bronquitis crónica pueden no ser suficientes. En este caso debemos plantear su uso combinado con un fármaco antiinflamatorio.

- Como antiinflamatorio se puede utilizar un $\mathrm{CI}$ o roflumilast. En casos especialmente graves se pueden asociar ambos, aunque no existen estudios controlados de la eficacia y seguridad de esta asociación.

- En casos en que haya contraindicaciones o intolerancia a alguno de los antiinflamatorios anteriores se puede administrar carbocisteína.

- En el paciente agudizador con bronquitis crónica se debe investigar la existencia de bronquiectasias y de infección bronquial crónica, que precisarán un tratamiento especializado.

La presencia de tos y expectoración crónica es un factor reconocido que predispone a las agudizaciones en la $\mathrm{EPOC}^{51}$. El primer escalón 
de tratamiento en nivel de gravedad I serán los BDLD, por su capacidad de reducir las agudizaciones. En el nivel de gravedad II se recomienda un tratamiento doble con dos BDLD o con un BDLD más un antiinflamatorio, sea un $\mathrm{CI}$ o roflumilast (fig. 11).

\section{Inhibidores de la fosfodiesterasa-4}

Roflumilast es un fármaco antiinflamatorio oral que actúa mediante la inhibición selectiva de la fosfodiesterasa-4 (IPD4) y que ha demostrado prevenir las agudizaciones en pacientes con EPOC grave que presentan tos y expectoración crónica, y que además sufren agudizaciones frecuentes ${ }^{213,218}$, por lo que es un fármaco indicado para el fenotipo agudizador con bronquitis crónica. Este efecto se mantiene cuando se añade roflumilast al tratamiento de mantenimiento con un BDLD, sea LABA o LAMA. Además, consigue un incremento significativo del FEV ${ }_{1}$ mínimo de $50-70 \mathrm{ml}$ sobre el conseguido con salmeterol o tiotropio ${ }^{218,219}$. La dosis habitual es de $500 \mu$ g por vía oral una vez al día ${ }^{219,220}$

Tanto el roflumilast como los CI son fármacos antiinflamatorios, aunque sus modos de acción son diferentes. De hecho, la inflamación neutrofílica típica de la EPOC es relativamente resistente a altas dosis de corticoides orales o inhalados. Por contra, en estudios in vitro e in vivo, roflumilast ha mostrado efectos sobre los neutrófilos y también sobre los macrófagos y linfocitos CD8+. Todo ello indica que sus acciones son claramente distintas. Los resultados obtenidos en ensayos clínicos con la administración concomitante de $\mathrm{Cl}$ y roflumilast indican que esta asociación es segura y que roflumilast mantiene su eficacia clínica ${ }^{220}$. Puede ser útil cuando se considere asociar ambas acciones antiinflamatorias en pacientes de alto riesgo de agudizaciones, siempre asociados con un BDLD. No se recomienda la utilización de roflumilast con teofilinas.

Los efectos adversos con roflumilast suelen aparecer al inicio del tratamiento, son rápidamente detectados por el paciente y suelen desaparecer en las primeras 4 semanas. Los más frecuentes son pérdida de peso, efectos gastrointestinales, náuseas, dolor de cabeza y pérdida de apetito. Entre los efectos gastrointestinales, la diarrea es el más frecuente y aparece en el 8-9\% de los pacientes incluidos en ensayos clínicos. Las náuseas se notificaron en el 3-5\% de los pacientes. La pérdida de peso se produce en un $6-12 \%$ de los casos. Esta pérdida de peso se aprecia en los primeros 6 meses de tratamiento, no progresa de forma significativa y se resuelve en la mayoría de los pacientes cuando se interrumpe el tratamiento. Por todo ello, y debido a que roflumilast es un tratamiento crónico, es recomendable controlar el peso, especialmente en los primeros meses de tratamiento. El perfil de seguridad de roflumilast no se modifica en función del tratamiento concomitante que el paciente pueda estar tomando para la EPOC.

Recomendación: ¿Puede roflumilast ser una alternativa a la utilización de corticoides inhalados como terapia adicional al tratamiento de mantenimiento con broncodilatadores en pacientes con EPOC? (anexo 2).

\section{Recomendación para la investigación}

En pacientes con EPOC en fase estable en tratamiento de mantenimiento con broncodilatadores, la terapia adicional con roflumilast, como alternativa al tratamiento adicional con corticoides inhalados, sólo debe utilizarse en un contexto de investigación

\section{Mucolíticos}

En tres revisiones sistemáticas se demostró una reducción de las exacerbaciones con el tratamiento mucolítico frente a placebo en el paciente con $\mathrm{EPOC}^{221-223}$. Estos resultados deben interpretarse con cautela, ya que los estudios incluidos tenían un escaso tamaño muestral y eran heterogéneos. Sin embargo, los mismos resultados se confirmaron en un ensayo clínico de mayor envergadura en el que el uso de carbocisteína a largo plazo, comparado con placebo, reducía el número de exacerbaciones, retrasaba el empeoramiento de los síntomas y mejoraba la calidad de vida de los pacientes con EPOC ${ }^{224}$. Los efectos de la N-acetilcisteína (NAC) a largo plazo en pacientes con EPOC se han evaluado en un ensayo clínico, en el que se demostró una disminución del número de exacerbaciones en pacientes no tratados con $\mathrm{CI}$ de forma concomitante ${ }^{225}$; no obstante, las pruebas científicas disponibles son insuficientes para generar una recomendación sobre los efectos de la NAC en los pacientes con EPOC que no están tratados con $\mathrm{CI}$.

La carbocisteína se puede emplear como tratamiento de segunda línea en pacientes con niveles de gravedad III y IV, con agudizaciones frecuentes a pesar de un tratamiento broncodilatador óptimo. El perfil de tolerancia y seguridad de ambos fármacos es excelente. La eficacia de los mucolíticos en general es superior en pacientes que por cualquier motivo no toman $\mathrm{CI}$.

Recomendación: ¿La utilización del mucolítico-antioxidante $\mathrm{N}$-acetilcisteína está justificada en los pacientes con EPOC? (anexo 2).

\begin{tabular}{|l|l|}
\hline Débil & $\begin{array}{l}\text { En los pacientes con EPOC en fase estable se indica no } \\
\text { utilizar de manera generalizada la N-acetilcisteína como } \\
\text { tratamiento de mantenimiento* }\end{array}$ \\
\hline
\end{tabular}

* Según el análisis de subgrupos de uno de los ECA identificados (calidad de la evidencia muy baja), la NAC podría reducir el riesgo de exacerbaciones en pacientes que no están recibiendo $\mathrm{CI}$. No obstante, los resultados de otro ensayo clínico reciente no han permitido confirmar este hecho. Por tanto, actualmente, las pruebas científicas disponibles son insuficientes para generar una recomendación sobre los efectos de la NAC en los pacientes con EPOC que no están siendo tratados con $\mathrm{CI}$.

Recomendación: ¿La utilización del mucolítico carbocisteína está justificada en los pacientes con EPOC? (anexo 2).

\begin{tabular}{|l|l|}
\hline Débil & $\begin{array}{l}\text { En los pacientes con EPOC en fase estable y fenotipo } \\
\text { agudizador con bronquitis crónica se indica utilizar } \\
\text { carbocisteína como tratamiento de mantenimiento de } \\
\text { la EPOC }\end{array}$ \\
\hline
\end{tabular}

Utilización de antibióticos en la EPOC estable

La utilización de antibióticos en la EPOC estable se ha llevado a cabo empíricamente desde la década de 1960 en lo que se llamaba profilaxis antibiótica. Una revisión sistemática de los ensayos realizados hasta la década de 1980 concluyó que existía un efecto beneficioso significativo en la reducción de agudizaciones, aunque de escasa magnitud ${ }^{226}$. En estos estudios se incluían poblaciones mal definidas, con frecuencia pacientes con bronquitis crónica, sin confirmación diagnóstica de EPOC.

En la última década se han llevado a cabo ensayos clínicos con un diseño más riguroso que pretenden conocer la eficacia de los antibióticos administrados en fase estable para la prevención de las agudizaciones. Podemos dividir estos estudios en dos grupos: $a$ ) los que utilizan macrólidos con la intención de aprovechar también su acción antiinflamatoria, y b) los que utilizan quinolonas para lograr la prevención de agudizaciones a través de una máxima erradicación bacteriana.

\section{Macrólidos en la EPOC en fase estable}

Los macrólidos, administrados de forma prolongada y en dosis bajas, por su actividad antinflamatoria e inmunomoduladora ${ }^{227}$, han demostrado, en pacientes estables con EPOC grave, reducir de forma significativa el número de agudizaciones. Las pautas utilizadas han sido: eritromicina $250 \mathrm{mg} / 12$ h durante un año ${ }^{228}$, azitromicina $500 \mathrm{mg} /$ día/3 días por semana durante un año ${ }^{229}$ y azitromicina $250 \mathrm{mg} /$ día durante un año ${ }^{230}$. Los resultados de los 3 estudios han 


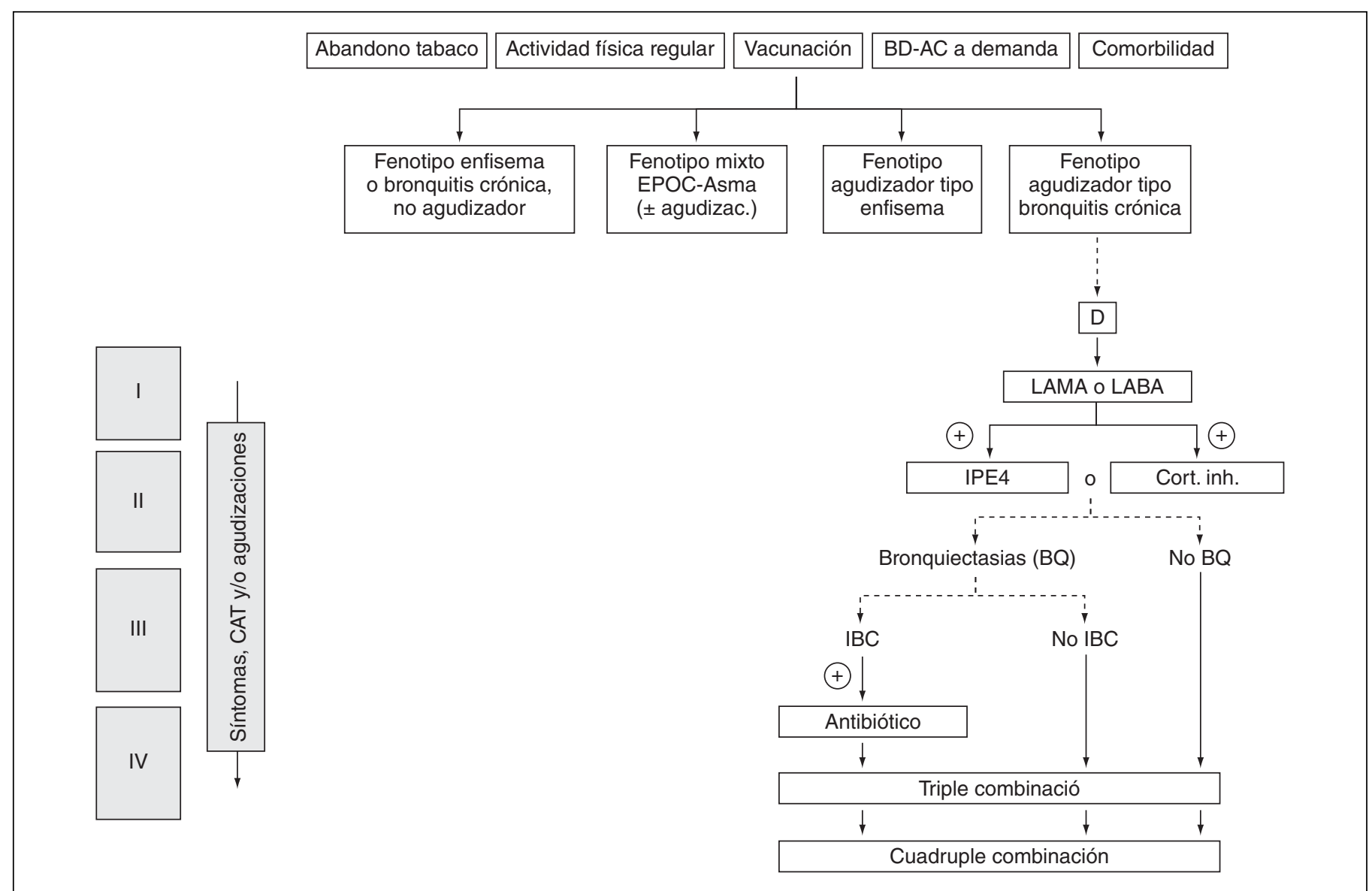

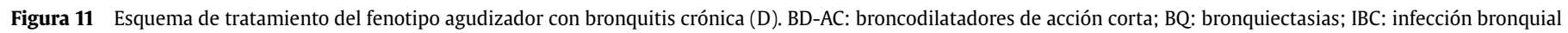
crónica; IPE4: inhibidores de la fosfodiesterasa 4; CAT: COPD Assessment Test; LABA: beta-2 adrenérgicos de larga duración; LAMA: antimuscarínicos de larga duración.

coincidido en demostrar una reducción significativa de las agudizaciones. Sin embargo, las poblaciones estudiadas fueron distintas y las pautas diferentes, por lo que es difícil hacer una recomendación. Cabe destacar que en el estudio de Albert et al $^{230}$ se comprobó un aumento de las resistencias bacterianas a macrólidos y un ligero incremento de los problemas auditivos en los pacientes tratados con azitromicina. Estos resultados hacen que este tratamiento deba considerarse aún en fase de experimentación. Los pacientes candidatos serían aquellos con nivel de gravedad IV, agudizaciones frecuentes que precisaron múltiples tratamientos antibióticos o ingreso hospitalario en el año previo, a pesar de un tratamiento broncodilatador y antiinflamatorio óptimo, y especialmente si además se detecta una infección bronquial crónica por Pseudomonas aeruginosa. Por analogía a las pautas utilizadas en pacientes con similares características y afectados de bronquiectasias, la dosis recomendada sería azitromicina $500 \mathrm{mg} /$ día/3 días por semana durante un año, con repetición en sucesivos períodos invernales (de noviembre a mayo) en caso de respuesta (ausencia de agudizaciones). Este tratamiento debe reservarse a centros de referencia con seguimiento clínico, auditivo y de bioquímica hepática y microbiológico con identificación de microorganismos en el esputo y estudio de sensibilidad a los antibióticos.

\section{Quinolonas en la EPOC en fase estable}

La utilización de quinolonas durante los períodos de estabilidad (tratamiento de la infección bronquial crónica) ha demostrado erradicar las bacterias presentes en el esputo en la mayoría de pacientes con EPOC grave y agudizaciones frecuentes ${ }^{231}$. En el ensayo clínico PULSE (Pulsed moxifloxacin Usage and its Long-term impact on the reduction of Subsequent Exacerbation) se evaluó la eficacia de la administración cíclica de moxifloxacino ( $400 \mathrm{mg} /$ día, 5 días cada 2 meses) durante un año en pacientes con EPOC estable ${ }^{232}$. Los resultados demostraron que el tratamiento redujo de forma significativa un $45 \%$ las agudizaciones en los pacientes que presentaban esputo purulento 0 mucopurulento, es decir, con mayor probabilidad de presentar una infección bronquial bacteriana crónica. En este estudio no se observó un incremento significativo de las resistencias.

De nuevo, nos encontramos en un terreno experimental, sin indicación aprobada y con muchos interrogantes. No se conoce la duración óptima de este tratamiento, el intervalo más adecuado, ni si sería más útil la rotación de antibióticos que mantener siempre una quinolona. Tampoco se puede asegurar que la falta de desarrollo de resistencias observada durante un año de tratamiento pulsátil se extienda con usos más prolongados. Este tratamiento se reservará a casos muy seleccionados de pacientes con nivel de gravedad IV y agudizaciones frecuentes que requirieron múltiples antibióticos o ingresos hospitalarios el año previo a pesar de un tratamiento correcto de su EPOC. Además, deben tener confirmación de infección bronquial crónica por cultivo de esputo que aísle un patógeno respiratorio en fase de EPOC estable. Se debe excluir de este tratamiento a los pacientes con colonización bronquial por Pseudomonas aeruginosa. Si hay respuesta, se pueden repetir ciclos en años sucesivos durante el período invernal. Este tratamiento es experimental y reservado a centros de referencia con estricto control clínico y microbiológico.

Los pacientes candidatos a tratamiento crónico o cíclico con antibióticos son pacientes con una alta probabilidad de ser portadores de bronquiectasias. La presencia de bronquiectasias confirmada mediante TACAR debe ser siempre investigada en los pacientes con fenotipo agudizador, ya que pueden actuar como un factor favorecedor de la infección bronquial crónica y contribuir a mantener un círculo vicioso 
Tabla 13

ratamiento farmacológico de la EPOC según fenotipos y niveles de gravedad (para niveles de gravedad I a IV)

\begin{tabular}{|c|c|c|c|c|}
\hline & Estadio de grav & & & \\
\hline Fenotipo & I & II & III & IV \\
\hline $\begin{array}{l}\text { A } \\
\text { No agudizador con } \\
\text { enfisema o } B C\end{array}$ & $\begin{array}{l}\text { LAMA o LABA } \\
\text { SABA o SAMA* }\end{array}$ & $\begin{array}{l}\text { LAMA o LABA } \\
\text { LAMA + LABA }\end{array}$ & LAMA + LABA & LAMA + LABA + teofilina \\
\hline $\begin{array}{l}\text { B } \\
\text { Mixto EPOC-asma }\end{array}$ & $\mathrm{LABA}+\mathrm{CI}$ & $\mathrm{LABA}+\mathrm{CI}$ & $\mathrm{LAMA}+\mathrm{LABA}+\mathrm{CI}$ & $\begin{array}{l}\mathrm{LAMA}+\mathrm{LABA}+\mathrm{CI} \\
\text { (valorar añadir Teofilina o IPE4 si expectoración } \\
\text { y agudizaciones) }\end{array}$ \\
\hline $\begin{array}{l}\text { C } \\
\text { Agudizador con enfisema }\end{array}$ & LAMA o LABA & $\begin{array}{l}(\text { LABA o LAMA })+C I \\
\text { LAMA + LABA } \\
\text { LAMA o LABA }\end{array}$ & $\mathrm{LAMA}+\mathrm{LABA}+\mathrm{CI}$ & $\begin{array}{l}\mathrm{LAMA}+\mathrm{LABA}+\mathrm{CI} \\
\text { (valorar añadir teofilina) }\end{array}$ \\
\hline $\begin{array}{l}\text { D } \\
\text { Agudizador con BC }\end{array}$ & LAMA o LABA & $\begin{array}{l}(\text { LAMA o LABA })+(C I \text { o IPE4 }) \\
\text { LAMA + LABA } \\
\text { LAMA o LABA }\end{array}$ & $\begin{array}{l}\text { LAMA + LABA + (CI o IPE4) } \\
\text { (LAMA o LABA) + CI + IPE4 } \\
\text { (Valorar añadir carbocisteína) }\end{array}$ & $\begin{array}{l}\text { LAMA + LABA + (CI o IPE4) } \\
\text { LAMA + LABA + CI + IPE4 } \\
\text { (Valorar añadir carbocisteína) } \\
\text { (Valorar añadir teofilina) } \\
\text { (Valorar añadir antibióticos) }\end{array}$ \\
\hline
\end{tabular}

${ }^{*}$ En caso de síntomas intermitentes.

BC: bronquitis crónica; SABA: beta-2 agonista de corta duración; SAMA: anticolinérgico de corta duración; CI: corticosteroide inhalado; LAMA: anticolinérgico de larga duración; LABA: beta-2 agonista de larga duración; IPE4: inhibidor de la fosfodiesterasa 4.

amplificando la inflamación subyacente e induciendo la presencia de agudizaciones frecuentes ${ }^{233}$. Así, las bronquiectasias se han vinculado a la existencia de agudizaciones repetidas y más graves ${ }^{33,54}$. Los pacientes con EPOC, agudizadores frecuentes e infección bronquial crónica deben ser tratados con antibióticos, de acuerdo con las normativas de tratamiento de las bronquiectasias ${ }^{128}$ (evidencia moderada, recomendación fuerte a favor).

Se debe tener mayor cautela al prescribir $\mathrm{CI}$ para la prevención de agudizaciones de tipo infeccioso, en pacientes con expectoración purulenta ya sea en fase estable o durante las agudizaciones, con bronquiectasias y/o con infección bronquial crónica. Estos pacientes pueden ser candidatos a recibir tratamiento con inhibidores de la PDE4 (si presentan tos y expectoración crónica), mucolíticos, antioxidantes ${ }^{223} y$, en casos muy seleccionados, antibióticos de forma crónica o cíclica ${ }^{230,232,233}$ (fig. 11).

En la tabla 13 se expone un resumen del tratamiento farmacológico de la EPOC según el fenotipo y el nivel de gravedad.

\section{Esquema de tratamiento de la EPOC estable}

El esquema de tratamiento de la EPOC estable se presenta en las figuras 8-11.

\section{Esquema de seguimiento de la EPOC estable}

El seguimiento del paciente con EPOC debe efectuarse de manera coordinada entre los diferentes ámbitos asistenciales.

\section{Primera valoración en el primer ámbito asistencial}

1. Historia clínica con especial atención al tabaquismo, los antecedentes de asma o atopia, antecedentes de tos y expectoración crónica, la frecuencia de agudizaciones para valorar la posibilidad de un fenotipo agudizador ( 2 o más al año), las posibles comorbilidades y tratamientos concomitantes.

2. Evaluación del nivel de disnea mediante el cuestionario mMRC.

3. Espirometría con prueba broncodilatadora para establecer el diagnóstico definitivo de EPOC, valorar la gravedad de la obstrucción y la posibilidad de un fenotipo mixto. Con el peso y la talla, calcular el índice de masa corporal.

4. En caso confirmado de EPOC, realizar radiografía de tórax para descartar complicaciones y valorar un posible fenotipo enfisema.

5. Analítica sanguínea básica con especial atención a leucocitosis y fibrinógeno (marcadores de inflamación), poliglobulia, eosinofilia e IgE (marcadores de fenotipo mixto) y determinación de alfa- 1 antitripsina.
6. Evaluación de la calidad de vida y grado de control con el cuestionario CAT.

7. Con los datos obtenidos, identificar el fenotipo clínico y calcular el índice BODE o BODEx para obtener el nivel de gravedad.

\section{Remisión al segundo ámbito asistencial}

En las siguientes situaciones se recomienda remitir el paciente al segundo ámbito asistencial:

- Dudas en el diagnóstico o en la determinación del fenotipo.

- Si no se dispone de espirómetro, hay que remitir siempre al paciente al segundo ámbito asistencial para confirmar el diagnóstico.

- Pacientes con frecuentes exacerbaciones (2 o más al año).

- Presencia de cor pulmonale.

- Tras un ingreso hospitalario a causa de la EPOC (en caso de que no haya sido atendido por un neumólogo).

- Indicación de oxigenoterapia continua domiciliaria.

- Enfermedad en sujetos jóvenes o con sospecha de déficit de alfa-1 antitripsina o con concentraciones plasmáticas bajas de la enzima.

- Valoración de posibles tratamientos quirúrgicos (bullectomía, reducción de volumen, trasplante) o de ventilación mecánica no invasiva.

- Disnea desproporcionada en pacientes con obstrucción de grado moderado $\left(\mathrm{FEV}_{1}>50 \%\right)$.

- Rápido deterioro clínico o de la función pulmonar.

- Si no es posible, realizar la prueba de la marcha y es necesario calcular el índice BODE.

La evaluación por el neumólogo es más útil en el caso del estudio inicial, sobre todo en pacientes moderados o graves. Las revisiones habituales por el segundo ámbito asistencial en pacientes estables con buena evolución son menos necesarias.

\section{Visita de control en la EPOC estable}

En cada visita de control se ha de realizar una evaluación que incluya:

- Valoración clínica: con registro de síntomas respiratorios y escala de disnea mMRC, estado nutricional mediante el IMC.

- Identificación de agudizaciones (número, gravedad y necesidades de tratamiento).

- Interrogar por síntomas de posibles comorbilidades, como la enfermedad cardiovascular, la diabetes mellitus, los trastornos de ansie- 


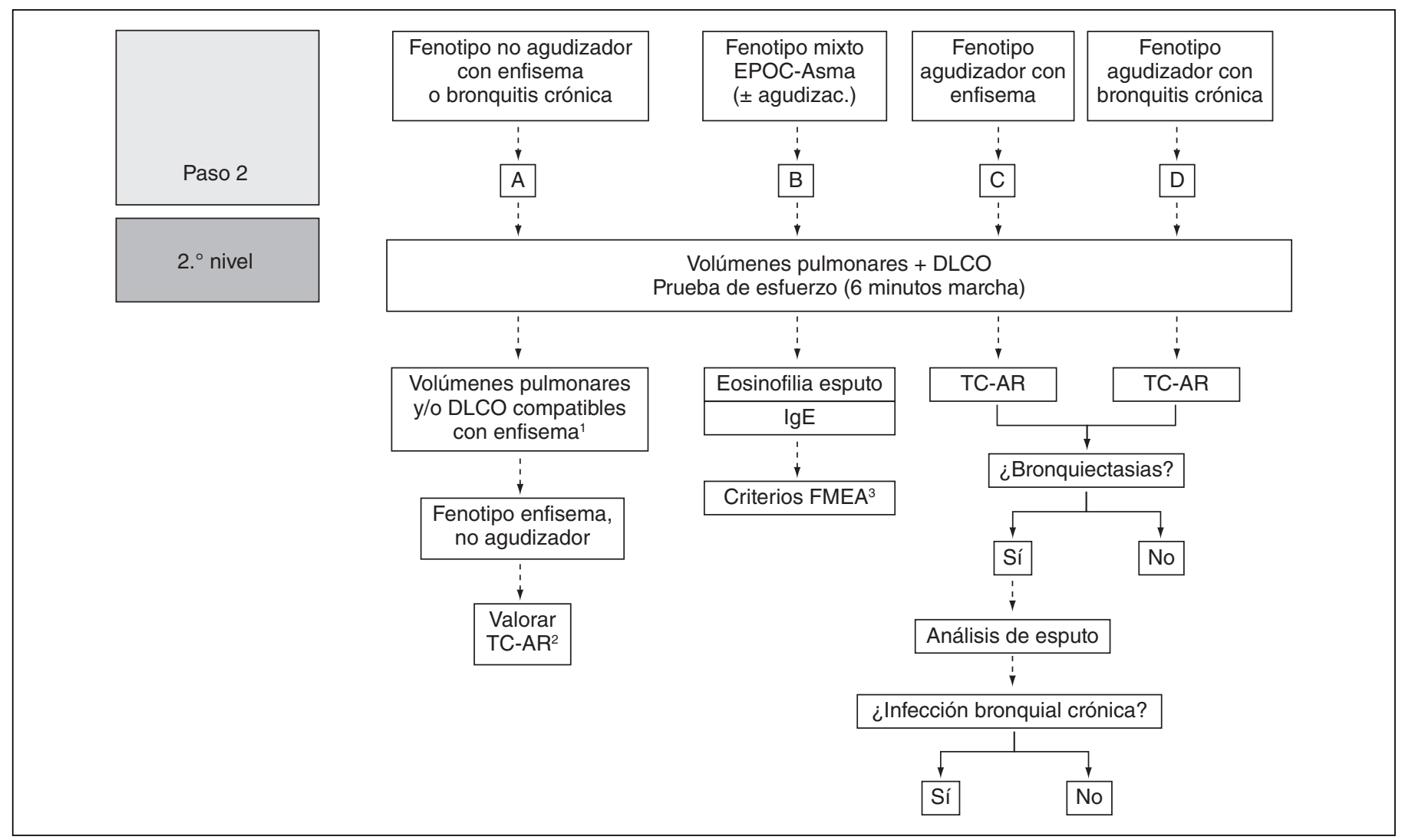

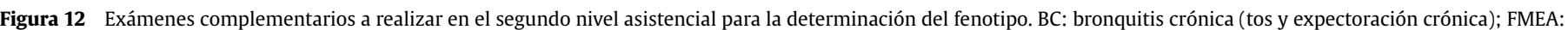
fenotipo mixto EPOC-asma. DLCO: prueba de transferencia del CO; IgE: Inmunoglobulina E; TC-AR: tomografía computerizada de alta resolución.

dad-depresión y la osteoporosis, por su impacto en la historia natural de la enfermedad y la necesidad de adecuar su tratamiento.

- Cuantificar el impacto de la EPOC sobre la calidad de vida y el grado de control clínico mediante el cuestionario CAT.

- Espirometría, para estimar el pronóstico y la evolución de la función pulmonar, así como su respuesta al tratamiento. Se recomienda repetir la espirometría forzada anualmente en todos los pacientes diagnosticados de EPOC. En caso de realizar cambios en el tratamiento se puede repetir a los 2-3 meses para valorar la respuesta.

- En las visitas de seguimiento debe incidirse en el consejo antitabaco y comprobar la adecuación del tratamiento (detección de posibles efectos adversos, revisión de la técnica inhalatoria y del correcto cumplimiento del tratamiento).

- Además, debe evaluarse la respuesta al tratamiento, es decir, si se han alcanzado los objetivos propuestos. En función de los logros conseguidos con el tratamiento, y a tenor del nivel de gravedad (medido por índice BODE o BODEx), del control de síntomas (grado de disnea), del impacto sobre la calidad de vida (mediante el CAT) y el número de exacerbaciones desde el último control, debe decidirse el ajuste de dicho tratamiento.

Visita en el segundo ámbito asistencial

Además de las acciones enumeradas en la visita en el primer ámbito asistencial, en este segundo ámbito se pueden solicitar otras exploraciones que pueden ayudar a establecer el diagnóstico, categorizar el fenotipo y evaluar la gravedad, siempre que sea necesario y siguiendo los criterios de remisión indicados anteriormente (fig. 12):

1. Evaluar la tolerancia al ejercicio mediante la prueba de la marcha de 6 minutos, un examen sencillo que se correlaciona con las mediciones objetivas de la actividad física habitual y servirá para calcular el índice BODE.
2. TC de tórax de alta resolución en pacientes agudizadores ( 20 más agudizaciones al año) para diagnosticar la posible presencia y extensión de bronquiectasias. En pacientes con enfisema se realizará, si se precisa, la evaluación de posibles tratamientos quirúrgicos.

3. Volúmenes pulmonares estáticos y prueba de transferencia del CO para el estudio del enfisema y de disnea desproporcionada con el grado de obstrucción al flujo aéreo.

4. Determinaciones analíticas más complejas en el caso de pacientes con agudizaciones frecuentes o EPOC especialmente grave: estudio de la inmunidad humoral y celular, fenotipos de la alfa- 1 antiripsina, etc.

5. Cultivo de esputo y susceptibilidad antibiótica en pacientes con agudizaciones recurrentes, en número superior a dos al año que requieren tratamiento con antibióticos, fracaso terapéutico de las agudizaciones o sospecha de infección bronquial crónica.

6. Otras pruebas: estudio del sueño, pruebas de esfuerzo, estudio de comorbilidades, etc.

\section{Adecuación del tratamiento durante el seguimiento}

Está bien establecido el incremento del tratamiento de acuerdo con la progresión de la enfermedad o su gravedad. Sin embargo, son muy escasas las pruebas científicas disponibles acerca de una posible reducción o retirada de tratamiento en pacientes que consiguen una mejoría o estabilidad clínica. Según esta escasa evidencia se puede recomendar:

1. El tratamiento broncodilatador ejerce su efecto solamente durante su administración, por lo que es muy probable que la retirada de un broncodilatador o su sustitución por otro de menor potencia broncodilatadora o menor duración de acción produzca un empeoramiento funcional y/o sintomático ${ }^{234}$.

2. En pacientes con fenotipo mixto se puede ensayar la reducción de dosis de $\mathrm{CI}$ hasta conseguir la mínima dosis eficaz, al igual que se 
realiza en el asma. No se recomienda dejar a estos pacientes con tratamiento con BDLD sin CI.

3. En pacientes con fenotipo agudizador no es posible especificar una pauta de reducción de tratamiento en caso de estabilidad. Para plantear una reducción del tratamiento deberá haber transcurrido al menos un año sin agudizaciones. Deberá realizarse según juicio clínico empezando por la retirada de los fármacos que probablemente son menos activos o que presentan mayor probabilidad de efectos adversos a corto o largo plazo.

4. En pacientes leves o moderados (nivel de gravedad I-II), sin fenotipo mixto y que sigan tratamiento con $\mathrm{CI}$ en dosis altas, se debe reevaluar la necesidad de proseguir con estos fármacos. Algunos estudios indican que la retirada brusca de $\mathrm{CI}$ puede desencadenar una agudización ${ }^{235}$, aunque una revisión sistemática reciente concluye que no hay suficientes pruebas científicas para relacionar la retirada de $\mathrm{CI}$ con las agudizaciones ${ }^{236}$. En cualquier caso, se deberá individualizar la indicación, nunca en pacientes que persisten con una prueba broncodilatadora positiva o con eosinofilia en el esputo a pesar del tratamiento con $\mathrm{Cl}^{237,238}$, y realizarla solamente en pacientes estables, sin agudizaciones por lo menos durante un año, fuera de las temporadas invernales de mayor incidencia de agudizaciones ${ }^{238}$, con reducción progresiva de las dosis y con un seguimiento clínico y espirométrico estrecho.

\section{Intervenciones no farmacológicas en pacientes con EPOC en fase estable}

\section{Puntos clave:}

- La rehabilitación respiratoria mejora la disnea, la capacidad de ejercicio y la calidad de vida.

- La aplicación de programas domiciliarios de mantenimiento es una alternativa válida a la rehabilitación realizada en el hospital desde las fases iniciales de la enfermedad.

- Evitar el sedentarismo y estimular la actividad y el ejercicio físico cotidiano es beneficioso para el paciente EPOC y debe recomendarse de forma generalizada.

- La oxigenoterapia y la ventilación no invasiva tienen indicaciones precisas en pacientes con diversos grados de insuficiencia respiratoria.

\section{Oxigenoterapia crónica domiciliaria}

La oxigenoterapia crónica domiciliaria (OCD) es un tratamiento que consigue aumentar la supervivencia en pacientes con EPOC e insuficiencia respiratoria grave ${ }^{239-241}$. También ha demostrado reducir el número de exacerbaciones y hospitalizaciones, y mejorar la capacidad de esfuerzo y la calidad de vida ${ }^{242}$.

Los beneficios conseguidos con la oxigenoterapia dependen de la duración de su administración. La duración diaria de la OCD se recomienda que debe ser al menos de 16-18 $\mathrm{h}^{243,244}$, con el objetivo de mantener una $\mathrm{PaO}_{2} \geq 60 \mathrm{mmHg}$ o una saturación de oxígeno $\left(\mathrm{SpO}_{2}\right) \geq$ $90 \%$ en situación de reposo y a nivel del mar (evidencia moderada, recomendación fuerte a favor).

La indicación debe realizarse cuando la enfermedad está en fase estable, mediante la realización de una gasometría arterial (tabla 14). La gasometría arterial es el método de elección para establecer la indicación de la $\mathrm{OCD}^{245}$.

El seguimiento y la evaluación del cumplimiento del tratamiento es un objetivo clave ${ }^{246,247}$. Cuando se indica la OCD se debe comprobar que el paciente realiza un tratamiento adecuado de su EPOC, que incluya no sólo el tratamiento farmacológico, sino el cese del tabaquismo y un correcto tratamiento de las comorbilidades, fundamentalmente cardiovasculares. También es importante recordar la necesidad de reevaluar y confirmar la indicación de oxigenoterapia domiciliaria si su indicación se realizó en el contexto de una agudización.

Existe controversia sobre la utilización de la OCD en pacientes con hipoxemia intermitente como la que aparece durante el sueño o en
Tabla 14

Indicaciones de la oxigenoterapia crónica domiciliaria (OCD)

Paciente con EPOC estable en reposo y a nivel del mar, respirando aire ambiente
$\mathrm{PaO}_{2}<55 \mathrm{mmHg}$
$\mathrm{PaO}_{2}$ de 55-60 mmHg con repercusión por hipoxemia
Hipertensión arterial pulmonar/cor pulmonale
Insuficiencia cardíaca congestiva/arritmias
Hematocrito > 55\%

Tomada de: SEPAR-ALAT $2009^{247}$.

los pacientes con hipoxemia de leve a moderada, donde no se han demostrado efectos de la OCD sobre la supervivencia ${ }^{239}$. En ausencia de criterios de OCD, la oxigenoterapia durante el sueño está indicada si, además de desaturaciones prolongadas, hay poliglobulia o signos de insuficiencia cardíaca derecha ${ }^{247}$.

La oxigenoterapia durante la deambulación mejora la capacidad para realizar ejercicio en pacientes con EPOC de moderada a grave. En los pacientes con hipoxemia durante el ejercicio puede plantearse su utilización en casos de limitación por disnea y con desaturaciones inferiores al $88 \%$ en la prueba de la marcha. Debe reevaluarse en los primeros 2 meses la mejoría conseguida tanto en la disnea como en la distancia recorrida ${ }^{248}$. No obstante, son necesarios más estudios para definir los beneficios ${ }^{249}$.

\section{Soporte ventilatorio no invasivo}

Actualmente no hay suficientes criterios científicos para recomendar este tipo de tratamiento de forma generalizada en la EPOC estable con hipercapnia (evidencia moderada, recomendación débil en contra). La mayoría de los estudios y de las revisiones sistemáticas publicadas muestran unos resultados muy heterogéneos ${ }^{250}$.

Recientemente se ha publicado un estudio en el que el objetivo primario era analizar la supervivencia, y se observó que mejoraba durante los primeros 2 años de utilización de la ventilación mecánica no invasiva (VNI) más OCD, aunque a los 3 años y medio la supervivencia se igualaba a la de los pacientes con sólo OCD ${ }^{251}$.

No obstante, la indicación de la VNI en pacientes con EPOC estable puede valorarse en un subgrupo de pacientes que presentan hipercapnia diurna importante: $\mathrm{PaCO}_{2}>55 \mathrm{mmHg}$ o hipercapnia diurna $\left(\mathrm{PaCO}_{2}\right.$ $>45 \mathrm{mmHg}$ ) con desaturaciones nocturnas $\left(\mathrm{SaO}_{2}<90 \%\right.$, más del $10 \%$ del tiempo total de sueño) a pesar de la oxigenoterapia, o 2 o más hospitalizaciones anuales por insuficiencia respiratoria grave $\mathrm{e}^{252-254}$.

\section{Rehabilitación respiratoria}

La rehabilitación respiratoria (RR) se define en el consenso de la American Thoracic Society y European Respiratory Society (ATS/ ERS $)^{255}$ como una intervención multidisciplinaria y global que debe formar parte del tratamiento individualizado del paciente, dirigida a reducir los síntomas, optimizar la capacidad funcional, incrementar la participación y reducir los costes sanitarios, estabilizando o revirtiendo las manifestaciones sistémicas de la enfermedad.

La RR es una herramienta terapéutica fundamental en el tratamiento integral del paciente con EPOC, ya que ha demostrado mejorar el rendimiento físico y la autonomía del paciente al permitir un mejor control de la disnea, optimizar la función pulmonar, mejorar la capacidad de esfuerzo y reducir los factores psicosociales que modulan la evolución de la enfermedad (evidencia alta, recomendación fuerte a favor $)^{256,257}$. Su impacto sobre la supervivencia todavía no se puede determinar con los estudios de que disponemos ${ }^{258}$.

Los programas de RR deben contemplar la evaluación del paciente, el entrenamiento al ejercicio como componente fundamental (evidencia alta, recomendación fuerte a favor), la educación, que incluye la fisioterapia ${ }^{259}$, la intervención nutricional y el soporte psicosocial ${ }^{260}$. La duración necesaria de los programas de RR con supervisión profe- 
sional en los pacientes con EPOC debe ser de 3 sesiones a la semana durante 8 semanas ${ }^{261}$. Es importante, una vez finalizado este programa inicial supervisado, realizar un programa de mantenimiento de manera indefinida en su domicilio para mantener los beneficios conseguidos (evidencia alta, recomendación fuerte a favor).

La RR es una de las herramientas terapéuticas más eficaces para los pacientes que presentan una EPOC. Y así, las distintas guías americanas y europeas contemplan la RR como una medida terapéutica fundamental en el tratamiento de esta enfermedad ${ }^{4,5,262,263}$.

\section{Actividad física}

Diversos estudios han evaluado el papel beneficioso de la actividad física sobre el pronóstico y la evolución de la EPOC. En un estudio de cohortes con 11 años de seguimiento, las personas fumadoras con un nivel de ejercicio físico moderado y alto presentaron menos riesgo de desarrollar EPOC que los fumadores con bajo nivel de ejercicio físi$\mathrm{Co}^{153}$. Además, este estudio mostró que cuanto mayor era el nivel de actividad física, menor era la disminución de la función pulmonar, tanto en fumadores activos como en antiguos fumadores (evidencia moderada, recomendación débil a favor).

La reducción de la actividad física es una consecuencia bien conocida de la EPOC, pero la propia inactividad es en sí misma una causa que contribuye a la mayor pérdida de función pulmonar, de modo que los fumadores con bajos niveles de actividad física son más propensos a ser diagnosticados posteriormente de EPOC ${ }^{264}$.

El ejercicio físico reduce el estrés oxidativo, tiene un efecto antiinflamatorio y reduce la frecuencia de infecciones de las vías respiratorias, proporcionando una serie de mecanismos por los cuales podría atenuar los efectos nocivos del tabaco ${ }^{264}$.

Los resultados de un reciente ECA realizado en el contexto de la atención primaria en España han demostrado que el consejo individualizado es eficaz para aumentar la actividad física en las personas inactivas. El efecto es pequeño, pero relevante en términos de salud pública a nivel poblacional. Este efecto se considera mayor en individuos con enfermedades crónicas ${ }^{265}$ (evidencia moderada, recomendación fuerte a favor). Por último, hay pruebas científicas que indican que el ejercicio físico ayuda a los fumadores a dejar de fumar ${ }^{266}$ (evidencia moderada, recomendación fuerte a favor).

\section{Nutrición}

El mantenimiento de un estado nutricional óptimo en los pacientes con enfermedades respiratorias es crucial. La malnutrición produce una situación de riesgo y tiene efectos negativos en la evolución de la enfermedad, acompañándose de mayor morbimortalidad. En la repercusión de la desnutrición sobre el aparato respiratorio se ven afectados la musculatura respiratoria, el parénquima pulmonar y el sistema inmunitario ${ }^{267,268}$.

La valoración del estado nutricional del paciente se convierte en una necesidad para poder detectar de forma temprana a los sujetos con mayor riesgo de desnutrición y establecer el grado de soporte nutricional que se aplicará. La valoración de estos pacientes debe incluir: estudio dietético, antropométrico (peso, talla, IMC, pliegue cutáneo), estudio hematológico, bioquímico e inmunológico ${ }^{269}$. Técnicas como la bioimpedancia eléctrica son muy útiles para conocer la composición corporal. En pacientes con déficit nutricional se pueden seguir las estrategias indicadas en la tabla 15.

La obesidad es otro aspecto importante y cada vez más frecuente en la EPOC. Puede limitar la capacidad de ejercicio, producir restricción respiratoria y agravar la disnea. En estos casos es esencial el consejo dietético.

\section{Estrategias de autocuidado}

Los pacientes con EPOC deberían participar en programas de educación encaminados a enseñar las habilidades necesarias en el tratamiento de la enfermedad (evidencia baja, recomendación débil a favor). Comprende las actividades orientadas a mantener y mejorar el
Tabla 15

Estrategias de alimentación

Se deben realizar 5-6 comidas al día, repartidas en pequeñas cantidades, comer despacio y masticar bien

Consumir 3-4 raciones de fruta para asegurarse la ingesta de vitaminas y minerales

Consumir pescado 2-3 veces a la semana, considerando que al menos dos sean de pescado azul (sardina, boquerón, bonito, caballa, salmón)

Disminuir el consumo de grasa animal

Usar preferentemente aceite de oliva virgen para cocinar y condimentar

No consumir alimentos muy fríos o muy calientes, ya que pueden provocar sensación de tos y/o ahogo

Tomar abundantes líquidos (aproximadamente 1,5-2 l), siempre que no haya contraindicación al respecto

estado de salud y el bienestar. Constituye una estrategia importante para la protección de la salud y la prevención de la enfermedad. Entre las prácticas para el autocuidado se encuentran ${ }^{270}$ :

- Protegerse de las sustancias nocivas del ambiente (mascarillas).

- Mantener en el domicilio un ambiente óptimo (45\% de humedad y temperatura de $19-21^{\circ} \mathrm{C}$ ).

- Realizar correctamente el tratamiento. No sólo es importante tomarse la medicación, sino saber para qué sirve y cómo administrársela.

- El ejercicio regular desempeña un papel fundamental para mantener la forma física.

- Asegurar una higiene del sueño: establecer rutinas para acostarse, levantarse y descansar. Evitar la toma de alimentos que contengan cafeína y alcohol.

- La ingesta moderada de alcohol no está formalmente contraindicada en los pacientes con EPOC sin otras complicaciones. No es recomendable tomarlo durante la cena, para evitar el posible efecto sobre el patrón del sueño.

- La presencia de disnea y el uso de los equipos de oxigenoterapia pueden disminuir el deseo y la actividad sexual. Estas circunstancias no deben ser una limitación.

- No descuidar la higiene personal. Si se produce fatiga, adaptar las actividades a la situación (lavarse despacio, sentado y usando toallas pequeñas para secarse).

- Utilizar ropa holgada, adecuada a cada época del año.

- No renunciar a disfrutar. Mantener el interés en realizar actividades lúdico-sociales. Utilizar estrategias de distracción (técnicas de relajación, vacaciones).

\section{Tratamientos quirúrgicos}

Puntos clave:

- La cirugía de reducción de volumen pulmonar es eficaz en un subgrupo muy bien caracterizado de pacientes con enfisema.

- El trasplante pulmonar es una alternativa para pacientes muy graves con deterioro progresivo a pesar del tratamiento correcto.

\section{Bullectomía}

La indicación más común para la bullectomía es la disnea debida a una bulla gigante o neumotórax espontáneos secundarios. El término de bulla gigante se usa para la bulla que ocupa más del 30\% del hemitórax.

Los pacientes que más se benefician de esta técnica quirúrgica son los que tienen bullas que ocupan más del 50\% del hemitórax ${ }^{271}$ (evidencia baja, recomendación débil a favor). La evidencia radiológica de que la bulla comprime el tejido pulmonar adyacente es también un factor de pronóstico favorable para la cirugía. 
Tabla 16

Recomendaciones sobre tratamiento de la EPOC estable. Medidas generales

\begin{tabular}{|c|c|c|c|c|}
\hline Tratamiento & NR & Recomendación & Calidad de la evidencia & Fuerza de la recomendación \\
\hline \multirow[t]{2}{*}{ Vacunación } & R005 & $\begin{array}{l}\text { Todos los pacientes con EPOC deben ser vacunados anualmente contra } \\
\text { la gripe }\end{array}$ & Baja $^{a}$ & Fuerte a favor ${ }^{\mathrm{a}}$ \\
\hline & R006 & Todos los pacientes con EPOC deben recibir la vacuna neumocócica & Baja $^{a}$ & Fuerte a favor ${ }^{\mathrm{a}}$ \\
\hline Actividad física & R007 & $\begin{array}{l}\text { A todos los pacientes con EPOC se les debe aconsejar realizar actividad } \\
\text { física regular }\end{array}$ & Moderada $^{a}$ & Fuerte a favor ${ }^{\mathrm{a}}$ \\
\hline
\end{tabular}

NR: numeración de las recomendaciones.

${ }^{a}$ Referencia de SEPAR-semFyC ${ }^{6}$.

\section{Trasplante pulmonar}

La EPOC es la indicación más frecuente de trasplante pulmonar en todo el mundo ${ }^{272}$. Es objeto de controversia si el trasplante pulmonar proporciona un aumento significativo de la supervivencia en la EPOC, pero de lo que no hay duda es que produce una mejoría en la función pulmonar, el intercambio de gases, la tolerancia al esfuerzo y la calidad de vida ${ }^{273}$.

Según el Internacional Society for Heart and Lung Transplantation Registry (ISHLT), la mejor supervivencia de estos pacientes se obtiene en receptores menores de 50 años a los que se les realiza un trasplante bilateral (supervivencia del $62 \%$ a los 5 años) frente a los que son mayores de 50 años y se les realiza un trasplante unilateral (supervivencia del $48 \%$ a los 5 años) $)^{272}$.

El trasplante pulmonar debe ser considerado en pacientes con EPOC muy grave y deterioro progresivo a pesar de un tratamiento médico correcto (evidencia moderada, recomendación débil a favor). Las escalas multidimensionales como el BODE han tenido un gran impacto en la valoración pronóstica de la EPOC, pero no contemplan parámetros como las exacerbaciones hipercápnicas o la presencia de hipertensión pulmonar con signos de insuficiencia cardíaca.

La actual normativa SEPAR de trasplante ${ }^{274}$ recomienda:

1. Remitir a un paciente para trasplante si el BODE $>5$.

2. Indicación de trasplante si el BODE $=7-10$ y está presente alguno de los siguientes criterios:

- Hospitalización con hipercapnia (pCO2 > 50 mmHg) documentada.

- Cor pulmonale.

- $\mathrm{FEV}_{1}<20 \%$ y DLCO < 20\% o enfisema homogéneo difuso.

Técnicas de reducción de volumen pulmonar

Técnicas endoscópicas de reducción de volumen pulmonar

En los últimos años se han desarrollado métodos no quirúrgicos para reducir el volumen pulmonar mediante técnicas endoscópicas:

1. Válvulas unidireccionales que permiten la salida del aire pero no su entrada para intentar colapsar las zonas hiperinsufladas.

2. Reducción biológica del volumen pulmonar que conlleva la aplicación intrabronquial de sustancias biocompatibles que colapsan las zonas enfisematosas.

3. Bypass de vías aéreas con la creación de un stent entre el parénquima hiperinsuflado y el árbol bronquial.

Los resultados de los estudios nos muestran una menor eficacia de estos métodos frente a la cirugía de reducción de volumen pulmonar convencional (CRVP) ${ }^{275-277}$.

Técnicas quirúrgicas de reducción de volumen pulmonar

Las técnicas de reducción pulmonar son una opción válida para un grupo reducido de pacientes con enfisema grave. La CRVP consiste en eliminar las zonas pulmonares enfisematosas que no contribuyen al intercambio gaseoso para permitir una mejor mecánica ventilatoria del resto del parénquima pulmonar.

Algunos estudios demuestran que la CRVP mejora los síntomas, la función pulmonar, la tolerancia al ejercicio y aumenta la supervivencia en un grupo definido de pacientes enfisematosos 277,278 .

El estudio más amplio realizado hasta la fecha (NETT) ha demostrado que los pacientes que se benefician en mayor medida de la CRVP son aquellos con enfisema en los lóbulos superiores y baja capacidad de ejercicio. Por el contrario, los pacientes con un $\mathrm{FEV}_{1}<20 \%$ y enfisema homogéneo o $\mathrm{FEV}_{1}<20 \%$ y DLCO $<20 \%$ son los que no obtienen beneficio de la $\operatorname{CRVP}^{279}$ (evidencia alta, débil a favor).

En los pacientes enfisematosos con déficit de alfa-1 antitripsina el beneficio de la CRVP es menor y su efecto beneficioso es de menor duración ${ }^{275}$.

\section{Recomendaciones sobre tratamiento de la EPOC estable}

Medidas generales

Se presentan en la tabla 16.

Tratamiento farmacológico

Se resume en la tabla 17.

Tratamiento no farmacológico

Se resume en la tabla 18 .

Estándares de calidad asistencial sobre el tratamiento de la EPOC estable

Se muestran en la tabla 19.

\section{Agudización de la EPOC}

Puntos clave:

- La agudización se define como un empeoramiento mantenido de síntomas respiratorios, más allá de su variación diaria, que es agudo en su inicio.

- Es necesario distinguir una nueva agudización de un fracaso terapéutico previo o de una recaída.

- El diagnóstico de una agudización de la EPOC consta de tres pasos esenciales: a) diagnóstico diferencial de la agudización de EPOC; $b$ ) establecer la gravedad del episodio, y c) identificar su etiología.

- En la agudización de la EPOC de cualquier intensidad, la principal intervención es optimizar la broncodilatación, aumentando la dosis y/o la frecuencia de los broncodilatadores de acción corta y rápida.

- Los antibióticos están especialmente indicados en presencia de esputo purulento.

- Se deberá emplear una pauta corta de corticoides sistémicos en las agudizaciones moderadas, graves o muy graves.

- La administración de oxígeno, cuando esté indicada, debe realizarse siempre de forma controlada. 
Tabla 17

Tratamiento farmacológico de la EPOC estable

\begin{tabular}{|c|c|c|c|c|}
\hline Tratamiento & NR & Recomendación & Calidad de la evidencia & Fuerza de la recomendación \\
\hline $\begin{array}{l}\text { Broncodilatadores de } \\
\text { acción corta }\end{array}$ & R008 & $\begin{array}{l}\text { Los broncodilatadores de acción corta (agonistas beta- } 2 \text { y/o } \\
\text { anticolinérgicos) se deben utilizar a demanda, añadidos al tratamiento } \\
\text { de base sea cual sea el nivel de gravedad de la enfermedad, para el } \\
\text { alivio inmediato de los pacientes con EPOC }\end{array}$ & Moderada $^{\mathrm{a}}$ & Débil a favor ${ }^{\mathrm{a}}$ \\
\hline \multirow[t]{3}{*}{$\begin{array}{l}\text { Broncodilatadores de } \\
\text { larga duración (BDLD) }\end{array}$} & R009 & $\begin{array}{l}\text { Los broncodilatadores de larga duración (BDLD) se deben utilizar como } \\
\text { primer escalón en el tratamiento de todos los pacientes con síntomas } \\
\text { permanentes }\end{array}$ & Alta $^{\mathrm{a}}$ & Fuerte a favor ${ }^{\mathrm{a}}$ \\
\hline & R010 & $\begin{array}{l}\text { En pacientes con EPOC en fase estable, que hayan sufrido al menos una } \\
\text { exacerbación previa que ha requerido hospitalización y/o tratamiento } \\
\text { con glucocorticoides sistémicos y/o antibióticos durante el año anterior, } \\
\text { y que precisen un broncodilatador de acción mantenida en } \\
\text { monoterapia, se sugiere el uso de tiotropio frente a salmeterol }\end{array}$ & Moderada $^{\mathrm{b}}$ & Débil a favor ${ }^{\mathrm{b}}$ \\
\hline & R011 & $\begin{array}{l}\text { En pacientes con EPOC en fase estable que precisen un broncodilatador } \\
\text { de acción mantenida en monoterapia se sugiere basar la elección final } \\
\text { del broncodilatador en criterios como las preferencias de los pacientes } \\
\text { individuales, la respuesta individual al fármaco y/o aspectos } \\
\text { económicos }\end{array}$ & Muy baja ${ }^{\mathrm{b}}$ & Buena práctica clínicab \\
\hline Combinación de BDLD & R012 & $\begin{array}{l}\text { Las combinaciones de BDLD deben emplearse en los pacientes con } \\
\text { EPOC que persistan sintomáticos a pesar de la monoterapia }\end{array}$ & Alta $^{\mathrm{a}}$ & Fuerte a favor ${ }^{\mathrm{a}}$ \\
\hline Teofilinas & R013 & $\begin{array}{l}\text { Las teofilinas no deberían utilizarse como tratamiento de primera línea } \\
\text { debido a sus potenciales efectos adversos }\end{array}$ & Moderada $^{\mathrm{a}}$ & Débil en contra ${ }^{\mathrm{a}}$ \\
\hline Corticoides inhalados & R014 & $\begin{array}{l}\text { Los corticoides inhalados se deben utilizar siempre en asociación con } \\
\text { BDLD }\end{array}$ & Moderada $^{\mathrm{a}}$ & Fuerte a favor ${ }^{\mathrm{a}}$ \\
\hline $\begin{array}{l}\text { Combinación de } \\
\beta_{2} \text {-adrenérgicos de } \\
\text { larga duración y } \\
\text { corticoides inhalados }\end{array}$ & R015 & $\begin{array}{l}\text { Las combinaciones de } \beta_{2} \text {-adrenérgicos de larga duración y corticoides } \\
\text { inhalados se deben utilizar en pacientes con EPOC que presentan } \\
\text { frecuentes agudizaciones, a pesar del tratamiento con BDLD }\end{array}$ & Alta $^{a}$ & Fuerte a favor ${ }^{\mathrm{a}}$ \\
\hline $\begin{array}{l}\text { Triple terapia } \\
\text { (combinación de } \\
\text { anticolinérgicos de } \\
\text { larga duración y } \\
\beta 2 \text {-adrenérgicos de } \\
\text { larga duración, más } \\
\text { corticoides inhalados) }\end{array}$ & R016 & $\begin{array}{l}\text { La triple terapia (añadir un antimuscarínico de larga duración a la } \\
\text { asociación previa de un } \beta 2 \text {-adrenérgico de larga duración y un } \\
\text { corticoide inhalado) debe utilizarse en pacientes con EPOC grave o muy } \\
\text { grave con mal control de los síntomas, a pesar del tratamiento con } \\
\text { BDLD }\end{array}$ & Alta $^{a}$ & Fuerte a favor ${ }^{\mathrm{a}}$ \\
\hline Mucolíticos & R017 & $\begin{array}{l}\text { En los pacientes con EPOC en fase estable y fenotipo agudizador con } \\
\text { bronquitis crónica se sugiere utilizar la carbocisteína como tratamiento } \\
\text { de mantenimiento de la EPOC }\end{array}$ & Bajab $^{b}$ & Débil a favor ${ }^{b}$ \\
\hline $\begin{array}{l}\text { Antibióticos en fase } \\
\text { estable }\end{array}$ & R018 & $\begin{array}{l}\text { La coexistencia de EPOC con frecuentes agudizaciones y bronquiectasias } \\
\text { con infección bronquial crónica, debe ser tratada con antibiótico, como } \\
\text { se recoge en las normativas de bronquiectasias }\end{array}$ & Baja $^{a}$ & Débil a favor \\
\hline
\end{tabular}

NR: numeración de las recomendaciones.

aReferencia de SEPAR-semFyC.

'Guía UETS-Laín Entralgo.

- La ventilación mecánica no invasiva se debe valorar en todo paciente que curse con acidosis respiratoria $(\mathrm{pH}<7,35)$.

\section{Definición de agudización}

La agudización o exacerbación se define como un episodio agudo de inestabilidad clínica que acontece en el curso natural de la enfermedad y se caracteriza por un empeoramiento mantenido de los síntomas respiratorios que va más allá de sus variaciones diarias. Los principales síntomas referidos son empeoramiento de la disnea, tos, incremento del volumen y/o cambios en el color del esputo.

Habitualmente estos cambios sintomáticos se acompañan de variaciones en la medicación, y por eso en muchos ensayos clínicos y estudios epidemiológicos se valora la utilización de fármacos (antibióticos y/o corticoides sistémicos) o el uso de recursos sanitarios (visitas a urgencias, hospitalizaciones, etc.) como marcadores indirectos de agudización. Sin embargo, utilizando registros diarios de síntomas, se ha observado que más de la mitad de las agudizaciones no se notifican al médico (agudizaciones no documentadas) ${ }^{282,283}$.
En promedio, los pacientes con EPOC experimentan 1-4 exacerbaciones/año ${ }^{284}$. Sin embargo, la distribución es muy variable. Mientras algunas personas no experimentan estos episodios, otros los presentan de forma repetida (fenotipo agudizador) ${ }^{36}$. Muchos de estos episodios se observan agrupados en racimos ${ }^{285}$, lo que plantea la duda de si realmente son nuevas exacerbaciones o son resoluciones incompletas del episodio precedente. Para distinguir estas situaciones, GesEPOC establece las siguientes definiciones (fig. 13):

- Fracaso terapéutico: se define como un empeoramiento de síntomas que sucede durante la propia agudización y que requiere un tratamiento adicional ${ }^{37}$.

La recuperación media después de sufrir una agudización es de aproximadamente 2 semanas No obstante, algunos pacientes no se recuperan de forma completa hasta las 4-6 semanas ${ }^{286,287}$.

- Recaída: cuando se produce un nuevo empeoramiento de síntomas entre la finalización del tratamiento de la agudización y las 4 semanas posteriores.

- Recurrencia: se produce cuando los síntomas reaparecen en un plazo inferior a un año desde la agudización precedente, después de 
Tabla 18

Tratamiento no farmacológico de la EPOC estable

\begin{tabular}{|c|c|c|c|c|}
\hline Tratamiento & NR & Recomendación & Calidad de la evidencia & Tipo de recomendación \\
\hline \multirow[t]{2}{*}{$\begin{array}{l}\text { Oxígenoterapia } \\
\text { crónica domiciliaria } \\
\text { (OCD) }\end{array}$} & R019 & $\begin{array}{l}\text { La oxigenoterapia crónica domiciliaria (OCD) debe utilizare en todos los } \\
\text { pacientes con EPOC en fase estable que presenten: } \\
-\mathrm{PaO}_{2}<55 \mathrm{mmHg} \\
-\mathrm{PaO}_{2} \text { entre } 55 \text { y } 60 \mathrm{mmHg} \text {, si cursan con poliglobulia, hipertensión } \\
\text { pulmonar, cor pulmonale o arritmias }\end{array}$ & Alta $^{a}$ & Fuerte a favora \\
\hline & R020 & $\begin{array}{l}\text { La OCD se debe administrar al menos durante } 16-18 \mathrm{~h} \text { al día, incluyendo las } \\
\text { horas del sueño }\end{array}$ & Moderada $^{a}$ & Fuerte a favor ${ }^{\mathrm{a}}$. \\
\hline $\begin{array}{l}\text { Ventilación } \\
\text { mecánica no } \\
\text { invasiva (VNI) }\end{array}$ & R021 & $\begin{array}{l}\text { Actualmente no hay suficientes criterios científicos para recomendar, de } \\
\text { forma generalizada, la VNI en el paciente con EPOC estable e hipercapnia }\end{array}$ & Moderada $^{\mathrm{a}}$ & Débil en contra ${ }^{a}$ \\
\hline \multirow[t]{3}{*}{$\begin{array}{l}\text { Rehabilitación } \\
\text { respiratoria (RR) }\end{array}$} & R022 & $\begin{array}{l}\text { La RR debería ofrecerse a todos los pacientes con EPOC que presenten una } \\
\text { disnea de grado } 2 \text { o superior en la escala MMRC, a pesar de recibir } \\
\text { tratamiento farmacológico adecuado }\end{array}$ & Altab $^{\mathrm{b}}$ & Fuerte a favor ${ }^{\mathrm{b}}$ \\
\hline & R023 & $\begin{array}{l}\text { El programa de RR debe incluir entrenamiento muscular, tanto en } \\
\text { extremidades inferiores como superiores }\end{array}$ & Alta $^{\mathrm{a}}$ & Fuerte a favor ${ }^{\mathrm{a}}$ \\
\hline & R024 & $\begin{array}{l}\text { Se debe aconsejar a los pacientes en programa de RR que, tras su finalización, } \\
\text { sigan realizando ejercicios de rehabilitación de forma indefinida en su } \\
\text { domicilio }\end{array}$ & Alta $^{\mathrm{a}}$ & Fuerte a favor ${ }^{\mathrm{a}}$ \\
\hline \multirow[t]{3}{*}{ Actividad física } & R025 & $\begin{array}{l}\text { A todos los pacientes con EPOC se les debe aconsejar que realicen actividad } \\
\text { física regular }\end{array}$ & Moderada $^{a}$ & Fuerte a favor ${ }^{\mathrm{a}}$ \\
\hline & R026 & $\begin{array}{l}\text { A los fumadores activos se les debería aconsejar que realicen actividad física } \\
\text { regular con el objetivo de reducir el riesgo de EPOC }\end{array}$ & Moderada $^{\mathrm{a}}$ & Débil a favor ${ }^{\mathrm{a}}$ \\
\hline & R027 & El ejercicio físico puede ayudar a dejar de fumar & Moderada $^{\mathrm{a}}$ & Fuerte a favor ${ }^{\mathrm{a}}$ \\
\hline $\begin{array}{l}\text { Autocuidado y } \\
\text { educación sanitaria }\end{array}$ & R028 & $\begin{array}{l}\text { Los pacientes deberían participar en programas de educación encaminados a } \\
\text { enseñar las habilidades necesarias en el manejo de la enfermedad }\end{array}$ & Baja $^{\mathrm{a}}$ & Débil a favor ${ }^{\mathrm{a}}$ \\
\hline \multirow[t]{3}{*}{ Cirugía } & R029 & $\begin{array}{l}\text { La bullectomía debería utilizarse en pacientes con EPOC grave y bullas } \\
\text { gigantes }\end{array}$ & Baja $^{a}$ & Débil a favor ${ }^{\mathrm{a}}$ \\
\hline & R030 & $\begin{array}{l}\text { El trasplante de pulmón debe ser considerado en pacientes con EPOC muy } \\
\text { grave y deterioro progresivo, a pesar de un tratamiento médico correcto }\end{array}$ & Moderada $^{\mathrm{a}}$ & Débil a favor ${ }^{\mathrm{a}}$ \\
\hline & R031 & $\begin{array}{l}\text { La cirugía reductora de volumen pulmonar debería emplearse en pacientes } \\
\text { con enfisema de predominio en lóbulos superiores y baja capacidad de } \\
\text { ejercicio }\end{array}$ & Alta $^{a}$ & Débil a favor ${ }^{\mathrm{a}}$ \\
\hline
\end{tabular}

NR: numeración de las recomendaciones.

aReferencia de SEPAR-semFyC ${ }^{6}$.

bECA de $\mathrm{RR}^{280}$

un período de relativo buen estado de salud. Para ello se establece que deben haber transcurrido al menos 4 semanas después de completar el tratamiento de la agudización previa o bien 6 semanas desde que se iniciaron los síntomas ${ }^{37}$.

Las recurrencias se considerarán tempranas si aparecen entre las 4 y 8 semanas del episodio anterior, y tardías si aparecen después de este período.

\section{Impacto de las agudizaciones}

La intensidad, la duración y la frecuencia de las agudizaciones varían enormemente de unos pacientes a otros e incluso en el mismo paciente, por lo que resulta difícil precisar sus consecuencias. Sin embargo, distintos estudios han demostrado que las agudizaciones producen un deterioro de la CVRS, generan elevados costes, afectan a la progresión multidimensional de la enfermedad y aumentan el riesgo de muerte $29,113,282,284,288$.

\section{Diagnóstico}

En la figura 14 se establecen los 3 pasos diagnósticos que se deben seguir para caracterizar adecuadamente una agudización. En primer lugar, se deberá confirmar que estamos ante una agudización de la EPOC, descartando otros procesos que cursan con síntomas similares; en segundo lugar, se valorará la gravedad de la agudización, y finalmente se intentará establecer su causa. Para este último punto, las pruebas diagnósticas que se realizarán pueden diferir según se trate de una agudización ambulatoria u hospitalaria.

\section{Paso 1: diagnóstico de agudización de EPOC}

La sospecha clínica de una agudización de EPOC se establecerá cuando se den los siguientes 3 criterios:

\section{Diagnóstico previo de EPOC.}

En los casos donde no se disponga de espirometría, no podrá establecerse el diagnóstico de EPOC y, por tanto, tampoco el de agudización de EPOC. En estos casos se recomienda utilizar el término "posible agudización de EPOC". Una vez estabilizado el paciente, se deberá realizar una espirometría para confirmar el diagnóstico.

2. Empeoramiento mantenido de síntomas respiratorios, especialmente aumento de la disnea respecto a la situación basal, incremento del volumen del esputo y/o cambios en su coloración.

Para documentar que existe empeoramiento de síntomas se deberá conocer y describir cuál es la situación basal del paciente. Para valorar el grado de disnea se recomienda utilizar la escala mMRC (tabla 6).

3. No haber recibido tratamiento para otra agudización en las últimas 4 semanas.

Si el paciente ha recibido tratamiento en las últimas 4 semanas por otra agudización no se puede etiquetar de nueva agudización, sino de recaída o fracaso terapéutico de la previa (véase apartado Definición de agudización). 
Tabla 19

Estándares de calidad asistencial sobre el tratamiento de la EPOC estable

\begin{tabular}{|c|c|c|c|}
\hline & ECA & Criterio de calidad & Indicador \\
\hline Actividad física & E10 & $\begin{array}{l}\text { A todo paciente con EPOC se le debe recomendar la realización } \\
\text { regular de ejercicio }\end{array}$ & $\begin{array}{l}\text { N. de pacientes a los que se les recomienda actividad } \\
\text { física regular/N. }{ }^{\circ} \text { total de pacientes con EPOC }\end{array}$ \\
\hline Vacuna antigripal & E11 & Se debe recomendar a todos los pacientes con EPOC & $\begin{array}{l}\text { N.o de pacientes que reciben vacuna antigripal/N } .^{\circ} \text { total } \\
\text { de pacientes con EPOC }\end{array}$ \\
\hline Vacuna neumocócica & E12 & Se debe recomendar a todos los pacientes con EPOC & $\begin{array}{l}\text { N.ํ de pacientes que reciben vacuna neumocócica/N.ำ } \\
\text { total de pacientes con EPOC }\end{array}$ \\
\hline $\begin{array}{l}\text { Broncodilatadores de acción } \\
\text { corta }\end{array}$ & E13 & $\begin{array}{l}\text { Los BD de acción corta son fármacos eficaces en el control } \\
\text { rápido de los síntomas. Se deben indicar a demanda cuando de } \\
\text { forma circunstancial haya deterioro sintomático }\end{array}$ & $\begin{array}{l}\text { N. }{ }^{\circ} \text { de pacientes a los que se les prescribe BDAC a } \\
\text { demanda/N. } . \text { total de agudizaciones de EPOC }\end{array}$ \\
\hline $\begin{array}{l}\text { Broncodilatadores de larga } \\
\text { duración (BDLD) }\end{array}$ & E14 & $\begin{array}{l}\text { Los BDLD están indicados en pacientes con síntomas } \\
\text { permanentes. En los pacientes que a pesar de emplear un BDLD } \\
\text { persisten sintomáticos podrán asociar un segundo BDLD }\end{array}$ & $\begin{array}{l}\text { N. de pacientes a los que se les prescribe un BDLD/N. }{ }^{\circ} \\
\text { de pacientes sintomáticos con EPOC }\end{array}$ \\
\hline Teofilinas & E15 & $\begin{array}{l}\text { Deben utilizarse en paciente que persista sintomático a pesar } \\
\text { una combinación de BDLD }\end{array}$ & $\begin{array}{l}\text { N. }{ }^{\circ} \text { de pacientes a los que se les prescribe teofilinas/N. } .^{\circ} \\
\text { de pacientes sintomáticos con EPOC, a pesar de utilizar } \\
\text { doble broncodilatación }\end{array}$ \\
\hline $\begin{array}{l}\text { Combinación de } \beta_{2}- \\
\text { adrenérgicos de larga duración } \\
\text { y corticoides inhalados }\end{array}$ & E16 & $\begin{array}{l}\text { Las combinaciones de } \beta_{2} \text {-adrenérgicos de larga duración (LABA) } \\
\text { y corticoides inhalados }(\mathrm{CI}) \text { se deben utilizar en pacientes con } \\
\text { EPOC que presentan frecuentes agudizaciones, a pesar del } \\
\text { tratamiento con BDLD }\end{array}$ & $\begin{array}{l}\text { N.․ de pacientes a los que se les prescribe un } \\
\text { LABA+CI/N. ․ de pacientes donde está indicado }\end{array}$ \\
\hline $\begin{array}{l}\text { Triple terapia (combinación de } \\
\text { anticolinérgicos de larga } \\
\text { duración y beta-2-adrenérgicos } \\
\text { de larga duración, más } \\
\text { corticoides inhalados }\end{array}$ & E17 & $\begin{array}{l}\text { La triple terapia (LAMA + LABA + CI) debe utilizarse en pacientes } \\
\text { con EPOC grave o muy grave con mal control de los síntomas y } \\
\text { frecuentes agudizaciones, a pesar del tratamiento con BDLD }\end{array}$ & $\begin{array}{l}\text { N. } .^{\circ} \text { de pacientes a los que se les prescribe un triple } \\
\text { terapia (LAMA+LABA+CI/N. }{ }^{\circ} \text { de pacientes donde está } \\
\text { indicado }\end{array}$ \\
\hline $\begin{array}{l}\text { Oxígenoterapia crónica } \\
\text { domiciliaria }\end{array}$ & E18 & $\begin{array}{l}\text { El tratamiento con OCD durante al menos } 15 \text { h diarias se debe } \\
\text { indicar en: } \\
-\mathrm{PaO}_{2} \leq 55 \mathrm{mmHg} \\
-\mathrm{PaO}_{2} 55-60 \mathrm{mmHg} \text {, que presenten hipertensión pulmonar, } \\
\text { poliglobulia (hematocrito }>55 \% \text { ), arritmias cardíacas o signos de } \\
\text { insuficiencia cardíaca derecha }\end{array}$ & $\begin{array}{l}\text { N. e de pacientes con } O C D / N .^{\circ} \text { de pacientes donde está } \\
\text { indicado la OCD }\end{array}$ \\
\hline Rehabilitación respiratoria (RR) & E19 & $\begin{array}{l}\text { Se debe indicar RR a todo paciente con una disnea de } 2 \text { o más } \\
\text { puntos en la escala mMRC, a pesar de un tratamiento } \\
\text { farmacológico adecuado }\end{array}$ & $\begin{array}{l}\text { N.. de pacientes incluidos en programas de } R R / N .^{\circ}{ }^{\circ} \text { total } \\
\text { de pacientes donde está indicada la } R R\end{array}$ \\
\hline $\begin{array}{l}\text { Cirugía de reducción de } \\
\text { volumen pulmonar (CRVP) }\end{array}$ & E20 & $\begin{array}{l}\text { Se debe considerar la CRVP en pacientes con enfisema } \\
\text { heterogéneo de predominio en lóbulos superiores y baja } \\
\text { tolerancia al esfuerzo }\end{array}$ & $\begin{array}{l}\text { N. } .^{\circ} \text { de pacientes sometidos a CRVP/N. } .^{\circ} \text { total de pacientes } \\
\text { donde está indicada la CRVP. }\end{array}$ \\
\hline Trasplante pulmonar & E21 & $\begin{array}{l}\text { Esta opción terapéutica debe considerarse en pacientes menores } \\
\text { de } 65 \text { años y enfermedad muy avanzada, que cumplan los } \\
\text { criterios generales de trasplante pulmonar }\end{array}$ & $\begin{array}{l}\text { N. . de pacientes con EPOC valorados para trasplante } \\
\text { pulmonar/N } .^{\circ} \text { total de pacientes donde está indicado }\end{array}$ \\
\hline
\end{tabular}

ECA: estándares de calidad asistencial ${ }^{29,280,281}$.

Se confirmará el diagnóstico de agudización de EPOC en los casos en que, además de cumplir los 3 criterios previos, se hayan descartado otras causas secundarias de disnea (fig. 15; tabla 20).

Diagnóstico diferencial de la agudización. En la tabla 20 se muestran las principales enfermedades que cabe considerar en el diagnóstico diferencial de la agudización de la EPOC. Todas estas otras enfermedades también producen aumento de síntomas respiratorios en pacientes con EPOC, especialmente disnea. Sin embargo, la fisiopatología es distinta y el tratamiento también, por lo que no se deben contemplar como causa de agudización, sino como diagnósticos alternativos.

En algunas ocasiones, la agudización de la EPOC se asocia a algunas de las enfermedades que figuran como diagnóstico diferencial y en tales casos resulta muy difícil discriminar cuál es la causa y cuál la consecuencia. En estos casos se recomienda utilizar el término "agudización de EPOC asociada a...". Por ejemplo, se ha descrito que hasta un $30 \%$ de las agudizaciones graves se asocia a insuficiencia cardíaca ${ }^{289}$, o que un $15-20 \%$ se asocia a daño miocárdico con elevación de troponinas ${ }^{290}$.

\section{Paso 2: valorar la gravedad de la agudización}

Una vez establecido el diagnóstico de agudización de la EPOC es muy importante describir la gravedad del episodio. En los últimos años, las principales guías de práctica clínica han utilizado una clasificación de gravedad de la agudización basada en el consumo de fármacos o en la utilización de recursos (p. ej., agudización grave si el paciente tenía una agudización que precisaba hospitalización, o agudización moderada si recibía tratamiento con corticoides orales y/o antibióticos). Sin embargo, esta clasificación no sigue criterios fisiopatológicos, no está vinculada a la toma de decisiones y puede estar influenciada por criterios socioeconómicos o de accesibilidad al sistema. GesEPOC propone una nueva clasificación que ha sido consensuada por un amplio grupo de expertos (tabla 21). Los criterios de agudización grave o muy grave identifican riesgo de muerte, mientras que los criterios que se utilizan para identificar la agudización moderada están relacionados con el riesgo de fracaso terapéutico.

\section{Paso 3: diagnóstico etiológico}

En la tabla 22 se recogen las causas más frecuentes de agudización de la EPOC ${ }^{291,292}$. Identificarlas es de gran importancia para un adecuado tratamiento. Sin embargo, aproximadamente en un tercio de los casos, la etiología no se llega a conocer. En el 50-70\% de las ocasiones, la causa de la exacerbación es la infección del árbol traqueobronquial. La contaminación ambiental puede ser la causante del 5-10\% de las exacerbaciones. 


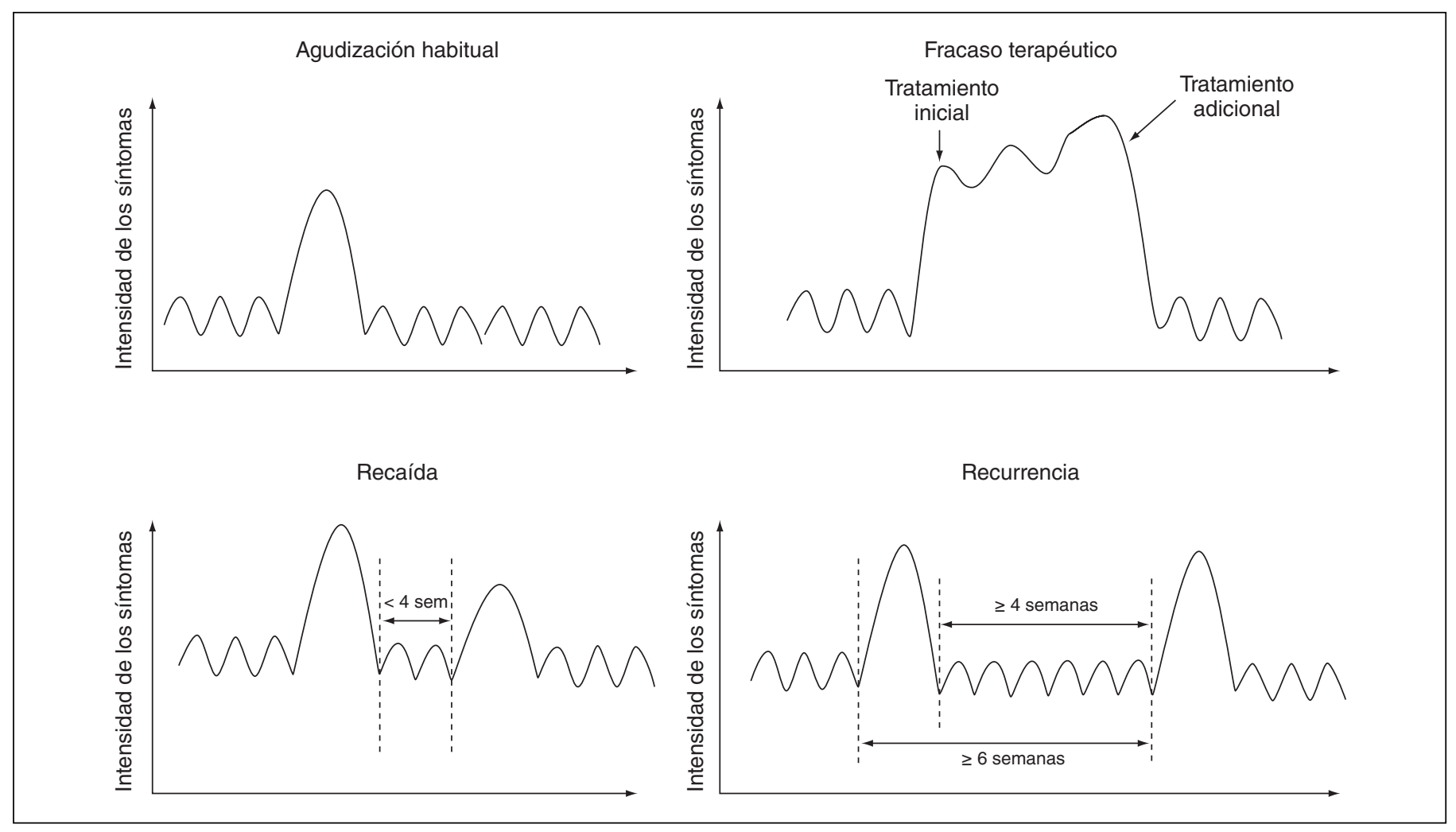

Figura 13 Evolución de las agudizaciones de la EPOC.

Las infecciones virales representan cerca del 30\% de todas las exacerbaciones de causa infecciosa, aunque algunos estudios recientes que emplean técnicas diagnósticas más precisas elevan hasta el 50\% el número de exacerbaciones infecciosas causadas por virus. Las bacterias identificadas con mayor frecuencia son Haemophilus influenzae, Streptococcus pneumoniae y Moraxella catarrhalis, aunque en agudizaciones graves, Enterobacterias y Pseudomonas aeruginosa pueden ser frecuente $^{293}$. La presencia de coinfección por bacterias y virus se ha descrito hasta en un $25 \%$ de los pacientes hospitalizados, lo que indica una cierta susceptibilidad a la infección bacteriana tras el proceso viral ${ }^{292}$.

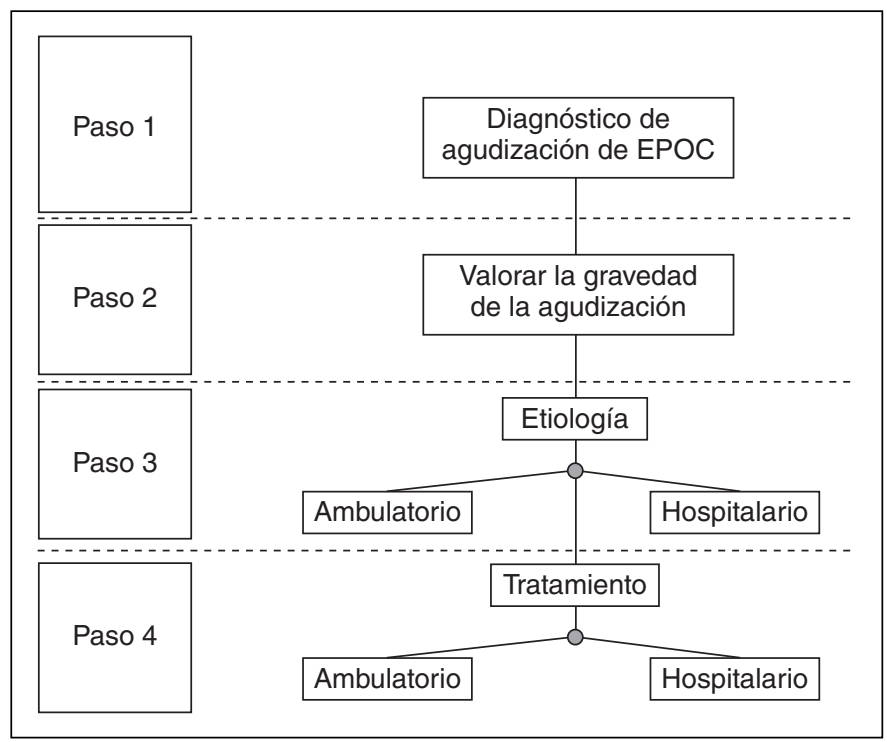

Figura 14 Evaluación por pasos de las agudizaciones de la EPOC.
Reconocer la etiología de la agudización no resulta sencillo. El análisis del esputo (tinción de Gram y cultivo) estará especialmente indicado en los pacientes con agudizaciones graves o muy graves que presenten frecuentes agudizaciones, necesidad de ventilación asistida o ante un fracaso antibiótico. Sin embargo, en la mayoría de los casos la aproximación diagnóstica será clínica. Anthonisen et al ${ }^{294}$ demostraron que la administración de antibióticos en la EPOC era más eficaz que el placebo en las agudizaciones que cumplían al menos dos de los siguientes 3 criterios: aumento de disnea, purulencia en el esputo o incremento del volumen del esputo. Sin embargo, de los 3 criterios recomendados, el que mejor predice la infección bacteriana es el cambio en la coloración del esputo (purulencia) ${ }^{295}$. Por el contrario, el esputo mucoso pocas veces se asocia a infección bacteriana ${ }^{296}$.

Existe una gran actividad de investigación sobre marcadores de infección bacteriana en las agudizaciones. Se han notificado resul-

Tabla 20

Diagnóstico diferencial ante un deterioro de síntomas en pacientes con EPOC

\begin{tabular}{l} 
Causas respiratorias: \\
Neumonía \\
Neumotórax \\
Embolia pulmonar \\
Derrame pleural \\
Traumatismo torácico \\
Causas cardíacas: \\
Insuficiencia cardíaca \\
Arritmias cardíacas \\
Cardiopatía isquémica aguda \\
Otras: \\
Obstrucción de vía aérea superior \\
\hline
\end{tabular}




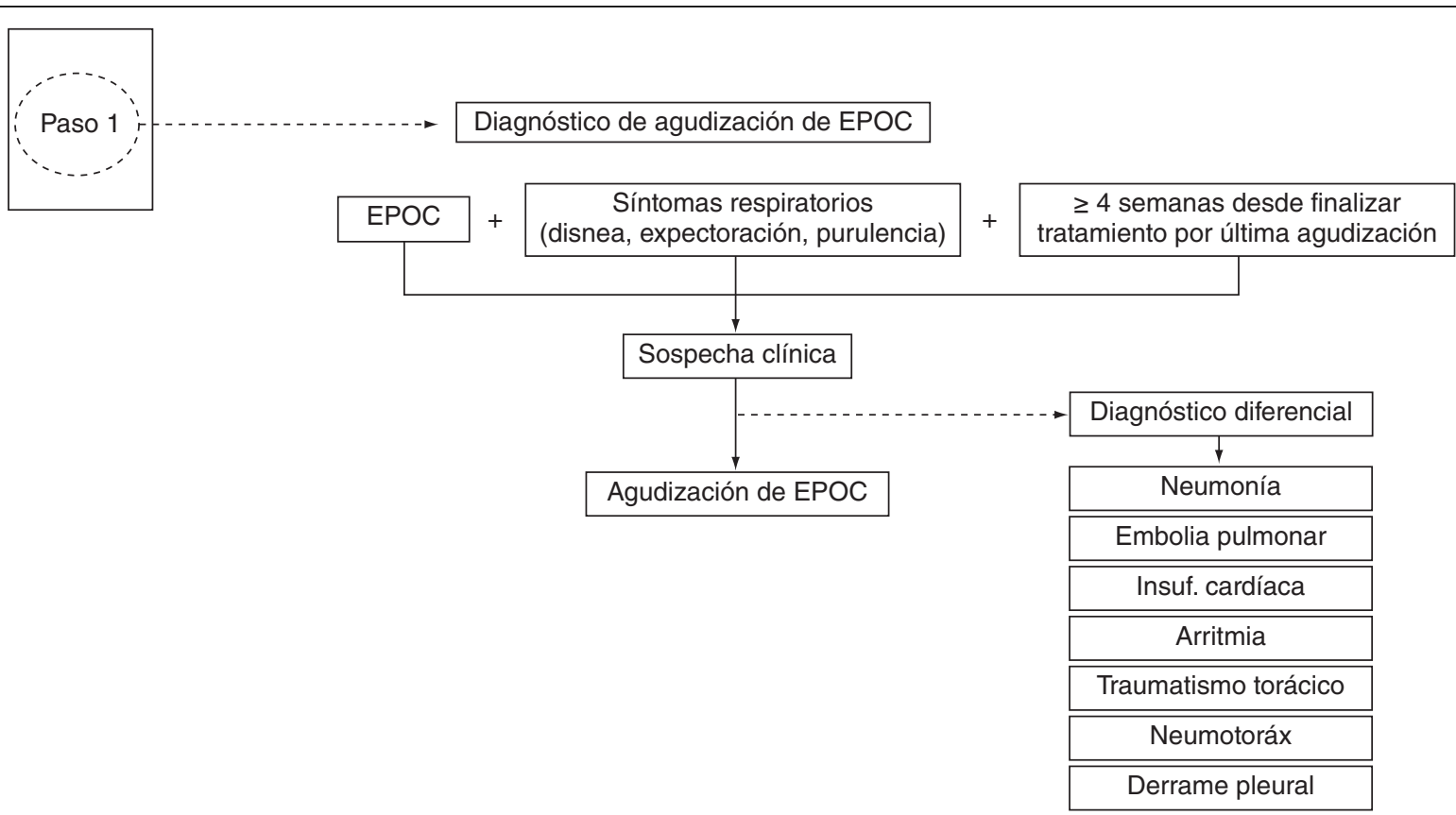

Figura 15 Primer paso. Diagnóstico de la agudización de la EPOC.

\section{Tabla 21}

Criterios para establecer la gravedad de la agudización de la EPOC

\begin{tabular}{|c|c|}
\hline Agudización muy grave (o amenaza vital) & $\begin{array}{l}\text { Se debe cumplir al menos uno de los siguientes criterios: } \\
\text { - Parada respiratoria } \\
\text { - Disminución del nivel de consciencia } \\
\text { - Inestabilidad hemodinámica } \\
\text { - Acidosis respiratoria grave }(\mathrm{pH}<7,30)\end{array}$ \\
\hline Agudización grave & $\begin{array}{l}\text { Se debe cumplir al menos uno de los siguientes criterios, y ninguno de los criterios de amenaza vital: } \\
\text { - Disnea 3-4 de la escala mMRC } \\
\text { - Cianosis de nueva aparición } \\
\text { - Utilización de musculatura accesoria } \\
\text { - Edemas periféricos de nueva aparición } \\
\text { - } \mathrm{SpO}_{2}<90 \% \text { o } \mathrm{PaO}_{2}<60 \mathrm{mmHg} \\
\text { - } \mathrm{PaCO}_{2}>45 \mathrm{mmHg} \text { (paciente sin hipercapnia previa) } \\
\text { - Acidosis respiratoria moderada (pH 7,30-7,35) } \\
\text { - Comorbilidad significativa grave } \\
\text { - Complicaciones (arritmias graves, insuficiencia cardíaca, etc.) }\end{array}$ \\
\hline Agudización moderada & $\begin{array}{l}\text { Se debe cumplir al menos uno de los siguientes criterios, y ninguno de de los anteriores: } \\
\text { - FEV }{ }_{1} \text { basal }<50 \% \\
\text { - Comorbilidad cardíaca no grave } \\
\text { - Historia de } 2 \text { o más agudizaciones en el último año }\end{array}$ \\
\hline Agudización leve & No se debe cumplir ningún criterio previo \\
\hline
\end{tabular}

mMRC: escala de disnea modificada de la Medical Research Council.

${ }^{a}$ Cardiopatía isquémica reciente, insuficiencia renal crónica, hepatopatía moderada-grave, etc.

tados contradictorios con la procalcitonina ${ }^{297}$, aunque algunos estudios señalan que la proteína $C$ reactiva es un mejor marcador de la necesidad de tratamiento antibiótico ${ }^{298}$. A la espera de estudios más amplios, no se puede establecer una recomendación general de uso de un biomarcador para establecer la etiología de una agudización.

Para tratar de identificar la causa de la agudización y establecer adecuadamente el diagnóstico diferencial, se propone una aproximación diferente según el ámbito asistencial donde se atienda la descompensación.

\section{Aproximación diagnóstica ambulatoria}

La figura 16 señala el proceso diagnóstico que se debe realizar en el ámbito ambulatorio. A todos los pacientes se les efectuará una anamnesis adecuada y una exploración física, de acuerdo con los criterios que se establecen a continuación. También es recomendable que se evalúe la saturación arterial periférica de oxígeno $\left(\mathrm{SpO}_{2}\right)$.

La historia clínica de toda agudización deberá contener como mínimo la siguiente información:

\section{Sintomatología de la agudización:}

- Disnea.

- Color del esputo.

- Volumen del esputo.

\section{Historial de agudizaciones previas:}

- La presencia de dos o más agudizaciones previas en el último año es un factor de riesgo de fracaso terapéutico (fenotipo agudizador). 
Tabla 22

Causas de agudización de la EPOC

\begin{tabular}{ll}
\hline Virus & Rinovirus (resfriado común) \\
& Influenza \\
& Parainfluenza \\
& Coronavirus \\
& Adenovirus \\
& Virus respiratorio sincitial \\
& Haemophilus influenzae \\
& Streptococcus pneumoniae \\
& Moraxella catarrhalis \\
Bacterias & Pseudomonas aeruginosa \\
& Chlamydophila pneumoniae \\
& Mycoplasma pneumoniae. \\
Organismos atípicos & Ozono \\
& Partículas $\leq 10$ pm de diámetro \\
Polución ambiental & Dióxido de sulfuro \\
& Dióxido de nitrógeno \\
\hline
\end{tabular}

Por este motivo, su sola aparición ya indica agudización moderada y un tratamiento diferencial.

3. Comorbilidad.

4. Gravedad basal de la EPOC.

5. Tratamiento previo.

En la exploración física se deberá registrar:

1. Nivel de consciencia.

2. Cianosis.

3. Utilización de la musculatura accesoria.

4. Edemas.

5. Presión arterial.

6. Frecuencia respiratoria y cardíaca.
Pulsioximetría: se aconseja el uso de la pulsioximetría, que evalúa de forma no invasiva la $\mathrm{SaO}_{2}$. Sin embargo, no mide la $\mathrm{PaCO}_{2}$ o el pH. Por tanto, no sustituye a la gasometría en la valoración del intercambio de gases, especialmente en situaciones críticas o donde haya sospecha de hipoventilación (hipercapnia).

El primer paso para reconocer la agudización de la EPOC es descartar la presencia de otras causas de empeoramiento sintomático (ver Diagnóstico diferencial, tabla 20).

- Radiografía de tórax: no se recomienda realizar la radiografía de tórax sistemática en el medio ambulatorio. Sin embargo, sí será pertinente en el caso de mala evolución clínica o sospecha de complicación (neumonía, insuficiencia cardíaca, etc.).

- Electrocardiograma (ECG): permite descartar arritmias o valorar signos de cardiopatía isquémica, por lo que está indicado en caso de sospecha.

Una vez confirmada la agudización de la EPOC, se deberá valorar el color del esputo. En caso de un cambio de color, la etiología posiblemente sea bacteriana.

- Análisis bacteriológico del esputo: no está indicado de forma habitual en las agudizaciones ambulatorias.

\section{Aproximación diagnóstica hospitalaria}

A todos los pacientes se les deberá realizar una adecuada historia clínica y una exploración física, como se describe en la agudización ambulatoria. En la figura 17 se recogen las principales pruebas diagnósticas que se deben realizar para caracterizar adecuadamente la agudización hospitalaria:

- Historia clínica y exploración física.

- Analítica de sangre: debe incluir hemograma y parámetros bioquímicos como glucemia, urea, creatinina y electrolitos.

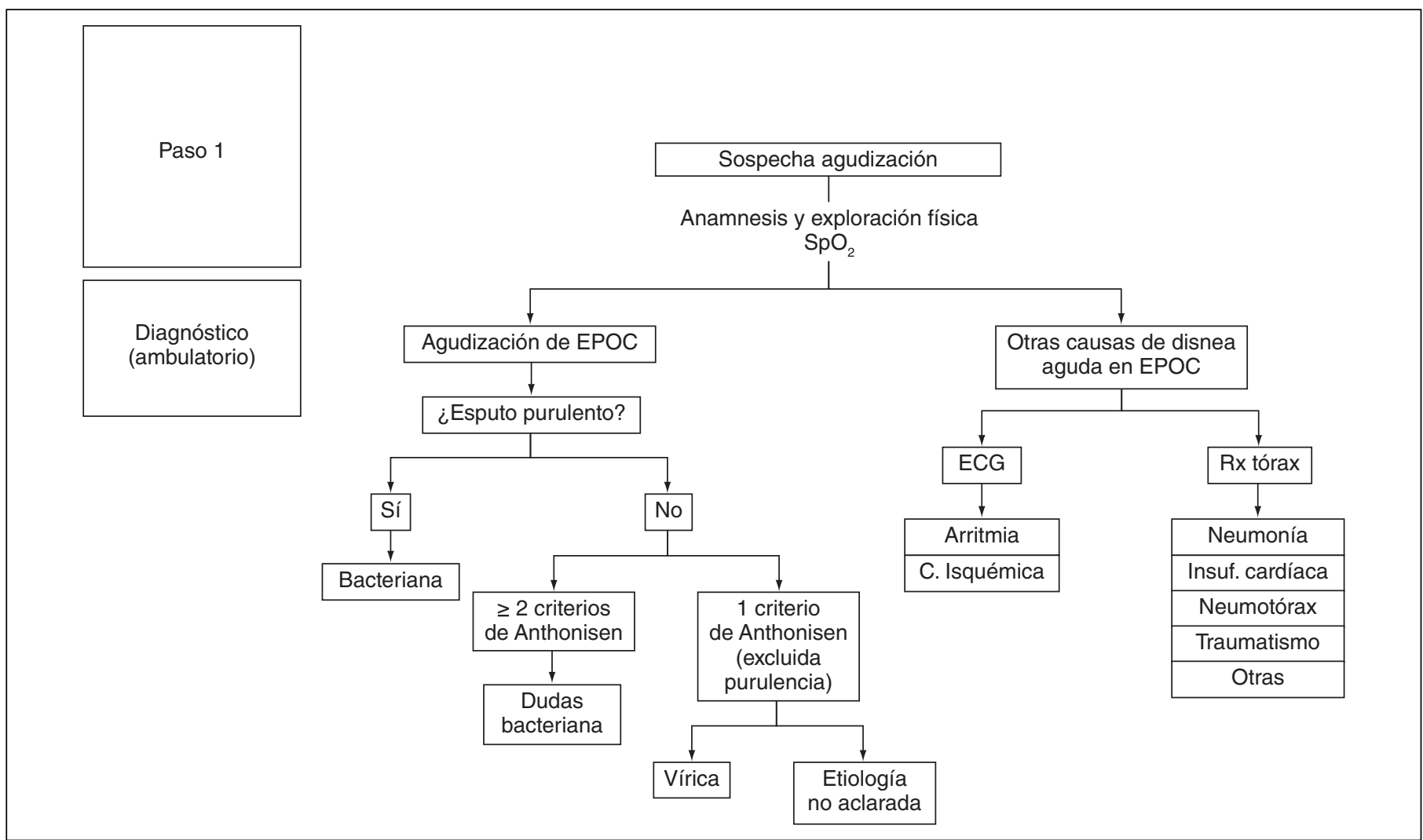

Figura 16 Diagnóstico ambulatorio de la etiología de la agudización de la EPOC. C. isquémica: cardiopatía isquémica; ECG: electrocardiograma; SpO 2 : saturación arterial periférica de oxígeno. 


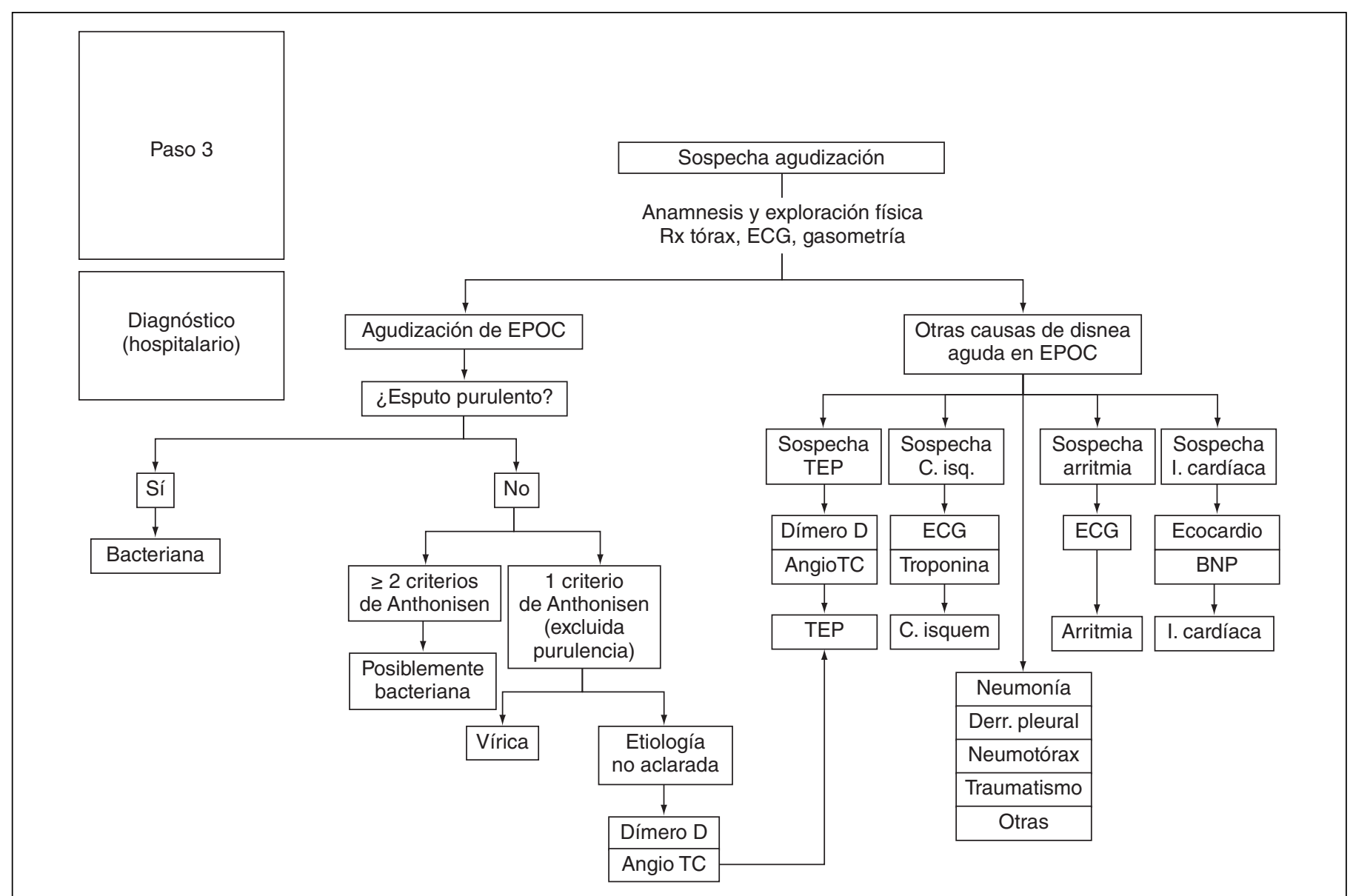

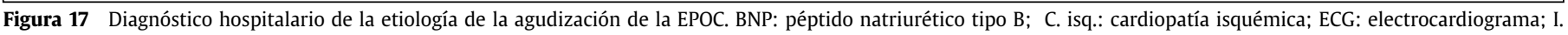
cardiaca: insuficiencia cardiaca; Rx: radiografía; TC: tomografía computerizada; TEP: tromboembolismo pulmonar.

- Gasometría arterial: siempre se deberá recoger la fracción inspiratoria de oxígeno a la que se realiza la técnica. En los pacientes que presenten hipercapnia y/o acidosis inicial deberá repetirse una segunda gasometría de control a los 30-60 minutos.

- Radiografía de tórax.

- Electrocardiograma (ECG).

- Análisis microbiológico del esputo: se deberá realizar una tinción de Gram y cultivo aerobio.

Tras la valoración inicial, se descartarán otras causas de disnea (véase Diagnóstico diferencial, tabla 20). La radiografía de tórax y el ECG pueden ser de ayuda para ello. En caso de sospecha de insuficiencia cardíaca, también puede ser de ayuda la ecocardiografía. La angiografía por tomografía computarizada (angio-TC) estará indicada en pacientes con sospecha moderada-alta de tromboembolia pulmonar (TEP) y también en las agudizaciones de causa no aclarada. En una revisión sistemática reciente se indica que uno de cada 4 pacientes que requiere hospitalización por agudización de EPOC puede tener una TEP299.

La determinación de algunos biomarcadores plasmáticos, como el dímero $\mathrm{D}$, la troponina o el péptido natriurético tipo $\mathrm{B}$ (BNP), puede ser de utilidad en caso de sospecha de TEP, cardiopatía isquémica o insuficiencia cardíaca, respectivamente. De manera reciente se ha descrito que algunos de estos biomarcadores, como la troponina $\mathrm{T}$ o el BNP, pueden estar elevados en agudizaciones de EPOC sin cardiopatía conocida asociada. En estos casos, la elevación de estos biomarcadores se asocia a un peor pronóstico ${ }^{290}$.

En los casos donde la etiología continúe sin ser conocida después de esta valoración inicial, se buscará la posible existencia de una em- bolia pulmonar, recomendándose la determinación de dímero D y de angio- $\mathrm{TC}^{300}$.

Las pautas de tratamiento deberán ser adecuadas a cada paciente en función de la posible etiología de la agudización y de su gravedad. En este sentido, se distinguen dos escenarios de tratamiento: el ambulatorio y el hospitalario.

En todos los casos, el tratamiento broncodilatador destinado al alivio inmediato de los síntomas se considera fundamental, mientras que el uso de antibióticos, corticoides sistémicos, oxigenoterapia, ventilación asistida, rehabilitación respiratoria o el tratamiento de la propia comorbilidad variará según las características de la propia agudización. Se deberá valorar la necesidad de tratamiento antibiótico, como se ha descrito previamente.

\section{Tratamiento farmacológico de la agudización}

\section{Broncodilatadores}

En la agudización de la EPOC, de cualquier intensidad, la principal intervención consiste en la optimización de la broncodilatación, aumentando la dosis y/o la frecuencia de los broncodilatadores (evidencia alta, recomendación fuerte a favor $)^{301}$.

Broncodilatadores de acción corta. Los broncodilatadores de acción corta son los de elección para el tratamiento de la agudización. Se deberá emplear fármacos de acción corta y rápida como los agonistas beta-2 adrenérgicos (salbutamol y terbutalina), y se pueden añadir al tratamiento, si fuera necesario, los anticolinérgicos de acción corta (ipratropio) (evidencia baja, recomendación fuerte a favor). 
Tabla 23

Recomendación sobre el uso de antibióticos en la agudización de la EPOC

\begin{tabular}{|c|c|c|c|}
\hline Gravedad de la agudización & Gérmenes & Antibiótico de elección & Alternativas \\
\hline Agudización leve & $\begin{array}{l}\text { H. influenzae. } \\
\text { S. pneumoniae. } \\
\text { M. catarrhalis }\end{array}$ & Amoxicilina-ácido clavulánico & $\begin{array}{l}\text { Cefditoren } \\
\text { Moxifloxacino } \\
\text { Levofloxacino }\end{array}$ \\
\hline Agudización moderada & $\begin{array}{l}\text { Igual que grupo A } \\
+ \\
\text { S. pneumoniae resistente a penicilina. } \\
\text { Enterobacterias }\end{array}$ & $\begin{array}{l}\text { Moxifloxacino } \\
\text { Levofloxacino }\end{array}$ & Amoxicilina-ácido clavulánico \\
\hline $\begin{array}{l}\text { Agudización grave-muy grave sin riesgo } \\
\text { de infección por Pseudomona }\end{array}$ & Igual que grupo B & $\begin{array}{l}\text { Moxifloxacino } \\
\text { Levofloxacino }\end{array}$ & $\begin{array}{l}\text { Amoxicilina-ácido clavulánico } \\
\text { Ceftriaxona } \\
\text { Cefotaxima }\end{array}$ \\
\hline $\begin{array}{l}\text { Agudización grave-muy grave con riesgo } \\
\text { de infección por Pseudomona }\end{array}$ & $\begin{array}{l}\text { Igual que grupo B } \\
+ \\
\text { P. aeruginosa }\end{array}$ & $\begin{array}{l}\text { Ciprofloxacino } \\
\text { Levofloxacino a dosis altas }\end{array}$ & $\begin{array}{l}\beta \text {-lactamasa con actividad } \\
\text { antipseudomona }^{\mathrm{b}}\end{array}$ \\
\hline
\end{tabular}

a500 mg cada $12 \mathrm{~h}$.

${ }^{\mathrm{b} C e f t a z i d i m a, ~ p i p e r a c i l i n a-t a z o b a c t a m, ~ i m i p e n e m ~ o ~ m e r o p e n e m, ~ c e f e p i m a . ~}$

Dispositivos de liberación. Para administrar los fármacos inhalados durante la agudización se pueden utilizar dispositivos presurizados de dosis medida (pMDI) con cámara de inhalación o nebulizadores (evidencia alta, recomendación fuerte a favor). En una revisión sistemática sobre las formas de administración de los broncodilatadores de acción corta se concluye que cuando la técnica inhalatoria es buena, no hay diferencias significativas sobre el $\mathrm{FEV}_{1}$ entre los cartuchos presurizados con o sin cámara espaciadora y los nebulizadores ${ }^{302}$.

La elección del sistema dependerá de la dosis que precise el paciente, su capacidad para utilizar el dispositivo y de la posibilidad de supervisión del tratamiento. Cuando se precisan dosis bajas de medicación (p. ej., 100-400 $\mu$ g de salbutamol), el pMDI con cámara es preferible, mientras que los nebulizadores pueden liberar dosis más elevadas con mayor facilidad. En los casos donde el nivel de colaboración sea insuficiente se podrá utilizar la medicación de forma nebulizada ${ }^{303}$.

En pacientes con hipercapnia o acidosis, la medicación nebulizada debe ser liberada utilizando dispositivos de aire comprimido y no mediante el uso de oxígeno a alto flujo, ya que esta última forma de administración puede empeorar la hipercapnia.

Dosis. Las dosis recomendadas son, para el caso del salbutamol, de 400-600 $\mu \mathrm{g} / 4-6 \mathrm{~h}$ (4-6 inhalaciones/4-6 h) o terbutalina 500-1.000 $\mu \mathrm{g} /$ 4-6 h (1-2 inhalaciones/6 h), y en el caso de ipratropio, de 80-120 $\mu \mathrm{g} /$ 4-6 h (4-6 inhalaciones/4-6 h). En el caso de utilizar la medicación nebulizada, la pauta será de 2,5-10 mg de salbutamol y/o 0,5-1 mg de ipratropio cada 4-6 h.

Broncodilatadores de larga duración. Los broncodilatadores de larda duración constituyen el tratamiento de mantenimiento y su eficacia en la agudización no está suficientemente documentada ${ }^{304}$. Sin embargo, es importante recordar que si el paciente ya utiliza BDLD para el control de su enfermedad de base, éstos no deberán suspenderse durante el tratamiento de la agudización.

Metilxantinas. Las teofilinas no se recomiendan habitualmente para el tratamiento de las agudizaciones de la EPOC (evidencia moderada, recomendación débil en contra). En una revisión sistemática se observó que las metilxantinas en pacientes con EPOC moderada-grave no mejoraron de forma importante el curso clínico de las agudizaciones, mostrando escasos beneficios sobre la función pulmonar $\left(\mathrm{FEV}_{1}\right)$, con una incidencia significativa de efectos secundarios (náuseas y vómitos) $)^{305}$.

\section{Optimizar el tratamiento de la comorbilidad}

En la EPOC es frecuente la coexistencia de distintas comorbilidades como hipertensión arterial, cardiopatía isquémica, arritmias, in- suficiencia cardíaca o diabetes. Por ello será necesario optimizar el tratamiento.

\section{Antibióticos}

Se recomienda utilizar un antibiótico durante una agudización siempre que aparezca un cambio en el color del esputo, como expresión indirecta de posible infección bacteriana (evidencia alta, recomendación fuerte a favor). En la agudización moderada o grave también estará indicado cuando, en ausencia de purulencia, haya incremento de la disnea y del volumen del esputo (evidencia moderada, recomendación fuerte a favor). En las agudizaciones muy graves, cuando el paciente requiere asistencia ventilatoria, la cobertura antibiótica es obligada, ya que ha demostrado reducir la incidencia de neumonía secundaria y también disminuir de forma significativa la mortalidad (evidencia baja, recomendación fuerte a favor $)^{306}$.

Elección del antibiótico. En la tabla 23 se indican cuáles son los principales antibióticos que se utilizarán durante una agudización de EPOC. Esta elección dependerá del conocimiento de las especies bacterianas involucradas, las resistencias antibióticas locales, la gravedad de la propia agudización y el riesgo de infección por Pseudomonas aeruginosa. Este riego se define por el uso de más de 4 ciclos de tratamiento antibiótico en el último año, una función pulmonar con un $\mathrm{FEV}_{1}<50 \%$ del predicho, la presencia de bronquiectasias significativas o el aislamiento previo de Pseudomonas en esputo en fase estable o en una agudización previa ${ }^{307}$.

Dosis y duración. En la tabla 24 se recogen las dosis recomendadas de cada fármaco, la vía de administración y su duración de acción.

\section{Corticoides sistémicos}

Los corticoides sistémicos han demostrado acelerar la recuperación de los síntomas, mejorar la función pulmonar y disminuir los fracasos terapéuticos ${ }^{301,308,309}$. En las agudizaciones moderadas (evidencia moderada, recomendación fuerte a favor) y en las graves-muy graves (evidencia alta, recomendación fuerte a favor) deberá emplearse una tanda corta de corticoides sistémicos durante 7-10 días. También se valorará el uso de estos fármacos en los pacientes con agudizaciones leves que no responden satisfactoriamente al tratamiento inicial.

Dosis, duración y vía de administración. Se recomienda administrar $0,5 \mathrm{mg} / \mathrm{kg} /$ día por vía oral (máximo de $40 \mathrm{mg} /$ día) de prednisona o equivalentes hasta obtener la mejoría clínica, y suspender el tratamiento lo antes posible (preferiblemente, antes de 7-10 días). Para las 
Tabla 24

Dosis recomendada, vía de administración y duración de los principales antibióticos

\begin{tabular}{|c|c|c|c|}
\hline Antibiótico & Dosis recomendada & Vía de administración & Duración del tratamiento \\
\hline Amoxicilina-ácido clavulánico & $\begin{array}{l}875 / 125 \mathrm{mg} / 8 \mathrm{~h} \\
2.000 / 125 \mathrm{mg} / 12 \mathrm{~h} \\
1-2 \mathrm{~g} / 200 \mathrm{mg} / 6-8 \mathrm{~h}\end{array}$ & $\begin{array}{l}\text { v.o. } \\
\text { v.o. } \\
\text { i.v. }\end{array}$ & 7 días \\
\hline Cefditoren & $200-400 \mathrm{mg} / 12 \mathrm{~h}$ & v.o. & 5 días \\
\hline Moxifloxacino & $400 \mathrm{mg} / 24 \mathrm{~h}$ & v.o. & 5 días \\
\hline Levofloxacino & $500 \mathrm{mg} / 12-24 \mathrm{~h}$ & v.o./i.v. & 7 días \\
\hline Ciprofloxacino & $\begin{array}{l}750 \mathrm{mg} / 24 \mathrm{~h} \\
400 \mathrm{mg} / 12 \mathrm{~h}\end{array}$ & $\begin{array}{l}\text { v.o. } \\
\text { i.v. }\end{array}$ & 10 días \\
\hline Ceftrixona & $1-2 \mathrm{~g} / 12-24 \mathrm{~h}$ & i.v. & 7 días \\
\hline Cefotaxima & $1-2 \mathrm{~g} / 6-8 \mathrm{~h}$ & i.v. & 7 días \\
\hline Ceftazidima & $2 \mathrm{~g} / 8 \mathrm{~h}$ & i.v. & 7 días \\
\hline Cefepima & $2 \mathrm{~g} / 8 \mathrm{~h}$ & i.v. & 7 días \\
\hline Piperacilina-tazobactam & $4 / 0,5 \mathrm{~g} / 6 \mathrm{~h}$ & i.v. & 7 días \\
\hline Imipenem & $0,5-1 \mathrm{~g} / 6-8 \mathrm{~h}$ & i.v. & 7 días \\
\hline Meropenem & $0,5-1 \mathrm{~g} / 6-8 \mathrm{~h}$ & i.v. & 7 días \\
\hline
\end{tabular}

v.o: vía oral; i.v.: vía intravenosa.

agudizaciones que precisen ingreso hospitalario se podrá utilizar la vía parenteral a razón de $0,5 \mathrm{mg} / \mathrm{kg} / 6 \mathrm{~h}$ los primeros 3 días y posteriormente la vía oral ${ }^{310}$. No obstante, en pacientes con agudizaciones no acidóticas ambas vías de administración ofrecen los mismos resul$\operatorname{tados}^{311}$. En la mayoría de los estudios las tandas cortas de corticoides sistémicos duran menos de 15 días y se interrumpen de forma brusca, sin que se produzcan efectos secundarios. La reducción progresiva de la dosis de corticoides no ha sido estudiada.

Recomendación: ¿Se deben emplear los corticoides sistémicos en las exacerbaciones moderadas de la EPOC? (anexo 2).

En pacientes con EPOC no hospitalizados se indica administrar prednisona oral durante 9 o 10 días para tratar las exacerbaciones moderadas

Recomendación: ¿Se deben emplear los corticoides sistémicos en las exacerbaciones leves de la EPOC? (anexo 2).

Recomendación
para la
investigación

En pacientes con EPOC no hospitalizados se indica utilizar corticoides sistémicos para el tratamiento de las exacerbaciones leves sólo en un contexto de investigación

\section{Corticoides inhalados}

En dos ensayos clínicos aleatorizados ${ }^{312,313}$ se ha evaluado la utilidad de la budesonida nebulizada en dosis altas ( $2 \mathrm{mg}$, 4 veces al día) frente a placebo en pacientes con EPOC hospitalizados por agudización moderada-grave no acidótica y han demostrado mejoría del FEV posbroncodilatación ${ }^{313}$ y de la $\mathrm{PaO}_{2}{ }^{312}$. En ambos casos se ha demostrado que este tratamiento puede ser una alternativa eficaz y segura a los corticoides orales cuando hay exacerbación de los pacientes con $\mathrm{EPOC}^{312,313}$

\section{Profilaxis de la enfermedad tromboembólica venosa (ETV)}

Las agudizaciones graves o muy graves de la EPOC comportan un riesgo alto de ETV, por lo que se recomienda el uso de heparinas de bajo peso molecular en dosis moderadas ${ }^{314}$ (evidencia alta, recomendación fuerte a favor). En las agudizaciones moderadas, en las que el paciente permanece encamado o inactivo, también está indicado su uso.

\section{Tratamiento no farmacológico de la agudización}

\section{Oxigenoterapia}

La administración de oxígeno suplementario se considera una de las piezas clave del tratamiento de la agudización grave de la EPOC que cursa con insuficiencia respiratoria (evidencia moderada, recomendación fuerte). El objetivo de la oxigenoterapia es alcanzar una $\mathrm{PaO}_{2}$ para prevenir la hipoxemia de amenaza vital y optimizar la liberación de oxígeno a los tejidos periféricos. Sin embargo, en los pacientes con EPOC, la administración de oxígeno debe realizarse de forma controlada, ya que en algunos pacientes el principal estímulo del centro respiratorio depende del grado de hipoxemia más que del habitual estímulo hipercápnico. La administración de oxígeno de forma incontrolada puede producir supresión del estímulo respiratorio, carbonarcosis e incluso parada respiratoria.

En la práctica clínica se deben administrar bajas concentraciones inspiratorias de oxígeno, del 24 o el $28 \%$, mediante mascarillas de alto flujo tipo Venturi o mediante gafas nasales a bajos flujos de 2-4 1/ min.

Durante las agudizaciones graves o muy graves se deberá realizar una gasometría arterial, antes y después de iniciar el tratamiento suplementario con oxígeno, especialmente si cursan con hipercapnia.

\section{Rehabilitación respiratoria temprana}

En pacientes con agudización grave, la rehabilitación respiratoria (RR) tras una agudización ofrece importantes beneficios. En una revisión sistemática reciente (6 ECA de moderada calidad metodológica y 219 pacientes) se concluye que la RR es efectiva y segura en términos de reducción de ingresos hospitalarios, disminución de la mortalidad y mejoría de la CVRS en pacientes con EPOC tras una exacerbación ${ }^{315}$. Las agudizaciones se asocian a disfunción muscular e inactividad físi$\mathrm{ca}$, que son factores de riesgo independientes de ingreso hospitalario. Las estrategias de entrenamiento han mostrado ser factibles y efectivas cuando se implementan tanto durante la agudización (entrenamiento de la resistencia muscular, estimulación neuromuscular) como en los días inmediatamente posteriores al alta hospitalaria (entrenamiento aeróbico, entrenamiento de la resistencia muscular). Las intervenciones centradas en el autocuidado y en promover la activi- 
dad física pueden desempeñar un papel importante en optimizar los resultados a largo plazo y prevenir el riesgo de recaídas ${ }^{316}$.

Recomendación: ¿Es beneficiosa la rehabilitación respiratoria en el contexto de una agudización? (anexo 2).

\begin{tabular}{|l|l|}
\hline Fuerte & $\begin{array}{l}\text { En pacientes con EPOC que han sufrido una agudiza- } \\
\text { ción, se recomienda iniciar la rehabilitación respirato- } \\
\text { ria inmediatamente después de finalizar el tratamiento } \\
\text { de la exacerbación o en el periodo comprendido en las } \\
\text { tres semanas siguientes. }\end{array}$ \\
\hline
\end{tabular}

\section{Ventilación asistida}

En los casos donde existe un fracaso ventilatorio grave, con alteración del nivel de conciencia, disnea invalidante o acidosis respiratoria, a pesar de tratamiento médico optimo, debe considerarse el empleo de soporte ventilatorio. La ventilación mecánica puede ser administrada de forma no invasiva (VNI) o invasiva (VI).

Ventilación mecánica no invasiva (VNI). Una revisión sistemática basada en diferentes ensayos clínicos aleatorizados y controlados proporciona evidencia de que la VNI, junto con el tratamiento médico convencional, disminuye la mortalidad, la necesidad de intubación endotraqueal (por cada 5 pacientes tratados con VNI uno de ellos evitará la intubación) y también reduce el fracaso terapéutico. Además, la VNI aumenta el $\mathrm{pH}$, reduce la hipercapnia y la frecuencia respiratoria de forma temprana, acorta la estancia hospitalaria y disminuye las complicaciones asociadas al tratamiento ${ }^{317}$. En la tabla 25 se indican las indicaciones y contraindicaciones de la VNI.

Ventilación mecánica invasiva. La VI debe considerarse en los casos donde se produzca acidemia y/o hipoxemia grave, junto con deterioro del estado mental ${ }^{5,206}$. Tradicionalmente se ha asumido que los pacientes con EPOC que precisan VI presentaban mortalidades muy elevadas, por lo que en muchas ocasiones su indicación podría ser controvertida. Sin embargo, datos consistentes indican que la mortalidad observada se sitúa alrededor del $20 \%$, una cifra incluso inferior a la hallada para otras enfermedades tratadas con VI. En la tabla 26 se muestran las indicaciones absolutas y relativas de la VI.

\section{Adecuar el tratamiento de base}

Si el paciente no recibía tratamiento previo, se deberá pautar un tratamiento adecuado para la fase estable de la enfermedad, de acuerdo con su fenotipo específico (véanse apartados Intervenciones farmacológicas en pacientes con EPOC en fase estable e Intervenciones no farmacológicas en pacientes con EPOC en fase estable).

\section{Tabla 25}

Indicaciones y contraindicaciones relativas de la ventilación no invasiva (VNI)

Indicaciones
Acidosis respiratoria $(\mathrm{pH}<7,35)$ con hipercapnia $\left(\mathrm{PaCO}_{2}>45 \mathrm{mmHg}\right)$ a pesar
de tratamiento óptimo
Contraindicaciones
Parada respiratoria
Inestabilidad cardiovascular
Somnolencia que impida la colaboración del paciente
Alto riesgo de aspiración
Cirugía facial o gastroesofágica reciente
Anomalías nasofaríngeas
Quemados

Tabla 26

Indicaciones absolutas y relativas de la ventilación invasiva (VI)

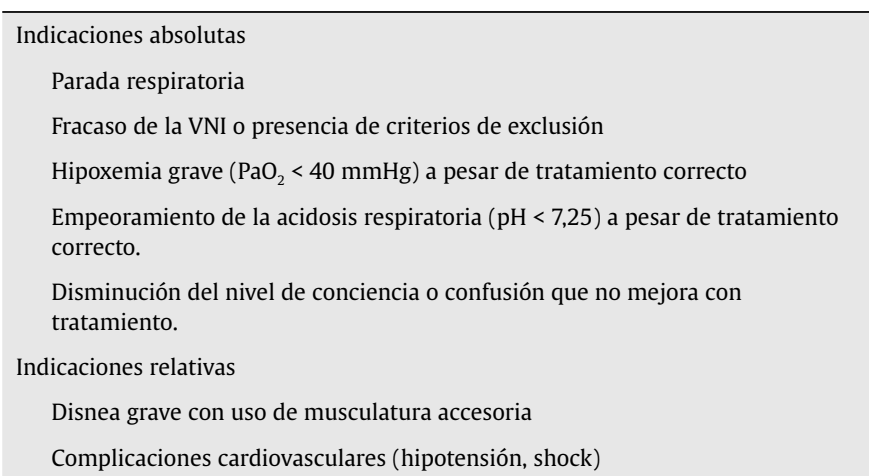

\section{Seguimiento}

Para las agudizaciones ambulatorias se establece un control evolutivo con una visita a las 48-72 h, con la intención de valorar la evolución del proceso de agudización. Este período es importante para poder identificar la existencia de fracasos terapéuticos tempranos. En el caso de que el paciente haya precisado ingreso hospitalario, el control evolutivo deberá realizarse dentro de las primeras 2 semanas tras el alta hospitalaria.

En todos los pacientes que no dispongan de espirometría previa, se etiquetará el caso como "Posible EPOC". Se deberá realizar una espirometría de confirmación en fase de estabilidad (al menos 4 semanas después de finalizar el tratamiento de la agudización).

\section{Criterios de valoración hospitalaria}

En función de la gravedad de la agudización, el paciente deberá recibir asistencia ambulatoria u hospitalaria. En la tabla 27 se recogen los criterios que se deben considerar para remitir al paciente al hospital en el transcurso de una agudización.

\section{Tabla 27}

Indicaciones para remitir al paciente a valoración hospitalaria

Agudización grave o muy grave
- Disnea 3-4 de la escala mMRC
- Inestabilidad hemodinámica
- Alteración del nivel de consciencia
- Cianosis de nueva aparición
- Utilización de musculatura accesoria
- Edemas periféricos de nueva aparición
- SpO ${ }_{2}^{<} 90 \%$ o PaO ${ }_{2}^{<} 60$ mmHg
- Comorbilidad significativa gravea
- Complicaciones (arritmias graves, insuficiencia cardíaca, etc.)
Fracaso terapéutico en las agudizaciones moderadas(falta de respuesta al
tratamiento)
Pacientes con EPOC estable graves/muy graves y agudizaciones frecuentes ( $\geq 2$ ) en
el año previo
Descartar otros diagnósticos (neumonía, neumotórax, insuficiencia cardíaca,
embolia pulmonar, etc.)
Apoyo domiciliario insuficiente
Deterioro del estado general

mMRC: escala de disnea modificada de la Medical Research Council. ${ }^{a}$ Cardiopatía isquémica reciente, insuficiencia renal crónica, hepatopatía moderadagrave, etc. 


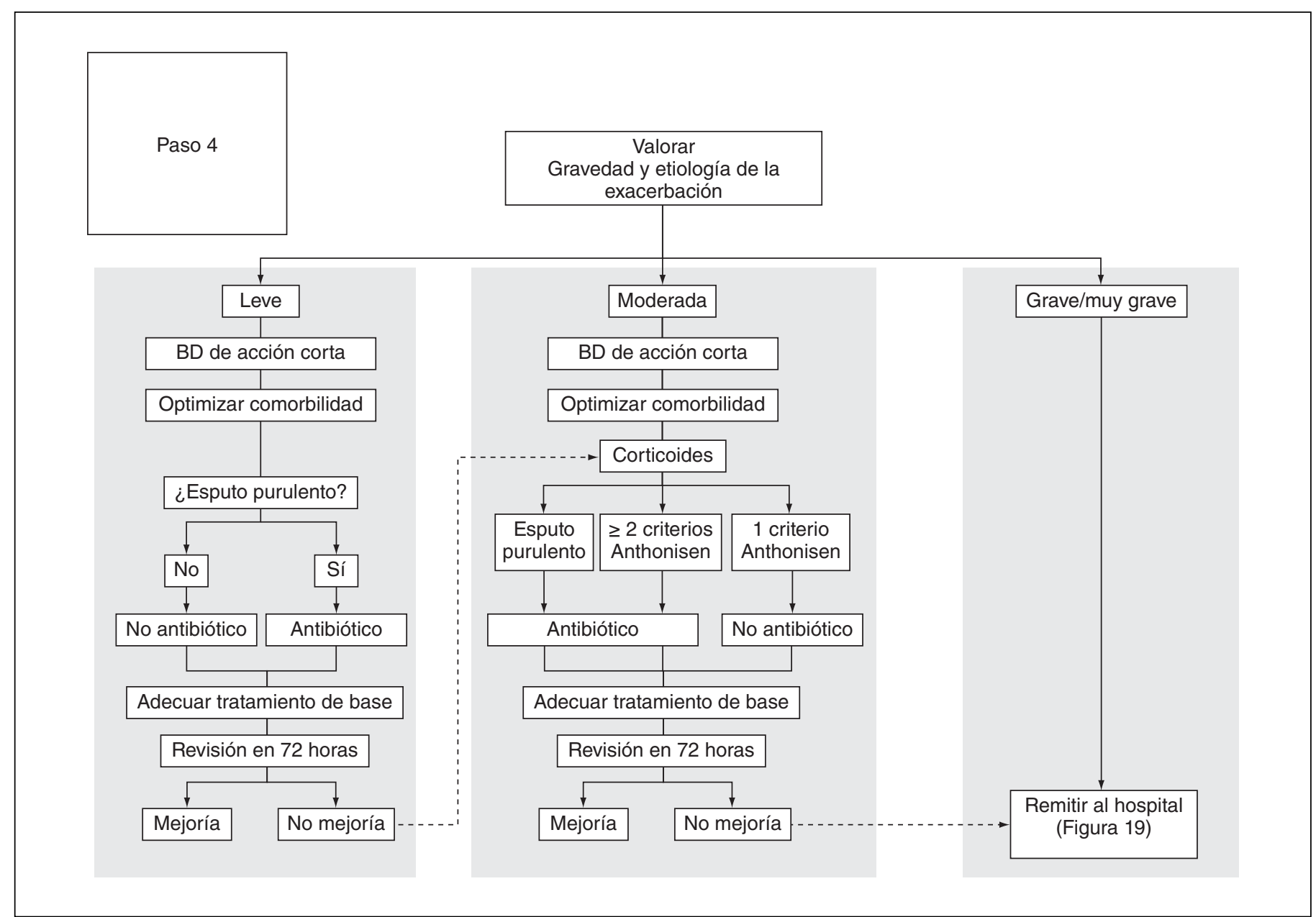

Figura 18 Tratamiento de la agudización según su etiología y gravedad. BD: broncodilatadores.

\section{Algoritmos terapéuticos de la agudización de la EPOC}

\section{Algoritmo terapéutico ambulatorio de la agudización de la EPOC}

La figura 18 muestra el esquema terapéutico que se recomienda en pacientes con agudizaciones leves y moderadas. Los pacientes que cumplan criterios de agudización grave o muy grave deberán ser remitidos al hospital.

Aunque existen pautas terapéuticas comunes, la intensidad del tratamiento administrado dependerá de la gravedad de la propia agudización. La principal diferencia entre las agudizaciones leves y moderadas la encontramos en el uso de corticoides sistémicos, recomendados para las agudizaciones moderadas (evidencia moderada, recomendación débil a favor). La pauta antibiótica dependerá de la sospecha de infección bacteriana. No obstante, mientras en la agudización leve se exige un cambio en la coloración del esputo (amarillento, verdoso o marronáceo), en la moderada podría pautarse antibiótico también en los casos donde, además de la disnea, aparece aumento de volumen del esputo, aunque no haya cambios en su color (evidencia moderada, recomendación fuerte a favor).

Algoritmo terapéutico hospitalario de la agudización de la EPOC

Aunque el esquema terapéutico para todas las agudizaciones graves o muy graves es similar, la estructura y organización de la asistencia será diferente según el lugar donde sea atendido el paciente: servicio de urgencias, sala de hospitalización o unidad especializadas de cuidados intermedios o de cuidados intensivos (UCI). Las recomenda- ciones para la atención al paciente en unidades de cuidados intensivos no se recogen en esta guía.

Asistencia en el servicio de urgencias hospitalarias. La asistencia al paciente con agudización de EPOC en el servicio de urgencias hospitalarias debe estar estructurada en 4 fases:

1. Admisión y clasificación.

2. Asistencia.

3. Evolución, espera y observación.

4. Resolución, orientación y transferencia.

Fase 1. Admisión y clasificación. Ante todo enfermo que consulte en urgencias hospitalarias, lo primero que se debe hacer es una clasificación con un sistema de cribado estructurado y validado. La base fundamental de cualquier sistema de cribado hospitalario moderno es el establecimiento de niveles o categorías en función de los síntomas que expresa el paciente y los signos observados. Los sistemas de cribado no se diseñan para realizar diagnósticos médicos, que son el resultado final de la asistencia, sino para conseguir una clasificación y priorización en la asistencia médica de los servicios de urgencia hospitalarios, y así conseguir una adecuación de los recursos disponibles según el nivel de gravedad de cada paciente en particular.

Clasificación de prioridad asistencial. El sistema español de triaje (SET) establece 5 niveles de priorización (tabla 28), a partir de la combinación de las siguientes circunstancias: 
Tabla 28

Niveles de priorización para la asistencia en el servicio de urgencias de la agudización de la EPOC según el sistema español de cribado (SET)

\begin{tabular}{|c|c|c|c|c|}
\hline Nivel & Recomendación & Recomendación & $\begin{array}{l}\text { Tiempo de atención } \\
\text { de enfermería }\end{array}$ & $\begin{array}{l}\text { Tiempo de atención } \\
\text { del facultativo }\end{array}$ \\
\hline I & $\begin{array}{l}\text { Se adjudica a los pacientes que requieren } \\
\text { resucitación, con riesgo vital inmediato }\end{array}$ & $\begin{array}{l}\text { Disnea clase V (preparada respiratoria) } \\
\text { Situación de shock }\end{array}$ & Inmediato & Inmediato \\
\hline II & $\begin{array}{l}\text { Pacientes en situación de emergencia o muy } \\
\text { urgentes, de riesgo vital inmediato y cuya } \\
\text { intervención depende radicalmente del tiempo, } \\
\text { son situaciones de alto riesgo, con inestabilidad } \\
\text { fisiológica o dolor intenso }\end{array}$ & $\begin{array}{l}\text { Disnea clase IV (muy grave) } \\
\text { Estridor } \\
\geq 2 \text { constantes o signos vitales alterados }\end{array}$ & Inmediato & 5-15 min. \\
\hline III & $\begin{array}{l}\text { Lo constituyen las situaciones urgentes, de riesgo } \\
\text { potencial, que generalmente requieren múltiples } \\
\text { exploraciones diagnósticas y/o terapéuticas en } \\
\text { pacientes con estabilidad fisiológica (constantes } \\
\text { vitales normales) }\end{array}$ & $\begin{array}{l}\text { Disnea clase III (grave) } \\
\text { Estabilidad hemodinámica } \\
\text { Síntomas y signos de insuficiencia respiratoria }\end{array}$ & $30 \mathrm{~min}$ & $15-60 \mathrm{~min}$ \\
\hline IV & $\begin{array}{l}\text { Son situaciones menos urgentes, potencialmente } \\
\text { serias y de una complejidad-urgencia significativa. } \\
\text { Suelen necesitar una exploración diagnóstica y/o } \\
\text { terapéutica }\end{array}$ & $\begin{array}{l}\text { Disnea clase I-II (leve-moderada) } \\
\text { Estabilidad hemodinámica } \\
\text { No insuficiencia respiratoria }\end{array}$ & $60 \mathrm{~min}$ & $30-120 \mathrm{~min}$ \\
\hline V & $\begin{array}{l}\text { Son situaciones no urgentes que generalmente no } \\
\text { requieren ninguna exploración diagnóstica y/o } \\
\text { terapéutica }\end{array}$ & & $120 \mathrm{~min}$ & $40-240 \mathrm{~min}$ \\
\hline
\end{tabular}

1. Categorización sintomática. En un paciente con una agudización de EPOC, el síntoma guía principal que le llevará a un servicio de urgencias hospitalario, en la gran mayoría de los casos, es el incremento de su disnea.

En la categoría sintomática disnea se aplican inicialmente los algoritmos y/o escalas de valoración globales que determinan el riesgo vital del paciente según los parámetros de sus constantes vitales. Esta valoración general puede determinar por sí misma un nivel I de prioridad si encuentra inestabilidad hemodinámica.

2. Valoración de los signos y síntomas. Las constantes y signos vitales alterados en el adulto discriminarán los pacientes entre el nivel II y III. Es decir, dos pacientes con idéntica sintomatología y situación clínica serán discriminados a nivel II si tienen las constantes o signos vitales alterados.

El SET considera constantes vitales alteradas en el adulto dos o más de las siguientes:

- Presión arterial sistólica (PAS) $<90$ o $\geq 200 \mathrm{mmHg}$.

- Frecuencia cardíaca $\leq 40$ o $\geq 125 \leq$ lat $/ \mathrm{min}$.

- Frecuencia respiratoria $\leq 100 \geq 30$ respiraciones/min.

- $\mathrm{SO}_{2}<92 \%$.

- Temperatura corporal $<35,50>40^{\circ} \mathrm{C}$.

- Glucemia capilar $<40 \mathrm{mg} / \mathrm{dl}$.

- Glasgow $\leq 14$.

Se consideran signos vitales alterados en el adulto:

- Piel fría y pálida, o sudada y caliente, o muy caliente.

- Falta de pulso radial, pulso débil o pulso muy fuerte.

- Pulso muy lento o muy rápido.

- Respiración lenta y profunda, o superficial y rápida.

- Somnolencia o confusión.

3. Escala de gravedad. La categoría disnea en el SET se evalúa de la siguiente forma:

- Clase I (leve): ausencia de síntomas con la actividad normal. Equivale a disnea 0 o 1 en la escala mMRC.

- Clase II (moderada): síntomas con la actividad moderada. Equivale a disnea 2 en la escala mMRC.
- Clase III (grave): síntomas con escasa actividad. Equivale a disnea 3 en la escala mMRC.

- Clase IV (muy grave): síntomas en reposo. Equivale a disnea 4 en la escala mMRC.

- Clase V (preparada respiratoria).

De acuerdo con esta clasificación del SET, y también atendiendo a los criterios de gravedad de la propia agudización (tabla 28), de la presencia de insuficiencia respiratoria y/o de comorbilidad grave, se establecen 3 códigos asistenciales iniciales, dentro del servicio de urgencias.

- Código I (amenaza vital): el paciente es subsidiario de ser atendido en una unidad de cuidados intensivos (tabla 29). Los criterios para traslado inicial a esta unidad son:

- Pacientes en nivel I del SET.

- Pacientes en nivel II del SET que además cumplan criterios de ingreso en intensivos.

- Código II: el paciente deberá ser atendido en una cama de observación.

- Pacientes en nivel II del SET que no cumplan criterios de ingreso en intensivos.

- Pacientes en nivel III del SET.

Tabla 29

Indicaciones de ingreso en unidad de cuidados intensivos

Agudización muy grave
- Parada respiratoria
- Alteración del nivel de conciencia (confusión, letargia, coma)
- Inestabilidad hemodinámica
- Acidosis respiratoria grave $(\mathrm{pH}<7,30)$
Disnea grave que no responde al tratamiento inicial
Hipoxemia grave, a pesar de tratamiento $\left(\mathrm{PaO}_{2}<40 \mathrm{mmHg}\right)$
Hipercapnia o acidosis respiratoria $(\mathrm{pH}<7,25)$ a pesar de ventilación no invasiva
Necesidad de ventilación mecánica invasiva




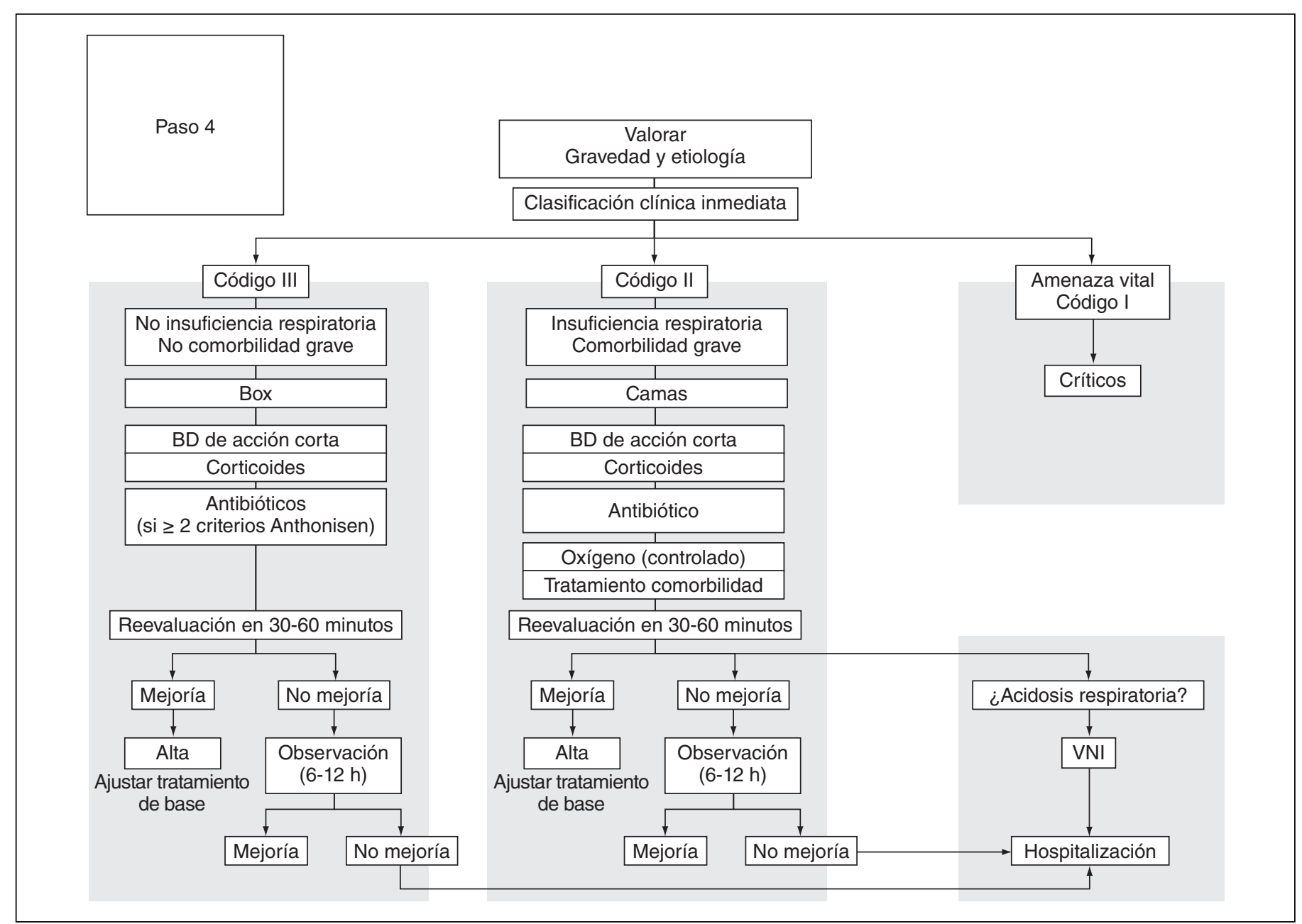

Figura 19 Tratamiento hospitalario de la agudización grave. BD: broncodilatadores.

- Código III: se podrá atender en el mismo box de urgencias:

- Pacientes en nivel IV y V del SET.

Fase 2. Asistencia. La figura 19 muestra el esquema terapéutico que se recomienda en pacientes con agudizaciones graves o muy graves atendidas en el hospital. En ocasiones, pacientes con agudizaciones más leves también acuden a un centro hospitalario. En este último caso, se recomienda seguir el esquema planteado para la agudización ambulatoria.

Los pacientes que cumplan criterios de código I (amenaza vital) deberán ser trasladados al box de críticos para el inicio inmediato del tratamiento. Los casos en los que no se produce una adecuada respuesta y todos los que cumplan criterios específicos deberán ser trasladados a una unidad de cuidados intensivos (tabla 29). En cuanto a los clasificados como código II y III, el tratamiento será muy similar, con broncodilatadores de acción corta y rápida, corticoides sistémicos y antibióticos, siempre que haya indicación. No obstante, los pacientes con código II deberán ser atendidos en camas de observación, ya que con frecuencia precisan oxigenoterapia controlada y/o tratamiento específico de comorbilidades graves (arritmias, insuficiencia cardíaca, etc.).

Fase 3. Evolución, espera y observación. Tras el tratamiento inicial, se aconseja una reevaluación a los 30-60 minutos. Si el paciente presentaba una hipercapnia inicial o acidosis, se deberá repetir la gasometría arterial para valorar la indicación de VNI (fig. 20). Se aconseja iniciar la VNI de forma temprana, antes de las $4 \mathrm{~h}$.
Se debe optimizar el tratamiento y mantener al paciente en la sala de observación durante un período de 6-12 h hasta decidir su destino.

Fase 4. Resolución, orientación y transferencia

Alta domiciliaria. Los pacientes que respondan favorablemente al tratamiento y cumplan los criterios de remisión domiciliaria podrán ser dados de alta. En este momento será muy importante adecuar el tratamiento de base, para reducir fracasos terapéuticos, recaídas o recurrencias (tabla 30). Asimismo, se deberá realizar un control clínico en un plazo de $72 \mathrm{~h}$. Para ello deben establecerse en cada territorio programas o protocolos destinados a asegurar esta continuidad asistencial.

En todos los pacientes que no dispongan de espirometría previa, se etiquetará el caso como "Posible EPOC". Se deberá realizar una espirometría de confirmación en fase de estabilidad.

Hospitalización a domicilio. La hospitalización a domicilio (HD) representa una alternativa asistencial para pacientes con EPOC que presentan exacerbaciones sin presentar acidosis ${ }^{318}$. Un metaanálisis ${ }^{319}$ confirma que este tipo de aproximaciones son seguras al compararlas con la hospitalización convencional. Los pacientes con alteraciones del estado mental, cambios radiológicos o electrocardiográficos agudos, comorbilidades significativas y bajo apoyo social no deben ser incluidos en estos programas.

Ingreso hospitalario en sala de hospitalización. La tabla 30 muestra los criterios de ingreso hospitalario. En los casos que finalmente re- 


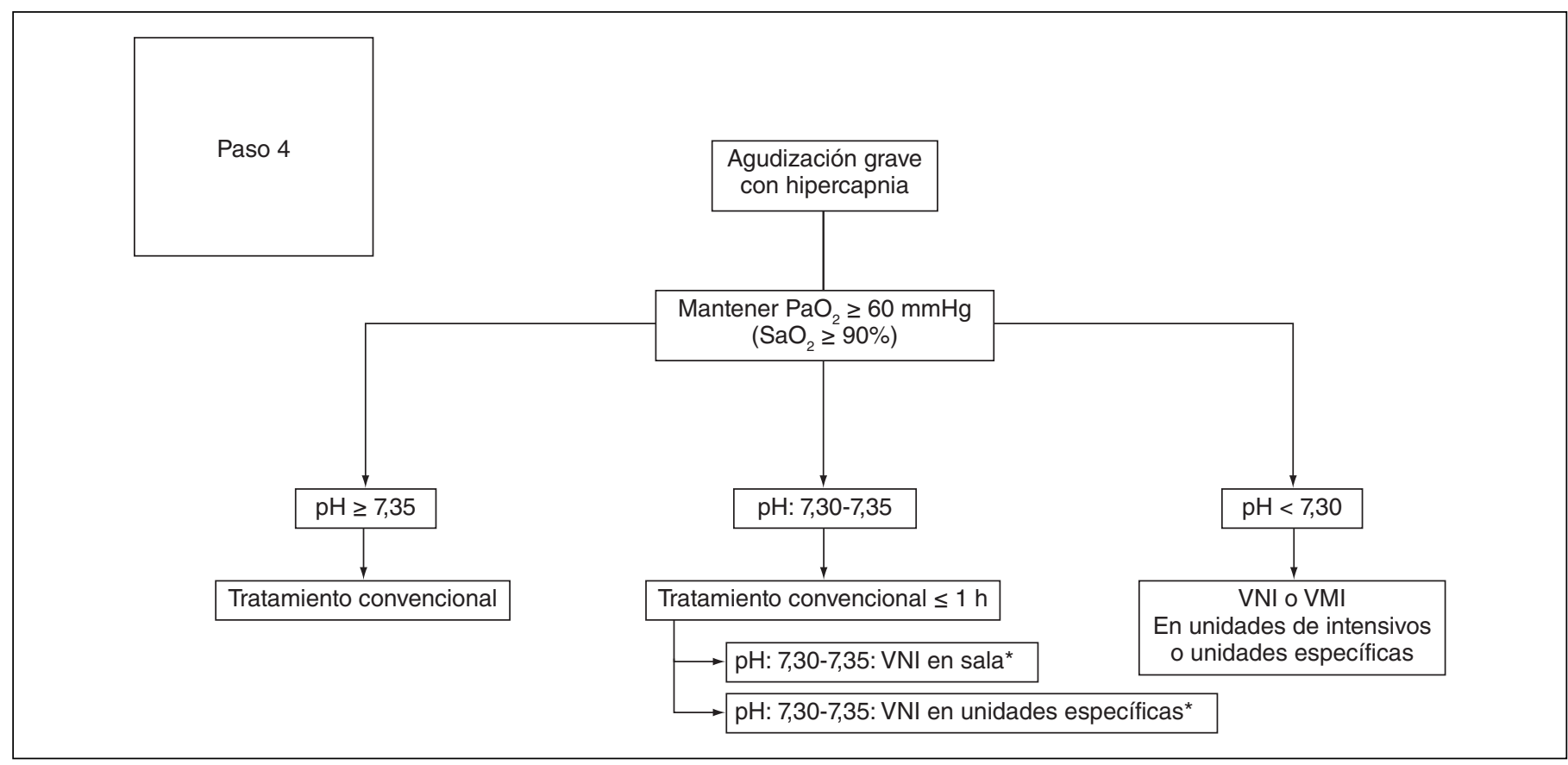

Figura 20 Tratamiento de la agudización grave con hipercapnia.

*Iniciar la VNI de forma precoz, antes de las 4 h. VNI: ventilación mecánica no invasiva; VMI: ventilación mecánica invasiva.

Tabla 30

Criterios de ingreso hospitalario en sala de hospitalización

Ausencia de mejoría tras tratamiento correcto y observación de 6-12 h
Acidosis respiratoria $(\mathrm{pH}<7,35)$
$\mathrm{PaO}_{2}<55 \mathrm{mmHg}$
$\mathrm{PaCO}_{2}>50 \mathrm{mmHg}$ en pacientes sin hipercapnia previa
Necesidad de ventilación mecánica no invasiva
Presencia de complicaciones o comorbilidades graves:
- Neumonía, siempre que se cumplan los criterios específicos de gravedad de la
neumonía que indican ingreso
- Derrame pleural
- Neumotórax
- Enfermedad venosa tromboembólica
- Traumatismo torácico con fracturas costales
- Alteraciones cardiovasculares (insuficiencia cardíaca, cardiopatía isquémica,
arritmias no controladas)
- Anemia grave
Soporte domiciliario insuficiente

quieran un ingreso hospitalario, la figura 21 muestra la pauta de tratamiento a seguir. En pacientes de edad avanzada y comorbilidad (habitualmente código II) que, sin estar en situación crítica, se considere que un ingreso prolongado puede comportar riesgo y se prevea una posible mejoría en 48-72 h, debe considerarse el ingreso en unidades de corta estancia (UCE) en los hospitales en los que haya. También pueden ser candidatos a UCE los pacientes que inicialmente pueden tener criterios de remisión a HD y que no reúnan las condiciones psicosociales y/o familiares para ello.

Criterios de alta hospitalaria

La duración de la estancia hospitalaria es variable de unos pacientes a otros, y no existen suficientes datos para establecer la duración óptima de la hospitalización en pacientes individuales con agudización de EPOC. La tabla 31 muestra los criterios que se deben cumplir para proceder al alta hospitalaria.
Tabla 31

Criterios de alta hospitalaria

La administración de broncodilatadores de acción corta no se precisa con una
frecuencia inferior a las $4 \mathrm{~h}$
El paciente es capaz de caminar por la habitación
El paciente es capaz de comer y dormir sin frecuentes despertares debidos a la
disnea
Estabilidad clínica de $12-24 \mathrm{~h}$
Estabilidad gasométrica durante $12-24 \mathrm{~h}$
Correcto uso de la medicación por parte del paciente y/o del cuidador
Garantía de la continuidad asistencial

Tratamiento tras el alta hospitalaria

Siempre que se produzca el alta hospitalaria, se deberá adecuar el tratamiento de base, con especial énfasis en reducir las posibles recaídas. Los fármacos antinflamatorios deben ser especialmente valorados en los pacientes con historial de frecuentes agudizaciones. En la tabla 32 se recogen las principales recomendaciones terapéuticas para el alta hospitalaria.

\section{Seguimiento tras el alta hospitalaria}

Tras el alta hospitalaria se deberá realizar un seguimiento en un plazo de 2-4 semanas, en el que se deberá revisar el estado clínico del paciente, la resolución de la infección respiratoria, la cumplimentación, la técnica inhalatoria y la necesidad de OCD.

En todos los pacientes que no dispongan de espirometría previa se etiquetará el caso como “Posible EPOC". Se deberá realizar una espirometría de confirmación en fase de estabilidad.

\section{Recomendaciones para la atención del paciente con agudización}

Se resumen en la tabla 33.

Estándares de calidad asistencial para la atención del paciente con agudización

Se presentan en la tabla 34 . 


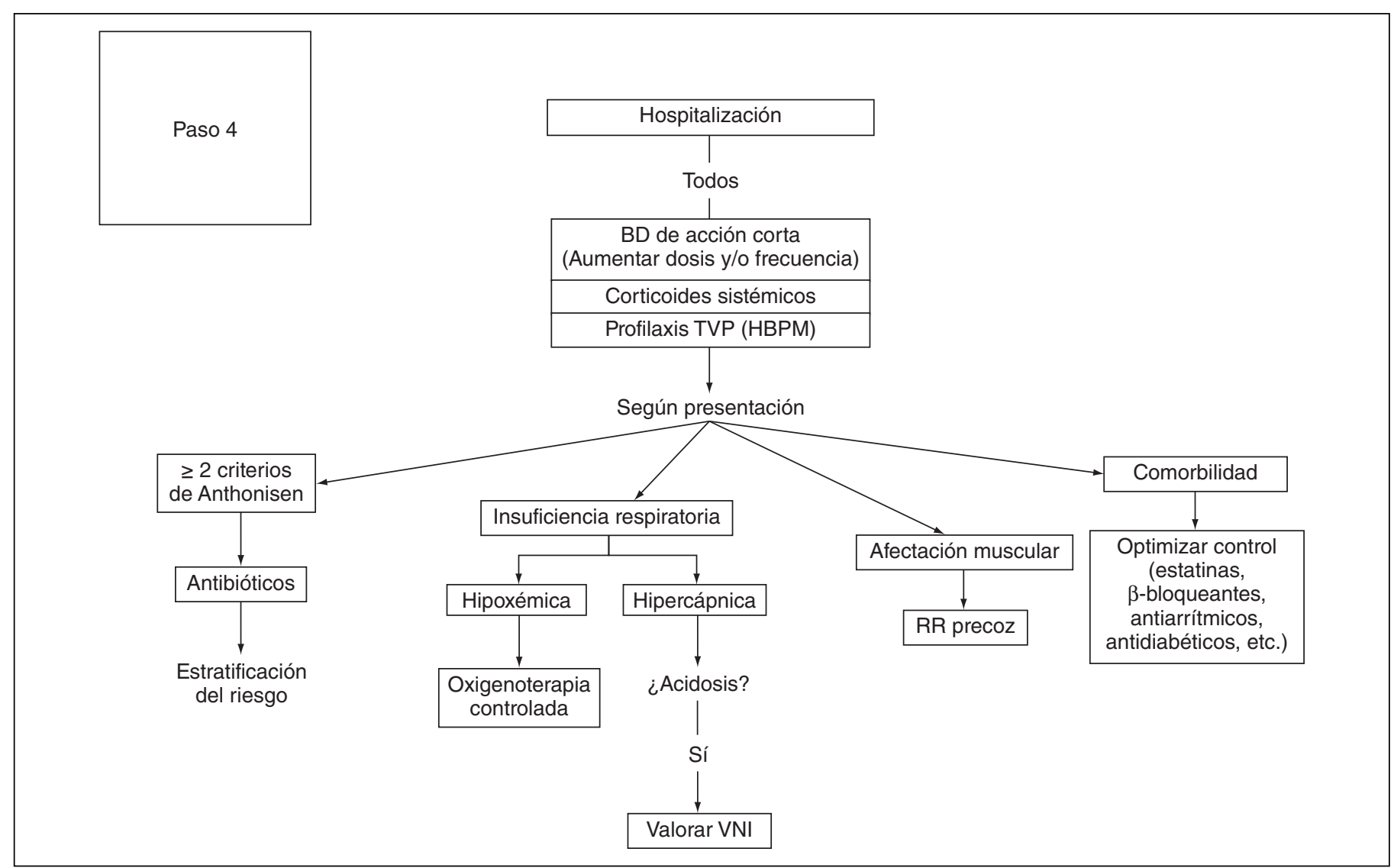

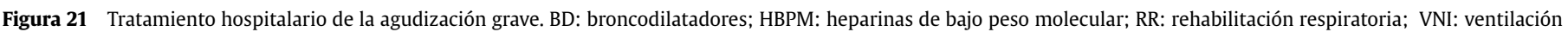
no invasiva; TVP: trombosis venosa profunda.

Tabla 32

Recomendaciones de tratamiento al alta hospitalaria

Abstinencia tabáquica
Recomendación de ejercicio regular. Valorar RR tras hospitalización
Mantener y ajustar el tratamiento habitual:
- Revisar la técnica inhalatoria del enfermo
- Broncodilatadores de larga duración de base
- Corticoides inhalados: indicados para pacientes con fenotipo agudizador o mixto
- Inhibidores de fosfodiesterasa 4: indicados para fenotipo agudizador con
bronqutis crónica
- Oxígenoterapia: reajustar según necesidades
Antibióticos si se cumplen las indicaciones
Corticoides orales: $30-40$ mg de prednisolona o equivalente durante 7-10 días
Ventilación mecánica no invasiva domiciliaria. Considerarla en pacientes con
agudizaciones acidóticas recurrentes y/o en paciente que asocien hipoventilación
por otras causas (síndrome de apnea-hipoapnea, obesidad-hipoventilación, etc.)
Control clínico en $2-4$ semanas
Asegurar correcta cumplimentación
Planificación de cuidados de enfermería
Garantizar continuidad asistencial

RR: rehabilitación respiratoria.

\section{Atención a la EPOC al final de la vida. Cuidados paliativos}

Puntos clave:

- Muchos pacientes con EPOC avanzada pueden beneficiarse de los cuidados paliativos.
- Estos cuidados se reservan a pacientes con elevada probabilidad de fallecer en los próximos meses.

- La comunicación con el paciente y los familiares o cuidadores es fundamental.

- Se debe atender de forma especial al tratamiento farmacológico de la disnea y de la ansiedad y/o depresión.

\section{Cuidados paliativos en la EPOC}

Los cuidados paliativos (CP) son las atenciones que se brindan para mejorar la calidad de vida de los pacientes con una enfermedad grave o potencialmente mortal. La meta de los cuidados paliativos es prevenir o tratar los síntomas de una enfermedad, los efectos secundarios del tratamiento y los problemas psicológicos, sociales y espirituales relacionados con una enfermedad o su tratamiento ${ }^{320,321 .}$

Los CP no se limitan a pacientes oncológicos con enfermedad terminal. Muchos pacientes con insuficiencia orgánica avanzada, como la EPOC, pueden beneficiarse de ellos. Los CP por sí mismos no aceleran la muerte y mejoran la calidad de vida ${ }^{322}$.

\section{Síntomas de los pacientes con EPOC avanzada}

Los pacientes con EPOC grave y muy grave (nivel de gravedad 4-5) tienen a menudo tantos o más síntomas físicos y emocionales, además de mayor limitación funcional y peor calidad de vida que los pacientes con neoplasias avanzadas ${ }^{323-325}$.

Entre los síntomas asociados a la EPOC avanzada el más prevalente es la disnea, presente en el $97 \%$ de los pacientes, la somnolencia, la falta de energía (68\%) y el dolor (43\%). La presencia de depresión se puede detectar en casi el 50\% de los pacientes, mientras que la prevalencia de ansiedad alcanza el 25\%. Muchas veces los síntomas coexisten. 
Tabla 33

Recomendaciones para la atención del paciente con agudización

\begin{tabular}{|c|c|c|c|c|}
\hline & NR & Recomendación & Calidad de la evidencia & Fuerza de la recomendación \\
\hline Informe clínico & R032 & $\begin{array}{l}\text { En el informe clínico de toda agudización de la EPOC debe constar su } \\
\text { gravedad y en la medida de lo posible su diagnóstico etiológico (p. ej., } \\
\text { agudización moderada de etiología infecciosa bacteriana) }\end{array}$ & Muy baja & Fuerte a favor \\
\hline \multirow[t]{3}{*}{ Broncodilatadores } & R033 & $\begin{array}{l}\text { Los broncodilatadores de acción corta (agonistas } \beta 2 \text { y/o anticolinérgicos) se } \\
\text { deben utilizar en el tratamiento de las agudizaciones de la EPOC }\end{array}$ & Alta $^{\mathrm{a}}$ & Fuerte a favor ${ }^{\mathrm{a}}$ \\
\hline & R034 & $\begin{array}{l}\text { En caso de que la respuesta clínica fuera insuficiente, debería asociarse un } \\
\text { agonista } \beta 2 \text { de acción corta más un anticolinérgico de acción corta duración }\end{array}$ & Baja $^{\mathrm{a}}$ & Fuerte a favor ${ }^{\mathrm{a}}$ \\
\hline & R035 & Las teofilinas no deben utilizarse en las agudizaciones de la EPOC & Moderada $^{\mathrm{a}}$ & Débil en contra ${ }^{a}$ \\
\hline \multirow[t]{3}{*}{ Antibióticos } & R036 & $\begin{array}{l}\text { Los antibióticos están indicados siempre que, en el contexto de una } \\
\text { agudización, aparezca un cambio en el color del esputo }\end{array}$ & Moderada $^{\mathrm{a}}$ & Fuerte a favor ${ }^{\mathrm{a}}$ \\
\hline & R037 & $\begin{array}{l}\text { En la agudización moderada o grave los antibióticos estarán indicados } \\
\text { cuando se cumplan al menos } 2 \text { de los } 3 \text { criterios de Anthonisen (aumento de } \\
\text { la disnea, aumento del volumen del esputo y/o cambios en la coloración del } \\
\text { esputo) }\end{array}$ & Moderada $^{\mathrm{a}}$ & Fuerte a favor ${ }^{\mathrm{a}}$ \\
\hline & R038 & $\begin{array}{l}\text { En la agudización muy grave, que requiere asistencia ventilatoria, la } \\
\text { cobertura antibiótica es obligada }\end{array}$ & Baja $^{a}$ & Fuerte a favor ${ }^{\mathrm{a}}$ \\
\hline \multirow[t]{3}{*}{$\begin{array}{l}\text { Corticoides } \\
\text { sistémicos }\end{array}$} & R039 & $\begin{array}{l}\text { En pacientes con EPOC no hospitalizados se sugiere administrar prednisona } \\
\text { oral durante } 9 \text { o } 10 \text { días para tratar las exacerbaciones moderadas }\end{array}$ & Moderada $^{\mathrm{b}}$ & Débil a favor ${ }^{\mathrm{b}}$ \\
\hline & R040 & $\begin{array}{l}\text { En las agudizaciones graves o muy graves deberá utilizarse una pauta corta } \\
\text { de corticoides sistémicos (orales o parenterales) }\end{array}$ & Alta $^{a}$ & Fuerte a favor ${ }^{\mathrm{a}}$ \\
\hline & R041 & $\begin{array}{l}\text { Los corticoides inhalados a dosis altas pueden ser una alternativa en el } \\
\text { tratamiento de la agudización moderada-grave de la EPOC }\end{array}$ & Moderada $^{a}$ & Débil a favora \\
\hline $\begin{array}{l}\text { Heparina de bajo } \\
\text { peso molecular }\end{array}$ & R042 & $\begin{array}{l}\text { En pacientes con EPOC que presenten una agudización de EPOC se } \\
\text { recomienda heparina de bajo peso molecular a dosis moderadas mientras } \\
\text { estén encamados }\end{array}$ & Alta $^{c}$ & Fuerte a favor ${ }^{c}$ \\
\hline $\begin{array}{l}\text { Rehabilitación } \\
\text { respiratoria }\end{array}$ & R043 & $\begin{array}{l}\text { En pacientes con EPOC que han sufrido una agudización, se recomienda } \\
\text { iniciar la rehabilitación respiratoria inmediatamente después de finalizar el } \\
\text { tratamiento de la exacerbación o en el periodo comprendido en las tres } \\
\text { semanas siguientes }\end{array}$ & Moderada $^{\mathrm{b}}$ & Fuerte a favor ${ }^{\mathrm{b}}$ \\
\hline $\begin{array}{l}\text { Ventilación no } \\
\text { invasiva (VNI) }\end{array}$ & R044 & $\begin{array}{l}\text { La ventilación no invasiva (VNI) es el tratamiento de elección para la } \\
\text { insuficiencia respiratoria hipercápnica que cursa con acidosis respiratoria } \\
\text { moderada a pesar de tratamiento médico óptimo }\end{array}$ & Alta $^{\mathrm{a}}$ & Fuerte a favor ${ }^{\mathrm{a}}$ \\
\hline $\begin{array}{l}\text { Ventilación no } \\
\text { invasiva (VI) }\end{array}$ & R045 & $\begin{array}{l}\text { La ventilación invasiva }(\mathrm{VI}) \text { está indicada en los pacientes con acidosis } \\
\text { respiratoria }(\mathrm{pH}<7,25) \text {, deterioro del nivel de conciencia y/o inestabilidad } \\
\text { hemodinámica }\end{array}$ & Moderada $^{\mathrm{a}}$ & Fuerte a favor ${ }^{\mathrm{a}}$ \\
\hline
\end{tabular}

NR: numeración de las recomendaciones.

'Referencia de SEPAR-semFyC ${ }^{6}$.

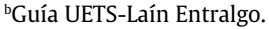

${ }^{\mathrm{c}}$ Normativa SEPAR TEP ${ }^{300}$.

Dada la larga evolución de la enfermedad, los síntomas pueden pasar desapercibidos si no se interroga dirigidamente. Los pacientes acaban incorporando los síntomas y las limitaciones derivadas de éstos a su estilo de vida ${ }^{326-328}$.

\section{Cuándo iniciar los cuidados paliativos}

La aproximación clásica se basa en iniciar los cuidados paliativos en los pacientes con una alta probabilidad de fallecer en los próximos meses (tabla 35). Sin embargo, determinar el pronóstico individual de un paciente con EPOC es extraordinariamente difícil. Algunos pacientes con EPOC grave permanecen estables durante meses, mientras que otros pierden rápidamente funcionalidad y fallecen. Además, las exacerbaciones que llevan a la insuficiencia respiratoria ocurren en ocasiones de forma brusca e impredecible, por lo que la toma de decisiones se debe realizar de forma precipitada si no se han trabajado previamente. Por tanto, la decisión de iniciar cuidados para el control de síntomas no debe basarse en la esperanza de vida, sino que se deben incorporar progresivamente según las necesidades del paciente (fig. 22).

Algunos expertos indican plantearse ante un paciente con EPOC la pregunta: ¿Me sorprendería que este paciente falleciese en los próxi- mos 12 meses? Aunque esta pregunta tiene la ventaja de obligarnos a plantear la necesidad de cuidados paliativos, muchos autores consideran que su utilización en las enfermedades crónicas con insuficiencia orgánica como la EPOC o la insuficiencia cardíaca es inadecuada y demora innecesariamente los beneficios del tratamiento ${ }^{329}$. Por tanto, la decisión de iniciar cuidados para el control de síntomas no debe basarse en la esperanza de vida, sino en las necesidades y la sintomatología del paciente y sus familiares ${ }^{330}$. Esto requiere la valoración periódica de los síntomas y la incorporación progresiva de las medidas de paliación sin abandonar el tratamiento reglado de la enfermedad de base.

\section{Qué información debe darse al paciente y familiares}

La comunicación es una herramienta terapéutica esencial que da acceso al principio de autonomía, al consentimiento informado, a la confianza mutua, a la seguridad y a la información que el enfermo necesita para ser ayudado y ayudarse a sí mismo. También permite la imprescindible coordinación entre el equipo cuidador, la familia y el paciente. La comunicación es un aspecto fundamental en el tratamiento de la EPOC al final de la vida (nivel de gravedad V) (fig. 23). 
Tabla 34

Estándares de calidad asistencial para la atención del paciente con agudización

\begin{tabular}{|c|c|c|c|}
\hline & ECA & Criterio de calidad & Indicador \\
\hline Historia clínica & $\mathrm{E} 22$ & $\begin{array}{l}\text { La historia clínica de toda agudización deberá contener como } \\
\text { mínimo la siguiente información: sintomatología (disnea, } \\
\text { volumen y coloración del esputo), historial de agudizaciones } \\
\text { previas, comorbilidad, gravedad basal y tratamiento previo }\end{array}$ & $\begin{array}{l}\text { N. }{ }^{\circ} \text { de agudizaciones donde se recoge toda la información } \\
\text { necesaria/N.. total de agudizaciones de EPOC }\end{array}$ \\
\hline $\begin{array}{l}\text { Exploraciones } \\
\text { complementarias }\end{array}$ & E23 & $\begin{array}{l}\text { En todos los pacientes que acuden al hospital se realizar las } \\
\text { siguientes pruebas: } \\
\text { - Radiografía de tórax } \\
\text { - Gasometría arterial, recogiéndose la fracción inspiratoria de } \\
\text { oxígeno a la que se realiza } \\
\text { - Electrocardiograma } \\
\text { - Analítica } \\
\text { - Esputo para tinción de Gram y cultivo en pacientes que } \\
\text { presentan frecuentes agudizaciones, necesidad de ventilación } \\
\text { asistida y/o fracaso terapéutico previo }\end{array}$ & $\begin{array}{l}\text { N. }{ }^{\circ} \text { de agudizaciones donde se recoge toda la información } \\
\text { necesaria/N. } .^{\circ} \text { total de agudizaciones de EPOC }\end{array}$ \\
\hline Broncodilatadores & E24 & $\begin{array}{l}\text { Durante la agudización se potenciará el tratamiento } \\
\text { broncodilatador con un agonista } \beta 2 \text { de acción corta y/o } \\
\text { bromuro de ipratropio }\end{array}$ & $\begin{array}{l}\mathrm{N} .{ }^{\circ} \text { pacientes a los que se les aumenta el tratamiento } \\
\text { broncodilatador durante una agudización/N. }{ }^{\circ} \text { total de pacientes } \\
\text { con agudización de EPOC }\end{array}$ \\
\hline Antibióticos & E25 & $\begin{array}{l}\text { La antibioterapia es necesaria en las agudizaciones moderadas- } \\
\text { graves que presenten, además de disnea, aumento del volumen } \\
\text { de la expectoración habitual y/o purulencia. En las } \\
\text { agudizaciones leves únicamente se utilizará en presencia de } \\
\text { esputo purulento }\end{array}$ & $\begin{array}{l}\text { N. }{ }^{\circ} \text { pacientes a los que se les prescribe antibióticos/N. } .{ }^{\circ} \text { total de } \\
\text { pacientes donde está indicado }\end{array}$ \\
\hline Corticoides sistémicos & E26 & $\begin{array}{l}\text { La corticoterapia sistémica es de elección en la agudización } \\
\text { grave o muy grave de la EPOC } \\
\text { También se utilizará en todas las agudizaciones moderadas y en } \\
\text { aquellas leves cuya evolución inicial no es favorable }\end{array}$ & 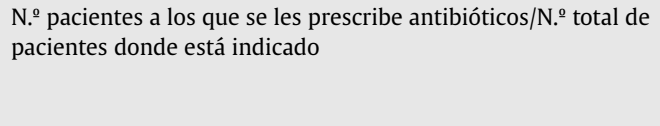 \\
\hline \multirow[t]{2}{*}{ Oxígeno } & E27 & $\begin{array}{l}\text { En las agudizaciones que cursen con insuficiencia respiratoria, } \\
\text { se deberá administrar oxígeno suplementario para conseguir } \\
\text { una } \mathrm{PaO}_{2}>60 \mathrm{mmHg} \text {, sin provocar acidosis respiratoria }\end{array}$ & $\begin{array}{l}\text { N.ํ pacientes que reciben oxígeno durante una agudización/N. } \\
\text { total de pacientes donde está indicado }\end{array}$ \\
\hline & E28 & $\begin{array}{l}\text { En pacientes con hipercapnia inicial y que precisen flujos } \\
\text { elevados de oxígeno será necesario realizar un control } \\
\text { gasométrico aproximadamente a los } 30 \text { minutos de iniciar el } \\
\text { tratamiento }\end{array}$ & $\begin{array}{l}\text { N.․ pacientes a los que se les realiza gasometría/N. } .^{\circ} \text { total de } \\
\text { pacientes donde está indicado }\end{array}$ \\
\hline $\begin{array}{l}\text { Ventilación no invasiva } \\
\text { (VNI) }\end{array}$ & E29 & $\begin{array}{l}\text { Debe indicarse ventilación no invasiva en pacientes con acidosis } \\
\text { respiratoria }(\mathrm{pH}<7,35) \text { a pesar de tratamiento optimizado }\end{array}$ & $\begin{array}{l}\text { N. }{ }^{\circ} \text { pacientes que reciben } \mathrm{VNI} / \mathrm{N} N \text { total de pacientes donde está } \\
\text { indicado }\end{array}$ \\
\hline Ventilación invasiva (VI) & E30 & $\begin{array}{l}\text { La ventilación invasiva está indicada en los pacientes con } \\
\text { acidosis respiratoria }(\mathrm{pH}<7,25) \text {, deterioro del nivel de } \\
\text { conciencia y/o inestabilidad hemodinámica }\end{array}$ & $\begin{array}{l}\text { N. }{ }^{\circ} \text { pacientes que reciben } \mathrm{VI} / \mathrm{N} .^{\circ} \text { total de pacientes donde está } \\
\text { indicado }\end{array}$ \\
\hline \multirow[t]{2}{*}{ Seguimiento } & E31 & $\begin{array}{l}\text { A todos los pacientes con exacerbación ambulatoria de la EPOC } \\
\text { se les deberá hacer un seguimiento dentro de las primeras } 72 \mathrm{~h}\end{array}$ & $\begin{array}{l}\text { N. }{ }^{\circ} \text { pacientes que reciben } \mathrm{VNI} / \mathrm{N} .^{\circ} \text { total de pacientes donde está } \\
\text { indicado }\end{array}$ \\
\hline & E32 & $\begin{array}{l}\text { Se debe realizar una visita médica a las } 2 \text { semanas siguientes al } \\
\text { alta hospitalaria }\end{array}$ & $\begin{array}{l}\mathrm{N} .{ }^{\circ} \text { pacientes que reciben } \mathrm{VI} / \mathrm{N} .^{\circ} \text { total de pacientes donde está } \\
\text { indicado }\end{array}$ \\
\hline
\end{tabular}

ECA: estándares de calidad asistencial ${ }^{29}$.

Es importante que el paciente y sus familiares entiendan que discutir sobre el pronóstico o realizar un plan terapéutico no significa dejar de cuidar al paciente ni suspender tratamientos que le sean útiles. Tampoco podemos obligar al enfermo a recibir información que no quiere. El profesional debe plantearse durante la entrevista si el paciente quiere más información, qué es lo que quiere saber y si está preparado para recibir la información. La comunicación no se alcanza en una única entrevista sino en múltiples, a través de un proceso de maduración. La información debe darse de forma lenta, continuada y paulatina, respetando el ritmo y las condiciones personales del enfermo. No se debe quitar la esperanza por mucha información que se facilite.

Un enfoque práctico es consensuar con el paciente lo que no quiere que le hagamos en caso de complicaciones, por ejemplo: en caso de que usted tuviese una parada cardíaca, ¿querría que intentásemos reanimarlo?, o en caso de una nueva exacerbación grave, ¿querría que lo ingresásemos en cuidados intensivos con un respirador? Esta información debe constar en los informes médicos y en los documentos de voluntades anticipadas.

\section{Opciones de tratamiento paliativo en la EPOC grave}

La valoración de los síntomas debe realizarse siempre que sea posible con escalas validadas, por ejemplo, para el dolor o la disnea se puede utilizar la escala visual analógica (EVA) de $10 \mathrm{~cm}$. Para valorar la ansiedad y la depresión las escalas sirven de guía, aunque no sustituyen a una entrevista formal realizada por un profesional experto. Una pregunta útil para iniciar la valoración es: ¿se siente a menudo triste o deprimido?

Para el tratamiento de la disnea, si el paciente persiste con síntomas incapacitantes a pesar de un tratamiento convencional correcto, estaría indicado iniciar tratamiento con mórficos si los beneficios esperados superan los previsibles efectos adversos ${ }^{331}$.

En general, los ensayos con mórficos para el alivio de la disnea en la EPOC se han realizado con pocos pacientes y durante un período breve, aunque la mayor parte de los estudios, incluida una revisión Cochrane y un metaanálisis, muestran mejoría con su uso comparado con placebo. En general, los efectos adversos son moderados y previsibles. En las dosis recomendadas no parecen provocar deprivación 
Tabla 35

Perfil del paciente que puede fallecer en los siguientes 6-12 meses

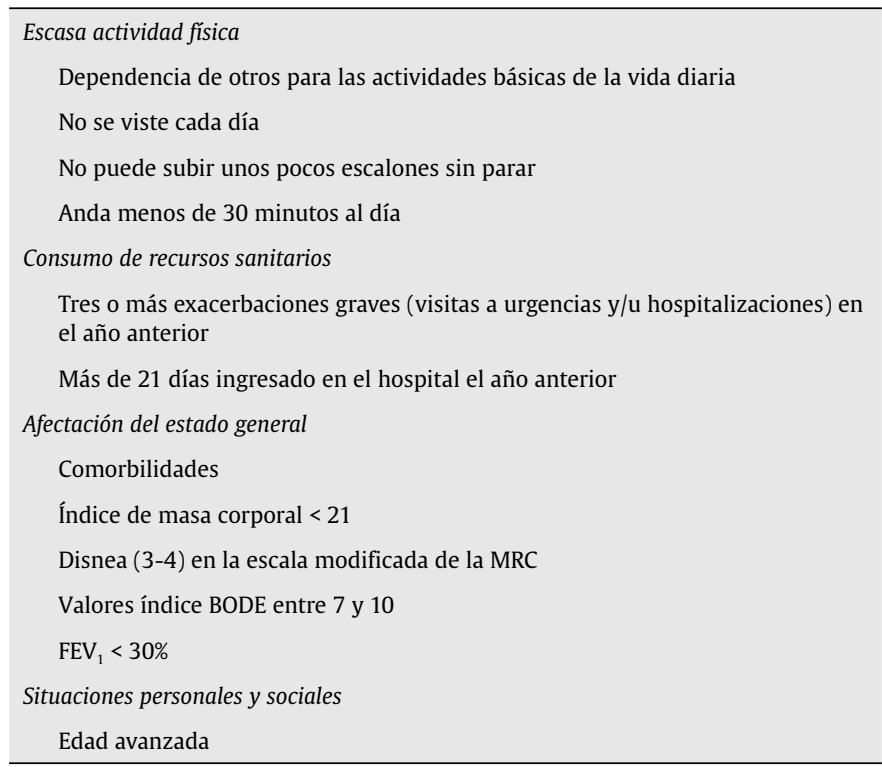

$\mathrm{FEV}_{1}$ : volumen espiratorio forzado en el primer segundo; MRC: Medical Research Council.

Adaptada de J.R. Curtis ${ }^{321}$.

respiratoria ${ }^{332-334}$. A pesar de ello, los pacientes con EPOC tienen la mitad de posibilidades de recibir tratamiento con mórficos durante sus últimos meses de vida que los pacientes con neoplasia ${ }^{335}$. Las recomendaciones de los expertos indican iniciar el tratamiento con sulfato de morfina entre 2 y $5 \mathrm{mg}$ y ajustar dosis según la respuesta ${ }^{336}$ (fig. 24).

El uso de la morfina para el alivio de la disnea en el paciente terminal se realizará con las mismas pautas empleadas para el control del dolor, considerando lo siguiente:

- En un paciente con disnea que no toma opioides puede iniciarse el tratamiento con morfina de liberación rápida a dosis de $5 \mathrm{mg} / 4 \mathrm{~h}$ por vía oral, doblando la dosis nocturna.

- En pacientes caquécticos o ancianos se recomienda empezar con $2,5 \mathrm{mg} / 4 \mathrm{~h}$.

- En caso de insuficiencia renal se debe espaciar la dosificación cada $6 \mathrm{~h}$.
- Si la disnea es muy aguda o muy grave se usará la vía parenteral, en dosis de $2,5 \mathrm{mg}$ por vía intravenosa cada $15 \mathrm{~min}$ o $5 \mathrm{mg}$ subcutáneos cada $20 \mathrm{~min}$, hasta que ceda la disnea.

- Una vez controlada la disnea se debe pasar a morfina de liberación sostenida, con dosis extra de morfina rápida oral, si se precisa. La morfina de liberación sostenida se administra cada 12 o 24 h, según presentación.

- Cuando el paciente ha pasado a tomar opioides de liberación sostenida, si aparece una etapa en que la disnea no se controla, se administrarán dosis de rescate de opioides de liberación rápida. La cantidad de morfina de estas dosis se calculará sumando las dosis totales de morfina (de liberación sostenida y rápida) de las últimas 24 h, dividiéndola entre 6 (para calcular la cantidad conveniente a la dosis que correspondería si se administrara cada $4 \mathrm{~h}$ ) y volviendo a dividir entre 2 (para calcular el 50\% de la dosis habitual). La dosis calculada será la que se usará como rescate cada $4 \mathrm{~h}$. Si las dosis de rescate son muy frecuentes se deberá ajustar la dosis de morfina de liberación sostenida en función, de nuevo, de la cantidad total consumida en las $24 \mathrm{~h}$.

- Si los pacientes no pueden tomar morfina por vía oral, la vía alternativa preferente es la subcutánea.

- La relación de equivalencia para el paso de morfina oral a morfina subcutánea es de 3:1 (30 mg de morfina por vía oral equivalen a 10 mg de morfina subcutánea).

- En pacientes que necesitan morfina parenteral continua, el método preferido de administración es la infusión subcutánea.

- No se recomiendan las vías bucal, sublingual y nebulizada para la administración de morfina, puesto que de momento no existen evidencias de un beneficio clínico frente a las vías convencionales.

- El fentanilo también puede ser útil en el tratamiento de la disnea del paciente en situación terminal.

- En casos de disnea aguda se puede utilizar fentanilo nebulizado, en una dosis de $25 \mu \mathrm{g}$ diluidos en $2,5 \mathrm{ml}$ de suero fisiológico, cada 2-3 h.

Las crisis de pánico respiratorio son episodios de agudización grave de una disnea crónica, a veces espontáneos pero habitualmente precipitados por la actividad física. Para su tratamiento es útil el lorazepam en dosis de 0,5-1 mg por vía oral o sublingual.

En casos más graves de disnea aguda se puede utilizar un bolo de 2,5 mg de midazolam por vía subcutánea y, si es eficaz, se puede continuar con una perfusión de $0,4 \mathrm{mg} / \mathrm{h}$ ( $10 \mathrm{mg} / 24$ h por vía subcutánea), que mejora la ansiedad sin producir pérdida de conciencia. Más tarde, si persiste la disnea, se puede continuar con lorazepam oral.

Se deben considerar los efectos secundarios más importantes por su frecuencia en el uso de la morfina: las náuseas-vómitos, frente a

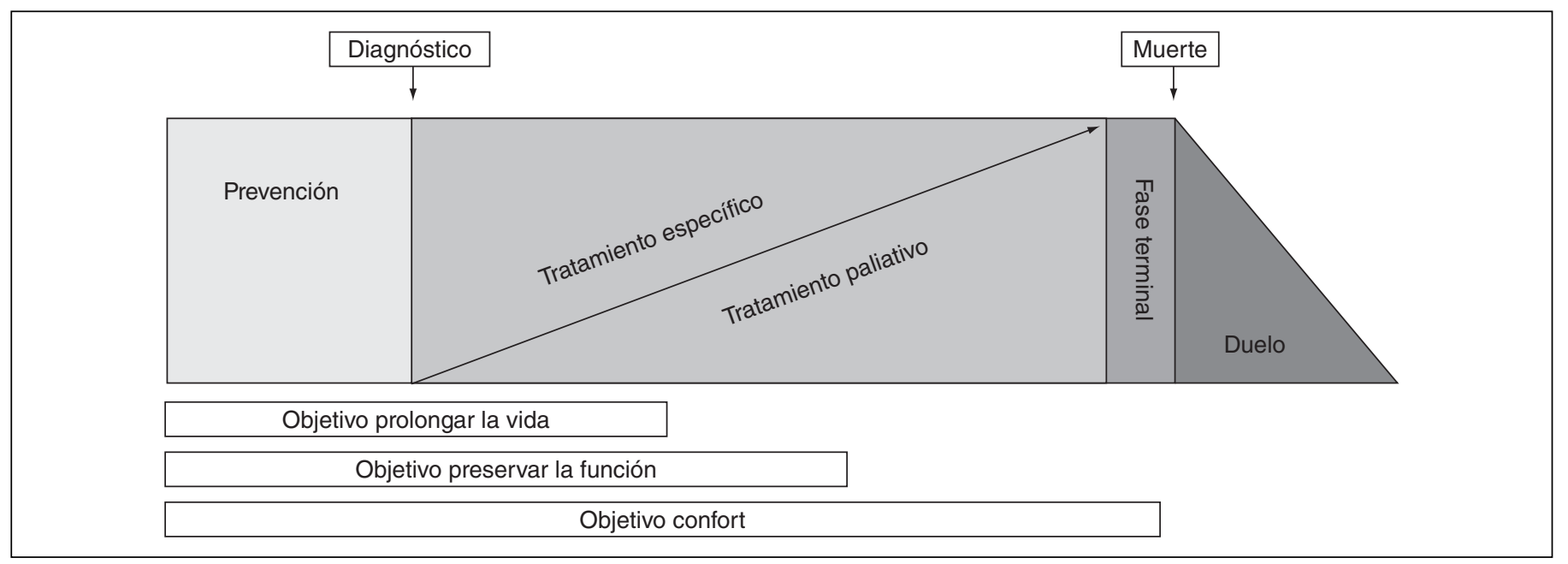

Figura 22 Tratamiento paliativo integrado de los pacientes con EPOC y sus familias. 


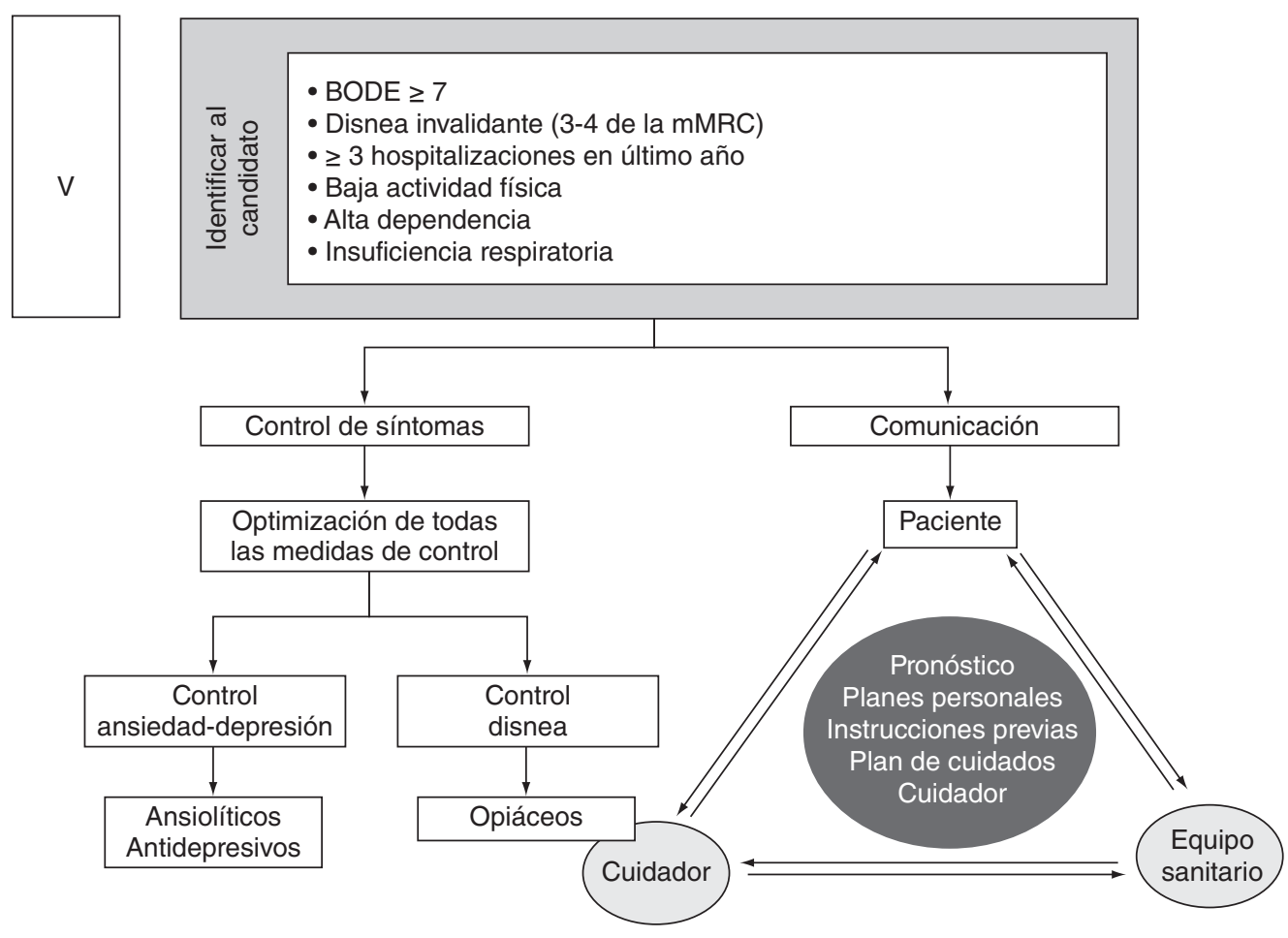

Figura 23 Actitud frente al paciente con EPOC al final de la vida. Nivel de gravedad V.

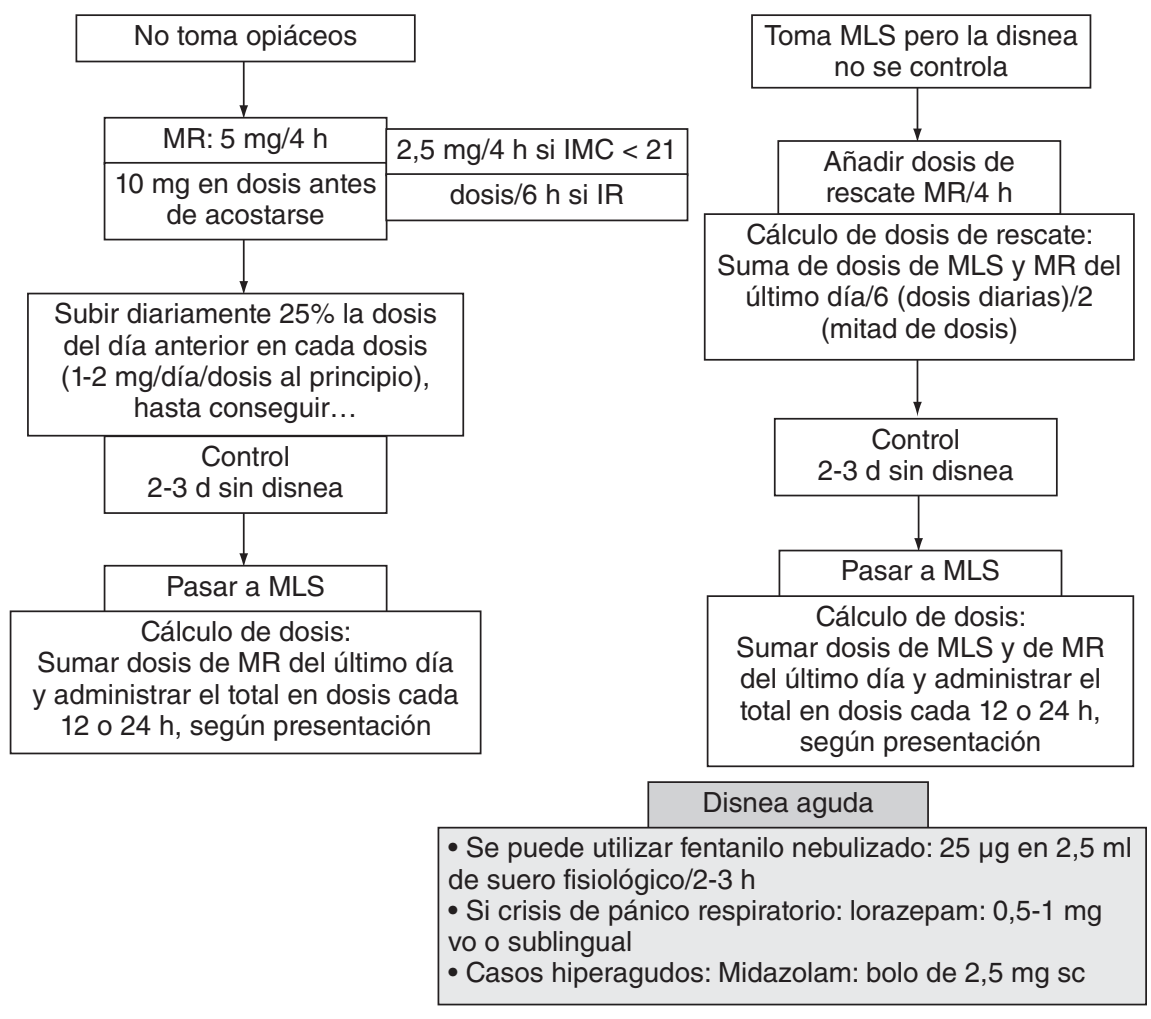

\begin{tabular}{l}
\hline \multicolumn{1}{|c|}{ Necesidad de vía SC } \\
- Vía sc si los pacientes no \\
pueden tomar morfina vo \\
- Relación de equivalencia \\
morfina vo-morfina sc: $3: 1$ \\
(30 mg vo = 10 mg sc) \\
- Si necesidad de morfina \\
parenteral continua: infusión sc \\
- Si disnea muy aguda: vía \\
parenteral (2,5 mg iv/15 minutos \\
o 5 mg sc/20 minutos, hasta que \\
ceda el episodio) \\
- No utilizar vías sublingual y \\
nebulizada para administración de \\
morfina \\
- El fentanilo en parches puede \\
ser útil en el tratamiento de la \\
disnea del paciente terminal
\end{tabular}

Precauciones con la morfina Náuseas y vómitos: estar atentos y tratar precozmente si aparecen Estreñimiento: utilizar tratamiento preventivo desde el comienzo

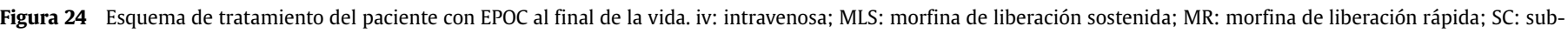
cutánea. 
Tabla 36

Recomendaciones de tratamiento al final de vida

\begin{tabular}{|c|c|c|c|c|}
\hline & NR & Recomendación & Calidad de la evidencia & Fuerza de la recomendación \\
\hline \multirow[t]{3}{*}{ Ansiedad-depresión } & R046 & $\begin{array}{l}\text { La ansiedad y la depresión en pacientes con EPOC deben ser tratadas } \\
\text { de manera habitual, si bien hay que tener en cuenta la edad de los } \\
\text { pacientes, efectos adversos de los fármacos e interacciones } \\
\text { farmacológicas, sobre todo en pacientes polimedicados }\end{array}$ & Muy baja ${ }^{a}$ & Buena práctica clínica ${ }^{a}$ \\
\hline & R047 & $\begin{array}{l}\text { En pacientes con EPOC con síntomas de ansiedad y/o depresión y con } \\
\text { escasa predisposición a seguir un tratamiento farmacológico, se } \\
\text { sugiere ofrecer tratamiento psicológico basado en principios de la } \\
\text { terapia cognitivo-conductual }\end{array}$ & Muy baja ${ }^{a}$ & Débil a favor ${ }^{\mathrm{a}}$ \\
\hline & R048 & $\begin{array}{l}\text { En pacientes con EPOC y síntomas de ansiedad y/o depresión } \\
\text { subsidiarios de rehabilitación respiratoria se sugiere un programa } \\
\text { multidisciplinar de rehabilitación respiratoria }\end{array}$ & Muy baja ${ }^{\mathrm{a}}$ & Débil a favor ${ }^{\mathrm{a}}$ \\
\hline
\end{tabular}

NR: numeración de las recomendaciones.

aGuía UETS-Laín Entralgo.

cuya aparición hay que estar alerta para atajarlos antes de que puedan empeorar el estado del paciente; y el estreñimiento, que hay que tratar con laxantes desde el primer momento de iniciar el uso de los opioides. Para los detalles sobre las medidas para combatir estos efectos secundarios dirigimos al lector a una guía de cuidados paliativos de referencia. Las benzodiacepinas no tienen un papel relevante en el tratamiento de la disnea de estos pacientes, como tampoco la morfina inhalada ${ }^{337}$.

Hay pocos estudios sobre el tratamiento farmacológico de la ansiedad y la depresión en los pacientes con EPOC y, en general, se han realizado con pocos pacientes y con un corto seguimiento. Tanto la nortriptilina como los fármacos inhibidores de la recaptación de serotonina (sertralina, paroxetina) son eficaces en el tratamiento de la ansiedad y la depresión, y seguros en estos pacientes, así como la rehabilitación y las terapias psicológicas. Por otra parte, no hay evidencia de que los pacientes con EPOC respondan de forma diferente a estos fármacos que el resto de la población ${ }^{338}$.

Las intervenciones en estos pacientes deben ser de carácter educativo y preventivo, incluidos aspectos dirigidos a la propia salud del cuidador, así como al paciente: movilización, higiene, nutrición, medicación, orientación en actividades de la vida diaria y autoestima. Para ello será imprescindible el uso de un lenguaje adaptado a sus conocimientos, revisiones y refuerzos positivos del aprendizaje, mantener una buena comunicación y apoyo emocional para asegurar la confianza mutua, la seguridad y la información que necesitan para ayudarse a sí mismo y ser ayudados. Esto facilita la coordinación entre el paciente, la familia y el equipo sanitario. Los cuidados deberán extenderse durante la fase de duelo en el proceso de adaptación a la pérdida ${ }^{339-341}$.

Las terapias complementarias como los masajes, la relajación u otras terapias no convencionales pueden desempeñar un papel importante en el alivio de síntomas, ayudando a calmar los efectos secundarios, el dolor y la ansiedad. En un estudio realizado en un grupo de pacientes con EPOC se utilizaron técnicas respiratorias tradicionales del yoga, con resultados positivos en la encuesta de satisfacción de los individuos, destacando que habían conseguido mejorar el ánimo, una mayor independencia para las actividades de la vida diaria, una mejora de las relaciones sociales, mejor expectoración, respiración nasal y mejoría de las constantes vitales ${ }^{342}$. Una revisión Cochrane reciente concluye que algunas de estas aproximaciones no farmacológicas son efectivas en el tratamiento de la disnea $^{331}$.

Los médicos y personal de enfermería que atienden a estos pacientes deberían estar familiarizados con los cuidados paliativos; si no lo están o la atención es compleja, debería contactarse con un equipo de soporte de cuidados paliativos.
Recomendación: ¿Qué tratamientos son los más adecuados para tratar la ansiedad y la depresión en los pacientes con EPOC? (anexo 2).

\begin{tabular}{|l|l|}
\hline $\begin{array}{l}\text { Buena } \\
\text { práctica } \\
\text { clínica }\end{array}$ & $\begin{array}{l}\text { La ansiedad y la depresión en pacientes con EPOC de- } \\
\text { ben tratarse de la manera habitual, si bien hay que te- } \\
\text { ner en cuenta la edad de los pacientes, los efectos } \\
\text { adversos de los fármacos y las interacciones farmaco- } \\
\text { lógicas, sobre todo en pacientes polimedicados }\end{array}$ \\
\hline Débil & $\begin{array}{l}\text { En pacientes con EPOC con síntomas de ansiedad y/o } \\
\text { depresión y con escasa predisposición a seguir un tra- } \\
\text { tamiento farmacológico, se sugiere ofrecer tratamiento } \\
\text { psicológico basado en principios de la terapia cogniti- } \\
\text { vo-conductual }\end{array}$ \\
\hline Débil & $\begin{array}{l}\text { En pacientes con EPOC y síntomas de ansiedad y/o de- } \\
\text { presión subsidiarios de rehabilitación respiratoria se } \\
\text { sugiere seguir un programa multidisciplinar de rehabi- } \\
\text { litación respiratoria }\end{array}$ \\
\hline
\end{tabular}

\section{Recomendaciones de tratamiento al final de vida}

Se resumen en la tabla 36 .

\section{Información al paciente y familiares del paciente}

El valor público de una institución (o de un producto creado por una institución) aumenta a medida que se adapta a las preferencias "refinadas" de los ciudadanos ${ }^{343}$. En el marco de GesEPOC se ha incorporado la visión de los pacientes a través de dos acciones:

1. Encuesta realizada a 104 pacientes de 9 hospitales, diagnosticados de EPOC.

2. Los resultados más relevantes de la encuesta son los siguientes:

- El 11\% de los pacientes manifiesta que la información recibida ha sido nula en el momento del diagnóstico.

- El 29\% indica que debería mejorarse la coordinación entre médicos.

- El 30\% tiene contacto con más de 4 profesionales.

- El cuidador suele ser la esposa.

- Poco papel del neumólogo en la agudización.

- El 27\% de los pacientes estarían dispuestos a tomar decisiones por ellos mismos en el curso de la agudización (previo consejo médico).

- El ingreso hospitalario es una de las situaciones que más temen los pacientes. 
Tabla 37

Puntos clave resultantes del debate estructurado con pacientes EPOC

\begin{tabular}{|c|c|}
\hline Información & $\begin{array}{l}\text { Especialmente al inicio de la enfermedad } \\
\text { Explicar la relación causal con el consumo de tabaco } \\
\text { Necesidad de recibir información escrita, sencilla y práctica } \\
\text { Información a lo largo de la evolución de la enfermedad, especialmente en las fases avanzadas }\end{array}$ \\
\hline Educación para la salud (autocuidado) & $\begin{array}{l}\text { Importancia de los programas de educación terapéutica } \\
\text { Buena valoración de las actividades grupales } \\
\text { Implicar al paciente en su propio cuidado (planes de acción) } \\
\text { Importancia del ejercicio físico y de la rehabilitación }\end{array}$ \\
\hline Deshabituación tabáquica & $\begin{array}{l}\text { Las unidades de deshabituación no son la única solución } \\
\text { Los pacientes requieren tratamientos personalizados }\end{array}$ \\
\hline Calidad asistencial & $\begin{array}{l}\text { Simplificar los procedimientos administrativos } \\
\text { Garantizar la continuidad de cuidados y la coordinación de los distintos dispositivos asistenciales } \\
\text { Valoración muy positiva del profesional responsable de la "gestión de casos" } \\
\text { Agilizar las remisiones cuando sean precisas } \\
\text { Promover la atención de proximidad siempre que sea posible }\end{array}$ \\
\hline Agudizaciones & $\begin{array}{l}\text { La agudización es uno de los problemas que más preocupa al paciente } \\
\text { La existencia de un profesional de referencia podría ejercer un papel muy importante en el tratamiento de las agudizaciones } \\
\text { Mecanismos para anticipar las agudizaciones y actuar de forma temprana }\end{array}$ \\
\hline Apoyo personal y social & $\begin{array}{l}\text { Se reconoce la importancia de garantizar el soporte al cuidador (incluido el acceso a recursos económicos) } \\
\text { Acceso de los profesionales sanitarios a la información sobre apoyo personal y social para poder difundirla } \\
\text { El apoyo psicológico debe considerarse tanto para el paciente como para el cuidador } \\
\text { Poca presencia práctica de las organizaciones de pacientes (debería aumentar el papel de estas organizaciones) }\end{array}$ \\
\hline
\end{tabular}

Los puntos clave del debate estructurado del grupo de pacientes se resumen en la tabla 37.

Estrategias para incorporar las perspectivas de los pacientes y para mejorar sus competencias y habilidades en salud

La capacidad del paciente y de sus cuidadores para comprender las manifestaciones clínicas de su enfermedad y actuar de la mejor manera posible es muy importante. Las carencias en este campo tienen un impacto negativo para el paciente en los resultados en salud ${ }^{344,345}$.

El concepto anglosajón de Health Literacy, que en nuestro medio podría traducirse por "competencias y habilidades en salud" (CHS), se refiere a la capacidad del paciente para obtener, procesar y comprender la información sanitaria básica que le permita tomar decisiones $^{346}$. Las CHS requieren conocimientos sobre los problemas de salud, habilidad para usar adecuadamente los dispositivos asistenciales, competencias intelectuales e iniciativa ${ }^{347}$. A veces puede resultar difícil identificar a los pacientes con déficit en las $\mathrm{CHS}^{348}$, especialmente en los casos en los que el nivel de expresión oral parece suficiente pero tienen problemas para comprender la información escrita $^{349}$. A la mayoría de pacientes les cuesta aceptar que no saben leer. Además, puede detectarse déficit en las CHS a pesar de tener estudios superiores.

\section{Identificación de las competencias y habilidades en salud}

Las CHS son las que permiten al paciente "navegar" adecuadamente por el sistema sanitario con el fin de resolver sus necesidades de salud. En los pacientes con EPOC se dan diversos elementos que contribuyen a los déficits en las CHS (p. ej., persistencia del hábito tabáquico, bajo nivel socioeconómico o depresión) y que conducen a un incumplimiento terapéutico que se sitúa por encima del $50 \%{ }^{350}$. Hay pocos instrumentos para valorar el grado de $\mathrm{CHS}^{351}$ y es preciso estar atentos a algunas pistas que pueden ayudar a identificar los pacientes con déficit de $\mathrm{CHS}^{352,353}$ :

- Dificultades para orientarse en el hospital.

- Dificultades para leer:

- Suele leer las instrucciones el acompañante.

- Excusas para no leer ("se han dejado las gafas").
- Dificultades para rellenar formularios o para concertar visitas.

- Dificultades para la comprensión oral:

- Dificultades para comprender las lenguas habituales en una sociedad.

- Problemas auditivos.

- Seguimiento de instrucciones:

- Escasa adhesión a los tratamientos.

- Dificultades para seguir instrucciones sobre hábitos personales o dietéticos.

- Dificultades para prepararse ante una prueba o procedimiento.

- Olvido de visitas.

- Posponer decisiones (especialmente cuando hay que leer).

- Conductas miméticas.

No hay un modelo estandarizado de atención a largo plazo a los pacientes con EPOC, pero parece claro que la combinación de diversas intervenciones mejora los resultados asistenciales ${ }^{354}$.

\section{Programas de autocuidados para pacientes}

La promoción del autocuidado no debe ser un sinónimo de educación ${ }^{355}$. La promoción del autocuidado debe tener en cuenta dos aspectos clave: la educación para la salud (en el sentido de proporcionar al paciente información inteligible para mejorar las $\mathrm{CHS}$ ) y colaboración con el paciente en la toma de decisiones. Bodenheimer et al ${ }^{356}$ indican que la propuesta de objetivos y la entrevista motivacional son herramientas que ayudan a promover el autocuidado.

La promoción del autocuidado puede desarrollarse en diversos ámbitos y en condiciones muy distintas.

\section{Papel activo de los profesionales sanitarios en la consulta}

La consulta es un momento idóneo para promover las CHS, pero es preciso mejorar las habilidades comunicativas de los profesionales ${ }^{357}$ para dar tiempo al paciente para exponer su situación ${ }^{358}$ y facilitar la toma de decisiones compartidas ${ }^{359}$. También los programas multidisciplinarios de rehabilitación respiratoria permiten promover las CHS de una manera progresiva y comprensible para el paciente. 
En la consulta es útil servirse de algunas herramientas.

- Materiales gráficos.

- Soporte audiovisual.

- Evitar la jerga técnica (pero usando un lenguaje correcto y riguroso).

- Información escrita personalizada para el paciente, con mensajes clave.

- Información escrita para los otros profesionales sanitarios que atienden al paciente.

- Contactos (teléfono, SMS, correo electrónico) entre visitas.

\section{Programa formativo en el domicilio}

Bourbeau et $\mathrm{al}^{360}$ et al demuestran los beneficios (reduce un $39,8 \%$ los ingresos por exacerbación y un $57,1 \%$ las visitas a urgencias) de un programa formativo global para promover el autocuidado de los pacientes con EPOC, que se desarrollaba en el domicilio del paciente, mediante una visita semanal de un profesional sanitario durante 2 meses. Cada visita tenía unos objetivos formativos y de consecución de habilidades y conocimientos bien estructurados.

\section{Visitas grupales}

Hay pocas experiencias sobre el papel de las visitas grupales en pacientes con EPOC. De Vries et al $^{361}$ proponen un esquema de visitas grupales (6 pacientes con EPOC muy motivados) que se desarrollan mensualmente durante 3 meses y, posteriormente, cada 3 meses durante 3 años. Las visitas duran 90 minutos y en los últimos 15 minutos discuten conjuntamente los planes de acción de cada paciente. A pesar de los beneficios potenciales de las visitas grupales, se requieren más estudios para comprobar la viabilidad de esta estrategia y la reproductibilidad de los modelos ${ }^{362}$.

\section{Plan de acción}

Uno de los elementos clave es facilitar herramientas al paciente para hacer frente a la exacerbación de una manera lo más temprana posible, que incluyen la identificación y el tratamiento. El plan de acción identifica síntomas y manifestaciones clínicas que indican que el propio paciente realice cambios terapéuticos. El plan de acción se refiere a modificaciones en el uso del oxígeno, el inicio de antibióticos, el incremento de la dosis de broncodilatadores o el uso de corticoides. En el plan de acción se establecen los signos de alarma y las acciones y contactos que se realizarán.

La adhesión a los planes de acción reduce el tiempo de recuperación en una exacerbación ${ }^{363}$

Papel activo (individual) de los pacientes: kit de la visita médica

La Universidad de los pacientes ha diseñado un "kit de la visita médica" ${ }^{364}$, que es una herramienta que proporciona consejos y recordatorios muy simples para ayudar al paciente a organizar mejor su visita al médico.

\section{Papel activo (colectivo) de los pacientes: paciente experto}

La mejora de las CHS debe entenderse en el marco de un nuevo rol del paciente que puede resumirse en el apoderamiento o empowerment ${ }^{365}$, es decir, en el papel activo del paciente en un marco nuevo de relaciones entre pacientes y profesionales sanitarios.

En este contexto surgen las experiencias que genéricamente se conocen como "paciente experto" ${ }^{366}$ (http://www.dh.gov.uk/prod_consum_dh/groups/dh_digitalassets/@dh/@en/documents/digitalasset/ dh_4018578.pdf. Acceso 8 de mayo de 2011). La intervención del "paciente experto" se desarrolla en grupos de 8-12 pacientes, en 9 sesiones de 90 minutos que se desarrollan a lo largo de 10 semanas $^{367}$. Es crucial la selección del paciente que debe actuar como "paciente experto". En definitiva, los pacientes aprenden unos de otros la mejor manera de resolver problemas ${ }^{368}$.

\section{Uso de tecnologías de apoyo}

El uso de tecnologías de la información y de la comunicación (TIC) puede desempeñar un papel importante en la mejora de las CHS. El objetivo de las TIC no es sustituir los contactos cara a cara, sino complementarlos de manera que, aunque se reduzca el número de visitas (convencionales), aumente el número total de contactos (visitas convencionales + interacciones tecnológicas).

Lorig et al ${ }^{369}$ muestran los beneficios de los programas de autocuidado basados en internet y Martí et al ${ }^{370}$ exponen los resultados de un centro de llamadas para enfermos crónicos, enfocado a mejorar el autocuidado. El uso del teléfono móvil es útil para dar soporte a los pacientes incluidos en un programa de rehabilitación pulmonar ${ }^{371}$. En definitiva, los servicios para pacientes que ofrecen las TIC pueden agruparse en ${ }^{372}$ : acceso directo a profesionales, monitorización (de signos vitales o síntomas), visita virtual o acceso a material educativo.

\section{Redes sociales}

Las nuevas tecnologías permiten la creación de redes sociales amplias que pueden ofrecer a los pacientes múltiples herramientas para comunicarse entre ellos ${ }^{373}$. La capacidad del propio paciente para generar información útil a otros pacientes es un elemento que no debe minusvalorarse ${ }^{374}$.

\section{Agradecimientos}

GesEPOC cuenta como socios estratégicos con Almirall, AstraZeneca, Boehringer Ingelheim-Pfizer, Faes Farma, Grupo Ferrer, GlaxoSmithKline, Novartis y Takeda-Nycomed. Como colaboradores, con Chiesi, Esteve Teijin y Grupo Uriach Pharma. Los patrocinadores no han influido en ninguna etapa de su elaboración.

\section{Bibliografía}

1. Miravitlles M, Calle M, Soler-Cataluña JJ. Clinical phenotypes of COPD. Identification, definition and implications for guidelines. Arch Bronconeumol. 2012;48:86-98

2. Soriano JB, Zielinski J, Price D. Screening for and early detection of chronic obstructive pulmonary disease. Lancet. 2009;374:721-32.

3. Estrategia en EPOC del Sistema Nacional de Salud. Plan de Calidad para el Sistema Nacional de Salud. Madrid: Ministerio de Sanidad y Política Social; 2009.

4. Global Strategy for the Diagnosis, Management and Prevention of COPD, Global Initiative for Chronic Obstructive Lung Disease (GOLD) 2011. Disponible en: http://www.goldcopd.org.

5. Peces-Barba G, Barberà JA, Agustí A, Casanova C, Casas A, Izquierdo JL, et al. Guía clínica de diagnóstico y tratamiento de la enfermedad pulmonar obstructiva crónica. Sociedad Española de Neumología y Cirugía Torácica (SEPAR) y Asociación Latinoamericana del Tórax (ALAT). Arch Bronconeumol. 2008;44:271-81.

6. Grupo de trabajo de la guía de práctica clínica sobre atención integral al paciente con enfermedad pulmonar obstructiva crónica (EPOC). Sociedad Española de Neumología y Cirugía Torácica (SEPAR) y Sociedad Española de Medicina de Familia (semFYC); 2010.

7. Han MK, Agustí A, Calverley PM, Celli BR, Criner G, Curtis JL, et al. Chronic obstructive pulmonary disease phenotypes. The future of COPD. Am J Respir Crit Care Med. 2010;182:598-604.

8. Miravitlles M. Tratamiento individualizado de la EPOC: una propuesta de cambio. Arch Bronconeumol. 2009;45 Supl 5:27-34.

9. Grupo de trabajo GESEPOC. Hacia un nuevo enfoque en el tratamiento de la EPOC. La Guía Española de la EPOC (GESEPOC). Arch Bronconeumol. 2011:47:379-81.

10. Anderson D, MacNee W. Targeted treatment in COPD: a multi-system approach for a multi-system disease. Int J Chron Obst Pulm Dis. 2009;4:321-35.

11. Manual Metodológico para la elaboración de guías de práctica clínica del Sistema Nacional de Salud. Madrid: Ministerio de Sanidad y Consumo; 2007. Disponible en: http//www.guiasalud.es/emanuales/elaboracion/documentos/Manual\%20 metodologico\%20\%20Elaboracion\%20GPC\%20en\%20el\%20SNS.pdf.

12. Guyatt G, Oxman AD, Akl EA, Kunz R, Vist G, Brozek J, et al. GRADE guidelines: 1. Introduction-GRADE evidence profiles and summary of findings tables. J Clin Epidemiol. 2011;64:383-94

13. Marzo Castillejo M, Montaño Barrientos A. El sistema GRADE para la toma de decisiones clínicas y la elaboración de recomendaciones y guías de práctica clínica. Aten Primaria. 2007;39:457-60.

14. Guyatt GH, Oxman AD, Kunz R, Woodcock J, Brozek J, Helfand M, et al. GRADE guidelines: 8. Rating the quality of evidenced indirectness. J Clin Epidemiol. 2011;64:1303-10 
15. Bousquet J, Kiley J, Bateman ED, Viegi G, Cruz AA, Khaltaev N, et al. Prioritised research agenda for prevention and control of chronic respiratory diseases. Eur Respir J. 2010;36:995-1001.

16. Buist AS, McBurnie MA, Vollmer WM, Gillespie S, Burney P, Mannino DM, et al. International variation in the prevalence of COPD (the BOLD study): a populationbased prevalence study. Lancet. 2007;370:741-50.

17. Halbert RJ, Natoli JL, Gano A, Badamgarav E, Buist AS, Mannino DM. Global burden of COPD: systematic review and meta-analysis. Eur Respir J. 2006;28:52332.

18. Atsou K, Chouaid C, Hejblum G. Variability of the chronic obstructive pulmonary disease key epidemiological data in Europe: systematic review. BMC Med. 2011;9:7.

19. Sobradillo-Peña VS, Miravitlles M, Gabriel R, Jiménez- Ruiz CA, Villasante C, Masa JF, et al. Geographic variations in prevalence and underdiagnosis of COPD: results of the IBERPOC multicentre epidemiological study. Chest. 2000;118:981-9.

20. Miravitlles M, Ferrer M, Pont A, Viejo JL, Masa JF, Gabriel R, et al. Characteristics of a population of COPD patients identified from a population-based study. Focus on previous diagnosis and never smokers. Respir Med. 2005;99:985-95.

21. Miravitlles M, Soriano JB, García-Río F, Muñoz L, Duran-Taulería E, Sánchez G, et al. Prevalence of COPD in Spain: Impact of undiagnosed COPD on quality of life and daily life activities. Thorax. 2009;64:863-8.

22. Soriano JB, Ancochea J, Miravitlles M, García-Río F, Duran E, Muñoz L, et al. Recent trends in COPD prevalence in Spain: a repeated cross-sectional survey 19972007. Eur Respir J. 2010;36:758-65.

23. WHO. World health statistics 2008. Disponible en: http://www.who.int/whosis/ whostat/EN_WHS08_Full.pdf. 2010.

24. Regidor E, Gutiérrez-Fisac JL, Alfaro M. Patrón de mortalidad en España, 2008 Madrid: Ministerio de Sanidad, Política Social e Igualdad, 2011. Disponible en: http://www.msc.es/ca/estadEstudios/estadisticas/estadisticas/estMinisterio/ mortalidad/docs/Patrones_de_Mortalidad_en_Espana_2008.pdf

25. Raziel: Mortalidad por todas las causas. Área de Análisis Epidemiológico y Situación de Salud. Disponible en: http://193.146.50.130/raziel.php.

26. Registro de Altas de los Hospitales Generales del Sistema Nacional de Salud. Disponible en: http://www.msc.es/estadEstudios/estadisticas/cmbd.htm.

27. Ministerio de Sanidad y Política Social. Plan de Calidad para el Sistema Nacional de Salud. Estrategia en EPOC del Sistema Nacional de Salud. Sanidad 2009. Ministerio de Sanidad y Política Social. Disponible en: http://www.msc.es organizacion/sns/planCalidadSNS/docs/EstrategiaEPOCSNS.pdf.

28. Miravitlles M, Murio C, Guerrero T, Gisbert R, on behalf of the DAFNE study group. Costs of chronic bronchitis and COPD. A one year follow-up study. Chest. 2003;123:784-91.

29. Soler-Cataluña JJ, Calle M, Cosio BG, Marín JM, Monso E, Alfageme I. Estándares de calidad asistencial en la EPOC. Arch Bronconeumol. 2009;45:361-2.

30. Celli BR, MacNee W; ATS/ ERS Task Force. Standards for the diagnosis and treatment of patients with COPD: a summary of the ATS/ERS position paper. Eur Respir J. 2004;23:932-46.

31. Celli BR, Thomas NE, Anderson JA, Ferguson GT, Jenkins CR, Jones PW, et al. Effect of pharmacotherapy on rate of decline of lung function in chronic obstructive pulmonary disease. Am J Respir Crit Care Med. 2008;178:332-8.

32. Patel BD, Coxson HO, Pillai SG, Agustí AGN, Calverley PMA, Donner CF, et al Airway wall thickening and emphysema show independente familial aggregation in chronic obstructive pulmonary disease. Am J Respir Crit Care Med. 2008; 178:500-5.

33. Martínez-García F, Soler-Cataluña JJ, Donat Y, Catalán P, Agramunt M, Ballestin V, et al. Factors associated with bronchiectasis in chronic obstructive pulmonary disease patients. Chest. 2011:140:1130-7.

34. Garcia-Aymerich J, Gómez FP, Benet M, Farrero E, Basagaña X, Gayete A, et al Identification and prospective validation of clinically relevant chronic obstructive pulmonary disease (COPD) phenotypes. Thorax. 2011;66:430-7.

35. Vidal R, Blanco I, Casas F, Jardí R, Miravitlles M y Comité del Registro Nacional de Pacientes con Déficit de Alfa-1-antitripsina. Normativa SEPAR: Diagnóstico y tratamiento del déficit de alfa-1-antitripsina. Arch Bronconeumol. 2006;42:64559.

36. Hurst JR, Vestbo J, Anzeto A, Locantore N, Müllerova H, Tal-Singer R, et al. Susceptibility to exacerbation in chronic obstructive pulmonary disease. N Engl Med. 2010;363:1128-38.

37. Soler Cataluña JJ, Martínez García MA, Catalán Serra P. The frequent exacerbator. A new phenotype in COPD? Hot Topics Respir Med. 2011; 6: 7-12.

38. Quint JK, Donaldson GC, Hurst JR, Goldring JJP, Seemungal TR, Wedzicha JA Predictive accuracy of patient-reported exacerbation frequency in COPD. Eu Respir J. 2011;37:501-7.

39. Bafadhel M, McKenna S, Terry S, Mistry V, Reid C, Haldar P, et al. Acute exacerbations of chronic obstructive pulmonary disease. Identification of biologic clusters and their biomarkers. Am J Respir Crit Care Med. 2011;184;662-71.

40. Gibson PG, Simpson JL. The overlap syndrome of asthma and COPD: what are its features and how important is it? Thorax. 2009:64:728-35.

41. Contoli M, Baraldo S, Marku B, Casolari P, Marwick JA, Turato G, et al. Fixed airflow obstruction due to asthma or chronic obstructive pulmonary disease: a 5-year follow-up. J Allergy Cin Immunol. 2010;125:830-7.

42. Boulet LP, Lemiere C, Archambault F, et al. Smoking and asthma: clinical and radiological features, lung function, and airway inflammation. Chest. 2006;129:661-8.

43. O'Donnell DE, Aaron S, Bourbeau J, Hernandez P, Marciniuk DD, Balter M, et al Canadian Thoracic Society recommendations for management of chronic obstructive pulmonary disease: 2007 update. Can Respir J. 2007;14 Suppl B:5B32B.
44. Nagai A, Aizawa H, Aoshiba K, Asano K, Hirata K, Ichinose M, et al. Guidelines for the diagnosis and treatment of COPD. 3rd ed. The Japanese Respiratory Society. Tokyo (Japan) Medical Review Co. Ltd.; 2009.

45. De Marco R, Accordini S, Cerveri I, Corsico A, Antó JM, Künzli N, et al. Incidence of chronic obstructive pulmonary disease in a cohort of young adults according to the presence of chronic cough and phlegm. Am J Respir Crit Care Med. 2007; $175: 32-9$

46. Miravitlles M. The overlap síndrome between asthma and COPD: implications for management. Hot Topics Respir Med. 2011;16:15-20.

47. Hardin M, Silverman EK, Barr RG, Hansel NH, Schroeder JD, Make BJ. The clinical features of the overlap between COPD and asthma. Respir Res. 2011:12:127.

48. Soriano JB, Davis KJ, Coleman B, Visick G, Mannino D, Pride NB. The proportional Venn diagram of obstructive lung disease. Chest. 2003;124:474-81.

49. American Thoracic Society. Chronic bronchitis, asthma, and pulmonary emphysema, a statement by the Committee on Diagnostic Standards for Nontuberculous Respiratory Diseases. Am Rev Respir Dis. 1962;85:762-8.

50. Prescott E, Lange P, Vestbo J. Chronic mucus hypersecretion in COPD and death from pulmonary infection. Eur Respir J. 1995;8:1333-8.

51. Miravitlles M. Cough and sputum production as risk factors for poor outcomes in patients with COPD. Respir Med. 2011;105:1118-28.

52. Montes de Oca M, Halbert RJ, López MV, Pérez-Padilla R, Tálamo C, Moreno D, et al. Chronic bronchitis phenotype in subjects with and without COPD: the PLATINO study. Eur Respir J. 2012 (on line).

53. Kim V, Han MK, Vance GB, Make BJ, Newel JD, Hokanson JE, et al. The chronic bronchitic phenotype of COPD. An analysis of the COPDGene study. Chest. 2011;140:626-33.

54. Patel IS, Vlahos I, Wilkinson TMA, Lloyd-Owen SJ, Donaldson GC, Wilks M, et al. Bronchiectasis, exacerbation índices, and inflammation in chronic obstructive pulmonary disease. Am J Respir Crit Care Med. 2004;170:400-7.

55. Casanova C, Cote C, De Torres JP, Aguirre-Jaime A, Marín JM, Pinto-Plata V, et al. Inspiratory-to-total lung capacity ratio predicts mortality in patients with chronic obstructive pulmonary disease. Am J Respir Crit Care Med. 2005;171:591-7.

56. Grydeland TB, Thorsen E, Dirksen A, Jensen R, Coxson HO, Pillai SG, et al. Quantitative CT measures of emphysema and airway wall thickness are related to D(L)CO. Respir Med. 2011;105:343-51.

57. Han MK, Kazerooni EA, Lynch DA, Liu LX, Murray S, Curtis JL, et al. Chronic obstructive pulmonary disease exacerbations in the COPDGene study: associated radiologic phenotypes. Radiology. 2011;261:274-82.

58. Nishimura M, Makita H, Nagai K, Konno S, Nasuhara Y, Hasegawa M, et al. Annual change in pulmonary function and clinical phenotype in chronic obstructive pulmonary disease. Am J Respir Crit Care Med. 2012;185:44-52.

59. Oswald NC, Medvei VC. Chronic bronchitis: the effect of cigarette-smoking. Lancet. 1955;269:843-44.

60. Anderson D, Ferris BG Jr. Role of tobacco smoking in the causation of chronic respiratory disease. N Engl J Med. 1962;267:787-94.

61. Fletcher C, Peto R. The natural history of chronic airflow obstruction. Br Med J. 1977; $1: 1645-48$

62. Kohansal R, Martinez-Camblor P, Agusti A, Buist AS, Mannino DM, Soriano JB. The natural history of chronic airflow obstruction revisited: an analysis of the Framingham off spring cohort. Am J Respir Crit Care Med. 2009;180:3-10.

63. Lokke A, Lange P, Scharling H, Fabricius P, Vestbo J. Developing COPD: a 25 year follows up study of the general population. Thorax. 2006;61:935-9.

64. Encuesta de salud de España. Disponible en: http:// www.msc.es.

65. Salvi SS, Barnes PJ. Chronic obstructive pulmonary disease in nonsmokers. Lancet. 2009;374:733-43.

66. Jaakkola MS, Jaakkola JJ. Effects of environmental tobacco smoke on the respiratory health of adults. Scand J Work Environ Health. 2002;28 Suppl 2:52-70.

67. Larsson ML, Loit HM, Meren M, Põlluste J, Magnusson A, Larsson K, et al. Passive smoking and respiratory symptoms in the FinEsS Study. Eur Respir J. 2003;21:672-6.

68. Yin P, Jiang CO, Cheng KK, Lam TH, Lam KH, Miller MR, et al. Passive smoking exposure and risk of COPD among adults in China: the Guangzhou Biobank Cohort Study. Lancet. 2007;370:751-7.

69. Ho SY, Lam TH, Chung SF, Lam TP. Cross-sectional and prospective associations between passive smoking and respiratory symptoms at the workplace. Ann Epidemiol. 2007:17:126-31.

70. González Barcala FJ, Takkouche B, Valdés L, Temes E, Leis R, Cabanas R, et al. Tabaquismo parental y función pulmonar en niños y adolescentes. Arch Bronconeumol. 2007:43:81-5.

71. Torres-Duque C, Maldonado D, Pérez-Padilla R, Ezzati M, Viegi G, Forum of International Respiratory Studies (FIRS) Task Force on Health Effects of Biomass. Exposure biomass fuels and respiratory diseases: a review of the evidence. Proc Am Thorac Soc. 2008;5:577.

72. Hu G, Zhou Y, Tian J, Yao W, Li J, Li B, et al. Risk of COPD from exposure to biomass smoke: a metaanalysis. Chest. 2010;138:20-31.

73. Kurmi OP, Semple S, Simkhada P, Smith WC, Ayres JG. COPD and chronic bronchitis risk of indoor air pollution from solid fuel: a systematic review and meta-analysis. Thorax. 2010;65:221-8.

74. Po JY, FitzGerald JM, Carlsten C. Respiratory disease associated with solid biomass fuel exposure in rural women and children: systematic review and meta-analysis. Thorax. 2011;66:232-9.

75. Orozco-Levi M, García-Aymerich J, Villar J, Ramírez-Sarmiento A, Antó JM, Gea J. Wood smoke exposure and risk of chronic obstructive pulmonary disease. Eur Respir J. 2006;27:542-6.

76. Eisner MD, Anthonisen N, Coultas D, Kuenzli N, Pérez-Padilla R, Postma D, et al; Committee on Nonsmoking COPD, Environmental and Occupational Health 
Assembly. An official American Thoracic Society public policy statement: novel risk factors and the global burden of chronic obstructive pulmonary disease. Am J Respir Crit Care Med. 2010;182:693-718.

77. Arbex MA, De Souza Conceição GM, Cendon SP, Arbex FF, Lopes AC, Moysés EP, et al. Urban air pollution and COPD-related emergency room visits. J Epidemiol Community Health. 2009;63:777-83.

78. Andersen ZJ, Hvidberg M, Jensen SS, Ketzel M, Loft S, Sørensen M, et al. Chronic obstructive pulmonary disease and long-term exposure to traffic-related air pollution: a cohort study. Am J Respir Crit Care Med. 2011;183:455-61.

79. EURAD [acceso 18 de mayo de 2011]. Disponible en: http://www.eurad.unikoeln.de/

80. Rushton L. Occupational causes of chronic obstructive pulmonary disease. Rev Environ Health. 2007;22:195-212.

81. Rodríguez E, Ferrer J, Martí S, Zock JP, Plana E, Morell F. Impact of occupational exposure on severity of COPD. Chest. 2008;134:1237-43.

82. Lam KB, Jiang CQ Jordan RE, Miller MR, Zhang WS, Cheng KK, et al. Smoking and airflow obstruction: a cross-sectional analysis of the Guangzhou Biobank Cohort Study. Chest. 2010;137:593-600.

83. Menezes AMB, Hallal PC, Perez-Padilla R, Jardim JRB, Muiño A, Lopez MV, et al. Tuberculosis and airflow obstruction: evidence from the PLATINO study in Latin America. Eur Respir J. 2006;30:1180-5.

84. Chronic obstructive pulmonary disease: risk factors and risk reduction [acceso julio 2009]. Disponible en: http://www.uptodate.com/online/

85. Kohnlein T, Welte T. Alpha-1 antitrypsin deficiency: pathogenesis, clinical presentation, diagnosis, and treatment. Am J Med. 2008;121:3-9.

86. Miravitlles M, Herr C, Ferrarotti I, Jardi R, Rodriguez-Frias F, Luisetti M, et al. Laboratory testing of individuals with severe AAT deficiency in three European centres. Eur Respir J. 2010;35:960-8.

87. Mannino DM, Buist AS. Global burden of COPD: risk factors, prevalence, and future trends. Lancet. 2007;370:765-73.

88. Roche N, Marthan R, Berger P, Chambellan A, Chanez P, Aguilaniu B, et al. Beyond corticosteroids: future prospects in the management of inflammation in COPD. Eur Respir Rev. 2011;20:175-82.

89. Yang IA, Relan V, Wright CM, Davidson MR, Sriram KB, Savarimuthu Francis SM, et al. Common pathogenic mechanisms and pathways in the development of COPD and lung cancer. Expert Opin Ther Targets. 2011;15:439-56.

90. Chatila WM, Thomashow BM, Minai OA, Criner GJ, Make BJ. Comorbidities in chronic obstructive pulmonary disease. Proc Am Thorac Soc. 2008;5:549-55.

91. Barnes P, Celli BR. Systemic manifestations and comorbidities in COPD. Eur Respir J. 2009:33:1165-85

92. Soriano JB, Sauleda J. Chapter 12. How the COPD patient should be assessed for co-morbidities. En: Rennard I, et al, eds. Clinical management of chronic obstructive lung disease. 2nd ed. Boston: Informa Healthcare; 2007.

93. Calverley PM, Anderson JA, Celli B, Ferguson GT, Jenkins C, Jones PW, et al Salmeterol and fluticasone propionate and survival in chronic obstructive pulmonary disease. N Engl J Med. 2007;356:775-89.

94. Soriano JB, Visick GT, Muellerova H, Payvandi N, Hansell AL.Patterns of comorbidities in newly diagnosed COPD and asthma in primary care. Chest. 2005;128:2099-107.

95. Mannino DM, Thorn D, Swensen A, Holguin F. prevalence and outcomes of diabetes, hypertension, and cardiovascular disease in chronic obstructive pulmonary disease. Eur Respir J. 2008;32:962-9.

96. Almagro P, López García F, Cabrera FJ, Montero L, Morchón D, Díez J, et al. Study of the comorbidities in hospitalized patients due to decompensated chronic obstructive pulmonary disease attended in the Internal Medicine Services. ECCO Study. Rev Clin Esp. 2010;210:101-8.

97. Finkelstein J, Cha E, Scharf SM. Chronic obstructive pulmonary disease as an independent risk factor for cardiovascular morbidity. Int J Chron Obstruct Pulmon Dis. 2009; 4:337-49.

98. Feary JR, Rodrigues LC, Smith CJ, Hubbard RB, Gibson JE. Prevalence of major comorbidities in subjects with COPD and incidence of myocardial infarction and stroke: a comprehensive analysis using data from primary care. Thorax. 2010;65:956-62.

99. Donaldson GC, Hurst JR, Smith CJ, Hubbard RB, Wedzicha JA. Increased risk of myocardial infarction and stroke following exacerbation of COPD. Chest. 2010;137:1091-7.

100. Rutten FH, Cramer MJ, Grobbee DE, Sachs AP, Kirkels JH, Lammers JW, et al. Unrecognized heart failure in elderly patients with stable chronic obstructive pulmonary disease. Eur Heart J. 2005;26:1887-94.

101. Render ML, Weinstein AS, Blaustein AS. Left ventricular dysfunction in deteriorating patients with chronic obstructive pulmonary disease. Chest. 1995;107:162-8.

102. Almagro P, Calbo E, Ochoa de Echagüen A, Barreiro B, Quintana S, Heredia JL, et al. Mortality after hospitalization for COPD. Chest. 2002;121:1441-8.

103. Barr RG, Bluemke DA, Ahmed FS, Carr JJ, Enright PL, Hoffman EA, et al. Percent emphysema, airflow obstruction, and impaired left ventricular filling. N Engl J Med. 2010;362:217-27.

104. Young RP, Hopkins RJ, Christmas T, Black PN, Metcalf P, Gamble GD. COPD prevalence is increased in lung cancer, independent of age, sex and smoking history. Eur Respir J. 2009;34:380-6.

105. Brenner DR, McLaughlin JR, Hung RJ. Previous lung diseases and lung cancer risk: a systematic review and meta-analysis. PLoS ONE. 2011;6:e17479.

106. Yohannes AM, Willgoss TG, Baldwin RC, Connolly MJ. Depression and anxiety in chronic heart failure and chronic obstructive pulmonary disease: prevalence, relevance, clinical implications and management principles. Int J Geriatr Psychiatry. 2010;25:1209-21.
107. Ng TP, Niti M, Tan WC, Cao Z, Ong KC, Eng P. Depressive symptoms and chronic obstructive pulmonary disease: effect on mortality, hospital readmission, symptom burden, functional status, and quality of life. Arch Intern Med. 2007; 167:60-7.

108. Mortensen EM, Copeland LA, Pugh MJ, Restrepo MI, De Molina RM, Nakashima B, et al. Impact of statins and ACE inhibitors on mortality after COPD exacerbations. Respir Res. 2009; 10:45.

109. Salpeter S, Ormiston T, Salpeter E. Betabloqueantes cardioselectivos para la enfermedad pulmonar obstructiva crónica (Revisión Cochrane traducida). La Biblioteca Cochrane Plus, 2008 Número 4

110. Short PM, Lipworth SI, Elder DH, Schembri S, Lipworth BJ. Effect of beta blockers in treatment of chronic obstructive pulmonary disease: a retrospective cohort study. Br Med J. 2011;10;342:d2549.

111. Decramer M, Celli B, Kesten S, Lystig T, Mehra S, Tashkin DP; UPLIFT investigators. Effect of tiotropium on outcomes in patients with moderate chronic obstructive pulmonary disease (UPLIFT): a prespecified subgroup analysis of a randomised controlled trial. Lancet. 2009;374:1171-8.

112. Jenkins CR, Jones PW, Calverley PM, et al. Efficacy of salmeterol/ fluticasone propionate by GOLD stage of chronic obstructive pulmonary disease: analysis from the randomised, placebo-controlled TORCH study. Respir Res. 2009;10:59.

113. Donaldson GC, Seemugal TAR, Bhowmik A, Wedzicha JA. Relationship between exacerbation frequency and lung function decline in chronic obstructive pulmonary disease. Thorax. 2002;57:847-52.

114. Vestbo J, Edwards ED, Scanlon PD, Yates JC, Agustí A, Bakke P, et al. Changes in forced expiratory volume in 1 second over time in COPD. $\mathrm{N}$ Engl J Med. 2011;365:1184-92.

115. Rennard SI, Stolel JK, Wilson KC. Chronic obstructive pulmonary disease: Definition, clinical manifestations, diagnosis, and staging. Uptodate v16.1 [accedido Abr 2011. Disponible en: http://www.uptodate.com/online/.

116. Sanchís Aldás J, Casan Clarà P, Castillo Gómez J, Honzález Mangado N, Palenciano Ballesteros L, Roca Torrent J. Normativa para la práctica de la espirometría forzada. Arch Bronconeumol. 1989;25:132-42.

117. Monteagudo M, Rodriguez-Blanco T, Parcet J, Peñalver N, Rubio C, Ferrer M, et al Variabilidad en la realización de la espirometría y sus consecuencias en el tratamiento de la EPOC en Atención Primaria. Arch Bronconeumol. 2011;47:22633.

118. Naberan K, De la Roza C, Lamban M, Gobartt E, Martín A, Miravitlles M. Use of spirometry in the diagnosis and treatment of chronic obstructive pulmonary disease in Primary Care. Arch Bronconeumol. 2006;42:638-44.

119. Hardie JA, Buist AS, Vollmer WM, Ellingsen I, Bakke PS, Morkve O. Risk of overdiagnosis of COPD in asymptomatic elderly never-smokers. Eur Respir J 2002:20:1117-22

120. Celli BR, Halbert RJ, Isonaka S, Schau B. Population impact of different definitions of airway obstruction. Eur Respir J. 2003;22:268-73.

121. Matthay RA, Niederman MS, Wiedemann HP. Cardiovascular-pulmonary interaction in chronic obstructive pulmonary disease with special reference to the pathogenesis and management of cor pulmonale. Med Clin North Am. 1990;74:571.

122. Badgett RG, Tanaka DJ, Hunt DK, et al. Can moderate chronic obstructive pulmonary disease be diagnosed by historical and physical findings alone? Am J Med. 1993;94:188.

123. Miniati M, Monti S, Stolk J, Mirarchi G, Falaschi F, Rabinovich R, et al. Value of chest radiography in phenotyping chronic obstructive pulmonary disease. Eur Respir J. 2008;31:509-14.

124. Grydeland TB, Dirksen A, Coxson HO, Eagan TML, Thorsen E, PIllai SG, et al Quantitative computed tomography measures of emphysema and airway Wall thickness are related to respiratory symptoms. Am J Respir Crit Care Med. 2010;181:353-9.

125. Mair G, Maclay J, Miller JJ, MacAllister D, Connell M, Murchison JT, et al. Airway dimensions in COPD: relationship with clinical variables. Respir Med. 2010;104:1683-90.

126. Yuan R, Hogg JC, Sin DD, et al. Prediction of the rate of decline in FEV1 in smoker using quantitative computed tomography. Thorax. 2009;64:944-9.

127. Haruna A, Muro S, Nakano Y, Ohara T, Hoshino Y, Ogawa E, et al. CT scan findings of emphysema predict mortality in COPD. Chest. 2010;138:635-40.

128. Vendrell M, De Gracia J, Olveira C, Martínez MA, Girón R, Máiz L, et al. Diagnóstico y tratamiento de las bronquiectasias. Arch Bronconeumol. 2008;44:629-40.

129. John M, Hoernig S, Doehner W, Okonko DD, Witt C, Anker SD. Anemia and inflammation in COPD. Chest. 2005;127:825-9.

130. Alpha 1-antitrypsin deficiency: memorandum from a WHO meeting. Bull World Health Organ. 1997;75:397-415.

131. Vilaró J. Prueba de la marcha de los 6 minutos. En: Burgos Rincón F, Casan Clará P, coordinadores. Manual de procedimientos SEPAR n.․ 4: Procedimientos de evaluación de la función pulmonar-II. Madrid: SEPAR; 2004. p. 100-13.

132. Boushey H, Enright P, Samet J. spirometry for chronic obstructive pulmonary disease case finding in primary care? Am J Respir Crit Care Med. 2005; $172: 1481-6$

133. Wilt TJ, Niewoehner D, Kim C, et al. Use of spirometry for case finding, diagnosis, and management of chronic obstructive pulmonary disease (COPD). Summary, Evidence Report/Technology Assessment: Number 121. AHRQ Publication Number 05-E017-1, August 2005. Agency for Healthcare Research and Quality, Rockville, MD. Disponible en: http://www.ahrq.gov/clinic/epcsums/spirosum. htm

134. Miravitlles M, Llor C, Calvo E, Díaz S, Díaz-Cuervo H, González-Rojas N. Validación de la versión traducida del chronic obstructive pulmonary disease-population screener (COPD-PS). Su utilidad y la del FEV1/FEV6 para el diagnóstico de EPOC. Med Clin (Barc) 2012 (en prensa). 
135. Martinez FJ, Raczek AE, Seifer FD, Conoscenti CS, Curtice TG, D'Eletto T, et al Development and initial validation of a self-scored COPD Population Screener Questionnaire (COPD-PS). COPD. 2008;5:85-95.

136. Van Schayck CP, Loozen JMC, Wagena E, Akkermans RP, Wesseling GJ. Detecting patients at a high risk of developing chronic obstructive pulmonary disease in general practice: cross sectional case finding study. Br Med J. 2002;324:1370.

137. Rodríguez Nieto MJ, Galán Gallego J, Martín García M, Batanero A, García E, Peces-Barba G. Fiabilidad y facilidad de uso de un nuevo espirómetro portátil en el diagnóstico de la EPOC. Rev Patol Respir. 2011;14:53-89.

138. Jing JY, Huang TC, Cui W, Xu F, Shen HH. Should FEV1/FEV6 replace FEV1/FVC ratio to detect airway obstruction? A meta-analysis. Chest. 2009;135:991-8.

139. Represas Represas C, Botana Rial M, Leiro Fernández V, González Silva AI, Del Campo Pérez V, Fernandez-Villar A. Validación del dispositivo portátil COPD-6 para la detección de patologías obstructivas de la vía aérea. Arch Bronconeumol. 2010;46:426-32.

140. Soler-Cataluña JJ, Cosío B, Izquierdo JL, López-Campos JL, Marín JM, Agüero R, et al. Documento de consenso sobre el fenotipo mixto EPOC-asma en la EPOC. Arch Bronconeumol. 2012 (en prensa).

141. Miravitlles M, Marin A, Monsó E, Vilà S, De la Roza C, Hervás R, et al. Colour of sputum is a marker of bacterial colonization in COPD. Respir Res. 2010;11:58.

142. Burrows B, Earle RH. Prediction of survival in patients with chronic airway obstruction. Am Rev Respir Dis. 1969;99:865-71.

143. Nishimura K, Izumi T, Tsukino M, Oga T, en representación del Kansai COPD registry and research group in Japan. Dyspnea is a better predictor of 5-year survival than airway obstruction in patients with COPD. Chest. 2002;121:143440.

144. Pinto-Plata VM, Cote C, Cabral H, Taylor J, Celli BR. The 6-min walk distance: change over time and value as a predictor of survival in severe COPD. Eur Respir J. 2004;23:28-33.

145. Celli BR, Cote CG, Marín JM, Casanova C, Montes de Oca M, Mendez RA, et al. The body-mass index, airflow obstruction, dyspnea, and exercise capacity index in chronic obstructive pulmonary disease. N Engl J Med. 2004;350:1005-12.

146. Ong KC, Earnest A, Lu SJ. A Multidimensional grading system (BODE Index) as predictor of hospitalization for COPD. Chest. 2005;128:3810-6

147. An L, Lin YX, Yang T, Zhang H, Jiao X, Zhang S, et al. Predictive validity of BODE index for anxious and depressive symptoms in patients with chronic obstructive pulmonary disease. Chin Med J. 2010;123:1845-51.

148. Cote CG, Celli BR. Pulmonary rehabilitation and the BODE index in COPD. Eur Respir J. 2005;26:630-6.

149. Imfeld S, Bloch KE, Weder W, Russi EW. The BODE index after lung volume reduction correlates with survival in COPD. Chest. 2006;129:835-6.

150. Soler-Cataluña JJ, Martínez-García MA, Sánchez L, Perpiña M, Román P. Severe exacerbations and BODE index: two independent risk factors for death in male COPD patients. Respir Med. 2009;103:692-9.

151. Bestall JC, Paul EA, Garrod R, Garnham R, Jones PW, Wedzicha JA. Usefulness of the Medical Research Council (MRC) dyspnoea scale as a measure of disability in patients with chronic obstructive pulmonary disease. Thorax. 1999;54:581-6.

152. Esteban C, Quintana JM, Aburto M, Moraza J, Egurrola M, Pérez-Izquierdo J, et al. Impact of changes in physical activity on health-related quality of life among patients with COPD. Eur Respir J. 2010;36:292-300.

153. García-Aymerich J, Lange P, Benet M, Schnohr P, Antó JM. Regular physical activity modifies smoking-related lung function decline and reduces risk of chronic obstructive pulmonary disease. Am J Respir Crit Care Med. 2007;175:458-63.

154. Waschki B, Kirsten A, Holz O, Müller KC, Meyer T, Watz H, et al. Physical activity is the strongest predictor of all-cause mortality in patients with COPD. Chest 2011;140:331-42

155. Pitta F, Troosters T, Probst VS, Spruit MA, Decramer M, Gosselink R. Quantifying physical activity in daily life with questionnaires and motion sensors in COPD. Eur Respir J. 2006;27:1040-55.

156. Watz H, Waschki B, Meyer T, Magnussen H. Physical activity in patients with COPD. Eur Respir J. 2009;33:262-72.

157. García-Aymerich J, Serra Pons I, Mannino DM, Maas AK, Miller DP, Davis KJ. Lung function impairment, COPD hospitalisations and subsequent mortality. Thorax. 2011;66:585-90.

158. Jones PW, Harding G, Berry P, Wiklund I, Chen W-H, Kline Leidy N. Development and first validation of the COPD Assessment Test. Eur Respir J. 2009:34:648-54.

159. Jones P, Harding G, Wiklund I, Berry P, Leidy N. Improving the process and outcome of care in COPD: development of a standardised assessment tool. Prim Care Respir J. 2009;18:208-15.

160. Jones P, Tabberer M, Chen WG. Creating scenarios of the impact of COPD and their relationship to COPD asessment test (CATTM) socres. BMC Pulm Med. $2011 ; 11: 42$.

161. Jones PW, Brusselle G, Dal Negro RW, Ferrer M, Kardos P, Levy ML, et al. Properties of the COPD assessment test in a cross-sectional European study. Eur Respir J 2011;38:29-35.

162. Anthonisen NR, Skeans MA, Wise RA, Manfreda J, Kanner RE, Connett JE. The effects of a smoking cessation intervention on 14,5-year mortality: a randomized clinical trial. Ann Intern Med. 2005;142:233-9.

163. Godtfredsen NS, Lam TH, Hansel TT, Leon ME, Gray N, Dresler C, et al. COPDrelated morbidity and mortality after smoking cessation: status of the evidence. Eur Respir J. 2008;32:844-53.

164. Hylkema MN, Sterk PJ, De Boer WI, Postma DS. Tobacco use in relation to COPD and asthma. Eur Respir J. 2007;29:438-45.

165. Wagena EJ, Zeegers MPA, Van Schayck CP, Wouters EFM. Benefits and risks of pharmacological smoking cessation therapies in chronic obstructive pulmonary disease. Drug Saf. 2003;26:381-403.
166. Jiménez Ruiz CA, De Granda Orive JI, Riesco Miranda JA. Abordaje diagnóstico y terapéutico del tabaquismo en EPOC. En: Güell R, De Lucas P, eds. Tratado de rehabilitación respiratoria. Madrid: Ars Medica; 2005.

167. Jiménez CA, Masa F, Miravitlles M, Gabriel R, Viejo JL, Villasante C, et al. Smoking characteristics: attitudes and dependence. Differences between healthy smokers and smokers with COPD. Chest. 2001;119:1365-73.

168. Fiore MC, Jaén CR, Baker TG, Bailey WC, Benowitz NL, Curry SJ, et al. Treating tobacco use and dependence: 2008 Update. Clinical Practice Guideline. Rockville, MD: US Department of Health and Human Services, Public Health Service; 2008.

169. Tashkin DP, Rennard S, Taylor J, Wendy Ma, Lawrence D, Lee TC. Effects of varenicline on smoking cessation in patients with mild to moderate COPD. A randomized controlled trial. Chest. 2011;139:591-9.

170. Postma D, Anzueto A, Calverley P, Jenkins C, Make BJ, Sciurba FC, et al. A new perspective on optimal care for patients with COPD. Prim Care Respir J. 2011;20:205-9.

171. Poole PJ, Chacko E, Wood-Baker RW, Cates CJ. Influenza vaccine for patients with chronic obstructive pulmonary disease. Cochrane Database Syst Rev. 2006;(1):CD002733.

172. Michiels B, Govaerts F, Remmen R, Vermeire E, Coenen S. A systematic review of the evidence on the effectiveness and risks of inactivated influenza vaccines in different target groups. Vaccine. 2011;29:9159-70.

173. Walters JA, Smith S, Poole P, Granger RH, Wood-Baker R. Injectable vaccines for preventing pneumococcal infection in patients with chronic obstructive pulmonary disease. Cochrane Database Syst Rev. 2010;(11):CD001390.

174. Alfageme I, Vazquez R, Reyes N, Muñoz J, Fernández A, Hernandez M, et al. Clinical efficacy of anti-pneumococcal vaccination inpatients with COPD. Thorax. 2006;61:189-95.

175. Lopez-Campos JL. Estrategias de tratamiento en la enfermedad pulmonar obstructiva crónica: una propuesta de sistematización. Arch Bronconeumol. 2010;46:617-20

176. Sestini P, Renzoni E, Robinson S, Poole P, Ram FS. Short-acting beta-2 agonists for stable chronic obstructive pulmonary disease. Cochrane Database Syst Rev. 2002;(4):CD001495.

177. Boyd G, Morice AH, Pounsford JC, Siebert M, Peslis N, Crawford C. An evaluation of salmeterol in the treatment of the chronic obstructive pulmonary disease (COPD). Eur Respir J. 1997;10:815-21.

178. Aalbers R, Ayres J, Backer V, Decramer M, Lier PA, Magyar P, et al. Formoterol in patients with chronic obstructive pulmonary disease: a randomized, controlled, 3-month trial. Eur Respir J. 2002;19:936-43.

179. Stockley RA, Whitehead PJ, Williams MK. Improved outcomes in patients with chronic obstructive pulmonary disease treated with salmeterol compared with placebo/usual therapy: results of a meta-analysis. Respir Res. 2006;7:147.

180. Tashkin DP, Cooper CB. The role of long-acting bronchodilators in the management of stable COPD. Chest. 2004;125:249-59.

181. Beier J, Beeh KM. Long-acting beta-adrenoceptor agonists in the management of COPD: focus on indacaterol. Int J Chron Obstruct Pulmon Dis. 2011;6:237-43.

182. Brusasco V, Hodder R, Miravitlles M, Korducki L, Towse L, Kesten S. Health outcomes following six months treatment with once daily tiotropium compared to twice daily salmeterol in patients with COPD. Thorax. 2003;58:399-404.

183. O'Donnell J, Flüge T, Gerken F, Hamilton A, Webb K, Aguilaniu B, et al. Effects of tiotropium on lung hyperinflation, dyspnoea and exercise tolerance in COPD. Eur Respir J. 2004; 23:832-40.

184. Man WDC, Mustfa N, Nikoletou D, Kaul S, Hart N, Rafferty GF, et al. Effect of salmeterol on respiratory muscle activity during exercise in poorly reversible COPD.Thorax. 2004:59:471-6.

185. Celli B, Decramer M, Kesten S, Liu D, Mehra S, Tashkin DP. Mortality in the 4-year trial of Tiotropium (UPLIFT) in patients with chronic obstructive pulmonary disease. Am J Respir Crit Care Med. 2009;180:948-55.

186. Puhan MA, Bachmann LM, Kleijnen J, Ter Riet G, Kessels AG. Inhaled drugs to reduce exacerbations in patients with chronic obstructive pulmonary disease: a network meta-analysis. BMC Med. 2009;7:2.

187. Appleton S, Jones T, Poole P, Pilotto L, Adams R, Lasserson TJ, et al. Ipratropium bromide versus short acting beta-2 agonists for stable chronic obstructive pulmonary disease. Cochrane Database Syst Rev. 2006;(2):CD001387.

188. Appleton S, Poole P, Smith B, Veale A, Lasserson TJ, Chan MM. Long-acting beta-2 agonists for poorly reversible chronic obstructive pulmonary disease. Cochrane Database Syst Rev. 2006;3:CD001104.

189. Wilt TJ, Niewoehner D, MacDonald R, Kane RL. management of stable chronic obstructive pulmonary disease: a systematic review for a clinical practice guideline. Ann Intern Med. 2007;147:639-53.

190. Tashkin DP, Celli B, Senn S, Burkhart D, Kesten S, Menjoge S, et al. A 4-year trial of tiotropium in chronic obstructive pulmonary disease. N Engl J Med. 2008;359:1543-54.

191. Vogelmeier C, Hederer B, Glaab T, Schmidt H, Rutten van Molkën MPMH, Beeh $\mathrm{KM}$, et al. Tiotropium versus salmeterol for the prevention of exacerbations of COPD. N Engl J Med. 2011;364:1093-103.

192. Barr RG, Bourbeau J, Camargo CA, Ram FSF. Tiotropium for stable chronic obstructive pulmonary disease: a metaanalysis. Thorax. 2006;61:854-62.

193. Van Noord JA, Aumann J-L, Janssens E, Smeets JJ, Verhaert J, Disse B, et al. Comparison of tiotropium once daily, formoterol twice daily and both combined oncedaily in patients with COPD. Eur Respir J. 2005;26:214-22.

194. Van Noord JA, Buhl R, LaForce C, Martin C, Jones F, Dolker M, et al. QVA149 demonstrates superior bronchodilation compared with indacaterol or placebo in patients with chronic obstructive pulmonary disease. Thorax. 2010;65:108691. 
195. Ram FSF, Jardim JR, Atallah A, et al. Efficacy of theophylline in people with stable chronic obstructive pulmonary disease: a systematic review and meta-analysis. Respir Med. 2005;99:135-44.

196. Zhou Y, Wang X, Zeng X, Oiu R, Xie J, Liu S, et al. Positive benefits of theophylline in a randomized, double-blind, parallel-group, placebo-controlled study of lowdose, slow-release theophylline in the treatment of COPD for 1 year. Respirology. 2006;11:603-10.

197. American Thoracic Society/European Respiratory Society Statement: standards for the diagnosis and management of individuals with alpha1-antitrypsin deficiency. Am J Respir Crit Care Med. 2003;168:818-900.

198. Task Force on COPD. Moving towards a new focus on COPD. The Spanish COPD guidelines (GESEPOC). Arch Bronconeumol. 2011;47:379-81.

199. Papi A, Romagnoli M, Baraldo S, et al. Partial reversibility of airflow limitation and incresead exhaled NO and sputum eosinophilia in chronic obstructive pulmonary disease. Am J Respir Crit Care Med. 2000;162:1773-7.

200. Miravitlles M. Arguments in favor of inhaled corticosteroids in COPD by phenotype instead of by severity. Arch Bronconeumol. 2011;47:271.

201. Siva R, Green RH, Brightling CE, Shelley M, Hargadon B, McKenna S, et al. Eosinophilic airway inflammation and exacerbations of COPD: a randomised controlled trial. Eur Respir J. 2007;29:906-13.

202. GEMA 2009. Guía Española para el Manejo del Asma 2009. Arch Bronconeumol. 2009;45:2-35.

203. Welte T, Miravitlles M, Hernandez P, Eriksson G, Peterson S, Polanowski T, et al. Efficacy and tolerability of budesonide/formoterol added to tiotropium in patients with chronic obstructive pulmonary disease. Am J Respir Crit Care Med. 2009; $180: 741-50$

204. Peters SP, Kunselman SJ, Nikolina Icitovic MA, Moore WC, Pascual R, Ameredes BT, et al. Tiotropium bromide step-up therapy for adults with uncontrolled asthma. N Engl J Med. 2010;363:1715-26.

205. American Thoracic Society. Standards for diagnosis and care of patients with chronic obstructive pulmonary disease. Am J Respir Crit Care Med. 1995;152:77121.

206. Rabe KF, Hurd S, Anzueto A, Barnes PJ, Buist SA, Calverley P, et al. Global strategy for the diagnosis, management, and prevention of chronic obstructive pulmonary disease. GOLD executive summary. Am J Respir Crit Care Med. 2007;176;532-55.

207. Kardos P, Wencker M, Glaab T, Vogelmeier C. Impact of salmeterol/fluticasone propionate versus salmeterol on exacerbations in severe chronic obstructive pulmonary disease. Am J Respir Crit Care Med. 2007;175:144-9.

208. Szafransky W, Cukier A, Ramirez A, Menga G, Sansores R, Nahabedian S, et al Efficacy and safety of budesonide/formoterol and formoterol in chronic obstructive pulmonary diseases. Eur Respir J. 2003;21:74-81.

209. Nannini LJ, Cates CJ, Lasserson TJ, Poole P. Combined corticosteroid and longacting beta-agonistin one inhaler versus long-acting beta-agonists for chronic obstructive pulmonary disease. Cochrane Database Syst Rev. 2007;(4):CD006829.

210. Sobieraj DM, White CM, Coleman CI. Benefits and risks of adjunctive inhaled corticosteroids in chronic obstructive pulmonary disease: a metaanalysis. Clin Ther. 2008;30:1416-25.

211. Nieto A, Mazon A, Pamies R, et al. Adverse effects of inhaled corticosteroids in funded and nonfunded studies. Arch Intern Med. 2007;167:2047-53.

212. Scanlon PD, Connett JE, Wise RA, et al. Loss of bone density with inhaled triamcinolone in Lung Health Study II. Am J Respir Crit Care Med. 2004; 170:1302-9.

213. Calverley PMA, Sanchez-Toril F, Mclvor A, Teichmann P, Bredenbroeker D, Fabbri LM. Effect of 1-year treatment with roflumilast in severe chronic obstructivepulmonary disease. Am J Respir Crit Care Med. 2007;176:154-61.

214. Aaron SD, Vandemheen KL, Fergusson D, Maltais F, Bourbeau J, Goldstein R, et al. Tiotropium in combination with placebo, salmeterol, or fluticasone-salmeterol for treatment of chronic obstructive pulmonary disease: a randomized trial. Ann Intern Med. 2007;146:545-55.

215. Karner C, Cates CJ. The effect of adding inhaled corticosteroids to tiotropium and long-acting beta2-agonists for chronic obstructive pulmonary disease. Cochrane Database of Systematic Reviews 2011, Issue 9. Art. No.: CD009039. DOI: 10.1002/14651858.CD009039.pub2.

216. Barnes PJ. Theophylline for COPD. Thorax. 2006;61:742-4.

217. Cosio BG, Tsaprouni L, Ito K, Jazrawi E, Adcock IM, Barnes PJ.Theophylline restores histone deacetylase activity and steroid responses in COPD macrophages. J Exp Med. 2004;200:689-95.

218. Fabbri LM, Calverley PMA, Izquierdo-Alonso JL, Bundschuh DS, Brose M, Martinez FJ, et al. Roflumilast in moderate-to-severe chronic obstructive pulmonary disease treated with long acting bronchodilators: two randomised clinical trials. Lancet. 2009;374:695-703.

219. Bateman ED, Rabe KF, Calverley PMA, Goehring UM, Brose M, Bredenbroker D, et al. Roflumilast with long-acting b2-agonists for COPD: influence of exacerbation history. Eur Respir J. 2011;38:553-60.

220. Rennard SI, Calverley PMA, Goehring UM, et al. Reduction of exacerbations by the PDE4 inhibitor roflumilast: the importance of defining different subsets of patients with COPD. Respir Res. 2011;12:18.

221. Grandjean EM, Berthet P, Ruffmann R, Leuenberger M. Efficacy of oral long-term $\mathrm{N}$-acetylcysteine in chronic bronchopulmonary disease: a metaanalysis of published double-blind, placebo-controlled clinical trials. Clin Ther. 2000;22:20921.

222. Sutherland ER, Crapo JD, Bowler RP. N-Acetylcysteine and exacerbations of chronic obstructive pulmonary disease. COPD. 2006;3:195-202.

223. Poole PJ, Black PN. Mucolytic agents for chronic bronchitis or chronic obstructive pulmonary disease. Cochrane Database Syst Rev. 2006;(3):CD001287.
224. Zheng JP, Kang J, Huang SG. Effect of carbocisteine on acute exacerbation of chronic obstructive pulmonary disease (PEACE Study): a randomized placebocontrolled study. Lancet. 2008;371:2013-18.

225. Decramer M, Rutten-van MM, Dekhuijzen PN, Troosters T, Van Herwaarden C Pellegrion R, et al. Effects of N-acetylcysteine on outcomes in chronic obstructive pulmonary disease (Bronchitis Randomized on NAC Cost-Utility Study, BRONCUS): a randomized placebo-controlled trial. Lancet. 2005;365:1552-60.

226. Staykova T, Black PN, Chacko EE, Poole P. Prophylactic antibiotic therapy for chronic bronchitis. Cochrane Review. Published online: 21 Jan 2009. DOI: 10.1002/14651858.CD004105.

227. Sevilla-Sánchez D, Soy-Muner D, Soler-Porcar N. Utilidad de los macrólidos como antiinflamatorios en las enfermedades respiratorias. Arch Bronconeumol. 2010;46 244-54.

228. Seemungal TAR, Wilkinson TMA, Hurst JR, Perera WR, Sapsford RJ, Wedzicha JA Long-term erythromycin therapy is associated with decreased chronic obstructive pulmonary disease exacerbations. Am J Respir Crit Care Med. 2008;178:1139-47.

229. Pomares X, Montón C, Espasa M, Casabon J, Monsó E, Gallego M. Long-term azithromycin therapy in patients with severe COPD and repeated exacerbations. Int J Chron Obst Respir Dis. 2011;6:449-56.

230. Albert RK, Connett J, Biley WC, Casaburi R, Cooper JAD, Criner GJ, et al Azithromycin for prevention of exacerbations of COPD. N Engl J Med. 2011;365:689-98.

231. Miravitlles M, Marín A, Monsó E, Vilà S, De la Roza C, Hervás R, et al. Efficacy of moxifloxacin in the treatment of bronchial colonization in COPD. Eur Respir J. 2009;34:1066-71.

232. Sethi S, Jones PW, Theron MS, Miravitlles M, Rubinstein E, Wedzicha JA, et al Pulsed moxifloxacin for the prevention of exacerbations of chronic obstructive pulmonary disease: a randomized controlled trial. Respir Res. 2010;11:10.

233. Sethi S, Murphy TF. Infection in the pathogenesis and course of chronic obstructive pulmonary disease. N Engl J Med. 2008;359:2355-65.

234. Adams SG, Anzueto A, Briggs Jr DD, Leimer I, Kesten S. Evaluation of withdrawal of maintenance tiotropium in COPD. Respir Med. 2009;103:1415-20.

235. Van der Valk P, Monninkhof E, Van del Palen J, Zielhuis G, Van Herwaarden C Effect of discontinuation of inhaled corticosteroids in patients with chronic obstructive pulmonary disease. The COPE study. Am J Respir Crit Care Med. 2002;166:1358-63.

236. Nighat J Nadeem NJ, Taylor S, Eldridge SM. Withdrawal of inhaled corticosteroids in individuals with COPD: a systematic review and comment on trial methodology. Respir Res. 2011;12:107.

237. Schermer TRJ, Hendriks AJC, Chavannes NH, Dekhuijzen PNR, Wouters EFM, Van der Hoogen $\mathrm{H}$, et al. probability and determinants of relapse after discontinuation of inhaled corticosteroids in patients with COPD treated in general practice. Prim Care Respir J. 2004;13:48-55.

238. Liesker JJW, Bathoorn E, Postma DS, Vonk JM, Timens W, Kerstjens HAM. Sputum inflammation predicts exacerbations after cessation of inhaled corticosteroids in COPD. Respir Med. 2011;105:1853-60.

239. Cranston JM, Crockett AJ, Moss JR, Alpers JH. Domiciliary oxygen for COPD. Cochrane Database Syst Rev. 2005:CD001744.

240. Report of Medical Research Council Working Party. Long term domiciliary oxygen therapy in chronic hypoxic cor pulmonale complicating chronic bronchitis and emphysema. Lancet. 1981;681-6.

241. Nocturnal Oxygen Therapy Trial Group. Continuous of nocturnal oxygen therapy in hypoxemic chronic obstructive lung disease. An Intern Med.1980;93:391-8.

242. Kim V, Benditt JO, Wise RA, Sharafkhaneh A. Oxygen therapy in chronic obstructive pulmonary disease. Proc Am Thorac Soc. 2008;5:513-8.

243. Chailleux E, Fauroux B, Bidet F, Dautzenberg B, Polu JM. Predictors of survival in patients receiving domiciliary oxigen therapy or mechanical ventilation. A $10-$ year analysis of ANTADIR Observatory. Chest. 1996;109:741-9.

244. O'Donell DE, D'Arsigny C, Webb KA. Effects of hyperoxia on ventilatory limitation during exercise in advanced chronic obstructive pulmonary disease. Am J Respir Crit Care Med. 2001;163:892-8.

245. Wijkstra PJ, Guyatt GH, Ambrosino N, Celli BR, Güell R, Muir JF, et al. International approaches to the prescription of long-term oxygen therapy. Eur Respir J. 2001;18:909-13.

246. Atención integral al paciente con EPOC. Desde la Atención Primaria a la Especializada. Guía de práctica clínica 2010. SEPAR-semFYC.

247. Guía de práctica clínica de diagnóstico y tratamiento de la enfermedad pulmonar obstructiva crónica. SEPAR-ALAT, 2009.

248. Bradley JM, Lasserson T, Elborn S, Macmahon J, O'Neill B. A systematic review of randomized controlled trials examining the short-term benefit of ambulatory oxygen in COPD. Chest. 2007;131:278-85.

249. Bradley JM, O'Neill B. Short-term ambulatory oxygen for chronic obstructive pulmonary disease. Cochrane Database Syst Rev. 2005;(4):CD004356.

250. Kolodziej MA, Jensen L, Rowe B, Sin D .Systematic review of noninvasive positive pressure ventilation in severe stable COPD. Eur Respir J. 2007;30:293-306.

251. McEvoy RD, Pierce RJ, Hillman D, et al. Nocturnal non-invasive nasal ventilation in stable hypercapnic COPD: a randomised controlled trial. Thorax. 2009;64:561-6.

252. Budweiser S, Jörres RA, Pfeifer M. Treatment of respiratory failure in COPD. Int J COPD. 2008; 3:605-18.

253. Goldberg A, Leger P, Hill N, Criner G. Clinical indications for non-invasive positive pressure ventilation in chronic respiratory failure due to restrictive lung disease, OPD, and nocturnal hypoventilation. A consensus conference report. Chest. 1999;116:521-34.

254. Gay PC. UptoDate. Nocturnal ventilatory support in COPD. Last review version: september 2011 
255. Nice L, Donner $\mathrm{Cl}$, Wouters E, et al. American Thoracic Society/European Respiratory Society statement on pulmonary rehabilitation. Am J Respir Crit Care Med. 2006;173:1390-413.

256. ACCP/AACVPR Pulmonary Rehabilitation Guidelines Panel. Pulmonary rehabilitation. Joint ACCP/AACVPR Evidence-Based Guidelines. Chest. 2007; 131:4S-51S.

257. Güell R, Resqueti V, Sangenis M, et al. Impact of pulmonary rehabilitation on pshychosocial morbidity in patients with severe chronic obstructive pulmonary disease. Chest. 2006;129:899-904.

258. Lacasse Y, Goldstein R, Lasserson TJ, Martin S. Pulmonary rehabilitation for chronic obstructive pulmonary disease. Cochrane Database Syst Rev. 2006;(4):CD003793.

259. Lötters F, Van Tol B, Kwakkel G et al. Effects of controlled inspiratory muscle training in patients with COPD: a meta-analysis. Eur Respir J. 2002;20:570-6.

260. British Thoracic Society. Standards of care subcommittee on pulmonary rehabilitation. Thorax. 2001;56:827-34

261. Beauchamp MK, Janaudis-Ferreira T, Goldstein RS, Brooks D. Optimal duration of pulmonary rehabilitation for individuals with chronic obstructive pulmonary disease: a systematic review. Chron Respir Dis. 2011;8:129-40.

262. Qaseem A, Wilt TJ, Weinberger SE, Hanania NA, Criner G, Van der Molen T, et al. Diagnosis and management of stable chronic obstructive pulmonary disease: a clinical practice guideline update from the American College of Physicians, American College of Chest Physicians, American Thoracic Society, and European Respiratory Society. Ann Intern Med. 2011;155:179-91.

263. Marciniuk DD, Brooks D, Butcher S, Debigare R, Dechman G, Ford G, et al; Canadian Thoracic Society COPD Committee Expert Working Group. Optimizing pulmonary rehabilitation in chronic obstructive pulmonary disease--practical issues: a Canadian Thoracic Society Clinical Practice Guideline. Can Respir J. 2010;17:159-68.

264. Hopkinson N, Polkey M. Does physical inactivity cause chronic obstructive pulmonary disease? Clin Sci. 2010;118:565-72.

265. Grandes G, Sánchez A, Sánchez-Pinilla RO, Torcal J, Montoya I, Lizarraga K, et al; PEPAF Group. Effectiveness of physical activity advice and prescription by physicians in routine primary care: a cluster randomized trial. Arch Intern Med. 2009;169:694-701.

266. Ussher MH, Taylor A, Faulkner G. Exercise interventions for smoking cessation. Cochrane Database Syst Rev. 2008;CD002295, doi: 10.1002/14651858.CD002295. pub 3.

267. Juan Díaz M, Serrano Lázaro A, Mesejo Arizmendi A. Aspectos nutricionales de la patología pulmonar. Nutr Clin Med. 2008;2:141-54.

268. Alcolea Batres S, Villamor León J, Álvarez-Sala R. EPOC y estado nutricional. Arch Bronconeumol 2007:43:283-8.

269. Martín Salinas C, Motilla Valeriano T. Valoración del estado nutricional. En: Martín Salinas C, Motilla Valeriano T, Díaz Gómez J, Martínez Montero P. Nutrición y Dietética. 2. ed. Madrid: DAE; 2002. p. 301-19.

270. Martín Zurro A, Cano Pérez JF. Atención primaria: conceptos, organización y práctica clínica. Barcelona: Elsevier; 2008. p. 991-1006.

271. Martinez FJ. Bullectomy for giant bullae in COPD. Last review version: september 2011.

272. Christie TD, Edwards LB, Aurora P, Dobbels F, Kirk R, Rahmel AO, et al. Registry of the Internacional Society for Heart and Lung Transplantation Report-2008. J Heart Lung Transplant. 2008;27:957-69.

273. Lahzami S, Aubert JD . Lung transplantation for COPD- evidence-based? Swiss Med WKI. 2009;139:4-8

274. Normativa para la selección de pacientes candidatos a trasplante pulmonar. Arch Bronconeumol. 2011:47:303-9.

275. Martinez FJ. Lung volume reduction surgery in COPD. Uptodate. Last review version: september 2011

276. Reilly J, Waskho G, Pinto-Plata V, Velez E, Kenney L, Berger R, et al. Biological lung volume reduction:a new bronchoscopic therapy for advance emphysema. Chest. 2007; 131:1108-13.

277. Berger RL, Decamp MM, Criner GJ, Celli BR. Lung volume reduction therapies for advanced emphysema: an update. Chest. 2010;138:407-17.

278. National Emphysema Treatment Trial Research Group.Rationale and desing of the National Emphysema Treatment trial (NETT): a prospective randomized trial of lung volumen reduction surgery. J Thorac Cardiovasc Surg. 1999;118:51828.

279. National Emphysema Treatment Trial Research. A randomized trial comparing lung-volume-reduction surgery with medical therapy for severe emphysema. Engl J Med. 2003;348:2059-73.

280. Güell MR, Cejudo MP, Rodríguez-Trigo G, Gáldiz JB, Casolive V, Reguerio M, et al Estándares de calidad asistencial en rehabilitación respiratoria en pacientes con enfermedad pulmonar crónica. Arch Bronconeumol 2012 (en prensa).

281. De Blasio F, Polverino M. Current best practice in pulmonary rehabilitation for chronic obstructive pulmonary disease. Ther Adv Respir Dis 2012; PMID 22563010

282. Seemungal TAR, Donaldson GC, Paul EA, Bestall JC, Jeffries DJ, Wedzicha JA. Effect of exacerbation on quality of life in patients with chronic obstructive pulmonary disease. Am J Respir Crit Care Med. 1998;157:1418-22.

283. Langsetmo L, Platt RW, Ernst P, Bourbeau J. Underreporting exacerbation of chronic obstructive pulmonary disease in a longitudinal cohort. Am J Respir Crit Care Med. 2008;177:396-401.

284. Miravitlles M, Ferrer M, Pont A, Zalacaín R, Álvarez-Sala JL, Masa JF, et al, for the IMPAC study group. Exacerbations impair quality of life in patients with chronic obstructive pulmonary disease. A two-year follow-up study. Thorax. 2004;59:38795.
285. Hurst JR, Donaldson GC, Perera WR, Wilkinson TM, Bilello JA, Hagan GW, et al. Use of plasma biomarkers at exacerbation of chronic obstructive pulmonary disease. Am J Respir Crit Care Med. 2006;174:867-74.

286. Parker CM, Voduc N, Aaron SD, Webb KA, O'Donnell DE. Physiologic changes during symptom recovery from moderate exacerbation of COPD. Eur Respir J. 2005;26:420-8.

287. Perera WR, Hurst JR, Wilkinson TMA, Sapsford RJ, Müllerova H, Donaldson GC, et al. Inflammatory changes, recovery and recurrence at COPD exacerbation. Eur Respir J. 2007;29:527-34.

288. Soler-Cataluña JJ, Martínez-García MA, Román-Sanchez P, Salcedo E, Navarro M, Ochando R. Severe acute exacerbations and mortality in patients with chronic obstructive pulmonary disease. Thorax. 2005;60:925-31.

289. Abroug F, Quanes-Besbes L, Nciri N, Sellami N, Addad F, Ben Hamda K, et al. Association of left-heart dysfunction with severe exacerbation of chronic obstructive pulmonary disaase. Diagnostic performance of cardiac biomarkers. Am J Respir Crit Care Med. 2006;174:990-6.

290. Chang CL, Robinson SC, Mills GD, Sullivan GD, Karalus NC, McLachlan JD, et al. Biochemical markers of cardiac dysfunction predict mortality in acute exacerbations of COPD. Thorax. 2011;66:764-8.

291. Sapey E, Stockley A. COPD exacerbations: aetiology. Thorax. 2006;61:250-8.

292. Papi A, Bellettato CM, Braccioni F, Romagnoli M, Casolari P, Caramori G, et al. Infections of airway inflammation in chronic obstructive pulmonary disease severe exacerbations. Am J Respir Crit Care Med. 2006;173:1114-21.

293. Miravitlles M, Espinosa C, Fernández-Laso E, Martos JA, Maldonado JA, Gallego M, and Study Group of Bacterial Infection in COPD. Relationship between bacterial flora in sputum and functional impairment in patients with acute exacerbations of COPD. Chest. 1999;116:40-6.

294. Anthonisen NR, Manfreda J, Warren CP, Hershfield ES, Harding GK, Nelson NA. Antibiotic therapy in exacerbations of chronic obstructive pulmonary disease. Ann Intern Med. 1987;106:196-204.

295. Stockley RA, O'Brien C, Pye A, Hill SL. Relationship of sputum color to nature and outpatient management of acute exacerbations of COPD. Chest. 2000;117:163845.

296. Soler N, Agustí C, Angrill J, Puig de la Bellacasa J, Torres A. Bronchoscopic validation of the significance of sputum purulence in severe exacerbations of chronic obstructive pulmonary disease. Thorax. 2007;62:29-35.

297. Tokmas S, Schuetz P, Bent S. Procalcitonin-guided antibiotic therapy for chronic obstructive pulmonary disease exacerbations. Expert Rev Anti Infect Ther. 2011;9:727-35.

298. Daniels JM, Schoorl M, Snijders D, et al. Procalcitonin vs C-reactive protein as predictive markers of response to antibiotic therapy in acute exacerbations of COPD. Chest. 2010:138:1108-15.

299. Rizkallah J, Man SF, Sin DD. Prevalence of pulmonary embolism in acute exacerbation of COPD: a systematic review and metaanalysis. Chest. 2009;135:786-93.

300. Uresandi F, Blanquer J, Conget F, De Gregorio MA, Lobo JL, Otero R, et al. Guía para el diagnóstico, tratamiento y seguimiento de la tromboembolia pulmonar. Arch Bronconeumol. 2004;580-94.

301. McCrory DC, Brown C, Gelfand SE, Bach PB. Management of acute exacerbations of COPD: a summary and appraisal of published evidence. Chest. 2001;119:1190209.

302. Turner MO, Patel A, Ginsburg S, FitzGerald JM. Bronchodilator delivery in acute airflow obstruction. A meta-analysis. Arch Intern Med. 1997;157:1736-44.

303. Boe J, Dennis JH, O'Driscoll BR, et al. European Respiratory Society Guidelines on the use of nebulizers. Eur Respir J. 2001:18:228-42.

304. Di Marco F, Verga M, Santus P, Morelli N, Cazzola M, Centanni S. Effect of formoterol, tiotropium, and their combination in patients with acute exacerbations of chronic obstructive pulmonary disease: a pilot study. Respir Med. 2006;100:1925-32.

305. Barr RG, Rowe BH, Camargo CA. Methylxanthines for exacerbations of chronic obstructive pulmonary disease. Cochrane Database Syst Rev. 2003;(2):CD002168.

306. Nouira S, Marghli S, Belghith M, Besbes L, Elatrous S, Abroug F. Once daily oral ofloxacin in chronic obstructive pulmonary disease exacerbation requiring mechanical ventilation: a randomised placebo-controlled trial. Lancet. 2001;358:2020-5.

307. Miravitlles M, Monsó E, Mensa J, Aguarón Pérez J, Barberán J, Bárcena Caamaño $\mathrm{M}$, et al. Tratamiento antimicrobiano de la agudización de EPOC: Documento de Consenso 2007. Arch Bronconeumol 2008:44:100-8.

308. Singh JM, Palda VA, Stanbrook MB, Chapman KR. Corticosteroid therapy for patients with acute exacerbations of chronic obstructive pulmonary disease: a systematic review. Arch Intern Med. 2002;162:2527-36.

309. Walters JA, Gibson PG, Wood-Baker R, Hannay M, Walters EH. Systemic corticosteroids for acute exacerbations of chronic obstructive pulmonary disease. Cochrane Database Syst Rev. 2009;(1):CD001288.

310. Albert RK, Martin TR, Lewis SW. Controlled clinical trial of methylprednisolone in patients with chronic bronchitis and acute respiratory insufficiency. Ann Intern Med. 1980;92:753-8.

311. Davies L, Angus RM, Calverley PM. Oral corticosteroids in patients admitted to hospital with exacerbations of chronic obstructive pulmonary disease: a prospective randomised controlled trial. Lancet. 1999;354:456-60.

312. Gunen H, Hacievliyagil SS, Yetkin O, Gulban G, Mutly LC, In E. The role of neublized budesonide in the treatment of exacerbations of COPD. Eur Respir J. 2007;29:660-7.

313. Maltais F, Ostinelli J, Bourbeau J, Tonnel AB, Jacquemet N, Haddon J, et al. Comparison of nebulized budesonide and oral prednisolone with placebo in the 
treatment of acute exacerbations of chronic obstructive pulmonary disease: a randomized controlled trial. Am J Respir Crit Care Med. 2002;165:698-703.

314. Otero R, Grau E, Jiménez D, Uresandi F, López JL, Calderón E, et al. Profilaxis de la enfermedad tromboémbólica venosa. Arch Bronconeumol. 2008;44:160-9.

315. Puhan MA, Gimeno-Santos E, Scharplatz M, Troosters T, Walters EH, Steurer J. Pulmonary rehabilitation following exacerbations of chronic obstructive pulmonary disease. Cochrane Database Syst Rev. 2011;(10):CD005305.

316. Burtin C, Decramer M, Gosselink R, Janssens W, Troosters T. Rehabilitation and acute exacerbations. Eur Respir Dis 2011;38:702-12.

317. Lightowler JV, Wedzicha JA, Elliott MW, Ram FS. Non-invasive positive pressure ventilation to treat respiratory failure resulting from exacerbations of chronic obstructive pulmonary disease: Cochrane systematic review and meta-analysis. Br Med J. 2003;326:185-7.

318. Hernandez C, Casas A, Escarrabill J, Alonso J, Puig-Junoy J, Farrero E, et al. Home hospitalization of exacerbated chronic obstructive pulmonary disease patients. Eur Respir J. 2003;21:58-67.

319. Ram FS, Wedzicha JA, Wright J, Greenstone M. Hospital at home for patients with acute exacerbations of chronic obstructive pulmonary disease: systematic review of evidence. Br Med J. 2004;329:315.

320. National Cancer Institute. Disponible en: www.cancer.gov

321. Curtis JR. Palliative and end-of-life care for patients with severe COPD. Eur Respir J. 2008;32:796-803.

322. Temel JS, Greer JA, Muzikansky A, et al. Early palliative care for patients with metastatic non-small-cell lung cancer. N Engl J Med. 2010;363:733-42.

323. Gore JM, Brophy CJ, Greenstone MA.How well do we care for patients with end stage chronic obstructive pulmonary disease (COPD)? A comparison of palliative care and quality of life in COPD and lung cancer. Thorax. 2000;55:1000-6.

324. Steinhauser KE, Arnold RM, Olsen MK, Lindquist J, Hays J, Wood LL, et al. Comparing three life-limiting diseases: does diagnosis matter or is sick, sick? J Pain Symptom Manage. 2011;42:331-41.

325. Bausewein C, Booth S, Gysels M, et al. Understanding breathlessness: crosssectional comparison of symptom burden and palliative care needs in chronic obstructive pulmonary disease and cancer. J Palliat Med. 2010;13:1109-18.

326. Lohne V, Heer HC, Andersen M, et al. Qualitative study of pain of patients with chronic obstructive pulmonary disease. Heart Lung. 2010;39:226-34.

327. Horton R, Rocker G. Contemporary issues in refractory dyspnoea in advanced chronic obstructive pulmonary disease. Curr Opin Support Palliat Care. 2010;4:5662.

328. Pinnock H, Kendall M, Murray SA, et al. Living and dying with severe chronic obstructive pulmonary disease: multi-perspective longitudinal qualitative study. Br Med J. 2011. doi: 10.1136/bmj.d142.

329. Small N, Gardiner C, Barnes S, et al. Using a prediction of death in the next 12 months as a prompt for referral to palliative care acts to the detriment of patients with heart failure and chronic obstructive pulmonary disease. Palliat Med. 2010;24:740.

330. Hardin $\mathrm{K}$, Meyers $\mathrm{F}$, Louie S. Integrating palliative care in severe chronic obstructive lung disease. COPD. 2008;5:207-20.

331. Bausewein C, Booth S, Gysels M, Higginson I. Nonpharmacological interventions for breathlessness in advanced stages of malignant and nonmalignant diseases. Cochrane Database Syst Rev. 2008:CD005623.

332. Jennings AL, Davies AN, Higgins JP, et al. A systematic review of the use of opioids in the management of dyspnoea. Thorax. 2002;57:939-44.

333. Abernethy AP, Currow DC, Frith P, et al. Randomised, double blind, placebo controlled crossover trial of sustained release morphine for the management of refractory dyspnoea. Br Med J. 2003;327:523-8.

334. Jennings AL, Davies AN, Higgins JPT, Broadley K Tratamiento paliativo con opiáceos para la disnea de la enfermedad terminal (Revisión Cochrane traducida). En: Biblioteca Cochrane Plus, 2008 Número 4. Oxford: Update Software Ltd. Disponible en: http://www.update-software.com.

335. Goodridge D, Lawson J, Rocker G, Marciniuk D, Rennie D. Factors associated with opioid dispensation for patients with COPD and lung cancer in the last year of life: a retrospective analysis. Int J Chron Obstruct Pulmon Dis. 2010;5:99-105.

336. Varkey B. Opioids for palliation of refractory dyspnea in chronic obstructive pulmonary disease patients. Curr Opin Pulm Med. 2010;16:150-4.

337. Simon ST, Higginson IJ, Booth S, et al. Benzodiazepinas para el alivio de la disnea en adultos con enfermedades malignas y benignas. En: Biblioteca Cochrane Plus 2010 Número 1. Oxford: Update Software Ltd. Disponible en: http://www.updatesoftware.com.

338. Putman-Casdorph $\mathrm{H}$, McCrone S.Chronic obstructive pulmonary disease, anxiety, and depression: state of the science. Heart Lung. 2009;38:34-47.

339. Sociedad Española de Cuidados Paliativos. Cuidados paliativos: la familia de la persona enferma. Disponible en: http://www.secpal.com/guiasm/index. php?acc=see guia\&id guia $=4$

340. Normativas SEPAR: Recomendaciones sobre la atención al final de la vida en pacientes con EPOC. Disponible en: http://www.separ.es/publicaciones/ normativa/normativa_052.html

341. Escarrabill J, Soler Cataluña JJ, Hernández C, et al. Recommendations for End-ofLife Care in Patients With Chronic Obstructive Pulmonary Disease. Arch Bronconeumol. 2009; 45:297-303.

342. Romero Roy ME, Jimeno Salgado JF. Yoga y EPOC. Abordaje desde las técnicas respiratorias. Medicina Naturista. 2007;I:30-5.

343. Hutton W. Putting the public at the heart of the NHS. Br Med J. 2007;334:69-70.
344. Health literacy: report of the Council on Scientific Affairs. Ad Hoc Committee on Health Literacy for the Council on Scientific Affairs, American Medical Association. JAMA. 1999;281:552-7.

345. Dewalt DA, Berkman ND, Sheridan S, Lohr KN, Pignone MP. Literacy and health outcomes: a systematic review of the literature. J Gen Intern Med. 2004;19:1228 39.

346. Selden CR, Zorn M, Ratzan SC. Health literacy. Acceso el 7 de mayo de 2011 : http://www.nlm.nih.gov/archive//20061214/pubs/cbm/hliteracy.pdf

347. Dewalt DA, Pignone MP. The role of literacy in health and health care. Am Fam Physician. 2005;72:387-8.

348. Easton P, Entwistle VA, Williams B. Health in the 'hidden population' of people with low literacy. A systematic review of the literature. BMC Public Health. 2010;10:459

349. Powers BJ, Trinh JV, Bosworth HB.Can this patient read and understand written health information? JAMA. 2010;304:76-84.

350. Roberts NJ, Ghiassi R, Partridge MR. Health literacy in COPD. Int J Chron Obstruct Pulmon Dis. 2008;3:499-507.

351. Davis TC, Wolf MS. Health literacy: implications for family medicine. Fam Med 2004;36:595-8.

352. Baker DW, Parker RM, Williams MV, Pitkin K, Parikh NS, Coates W, et al. The health care experience of patients with low literacy. Arch Fam Med. 1996;5:32934.

353. Safeer RS, Keenan J. Health literacy: the gap between physicians and patients. Am Fam Physician. 2005;72:463-8.

354. Adams SG, Smith PK, Allan PF, Anzueto A, Pugh JA, Cornell JE. Systematic review of the chronic care model in chronic obstructive pulmonary disease prevention and management. Arch Intern Med. 2007;167:551-61.

355. Bourbeau J, Van der Palen J. Promoting effective self-management programmes to improve COPD. Eur Respir J. 2009;33:461-3.

356. Bodenheimer T, MacGregor K, Sharifi C. Helping patients manage their chronic conditions. Oakland: California Healthcare Foundation; 2005.

357. Mauksch LB, Dugdale DC, Dodson S, Epstein R. Relationship, Communication, and Efficiency in the Medical Encounter. Arch Intern Med. 2008;168:1387-95.

358. Langewitz W, Denz M, Keller A, Kiss A, Rüttimann S, Wössmer B. Spontaneous talking time at start of consultation in outpatient clinic: cohort study. Br Med J. 2002;325:682-3.

359. Hanson JL. Shared decision making. Have we missed the obvious? Arch Intern Med. 2008;168:1368-70.

360. Bourbeau J, Julien M, Maltais F, Rouleau M, Beaupré A, Bégin R, et al. Reduction of hospital utilization in patients with chronic obstructive pulmonary disease: a disease-specific self-management intervention. Arch Intern Med. 2003;163:58591.

361. De Vries B, Darling-Fisher C, Thomas AC, Belanger-Shugart EB. Implementation and outcomes of group medical appointments in an outpatient specialty care clinic. J Am Acad Nurse Pract. 2008;20:163-9.

362. Jaber R, Braksmajer A, Trilling J. Group visits for chronic illness care: models, benefits and challenges. Fam Pract Manag. 2006;13:37-40.

363. Bischoff EW, Hamd DH, Sedeno M, Benedetti A, Schermer TR, Bernard S, et al Effects of written action plan adherence on COPD exacerbation recovery. Thorax. 2011;66:26-31.

364. Universidad de los pacientes [accedido 7 May 2011]. Disponible en: http://www. universidadpacientes.org/kitdevisitamedica/elkit/index.php?pag=descarga.

365. Jovell A, Navarro Rubio M, Fernández Maldonado L, Blancafort. S. Nuevo rol del paciente en el sistema sanitario. Aten Primaria 2006;38:234-7.

366. The Expert Patient A New Approach to Chronic Disease Managementfor the $21 \mathrm{st}$ Century [accedido 8 May 2011]. Disponible en: http://www.dh.gov.uk/prod consum_dh/groups/dh_digitalassets/@dh/@en/documents/digitalasset/ dh_4018578.pdf

367. González Mestre A, Fabrellas Padrés N, Agramunt Perelló M, Rodríguez Pérez E Grifell Martín E. De paciente pasivo a paciente activo. Programa Paciente Experto del Institut Català de la Salut. Revista de Innovación Sanitaria y Atención Integrada. 2008;1(1): Article 3. [accedido 8 May 2011]. Disponible en: http://pub. bsalut.net/risai/vol1/iss1/3.

368. Lorig K. Partnerships between expert patients and physicians. Lancet 2002;359:814-5

369. Lorig KR, Ritter PL, Dost A, Plant K, Laurent DD, McNeil I. The Expert Patients Programme online, a 1-year study of an Internet-based self-management programme for people with long-term conditions. Chronic Illn. 2008;4:247-56.

370. Martí M, Fabrellas N, Chicote S, Escribano V, Raventós A, Padilla N. Llamada a autocuidado. Seguimiento telefónico a enfermedades crónicas. Revista de Innovación Sanitaria y Atención Integrada. 2008;1(3): Artículo 7. [accedido 8 May 2011]. Disponible en: http://pub.bsalut.net/risai/vol1/iss3/7.

371. Marshall A, Medvedev O, Antonov A. Use of a smartphone for improved selfmanagement of pulmonary rehabilitation. Int J Telemed Appl. 2008:75:30-64.

372. De Toledo P, Jiménez S, Del Pozo F, Roca J, Alonso A, Hernandez C. Telemedicine experience for chronic care in COPD. IEEE Transactions on Information Technology in Biomedicine. 2006; 10:567-73.

373. Torrente E, Escarrabill J, Martí T. Impacto de las redes sociales de pacientes en la práctica asistencial. Revista de Innovación Sanitaria y Atención Integrada. 2010;2(1):Article 1. [accedido 8 May 2011]. Disponible en: http://pub.bsalut.net/ risai/vol2/iss1/1

374. Tapscott D, Williams D. Wikinomics. London: Atlantic Books; 2006. 